Configuring Masculinity in Theory and Literary Practice 


\title{
DQR Studies in Literature
}

\author{
Edited by \\ C.C. Barfoot \\ A.J. Hoenselaars \\ W.M. Verhoeven
}

VOLUME 58

The titles published in this series are listed at brill.com/dqr 


\title{
Configuring Masculinity in Theory and Literary Practice
}

\author{
Edited by
}

Stefan Horlacher

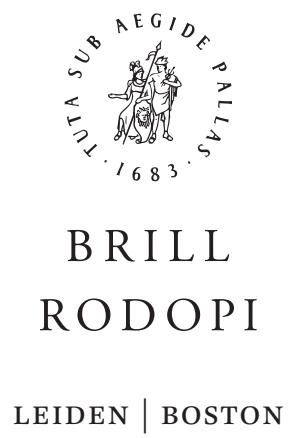


This is an open access title distributed under the terms of the CC BY-NC 4.o license, which permits any non-commercial use, distribution, and reproduction in any medium, provided the original author(s) and source are credited. Further information and the complete license text can be found at https://creativecommons.org/licenses/ by-nc/4.0/

The terms of the Cc license apply only to the original material. The use of material from other sources (indicated by a reference) such as diagrams, illustrations, photos and text samples may require further permission from the respective copyright holder.

An electronic version of this book is freely available, thanks to the support of libraries working with Knowledge Unlatched. More information about the initiative can be found at www. knowledgeunlatched.org.

Cover illustration: Chicago, August 2011, by Stefan Horlacher.

Library of Congress Control Number: 2015938553

ISSN 0921-2507

ISBN 978-90-04-29899-6 (hardback)

ISBN 978-90-04-29900-9 (e-book)

Copyright 2015 by the Authors. Published by Koninklijke Brill NV, Leiden, The Netherlands.

Koninklijke Brill NV incorporates the imprints Brill, Brill Hes \& De Graaf, Brill Nijhoff, Brill Rodopi,

Brill Sense, Hotei Publishing, mentis Verlag, Verlag Ferdinand Schöningh and Wilhelm Fink Verlag.

Koninklijke Brill NV reserves the right to protect the publication against unauthorized use and to authorize dissemination by means of offprints, legitimate photocopies, microform editions, reprints, translations, and secondary information sources, such as abstracting and indexing services including databases. Requests for commercial re-use, use of parts of the publication, and/or translations must be addressed to Koninklijke Brill NV.

This book is printed on acid-free paper. 


\section{CONTENTS}

Acknowledgments vii

Stefan Horlacher

Configuring Masculinity 1

Todd W. Reeser

Concepts of Masculinity and Masculinity Studies

Raewyn Connell

Masculinities: The Field of Knowledge

Richard Collier

On Reading Men, Law and Gender: Legal Regulation

and the New Politics of Masculinity

Christoph Houswitschka

Masculinity in Thomas Malory's Morte Darthur

Mark Bracher

From Antisocial to Prosocial Manhood:

Shakespeare's Rescripting of Masculinity in As You Like It

Rainer Emig

Sentimental Masculinity: Henry Mackenzie's

The Man of Feeling (1771) 
Stefan Horlacher

"Joseph the Dreamer of Dreams": Jude Fawley's Construction

of Masculinity in Thomas Hardy's Jude the Obscure

Sebastian Müller

From Angry Young Scholarship Boy to Male Role Model:

The Rise of the Working-Class Hero

Fatemeh Hosseini

"Filiarchy" and Masculinity in the Early Novels of

Ian McEwan

Bettina Schötz

"What Is a Man?", or the Representation of Masculinity

in Hanif Kureishi's Short Fiction

Bénédicte Ledent

Of Invisible Men and Native Sons: Male Characters in

Caryl Phillips' Fiction

Daniel Lukes

Surrogate Dads: Interrogating Fatherhood in Will Self's

The Book of Dave

Notes on Contributors

301

Index 


\section{ACKNOWLEDGMENTS}

This project has had a long gestation, and my thanks first and foremost go to the authors of the essays for their valuable contributions as well as for their patience in seeing the collection through to publication.

I am indebted to Sebastian Jansen for his excellent work in editing the manuscript and helping to get it ready for publication, to Mirjam Frotscher for critical proofreading and establishing the index, and to Sarah Larson and William Baker who also helped proofreading the manuscript.

Finally, I want to thank Cedric Barfoot not only for his support as series editor but also for his critical and exact readings of the contributions. This made the process of editing so much easier. 



\title{
Configuring Masculinity
}

\author{
STEFAN HORLACHER
}

\begin{abstract}
More than just an Introduction to the contributions which make up this volume, this article argues that masculinity studies is a social necessity, points to the problems the construction of male gender identities seems to pose (not only) in the twentieth and twenty-first centuries and stresses the outstanding contribution that literature can make with regard to male gender identity formation. Moreover, this contribution asks whether gender identity should not be seen as a potentially unstable, contradictory, and evolving cultural product akin to literature, whose medium, language, and chief "mode of operation", that is, narration, it shares. The article also contends that in literary texts, we find both, self- as well as externally-determined or enforced configurations of masculinity as well as the very mechanisms of their production or enforcement.
\end{abstract}

Masculinity studies is not a conservative backlash but a social necessity. ${ }^{1}$ While gender, women's, and feminist studies have been at least partly institutionalized and can look back into their own history - or histories - as (albeit sometimes contested) academic disciplines, the subject of masculinity has only much later begun to receive the attention of the academy. If, initially, masculinity was hardly more than an occasional topic in disciplines such as sociology, psychology, history, and literary studies, in the meantime it has become a field of study in its own right, at least in the US and the UK.

\footnotetext{
${ }^{1}$ It is necessary to clearly differentiate between current forms of "masculinity studies" or "critical studies on men and masculinities" to which I refer, and more conservative and reactionary perspectives which can rightly be considered as backlashes.
} 
This genesis of masculinity studies as a new field of research can be explained by the centuries in which, in real life as well as in research, masculinity had been more or less invisible, given that the traditional "overgeneralization from male to generic human experience" not only distorted the "understanding of what, if anything, is truly generic to humanity but also preclude[d] the study of masculinity as a specific male experience, rather than a universal paradigm for human experience". ${ }^{2}$

The fact that "notions of the 'human' ... obscure notions of the "masculine"" explains why (notwithstanding Freud and his emphasis on masculinity as "normalcy") masculinity remained something of an unmarked (and therefore invisible) gender in political, social, and cultural contexts.

However, whenever masculinity has become visible in the late twentieth and early twenty-first centuries, it has regularly presented an alarming picture, frequently mentioned in connection with violent incidents such as the Anders Behring Breivik massacres in Norway or shootings in universities and schools. In the current debate on education, at least in Germany, masculinity has been pronounced to be a problem: the latest statistics of the Federal Government and the World Health Organization (WHO) show men ${ }^{4}$ to be at a significantly higher risk of lapsing into alcoholism, exhibiting personality disorders and committing suicide.

Also with regard to life expectancy, chronic disorders, and the need for long-term care, men have been shown to be seriously disadvantaged. $^{5}$ If one follows media coverage, one could almost have the

\footnotetext{
${ }^{2}$ Harry Brod, "Introduction: Themes and Theses of Men's Studies", in The Making of Masculinities: The New Men's Studies, ed. Harry Brod, Boston: Allen and Unwin, 1987, 2 (emphases in the original).

${ }^{3}$ David Rosen, The Changing Fictions of Masculinity, Urbana: University of Illinois Press, 1993, xi-xii.

${ }^{4}$ Given the impressive work done in queer, intersex, and transgender studies, it seems necessary to inquire critically into concepts or definitions of masculinity and femininity at use in these statistics. If they are nevertheless mentioned here, it is mainly as a demonstration that the problem of what traditional models of "being a man" entail has reached public consciousness.

${ }^{5}$ See Doris Bardehle, "Gesundheit und gesundheitliche Versorgung von Männern", in Erster Deutscher Männergesundheitsbericht: Ein Pilotbericht, eds Doris Bardehle and Matthias Stiehler, Munich: Zuckschwerdt, 2010, 17-27; Männergesundheitsbericht 2013, eds Lothar Weißbach and Matthias Stiehler, Bern: Huber, 2013; HansJoachim Lenz, “Zwischen Men's Studies und männlicher Verletzungsoffenheit - Zur
} 
impression that the formerly strong sex is about to become the new weaker sex, ${ }^{6}$ mainly characterized by numerous physical and mental weaknesses ${ }^{7}$ - which brings me back to the very first sentence of this article, that is, the social necessity of what is called "masculinity studies" or "critical studies on men and masculinities". By this, I mean current research on masculinity as portrayed in the surveys by Todd Reeser, Raewyn Connell, and Stefan Horlacher, ${ }^{8}$ but most explicitly not the more conservative and reactionary perspectives, such as the men's rights perspective, the mythopoetic perspective, morally and socio-biologically conservative perspectives, or the Evangelical Christian Men's Movement (Promise Keepers). ${ }^{9}$

Many of the most influential approaches in contemporary masculinity studies are heavily influenced by sociological, historical, literary, and allegedly neutral biomedical knowledge. They collect and analyze gender-specific data with regard to violent behavior, life expectancy, drug abuse, and the susceptibility to particular diseases. Although archaic and obsolete images of men linking masculinity to risk-taking and dare-devil behavior have been called into question for decades, the old stereotypes, lurking everywhere, prove to be almost insurmountable. This has led to some kind of paradox: while current research has shown that in post-modern societies the construction of a monolithic or singular male gender identity has become problematic and increasingly impossible, the construction of a male gender identity based on the premises of an unrestricted plurality has turned out to be problematic and crises-ridden as well.

kurzen Geschichte der Männerforschung in Deutschland", Männer und Geschlecht: Freiburger GeschlechterStudien, XXI (2007), 41-77; Rainer Emig and Antony Rowland, Introduction, in Performing Masculinity, eds Rainer Emig and Antony Rowland, Houndmills: Palgrave Macmillan, 2010, 1-12.

${ }^{6}$ See Emig and Rowland, Introduction, 7-8; George Yúdici, "What's a Straight Man to Do?", in Constructing Masculinity, eds Maurice Berger, Wallis Brian and Simon Watson, New York: Routledge, 1995, 267-83.

${ }^{7}$ See Elisabeth Badinter, XY: Die Identität des Mannes, Munich: Piper, 1993, 49-50.

${ }^{8}$ See Todd Reeser's and Raewyn Connell's contributions in this volume; also Stefan Horlacher, "Masculinity Studies: Contemporary Approaches and Alternative Perspectives", in Beyond Gender: Future(s) of Women's/Feminist/Men's/Queer/Intersectionality Studies, eds Greta Olson, Daniel Hartley, Mirjam Horn, and Regina Schmidt, New York: Palgrave, under review.

${ }^{9}$ See Kenneth Clatterbaugh, Contemporary Perspectives on Masculinity: Men, Women, and Politics in Modern Society, Boulder, CO: Westview, 1997. 
In this context, Peter F. Murphy has correctly emphasized the role "[that] literature has played in reinforcing the assumptions about masculinity and, at times, [in] helping to establish the norm of manhood"; ${ }^{10}$ additionally, Vera Nünning has succinctly stated the outstanding contribution that literature - fictional constructions of masculinity - can make with regard to male gender identity formation when she stresses the "immense social and cultural relevance" of masculinity concepts that are "disseminated and to some extent critiqued" in literature as well as in non-fictional texts. ${ }^{11}$ Especially when discussing a potential crisis of masculinity, literary discourses become a privileged site for registering patriarchy's "loss of legitimacy" and how "different groups of men are now negotiating this loss in very different ways". ${ }^{12}$

If Murphy argues that literature can offer alternatives, that is, "other images, other roles, other options for men and masculinity", 13 we should not err by restricting this knowledge to the representative (if not normative) aspect of artistic works, but address the much more fundamental question concerning the extent and tendency of art especially literature - to possess a kind of knowledge about masculinity that is not only relevant for a better understanding of its construction or specific configuration, functioning, and supposed defects, but also features a co-constructive potential which enables the reader to critically re-construct their masculinity.

Over the last years, it is especially at the intersection of history and literature that interesting new results about masculinity have emerged, leading to a multitude of studies that focus on demythologizing the history of everyday life on a micro-structural level. These studies have produced what Clifford Geertz calls "thick descriptions" of "simple" narratives that question the validity of dominant master narratives of masculinity. In most of the disciplines dealing with masculinity and gender there has been a shift in focus towards narrative modes and structures, that is, to stories and genres as the most important components of the historical and current configuration of mas-

\footnotetext{
${ }^{10}$ Peter F. Murphy, "Introduction: Literature and Masculinity", in Fictions of Masculinity: Crossing Cultures, Crossing Sexualities, ed. Peter F. Murphy, New York: New York University Press, 1994, 1.

${ }^{11}$ See Vera Nünning, "Sammelrezension", Anglia, CXX/2 (November 2002), 301.

${ }^{12}$ R.W. Connell, Masculinities, 2nd edn, Cambridge: Polity, 2005, 202.

${ }^{13}$ Murphy, "Introduction: Literature and Masculinity", 1.
} 
culinities. ${ }^{14}$ "Narration" is about to become a key concept for the study of masculinity not only within British, American, and German Literary and Cultural Studies but also in sociology, history, and psychoanalysis. This shift towards narrative could be crucial for the further development of masculinity studies and for any endeavor to overcome the increasing fragmentation and partitioning of the field. From this perspective, masculinity - or, to be more precise, important aspects of masculinity - could be conceptualized and understood as a narrative which takes on different forms in different contexts and at different times. If language, narrative, literature, and gender identity are as intimately linked as this approach suggests, gender identity could probably best be conceived of as a narration that is constantly characterized by a certain fluidity or instability, by a precarious emplotment and a negotiation of change and mutability, with the postulation of a true gender identity being nothing but a regulatory fiction. ${ }^{15}$

Gender identity could then be seen as a potentially unstable, contradictory, and evolving cultural product akin to language and the narrative operations of literature. Without refuting its biological substratum and questions of embodiment, gender identity could then be understood as being created through a metaphorical act of writing that produces its precarious "unity" 16 and renders it a "narrative artifice, privileging a presence, or identity, that does not exist outside language". ${ }^{17}$ If this assumption is correct, then the literary text, this "ever-changing and interactive storehouse of knowledge for living", ${ }^{18}$ could really be seen as a privileged space and epistemological medium

\footnotetext{
${ }^{14}$ Narrative is here not restricted to literary and cultural artifacts but extends from the construction of individual gender identity by way of biographical, material and embodied social processes to collective national identities and images.

${ }^{15}$ See Judith Butler, Gender Trouble: Feminism and the Subversion of Identity, New York: Routledge, 1990, 141; also Bettina Schötz's contribution in this volume.

16 "Unity" refers here to the individual person's construction of a flexible gender identity over a lifetime and not to one single or stable concept of masculinity, femininity, etc.

${ }^{17}$ Sidonie Smith, A Poetics of Women's Autobiography: Marginality and the Fictions of Self-Representation, Bloomington, 1987, 5; see also Michael Bamberg, "Identity and Narration", in The Living Handbook of Narratology, eds Peter Hühn et al., Hamburg: Hamburg University, 23 July 2014: http://www.lhn.uni-hamburg.de/article/ identity-and-narration.

${ }^{18}$ Ottmar Ette, "Literature as Knowledge for Living, Literary Studies as Science for Living", trans. and ed. with an Introduction, Vera M. Kutzinski, PMLA, CXXV/4 (October 2010), 977-93.
} 
where the manifold mechanisms of configuring ever different and divergent masculinities in the discursive condition becomes readable, knowable, and thereby also rewriteable.

However, as the very concept of "configuration" evokes and as the following analyses which make up this volume will show, it is not necessarily the autonomous subject that in a creative act configures or constructs their masculinity. More often, it is the social and historical context and the existing power structures which configure the subject and their masculinity. Notwithstanding the question as to the agency of the subject, what is of importance here is that in literary texts, we find both, self- as well as externally-determined or enforced configurations of masculinity as well as the very mechanisms of their production or enforcement.

The articles collected in this volume not only offer analyses of how literary texts and the manifold worlds they represent (or, to be more precise, produce) configure masculinity, but also provide the theoretical framework for this undertaking, starting with Todd Reeser's conceptual history of the study of masculinity in the Englishspeaking Academy. Reeser's in-depth survey not only ranges from the birth of "men's studies" in the 1980's to current work on global masculinities, including work on the relations between masculinity and homosexuality, women, transgender, race, colonialism, and ethnicity, his contribution also expressly stresses the link between gender identity and literature:

In nearly all cases, questions of identity - whether cultural or individual - are central to masculinity studies, meaning that approaches to flesh-and-blood human beings and approaches to literary representations are not fully distinct. Sociological or anthropological understandings of masculinity can be and were in many ways imported to literary studies: literary constructs of masculinity may validate conceptions of gender in the social sciences, but literariness may also transform such conceptions in ways that only take place within the fictional text. ${ }^{19}$

The theoretical and conceptual framework which Reeser's text unfolds is further enhanced by Raewyn Connell's article "Masculinities: The Field of Knowledge" and Richard Collier's "On Reading Men, Law and Gender: Legal Regulation and the New Politics of Masculinity".

\footnotetext{
${ }^{19}$ See p. 13 of this volume.
} 
What these contributions also have in common is that, according to their specific scientific discipline and perspective, they offer different yet complementary definitions of and approaches to masculinity.

While Connell critically comments on the body of international masculinities research of the last twenty-five years, identifies the most important conclusions, and argues that men are most likely to change their gender practices when social justice as well as gender diversity (or de-gendering) are emphasized, Collier explores how an engagement with masculinity has developed in the field of legal studies almost unbeknown to many gender and masculinity studies scholars. Collier argues that particular ideas concerning men and masculinity have been constituted as distinctive "social problems" for law at varying historical moments and explores the relation between the law and masculinities in the context of debates about the politics of fathers' rights, a topic which is taken up again in Daniel Luke's article on fatherhood in The Book of Dave.

The contributions in the second and major part of this book take up the theoretical premises outlined by Reeser, Connell, and Collier, combining literary and cultural studies approaches with approaches currently deployed in masculinity studies, gender studies, legal studies, postcolonial studies, and cognitive psychology, to name but a few. The articles aim at elucidating how masculinity has been conceived and constructed within literature over a period of more than six centuries and how certain concepts of masculinity were created and continue to be created by the cultural systems and forms of knowledge underpinning literary discourse. As has already been indicated, literature is thereby understood as a productive and interactive medium by which a given society is not only reflected and critically reflects itself, but is actively shaped as well.

Including texts by canonical and established authors such as Thomas Malory, William Shakespeare, Henry Mackenzie, Thomas Hardy, John Osborne, John Braine, Allan Sillitoe, Ian McEwan, Caryl Phillips, Will Self, and Hanif Kureishi, Configuring Masculinity can be read as an exemplary diachronic analysis of varying configurations of masculinity in British literature. However, the literary production of six-hundred years can never be adequately represented by a few selected key texts only. Therefore, the main focus of this book cannot be on its diachronic or historical dimension: Configuring Masculinity is not meant to be a literary history. 
Nevertheless, texts such as Malory's Morte Darthur, Shakespeare's As You Like It, Mackenzie's The Man of Feeling, or Hardy's Jude the Obscure can open up a historical perspective which makes paradigmatic comparisons and the highlighting of similarities possible, while also displaying the differences and changes which configurations of masculinity have undergone over time. Thus, the diachronic dimension of the exemplary texts analyzed should make it possible to relativize presuppositions premised on archetypical patterns, on universal deep structure conflicts, and on biological determinism, thus enabling us to inquire whether the phenomena and configurations dealt with are not, in fact, indicative of and possibly restricted to a given age and cultural context.

In this sense, it should become possible to demonstrate that the instability of modern male gender identity can be understood as the consequence of historical processes, and male sexuality as a changing and historically conditioned product that has been falsely regarded as a natural constant. ${ }^{20}$ Therefore, the contributions analyzing the texts of Malory, Shakespeare, Mackenzie, and Hardy create an important historical backdrop, a temporal horizon before which the twentieth- and twenty-first-century texts, which make up the main part of this volume, can be more rewardingly analyzed than from a merely synchronic point of view.

Given the savoir litterraire or specific quality of literary texts briefly outlined above, it is not surprising that the analyses gathered in this volume furnish proof that texts which were written centuries ago still speak to us today: while Christoph Houswitschka's reading of Thomas Malory's Morte Darthur focuses on the timeless role of the male body, its importance for maintaining a strong masculinity, and the threats to which it is exposed, Mark Bracher's reading of Shakespeare's As You Like It convincingly illustrates how this Early Modern comedy offers a cogent critique of dominant masculinity together with a strong case for embracing alternative masculinity scripts that are less harmful to others and more fulfilling to their bearers themselves. Bracher repeatedly emphasizes the timelessness or extratemporality of literature, arguing that: "The first step in answering the question of how literature, and especially Shakespeare's As You Like It, might

\footnotetext{
${ }^{20}$ See Walter Erhart and Britta Herrmann, “Der erforschte Mann?", in Wann ist der Mann ein Mann? Zur Geschichte der Männlichkeit, eds Walter Erhart and Britta Herrmann, Metzler: Stuttgart 1997, 12.
} 
help us to overcome opposing and outdated scripts of masculinity is to understand the effects that Shakespeare's theatrical script can have on the cognitive scripts that variously constitute and determine readers' definition, understanding, evaluation, and enactment of masculinity." 21

While Bracher draws on cognitive psychology and uses the contemporary concept of internalized gender scripts to read Shakespeare, Rainer Emig stresses the relevance which The Man of Feeling has for contemporary society by arguing that in Mackenzie's country gentleman "Harley" we can see a trial run of modern masculinity, or rather of the various acceptable shapes of modern masculinities. My own metaphorical reading of Thomas Hardy's nineteenth-century novel Jude the Obscure advances a semiotic and Lacanian approach to demonstrate that the problems Hardy's protagonist Jude Fawley faces when constructing his male gender identity are by no means simply caused by or restricted to the social conditions of the nineteenth century, but rooted in Jude's fatal and fundamental misunderstanding of how signs work.

The analyses dedicated to literature of the twentieth and twentyfirst centuries, and therefore to highly contemporary configurations of masculinity, focus on texts by Ian McEwan, Will Self, Hanif Kureishi, Caryl Phillips, and others - on texts that are so popular that they more or less directly interfere with, and even shape, contemporary postmodern and postcolonial society and its concomitant constructions of male gender identity. In his contribution on the rise of the workingclass hero, Sebastian Müller argues that the "original angry young men", Jimmy Porter (Look Back in Anger) and Joe Lampton (Room at the Top), are not only in a class conflict, but also a gender conflict. Nevertheless, both of them "produce" themselves as typical workingclass heroes and follow a male role-model which provides a simple but effectively reaffirming mode of male identity formation in a twentieth-century world of shifting identities.

In her contribution on Ian McEwan, Fatemeh Hosseini emphasizes McEwan's obsessional, steady sketching and re-sketching of masculinities. She analyzes the portrayal of masculinity in a post-patriarchal era, the way it is intertwined with the thematic motif of death, and the emergence of a new socio-cultural era characterized by what she terms "filiarchy".

${ }^{21}$ See Mark Bracher's article in this volume, pp. 98-99. 
The next two articles deal with postcolonial, and to some degree, postethnic masculinities: Bettina Schötz's essay analyzes how Hanif Kureishi's postethnic short stories explore contemporary configurations of masculinity by depicting the disruption of traditional, patriarchal, and hegemonic notions of masculinity in the postfeminist era and imagining alternative forms of male gender practice. Moreover, Schötz argues in favor of a specific savoir littéraire, for example in Kureishi's "Morning in the Bowl of Night", and suggests a definition of masculinity based on a critical reading of both, Judith Butler and Elizabeth Deeds Ermarth.

In her article "Of Invisible Men and Native Sons: Male Characters in Caryl Phillips' Fiction", Bénédicte Ledent takes the prominent male presence in Phillips' In the Falling Snow as a starting point for an analysis of the relative deficit in masculine visibility in his earlier fiction, for example in texts such as The Final Passage or A Distant Shore. She argues that the male presence in In the Falling Snow not only begs for a re-examination of the male figures in Phillips' earlier work but also calls into question the dichotomies that often permeate conventional approaches to gender.

In the last contribution to this volume, Daniel Lukes' "Surrogate Dads: Interrogating Fatherhood in Will Self's The Book of Dave", the question of fathers' rights are taken up once again. Luke argues that The Book of Dave develops Self's ongoing interest in fathers, children, and fatherhood as a key nexus where masculinity and patriarchy are reproduced. Moreover, he depicts how the novel engages and interrogates matters of paternity, patriarchy, power, the religions of the father, the malaise of millennial British working-class masculinities, and the question of what it might mean to be a post-patriarchal dad. 


\title{
ConcePts of Masculinity ANd Masculinity Studies
}

\author{
TODD W. REESER
}

\begin{abstract}
This essay provides a conceptual history of the study of masculinity in the English-speaking academy from the birth of "men's studies" in the 1980s to current work on global masculinities. With a move away from masculinity as singular toward a focus on multiple masculinities, the influential system of theoretical types of masculinities largely attributed to the work of sociologist R.W. Connell-including especially the concept of "hegemonic masculinity" - set the stage for later work that extended or critiqued the relation between power and categories of masculinities. During this period, sociologists and historians such as Michael Kimmel demonstrated that there was a history of men and masculinity, and that historical crises of masculinity were possible and worthy objects of study. The importance accorded to questions of identities led to a large body of work on the relations between masculinity and homosexuality, women, transgender, race, colonialism, and ethnicity. In what might be considered a branch of masculinity studies that came of age under the influence of Eve Sedgwick, scholars invested in post-structuralist thought or in questions of literary/cultural representation, increasingly considered how masculinity is a complex phenomenon often or always defined by movement and change.
\end{abstract}

As Stefan Horlacher discusses in his introductory article to this volume, literature and masculinity go hand in hand. As a kind of conscious or unconscious fantasy or projection of other worlds, literature can reveal aspects of masculinity that might not come out or be visible in daily life or in other types of cultural artifacts. While it is true that film, painting, sculpture, performance art, and music channel and 
question masculinity and while it is true that literature is in no way the only purveyor of gendered representation, literary form necessarily produces its own unique representation of masculinity, and for this reason, literary analysis in the twenty-first century constitutes a crucial and vibrant wing of masculinity studies. Consequently, many academics and graduate students in the US take it for granted that literary representations of masculinity are a viable and desirable object of intellectual inquiry. In hindsight, it seems inevitable that literary scholars, with their interest in textual subjectivities more broadly, would take up questions around this type of subjectivity too.

But it was not always so. Early work on literary masculinity such as Coppélia Kahn's Man's Estate: Masculine Identity in Shakespeare (1981) and Peter Schwenger's Phallic Critiques: Masculinity and Twentieth-century Literature (1984) broke new ground, proving by example that masculinity could be a viable object of inquiry in the analysis of fiction. ${ }^{1}$ It was, however, Eve Sedgwick's Between Men (1985) that radically changed the terms of both literary studies and gender studies, as "homosocial" became a staple term in the academy. ${ }^{2}$ Despite this important work in literary criticism, the birth of the study of masculinity in the 1980s can be characterized as largely nonliterary in nature, with the social sciences taking the most visible lead in what was then a new and sometimes controversial approach to gender.

Meant to complement Horlacher's Introduction, this article focuses not on the question of the relation between literature and masculinity in theoretical terms, but rather on the actual trajectory of the study of men and masculinity in the English-speaking academy. It traces the trajectory of academic work among both literary scholars and social scientists, revealing both overlaps and disjunctions between the two sets of scholars. As a kind of introduction to the field of masculinity studies, it is intended especially for readers interested in the genealogy of the field of inquiry and in the concomitant history of the articulation of conceptual or theoretical elements around men and masculini-

\footnotetext{
${ }^{1}$ Coppélia Kahn, Man's Estate: Masculine Identity in Shakespeare, Berkeley: University of California Press, 1981; Peter Schwenger, Phallic Critiques: Masculinity and Twentieth-century Literature, London: Routledge and Kegan Paul, 1984.

${ }^{2}$ Eve Kosofsky Sedgwick, Between Men: English Literature and Male Homosocial Desire, New York: Columbia University Press, 1985.
} 
ty, most of which come to inflect readings of literary masculinity today.

In nearly all cases, questions of identity - whether cultural or individual - are central to masculinity studies, meaning that approaches to flesh-and-blood human beings and approaches to literary representations are not fully distinct. Sociological or anthropological understandings of masculinity can be and were in many ways imported to literary studies: literary constructs of masculinity may validate conceptions of gender in the social sciences, but literariness may also transform such conceptions in ways that only take place within the fictional text.

\section{The birth of "men's studies"}

Work on masculinity in the 1980s was often responding, directly or indirectly, to the idea that masculinity was natural or essential, or, in the social sciences, was responding to sex role theory, in which the male sex role was taken as a uniform, stable, and normative configuration to which actual males do or do not conform. In his pioneering book The Myth of Masculinity, the psychologist Joseph Pleck explained that there was at the time no systematic formulation of the male sex role identity paradigm (MSRI). ${ }^{3}$ Although his book aimed to critique that approach to gender, he provided a comprehensive overview of the paradigm in a series of eleven propositions.

The first and most important proposition was: "Sex role identity is operationally defined by measures of psychological sex typing, conceptualized in terms of psychological masculinity and/or femininity

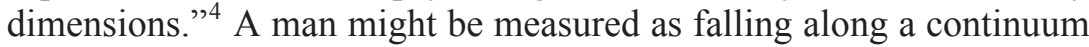
defined by traits or characteristics considered appropriate for his sex, with male traits at one end female traits at the other. ${ }^{5}$ In more complex cases, the unconscious might be part of this measurement, so that a man might be taken to have a conscious masculinity and an unconscious femininity. Or, psychological masculinity and femininity might be taken as independent of each other instead of as opposites on the same continuum (the "dual-unipolar conception", or the "androgynous conception"). But in all of these cases, Pleck points out, "sex-typed characteristics [are] organized along dimensions of psychological

\footnotetext{
${ }^{3}$ Joseph H. Pleck, The Myth of Masculinity, Cambridge, MA: MIT Press, 1981.

${ }^{4}$ Ibid., 16.

${ }^{5}$ Ibid., 17.
} 
masculinity and/or femininity" and they "assume dimensions of the personality experienced by the individual as masculine and/or feminine". ${ }^{6}$ Sex role identity was considered "necessary for good psychological adjustment because of an inner psychological need for it", with homosexuality considered a disturbance of an appropriate identity. ${ }^{7}$ Despite the seeming normativity of the propositions, sex role identity was not natural or God-given, but rather learned behavior (in particular, from adults, parents, and, especially, a parent of the same sex). ${ }^{8}$ Appropriate identity was seen as difficult to develop, especially for black males, and this difficulty could explain boys' trouble in school.

Against an intellectual background that tended to consider gender as singular, scholars increasingly moved to treating masculinity as plural, while not forgetting that it tends to manifest certain recurring characteristics such as homophobia, power, and dominance over women. After presenting the MSRI paradigm, for instance, Pleck took the approach to task, positing an alternative approach to the study of masculinity, termed the sex role strain (SRS) paradigm. His fundamental proposition in this paradigm was: "Sex roles are operationally de-

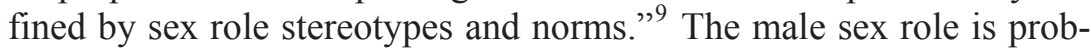
lematic in the sense that traits or qualities taken to define that role are based on shared ideas about what a man is or ought to be. Those definitions are not simple, Pleck explains, but are based in contradiction and inconsistency, and the percentage of men who violate such roles is high. ${ }^{10}$ Since roles change over time, this is another cause of sex role strain. ${ }^{11}$ Pleck's new model thus rejects simple notions of what a man is or should be as definitional of gender, and helps move the study of psychological masculinity toward the idea that the male sex role needs to be imagined as complicated and multiple. For if violation of the male sex role is normal, then that role cannot in fact define any single norm.

As new approaches came to be articulated, gender (even if culturally defined) was not assumed simply to precede human acts, but to be created by them. Consequently, revisioning masculinity as a critical enterprise meant that new types of masculinity could be created aca-

\footnotetext{
${ }^{6}$ Ibid., 18.

${ }^{7}$ Ibid., 21.

${ }^{8}$ Ibid., 19-20.

${ }^{9}$ Ibid., 135.

${ }^{10}$ Ibid., 143-44.

${ }^{11}$ Ibid., 152-53.
} 
demically and pedagogically. A defining moment - perhaps the defining moment - in the move toward multiplicity was the publication of the collection of essays The Making of Masculinities: The New Men's Studies (1987). In his Introduction, the editor Harry Brod (a humanities-based scholar) wrote that the volume is critical of the idea that "all too often, scholars have tended to write too simplistically of the male sex role, rather than the multiplicity of male roles". ${ }^{12}$ As the first chapter of the volume, Joseph Pleck's own essay offered a history of male sex-role identity since $1936,{ }^{13}$ which other authors played off as an outdated approach. Following Pleck's essay, Brod's own essay in the volume, "The Case for Men's Studies", articulated what this new approach to gender might mean. For him, one of the problems in the academy is that "while women's studies corrects the exclusion of women from the traditional canon caused by androcentric scholarship's elevation of man as male to man as generic human, the implications of this fallacy for our understanding of men have gone largely unrecognized".

Brod's volume, then, called for - but also put into practice - an approach to men as gendered beings, and positioned an emerging field of study as "a necessary complement to women's studies". Toward these ends, Brod defined the new men's studies in general terms as "the study of masculinities and male experiences as specific and varying social-historical-cultural formations". ${ }^{14}$ During this time, generally viewed as a second stage in men's studies, scholars increasingly thought through the specificity of masculinities - in time, place, and culture. The volume included essays on a wide variety of topics (for instance, race, athletics, career, myth, biology, male bonding) and from a variety of disciplines (especially sociology, history, literature).

Brod's volume can be taken as a beacon of a new body of research, which included new journals, conferences, and a growing number of publications in the social sciences and humanities on men and masculinities. As a sign that men's studies was reaching a wider audience, an article penned by Brod appeared in 1990 in the American mainstream academic publication The Chronicle of Higher Education un-

\footnotetext{
${ }^{12}$ Harry Brod, Introduction, in The Making of Masculinities: The New Men's Studies, ed. Harry Brod, Boston: Allen and Unwin, 1987, 7 (emphasis in the original).

${ }^{13}$ Joseph H. Pleck, "The Theory of Male Sex-Role Identity: Its Rise and Fall, 1936 to the Present", in ibid., 21-38.

${ }^{14}$ Harry Brod, "The Case for Men's Studies", in ibid., 40 (emphasis in the original).
} 
der the title "Scholarly Studies of Men: An Essential Complement to Women's Studies". ${ }^{15}$

One element of the coming of age of men's studies was the idea that masculinity had to be made visible, to be brought out as an object of study, and to not be considered an unmarked category (in the way that woman or homosexuality as categories were marked and could not easily be ignored or forgotten). Masculinity's traditional invisibility, it was widely thought, was one way in which it maintained its power: by denying implicitly or explicitly that men were gendered, they could escape close scrutiny and resist critique or the need to change. As Antony Easthope wrote: "Social change is necessary and a precondition of such change is an attempt to understand masculinity, to make it visible."16 For this to take place, various questions about masculinity would have to be explicitly asked, including questions about the male body, history, and cultural images. As Michael Kimmel asked in his essay "Invisible Masculinity": "If the pursuit of manhood has been a dominant theme in American history, at least rhetorically and metaphorically, why do American men still have no history?" For him, the response was: "In part because they do not even know what questions to ask." " Of particular importance in making the male body visible as a gendered body was the presence of masculinity on screen, which, consequently, led to an increase in studies of masculinity in film and in the media. ${ }^{18}$

During the period of transition in the 1980s, the study of men and masculinity remained in close dialogue with feminism. In fact, in some cases the line between feminism and masculinity studies was not entirely clear, with volumes such as Alice Jardine and Paul Smith's Men in Feminism (1987) and Joseph Boone and Michael Cadden's

${ }^{15}$ Harry Brod, "Scholarly Studies of Men: An Essential Complement to Women's Studies", Chronicle of Higher Education, 21 March 1990: http://chronicle.com/article/ Scholarly-Studies-of-Men-an/70081/.

${ }^{16}$ Antony Easthope, What a Man's Gotta Do: The Masculine Myth in Popular Culture, Boston: Unwin Hyman, 1990, 7 (emphasis in the original).

${ }^{17}$ Michael S. Kimmel, "Invisible Masculinity", in The History of Men: Essays in the History of American and British Masculinities, ed. Michael S. Kimmel, Albany: State University of New York Press, 2005, 4.

${ }^{18}$ See e.g. Steve Neale, "Masculinity as Spectacle", Screen, XXIV/6 (November 1983), 2-16; Screening the Male: Exploring Masculinities in Hollywood Cinema, eds Steven Cohan and Ina Rae Hark, London: Routledge, 1993; Susan Bordo, "Reading the Male Body", Michigan Quarterly, XXXII/4 (Fall 1993), 696-737. 
Engendering Men: The Question of Male Feminist Criticism (1990). ${ }^{19}$ It was considered crucial that the study of men and masculinity be articulated as part of a feminist project, or as "male feminist criticism". At the same time, an explicit element of the study of men and masculinity came to be a consideration of whether men were in fact co-opting women or feminine positions as a way to outdo or outwit women and, in this sense, issuing a backlash against feminism and the gains of women. Elaine Showalter's essay, titled "Critical CrossDressing: Male Feminists and the Woman of the Year", asks whether male feminism is "a form of critical cross-dressing, a fashion risk of the 1980s that is both radical chic and power play", and considers the question of male appropriation of power in texts such as the film Tootsie, in which a male character cross-dresses and becomes a better woman than the women characters. ${ }^{20}$ Considerations of whether a man who "becomes" a woman (by cross-dressing, by reading as a woman, by appropriating birth, etc.) was re-empowering men were feminist in origin, but this critical approach provided what became (and remains) a current of masculinity studies in which similar critical questions can be asked in configurations in which a man takes on characteristics not generally attributed to him.

The continuing relation between feminism and masculinity meant that, in other cases, scholars were suspicious of mythopoetic or Jungian-influenced attempts to reposition masculinity as essential or natural, to the point that such suspiciousness helped define men's studies in the 1990s. Most famously in an American context, the 1990 publication of Robert Bly's best-selling book Iron John: A Book about Men provoked scholarly discourse that was largely critical of the book. Bly posited some basic myths of manhood through ancient stories and legends, to give birth to a new, vigorous manhood simultaneously centered on emotion. Bly wrote in his Preface that his book "does not seek to turn men against women, not to return men to the domineering mode that has led to repression of women and their values for centuries". He viewed the men's movement as operating "on a separate timetable" from the women's movement, and as not

${ }^{19}$ Men in Feminism, eds Alice Jardine and Paul Smith, New York: Methuen, 1987; Engendering Men: The Question of Male Feminist Criticism, eds Joseph A. Boone and Michael Cadden, New York: Routledge, 1990.

${ }^{20}$ Elaine Showalter, "Critical Cross-Dressing: Male Feminists and the Woman of the Year", in Men in Feminism, 120; see also Tania Modleski, Feminism Without Women: Culture and Criticism in a 'Postfeminist' Age, New York: Routledge, 1991. 
excluding gay men. ${ }^{21}$ Scholars in men's studies from the early 1990 s, however, often responded rather negatively to the book, the book's popularity, and the mythopoetic approach in a larger sense, viewing the book as a challenge to many of the presuppositions about the study of men that they had worked to popularize and as perhaps symptomatic of the continuing need or desire to view masculinity as natural or essential.

Several of the essays in the important volume Theorizing Masculinities were specific in their critiques. ${ }^{22}$ Scott Coltrane, for instance, commented on the "misogynist overtones" of the community conjured up by Bly and critiqued such approaches to gender as reducing "historically and culturally specific myths and practices to universal psychological or biological truths, thereby ignoring the social structural conditions that produced them". "Pierrette Hondagneu-Sotelo and Michael Messner concluded that "the mythopoetic men's movement may be seen as facilitating the reconstruction of a new form of hegemonic masculinity - a masculinity that is less self-destructive, that has revalued and reconstructed men's emotional bonds with each other, and that has learned to feel good about its own Zeus power". ${ }^{24}$ The popularity of these kinds of mythopoetic approaches challenged the profeminist men's movement, and for scholars engaged in men's studies, brought concern that these two movements might be viewed as one and the same. However the mythopoetic movement helped men's studies define itself as an academic movement based not on an essential core of masculinity, but on an assumption of multiple masculinities.

As Brod had suggested in his call for a new men's studies, one element of a paradigm shift was to consider how masculinity had changed over time. To study historical changes of masculinity was to show its plurality. The historian-sociologist Michael Kimmel, one of

\footnotetext{
${ }^{21}$ Robert Bly, Preface, in Iron John: A Book about Men, New York: Random House, 1990, x.

${ }^{22}$ See Scott Coltrane, "Theorizing Masculinities in Contemporary Social Science", in Theorizing Masculinities, eds Harry Brod and Michael Kaufman, Thousand Oaks, CA: Sage, 1994, 39-60; Pierrette Hondagneu-Sotelo and Michael A. Messner, "Gender Displays and Men's Power: The 'New Man' and the Mexican Immigrant Man", in ibid., 200-18; Michael S. Kimmel and Michael Kaufman, "Weekend Warriors: The New Men's Movement", in ibid., 259-88.

${ }_{23}$ Coltrane, "Theorizing Masculinities in Contemporary Social Science", 45.

${ }^{24}$ Hondagneu-Sotelo and Messner, "Gender Displays and Men's Power”, 204.
} 
the best known and prolific scholars of men and masculinity, has published extensively on ways in which masculinity is constructed culturally and historically, especially in the US. In the Introduction to his comprehensive historical study Manhood in America, Kimmel defined the two key elements of writing about men as men: "first, to chart how the definition of masculinity has changed over time; second, to explore how the experience of manhood has shaped the activities of American men." ${ }^{25}$ His approach allowed for examinations of key aspects or morphologies of masculinity, such as "the self-made man". Whereas traditionally women's history was taken as reacting to men's history, the direction of the influence could be reversed, since, in his words, "definitions of masculinity are historically reactive to changing definitions of femininity". ${ }^{26}$ Historians in British history who have worked on men and masculinity include John Tosh, whose work on Victorian England traces key shifts in what it meant to be a man, and in Australian history, Martin Crotty who traces shifts in ideal middleclass masculinity in late-nineteenth and early-twentieth-century Australia. ${ }^{27}$

While this kind of diachronic change might be taken as the domain of history, literary representation, too, charts changing definitions of masculinity. Moderation, for instance, was a key definitional element of early-modern European masculinity, but today in much of the West may be seen quite differently. ${ }^{28}$ A key component of the study of the history of masculinity or of the representation of masculinity is the definition of cultural morphologies that change over time (for example, the courtier, the dandy, the gentleman, the metrosexual), and the question of the unstable relation among similar morphologies across time periods. ${ }^{29}$ The history of masculinity does not have to be studied, however, as morphologies or as a series of traits culturally associated

\footnotetext{
${ }^{25}$ Michael Kimmel, Introduction, in Manhood in America: A Cultural History, New York: Free Press, 1996, 2.

${ }^{26}$ Michael Kimmel, "The Contemporary 'Crisis' of Masculinity in Historical Perspective", in The Making of Masculinities, 123 (emphasis in the original).

${ }^{27}$ John Tosh, A Man's Place: Masculinity and the Middle-class Home in Victorian England, New Haven, CT: Yale University Press, 1999; Martin Crotty, Making the Australian Male: Middle-Class Masculinity, 1870-1920, Carlton South: Melbourne University Press, 2001.

${ }^{28}$ See Todd W. Reeser, Moderating Masculinity in Early Modern Culture, Chapel Hill, NC: University of North Carolina Press, 2006.

${ }^{29}$ See Todd W. Reeser, Masculinities in Theory: An Introduction, Malden, MA: Wiley Blackwell, 2010, 216-26.
} 
with men, but can also be studied as a series of tensions or contradictions within definitions of what a man means, mirroring Pleck's psychological ideas on masculinity as inherently contradictory.

One key strain of approaches to masculinity considers when and why men are in a state of crisis, or considers the socio-historical moments in which definitions of what a man is or should be change. The idea that masculinities change over time, and that certain historical moments are more stressful for men than others became canonical in thinking about historicity. While some took certain historical moments as more crisis-filled than other ones, other scholars viewed masculinity as always, in a certain sense, in a state of crisis and considered that labeling a given period as a crisis assumes that there are other periods when masculinity is somehow free of anxiety or crisis. Crises might be provoked by changes in the status or women or homosexuality, or by cultural shifts in labor, capital, or the nation. Within the area of American cultural studies, Bryce Traister isolated a crisis theory "rooted in a new historiography of American masculinity that locates instability at the base of all masculine identities constructed within American cultural matrices". ${ }^{30}$ As Traister's article suggests, the crisis model of masculinity has inflected historical studies as well as literary criticism. Consequently, what happens in a literary text might be taken to signify not a character's own crisis, but embody a larger cultural crisis resulting from shifts in what masculinity is taken to mean.

\section{Hegemonic masculinity}

Often considered the most influential theoretical concept in the history of the study of men and masculinity, "hegemonic masculinity" is widely attributed to R.W. Connell's seminal book Masculinities (1995). ${ }^{31}$ Tim Carrigan, Bob Connell, and John Lee's earlier essay, "Toward a New Sociology of Masculinity" (1987), however, also discussed the concept at length. Responding to assumptions of masculinity as stable, the three authors defined hegemonic masculinity as "a question of how particular groups of men inhabit positions of power and wealth, and how they legitimate and reproduce the social relation-

\footnotetext{
${ }^{30}$ Bryce Traister, "Academic Viagra: The Rise of American Masculinity Studies", American Quarterly, LII/2 (June 2000), 276.

${ }^{31}$ R.W. Connell, Masculinities, Berkeley: University of California Press, 1995. But see also R.W. Connell, Gender and Power: Society, the Person and Sexual Politics, Stanford, CA: Stanford University Press, 1987; and R.W. Connell, Which Way Is Up? Essays on Sex, Class and Culture, Sydney: Allen and Unwin, 1983.
} 
ships that generate their dominance". In a given culture, even if hegemonic masculinity may not be so common but "may only correspond to the actual characters of a small number of men", nonetheless "large numbers of men are complicit in sustaining the hegemonic model". ${ }^{32}$

Men's dominance over women was central to this definition, but so was the heterosexuality of hegemonic masculinity, at least in most modern cultures. One advantage of this approach to gender, then, was that it married "the gay movement's" and feminist approaches to masculinity by considering that hegemonic masculinity usually situates itself negatively vis-à-vis both gay men and women. The model also helped make historicity central to de-essentializing masculinity: "'Hegemony' ... always refers to a historical situation, a set of circumstances in which power is won and held. The construction of hegemony is not a matter of pushing and pulling between ready-formed groupings but is partly a matter of the formation of those groupings." 33 In particular, that construction takes place, the authors suggested, through commercial mass media, the gendered division of labor, and the state. These social relations are inextricably linked to the gendered psyche, meaning that the study of hegemonic masculinity should take both socio-historical as well as psychological factors into account.

To study hegemonic masculinity is essentially to employ a relational model predicated on power as the central organizing element of gender. In his book Masculinities, Connell called for considerations not only of diversity in considering masculinities, but also of "the relations between the different kinds of masculinity: relations of alliance, dominance and subordination". ${ }^{34}$ Such relations between types of masculinity are dynamic, not static, and a shift or change with respect to gender entails a corresponding shift or change in definitions of hegemonic masculinity. This approach transformed the study of masculinity in part by disbanding the idea that to study masculinity was to study types or static characteristics of men. Hegemonic masculinity should not be seen, then, as "a fixed character type, always and everywhere the same", but rather as "the masculinity that occupies the

\footnotetext{
${ }^{32}$ Tim Carrigan, Bob Connell and John Lee, "Toward a New Sociology of Masculinity", in The Making of Masculinities, 92.

${ }^{33}$ Ibid., 94 (emphasis in the original).

${ }^{34}$ R.W. Connell, Masculinities, 37 (emphasis in the original).
} 
hegemonic position in a given pattern of gender relations, a position always contestable". ${ }^{35}$

In order to sketch out the key relations in the model, Connell famously lays out four categories: hegemony, subordination, complicity, and marginalization. Taking the idea of hegemony from the Italian political theorist Antonio Gramsci, Connell defines a gendered revision of Gramsci's concept as "the configuration of gender practice which embodies the currently accepted answer to the problem of the legitimacy of patriarchy, which guarantees (or is taken to guarantee) the dominant position of men and the subordination of women". ${ }^{36}$ Hegemonic masculinity in a given context establishes subordinate masculinities, especially but not exclusively male homosexuality. Men who may benefit from gender hegemony, but may not actually meet its criteria, fall into the category of complicity: "Masculinities constructed in ways that realize the patriarchal dividend, without the tensions or risks of being the frontline troops of patriarchy, are complicit in this sense. ${ }^{37}$ Marginalized masculinities are not so much subordinate as much as they are dependent on hegemonic masculinity for authorization. Connell's examples in this category pertain largely to race: "in the United States, particular black athletes may be exemplars for hegemonic masculinity. But the fame and wealth of individual stars has no trickle-down effect; it does not yield social authority to black men generally." While these categories of analysis became widespread in academic studies, they were nonetheless sketchy and meant to be what Connell herself calls "a sparse framework" intended to bring about further study. ${ }^{38}$

The large scope of the concept of hegemonic masculinity meant that it was widely employed as a theoretical model, but also that it was criticized, often because of what it left out. Michael Flood studies the slippage in Connell's own use of the term. It is unclear, he writes, whether hegemonic masculinity represents "a particular configuration of gender practice related to patriarchal authority, or describes whatever type of masculinity is dominant in a given social order". ${ }^{39}$ For

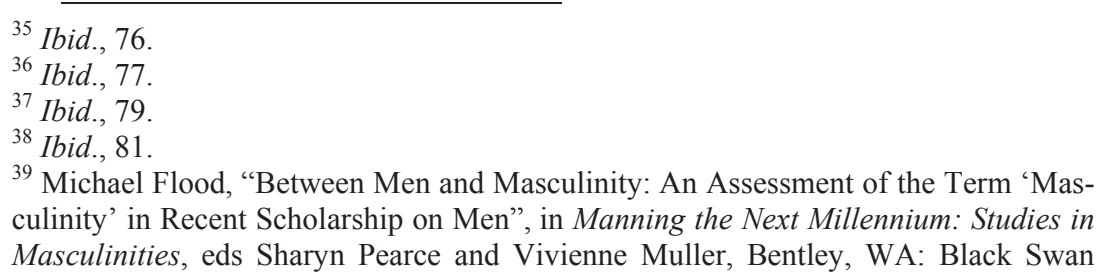


Flood, Connell's linkage between hegemonic masculinity as "cultural ideal" and as "patriarchal gender practice" is problematic since influential representations of masculinity circulating in culture may or may not correspond to practices of masculinity. ${ }^{40}$

Margaret Wetherell and Nigel Edley criticized the model because it does not treat the question of how the four categories "actually prescribe or regulate men's lives". 41 Taking a discourse-centered approach, they articulate the concepts of "imaginary positions" and "psycho-discursive practices" as linguistic techniques whereby individual men create relations to hegemonic masculinity in everyday interactions with other people. Another recurring critique resided in the idea that the model does not suggest the possibility that a minority or subordinate position can come to influence the hegemonic, but assumes discrete relations between types of masculinities.

For Demetrakis Demetriou, hegemonic masculinity should be taken not as pure, but as hybrid: by virtue of appropriating nonhegemonic elements, it can transform itself "in a very deceptive and unrecognizable way" by appropriating and transforming "what appears counter-hegemonic and progressive into an instrument of backwardness and patriarchal reproduction". ${ }^{42}$ While a man may seek to subordinate women, for instance, he may also incorporate elements of women or femininity into his own hegemonic identity. As was the case in the feminist work discussed earlier, men who cross-dress as women, for instance, may not become subordinate or marginal men at all, but rather reaffirm their status as hegemonic.

Connell's model could be taken as not creating sufficient space for resistance to masculine hegemony by subordinate groups. While Connell emphasizes the constant contestation of hegemonic masculinity, the question of how that contestation takes place or what its results might be is not articulated at much length. Conversely, the question of how women might in fact function as part of hegemonic masculinity

Press 2002, 208; see also Patricia Yancey Martin, "Why Can't a Man Be More Like a Woman? Reflections on Connell's Masculinities", Gender and Society, XII/4 (August 1998), 473.

${ }^{40}$ Flood, "Between Men and Masculinity", 208.

${ }^{41}$ Margaret Wetherell and Nigel Edley, "Negotiating Hegemonic Masculinity: Imaginary Positions and Psycho-Discursive Practices", Feminism and Psychology, IX/3 (August 1999), 336.

${ }^{42}$ Demetrakis Z. Demetriou, "Connell's Concept of Hegemonic Masculinity: A Critique", Theory and Society, XXX/3 (June 2001), 355 (emphasis in the original). 
except as subordinate is not a major concern in the model, as the male dominance of women is taken as a stable given. Could, for instance, a woman leader or businesswoman in fact be more hegemonic than a man? Challenging the theoretical hegemony of hegemonic masculinity, Eric Anderson allows for the concept of "inclusive masculinity" in contexts in which cultural homophobia is diminished or diminishing. ${ }^{43}$

In a recent essay, Connell and Messerschmidt responded to the lengthy reception of the concept of hegemonic masculinity. For them, two aspects of the early discussion of hegemonic masculinity should be rejected: first, "a single pattern of power, the 'global dominance' of men over women" and, second, the idea that masculinity is "an assemblage of traits" ${ }^{44}$ In their article, they defend the continuing use of hegemonic masculinity in academic work, but they also suggest ways to update and reformulate the concept through expanded thinking about gender hierarchy, geography (including the local, regional, and global), embodiment, and the dynamics of the concept itself.

\section{Race and masculinity}

Hegemonic masculinity relates not only to women and homosexuality, but also to race. Connell had labeled black masculinity in the US as marginal, because, while it may exemplify certain elements of hegemonic masculinity, it is still not recognized, nor can it remain as such, meaning that the whiteness of hegemonic masculinity cannot be ignored. Predating the publication of Connell's Masculinities by more than a decade, Robert Staples' landmark Black Masculinity: The Black Male's Role in American Society, took a conflict theory perspective, positioning black masculinity as inherently oppositional: "As a starting point, I see the black male as being in conflict with the normative definition of masculinity." "Staples defined black men's "dual dilemma": "their subordination as a racial minority has more than cancelled out their advantages as males in the larger society." ${ }^{46}$ Importing

\footnotetext{
${ }^{43}$ Eric Anderson, Inclusive Masculinity: The Changing Nature of Masculinities, New York: Routledge, 2009; see also Mark McCormack, The Declining Significance of Homophobia: How Teenage Boys Are Redefining Masculinity and Heterosexuality, New York: Oxford University Press, 2012.

${ }^{44}$ R.W. Connell and James W. Messerschmidt, "Hegemonic Masculinity: Rethinking the Concept", Gender and Society, XIX/6 (December 2005), 846-47.

${ }^{45}$ Robert Staples, Black Masculinity: The Black Male's Role in American Society, San Francisco, CA: Black Scholar Press, 1982, 2.

${ }^{46}$ Ibid., 7.
} 
the Francophone theorist Frantz Fanon's model of blackness and colonialism in an innovative way, Staples considered African American masculinity as a form of gender colonized through the history of slavery in the US. Yet, his study does not consider masculinity solely as a black man-white man conflict, as it takes homosexuality and relations with women into account as well.

Despite Staples' ground-breaking book, the role of blackness was far from a major concern of work in the 1980s, but since then black or African American masculinity has come to play an increasingly important role in the field. Majors and Billson treat a specific form of black masculinity - the cool pose, "a ritualized form of masculinity that entails behaviors, scripts, physical posturing, impression management, and carefully crafted performances that deliver a single, critical message: pride, strength, and control". ${ }^{47}$ Maurice Wallace's Constructing the Black Masculine participates in a new wave of work post-1994, with the express aim of "bringing race to bear on a crisis theory in order precisely to deny the normativity of those erstwhile deployments". ${ }^{48}$ Part of such a de-normatizing process is to focus not simply on how the black man is represented or relates to hegemonic masculinity, but on the question of how racialized bodies are framed visually. As Wallace explains his subject matter: "enframement ... is the ur-trope of black male specularity for this study."

While blackness might be the most widely considered racial configuration, scholars focusing on race and ethnicity in the Anglophone world have considered how given masculinities are analogically linked with the feminine or with effeminacy, how they relate to hypermasculinity or machismo, and how such analogies break down or do not function. Extending parallels between the primitive and castration in Freud, David Eng analyzes cultural representations of Asian American masculinity as symbolically castrated. His approach, however, is dual as he identifies "not only textual moments in which the Asian American male subject is coerced and held to certain (de)idealized sexual and racial identifications but also instances when these identifi-

\footnotetext{
${ }^{47}$ Richard Majors and Janet Mancini Billson, Cool Pose: The Dilemmas of Black Manhood in America, New York: Macmillan, 1992, 4.

${ }^{48}$ Maurice O. Wallace, Constructing the Black Masculine: Identity and Ideality in African American Men's Literature and Culture, 1775-1995, Durham, NC: Duke University Press, 2002, 6.

${ }^{49}$ Ibid., 8.
} 
cations fail or threaten to break down". ${ }^{50}$ Asian American masculinity has provoked a fair amount of discussion in American studies. ${ }^{51}$ In a different context, Mrinalini Sinha studies gender constructs of Asian men as effeminate during the British empire. ${ }^{52}$ Under the influence of Said's Orientalism, representations of a lacking masculinity in nonwestern men are often taken as viewed through an orientalizing lens by which European hegemony is established via gender. In addition, work on Jewish masculinity treats a variety of questions related to culture, ethnicity, and religion, including its perceived effeminacy and its status as marginalized. ${ }^{53}$ While Latino and Native American masculinity in the US have been discussed with less frequency than black masculinity, Pierrette Hondagneu-Sotelo and Michael Messner put Connell's model of hegemonic/marginalized/subordinated masculinities into dialogue with Mexican immigrant men, Alfredo Mirandé made a case for a profeminist Chicano/Latino men's studies, Richard Rogers studies visual representations of Native American masculinity in the figure of the Kokopelli, and Kathleen Glenister Roberts studied Native Americans and masculinity within the context of war. ${ }^{54}$ Shino

50 David L. Eng, Racial Castration: Managing Masculinity in Asian America, Durham, NC: Duke University Press, 2001, 29.

${ }^{51}$ See, for instance, King-Kok Cheung, "Of Men and Men: Reconstructing Chinese American Masculinity", in Other Sisterhoods: Literary Theory and U.S. Women of Color, ed. Sandra Kumamoto Stanley, Urbana: University of Illinois Press, 1998, 17399; Jinqi Ling, "Identity Crisis and Gender Politics: Reappropriating Asian American Masculinity", in An Interethnic Companion to Asian American Literature, ed. KingKok Cheung, New York: Cambridge University Press, 1997, 312-37; Joon Oluchi Lee, "The Joy of the Castrated Boy", Social Text, XXIII/3-4 (Fall-Winter 2005), 3556.

${ }^{52}$ Mrinalini Sinha, Colonial Masculinity: The "Manly Englishman" and the "Effeminate Bengali" in the Late Nineteenth Century, Manchester: Manchester University Press, 1995.

${ }^{53}$ See e.g. A Mensch Among Men: Explorations in Jewish Masculinity, ed. Harry Brod, Freedom, CA: Crossing Press, 1988; Harry Brod, "Some Thoughts on Some Histories of Some Masculinities: Jews and Other Others", in Theorizing Masculinities, 82-96.

${ }^{54}$ Hondagneu-Sotelo and Messner, "Gender Displays and Men's Power"; Alfredo Mirandé, Hombres y Machos: Masculinity and Latino Culture, Boulder, CO: Westview Press, 1997; Richard A. Rogers, "Deciphering Kokopelli: Masculinity in Commodified Appropriations of Native American Imagery", Communication and Critical/Cultural Studies, IV/3 (September 2007), 233-55; Kathleen Glenister Roberts, "War, Masculinity, and Native Americans", in Global Masculinities and Manhood, eds Ronald Jackson II and Murali Balaji, Urbana: University of Illinois Press, 2011, 141-60. 
Konishi engages with the question of the whiteness of hegemonic masculinity within the context of Australian Aboriginal masculinity. ${ }^{55}$

If masculinity should no longer be taken to be invisible, the same should be said of whiteness as a racial construct. To study white masculinity as racialized and as gendered, then, is to render visible two types of identities often invisible. Analogies between race and gender that privilege white masculinity include muscularity ${ }^{56}$ and explain, for instance, why bodybuilding may be imagined as a white sport or why muscular heroes such as Tarzan, Hercules, or Rambo are so often white, or perceived as white. Work on race and masculinity grew in other directions as well, as evidenced for instance by the essays collected in Stecopoulos and Uebel. ${ }^{57}$ Discussions of interracial masculinity show, too, how connections or relations between men of diverse races are gendered. With an American tradition of white-black males who love each other - as represented most famously by Huckleberry Finn and the slave Jim - interracial masculinities in US film have been a particular focus of this kind of work. ${ }^{58}$

\section{Complicating masculinity}

Over the course of the 1990s, "masculinity" or "masculinities" as terms increasingly came to replace "men's studies". To take one example, the name of the Men's Studies Review was changed to masculinities in 1993, a change implying that "men's studies" is not a direct reaction against "women's studies". Often, the phrase "men and masculinities" is employed in English to simultaneously allow for links and disjunctures between sex and gender. But the increasing use of the terms "masculinity" or "masculinities" is often thought to suggest that they do not have to be directly or naturally linked with the male body or with men, and that they are complicated and unstable phenomena, not easily pinned down and not necessarily what they appear to be, thus much more than simply the lives of actual men. Many scholars in

\footnotetext{
${ }^{55}$ Shino Konishi, “Aboriginal Masculinity in Howard's Australia”, in ibid., 161-85.

${ }^{56}$ See Richard Dyer, White, New York: Routledge, 1997.

${ }^{57}$ Race and the Subject of Masculinities, eds Harry Stecopoulos and Michael Uebel, Durham, NC: Duke University Press, 1997.

${ }^{58}$ See Donald Bogle, Toms, Coons, Mulattoes, Mammies, and Bucks: An Interpretive History of Blacks in American Films, New York: Continuum, 2001; Melvin Donalson, Masculinity in the Interracial Buddy Film, Jefferson, NC: McFarland, 2006; Brian Locke, Racial Stigma on the Hollywood Screen from World War II to the Present: The Orientalist Buddy Film, New York: Palgrave Macmillan, 2009.
} 
humanities fields such as literature, film, or cultural studies prefer the terms, possibly rejecting "men's studies" altogether, because they suggest a focus on questions of representation. This semantic shift is indicative, too, of other changes in the field, including the move away from an almost exclusive focus on male bodies and the move toward approaches inflected with post-structuralist thought.

The term "masculinity" may emphasize its social-constructedness, and consequently, that it is open to reconstruction. The plural "masculinities" is taken to reflect multiplicity, including those related to race and nation. While some scholars consider the vagueness and expansiveness of masculinity as a positive because it reflects the fact that gender itself is difficult to pin down, for others the shift creates confusion around the seemingly nebulous term or diverts attention from men's gendered practices. ${ }^{59}$ Clatterbaugh suggests some specific semantic confusions in this regard, including incoherencies produced by taking masculinity as discursively constructed. ${ }^{60}$

One way to study how masculinity is not what it appears to be is not to separate masculinity and homosexuality as two separate elements (as hegemonic and marginal for instance), but to consider them as overlapping identities. Men may not make direct reference to homosexuality, but it may nonetheless subtend masculine relations. While homophobia and the objectification of women were both often taken as central defining elements of masculinity in the 1980s, Eve Sedgwick's Between Men (1985) articulated a widely influential model of homosociality that brought together feminist and gay approaches to the study of literary representations of masculinity. Some scholars in literary studies consider it an inaugural book in the move from feminism to gender studies. Sedgwick herself writes that she is "assimilating 'French' feminist - deconstructive and/or Lacanian-oriented feminism - to the radical-feminist end of this spectrum". ${ }^{61}$

While Sedgwick's ground-breaking book made its way into some contemporaneous work in social-science work in men's studies, it is rarely cited or discussed, suggesting a rather strict separation between

59 Jeff Hearn, "Is Masculinity Dead? A Critique of the Concept of Masculinity/masculinities", in Understanding Masculinities: Social Relations and Cultural Arenas, ed. Máirtín Mac an Ghaill, Buckingham: Open University Press, 1996, 20217.

${ }^{60}$ Kenneth Clatterbaugh, "What Is Problematic about Masculinities?", Men and Masculinities, I/1 (July 1998), 24-45.

${ }^{61}$ Sedgwick, Between Men, 11. 
more literary/cultural approaches and social science ones, even as Sedgwick's work resembled that of other scholars in that it aimed to incorporate both feminist and gay approaches. Based partially on anthropological theory, Sedgwick's study posits that the relation between two seemingly heterosexual men and certain relations of desire between men and women should not be considered separate. Two men might desire the same woman as a way to displace the possibility of homoerotic desire for each other, meaning that the stronger interpersonal relation is not the heterosexual one, but that between the two men. That male-male relation, with patriarchal undertones, suggests that men are sharing power as much as desire through the objectification of the women mutually desired. Behind the triangular model of desire lies the presupposition that male-male relations are located on a continuum of desire that ultimately cannot locate or cannot stabilize male-male relations as strictly "heterosexual". As she writes: "To draw the 'homosocial' back into the orbit of 'desire,' of the potentially erotic ... is to hypothesize the potential unbrokenness of a continuum between homosocial and homosexual." ${ }^{\text {"2 }}$ Her notion of a continuum of desire mirrored previous work in feminist thought that considered women's relation with women on a continuum of desire, and disbanded the over-simple idea that women's sexuality is fluid while men's is not.

As a result of Sedgwick's book, the words "homosocial" and "homosociality" became widely used in the study of men and masculinity, as male-male interactions - even when two men do not specifically desire the same women - are taken to fall on a continuum of male homosocial desire and as the instability of men's interactions makes it difficult to term them purely heterosexual. The role of female homosociality is hardly discussed in Between Men, and Sedgwick herself calls for more work on "the relations between female-homosocial and male-homosocial structures". ${ }^{63}$ In addition, the question of whether her model could be taken to apply to non-European cultures is one that she raises: "any attempt to treat [this book's formulations] as crosscultural or (far more) as universal ought to involve the most searching and particular analysis." ${ }^{64}$ In terms of the analytic practice of masculinity, Sedgwick makes a case for thinking in sophisticated ways about

\footnotetext{
${ }^{62}$ Ibid., 1.

${ }^{63}$ Ibid., 18.

${ }^{64}$ Ibid., 19.
} 
representation as integral to the way in which power functions: "Before we can fully achieve and use our intuitive grasp of the leverage that sexual relations seem to offer on the relations of oppression, we need more - more different, more complicated, more diachronically apt, more off-centered - more daring and prehensile applications of our present understanding of what it may mean for one thing to signify another." ${ }^{65}$ From her first textual reading of Shakespeare's Sonnets to her last one on Charles Dickens' The Mystery of Edwin Drood, historicity and contextualization are central to reading homosociality, leaving open the adaption of her approach to other time periods that she does not specifically treat.

With her focus on interpretive complexity in the representation of gender relations, Sedgwick sets the stage to consider movementcentered approaches to masculinity, including the queerness within heterosexual masculinity. If one of the presuppositions of queer theory is that male homophobia is attempting to expel the abject queer from within, then there is necessarily something queer about or within masculinity in the first place. Or, alternately, excessive forms of masculinity may point to an instability of masculinity that contains something queer. An anti-normative gender presentation, the hypersexual man, for instance, may act the way he does because he is attempting to expel, or is responding to, an anxiety of queerness within.

If heterosexual masculinity can be taken as queer in some sense, it can also be taken as "performative". Judith Butler famously articulates the idea that gender is performative in her ground-breaking Gender Trouble. ${ }^{66}$ While the book focuses on gender and not masculinity specifically, her theoretical concepts can be brought to bear on masculinity in productive ways, ${ }^{67}$ and have had an immense influence on masculinity studies, particularly in the humanities. Butler famously suggests that the traditional distinction between sex and gender is no distinction at all, but that gender should be taken as "the very apparatus of production whereby the sexes themselves are established". ${ }^{6}$ In this sense, then, "maleness" or "manhood" in its biological configuration (as influenced by testosterone, the male sex drive, or the penis,

\footnotetext{
${ }^{65}$ Ibid., 11 .

${ }^{66}$ Judith Butler, Gender Trouble: Feminism and the Subversion of Identity, New York: Routledge, 1990.

${ }^{67}$ See Reeser, Masculinities in Theory, Chapter 3.

${ }^{68}$ Butler, Gender Trouble, 7.
} 
for instance) can be understood as elements of gender as constructed through the medium of language. It is not testosterone itself that makes a man, but how we understand this element of biology or what we make of it. The male body (like the sexed body in a larger sense) does not have inherent meaning, except as we ascribe meaning to it. In this sense, as per Butler's ideas in Bodies that Matter, ${ }^{69}$ men have to "assume" their maleness. They both take it on and take it for granted. In addition, men are not acting masculine because of something in their genes or in their blood, but by virtue of the fact that their gendered acts implicitly refer to or cite innumerable actions that others have already undertaken - actions that provide authority, meaning, and stability for the current act. So the masculinity of a given cowboy in a film is supported and made possible by an entire host of links between masculinity and space, the frontier, guns, etc. that have been previously made and repeated. From a Butlerian approach, masculinity can be considered as a "corporeal style", ${ }^{70}$ not unchanging and open to change over an individual's life or over a historical time period.

In parallel with the post-structuralist commonplace that signifier and signified do not naturally correspond, the term "masculinity" no longer has to be taken with respect to its supposedly natural receptacle, the male body. While almost all early work on masculinity focused on masculinity and the male body, American studies scholar Judith "Jack" Halberstam's influential book Female Masculinity broke new ground by arguing that a full understanding of masculinity requires that we include considerations of it as separate from the male body: "far from being an imitation of maleness, female masculinity actually affords us a glimpse of how masculinity is constructed as masculinity." ${ }^{71}$ This argument is part of a larger claim that masculinity "becomes legible as masculinity where and when it leaves the white male middle-class body". ${ }^{72}$ For Halberstam, then, it is necessary to maintain "a degree of indifference to the whiteness of the male and the masculinity of the white male and the project of naming his power" and to consider male masculinity as a "counterexample to

\footnotetext{
${ }^{69}$ Judith Butler, Bodies that Matter, New York: Routledge, 1993.

${ }^{70}$ Butler, Gender Trouble, 139.

${ }^{71}$ Judith Halberstam, Female Masculinity, Durham, NC: Duke University Press, 1998, 1 .

${ }^{72}$ Ibid., 2.
} 
the kinds of masculinity that seem most informative about gender relations and most generative of social change". ${ }^{73}$

But if female masculinity should be integral to the study of gender, Halberstam is asking, then why has female masculinity not been an object of study? In the same way that cultural discourses may render female masculinity a non-ideal gender presentation that should not exist, scholars of (male) masculinity may have been participating in an academic discourse in which masculinity can only be male. While Halberstam's book begins to fill the lacuna in the field, this lack in masculinity studies has still not been sufficiently filled, ${ }^{74}$ particularly with respect to heterosexual female masculinities. Aiming to position female masculinity as a diachronic phenomenon that should be integrated into histories of masculinity, Halberstam also established a methodology (termed "perverse presentism") by which previous morphologies of female masculinity can be studied.

If a complete study of masculinity must consider the role of women, the same must be said with respect to disabled, gay male, and transgender subjects. Analogies might be made between disability and lack of masculinity, or conversely between ability and masculinity, but more complicated relations between disability and masculinity might also obtain. ${ }^{75}$ Similarly, gay male masculinities have a varying relation to masculinity, and should be taken in their plurality. ${ }^{76}$ The historically recent notion that male homosexuality is closely connected to effeminacy is challenged in part by considering a range of gender presentations among gay men, including the rejection of effeminacy in favor of gay hegemonic masculinity and racial homosexualities. Gay male masculinity might also be taken as an oscillation between hegemonic and non-hegemonic positions, as dependent on situation, with the closet, passing, and "straight acting" as key elements of such a consideration.

\footnotetext{
${ }^{73}$ Ibid., 3.

${ }^{74}$ But in the literary realm, see Jean Bobby Noble, Masculinities without Men? Female Masculinity in Twentieth-Century Fictions, Vancouver: University of British Columbia Press, 2004.

${ }^{75}$ See Gill Valentine, "What It Means to be a Man: The Body, Masculinities, Disability", in Mind and Body Spaces: Geographies of Disability, Illness, and Impairment, eds Ruth Butler and Hester Parr, London: Routledge, 1999, 167-80; Nicole Markotić and Robert McRuer, "Leading with Your Head: On the Borders of Disability, Sexuality, and the Nation", in Sex and Disability, eds Robert McRuer and Anna Mollow, Durham, NC: Duke University Press, 2012, 165-82.

${ }^{76}$ See Peter M. Nardi, Gay Masculinities, Thousand Oaks, CA: Sage, 2000.
} 
Recent work in transgender studies rethinks masculinity from a new perspective barely acknowledged in the 1980s and 1990s. One of the major sections in the field-defining The Transgender Studies Reader focuses of transgender masculinities. ${ }^{77}$ Taking transgender into account means that masculinity cannot a priori be taken as natural or as the strict province of men, at least in the traditional sense of the word. That a woman can transition and be considered or pass as a man implies that the signifier "masculinity" does not correspond in any direct or natural way to a given signified. Perhaps more radically, if transgender is taken as a transition toward movement itself, not as a change from one discrete sex to another, then the trans body might destabilize stable definitions of masculinity by inventing new gendered configurations. Transgender as an analytic category forces a reconsideration of hegemonic masculinity as well. To transition to becoming a man might (re)affirm the desirability of hegemonic masculinity or, on the other hand, might permit it to be destabilized from within (as a man who challenges gender hegemony). Trans or drag king performance may also question assumptions of male biology as the basis of masculinity. ${ }^{78}$ Female-to-male transgender subjects may or may not challenge masculine hegemony, and if they believe that testosterone creates maleness, may envision sex in a non-Butlerian way as biological. In short, as Henry Rubin writes: "Transgender men have the potential to generate either alternative or hegemonic forms of masculinity." "79 Jason Cromwell discusses the cases of transmen who queer masculinity by revamping cultural discourses to construct a transidentity that can be conveyed to or understood by others. Further, the notion of a masculinity continuum (often thought of as masculinity opposed to femininity, or homosocial opposed to homoerotic) can be reconsidered in light of transgender. ${ }^{80}$ The sometimes very fluid borderline between butch and female-to-male transgender permits con-

\footnotetext{
${ }^{77}$ See The Transgender Studies Reader, eds Susan Stryker and Stephen Whittle, New York: Routledge, 2006.

${ }^{78}$ See Diane Torr and Stephen Bottoms, Sex, Drag, and Male Roles: Investigating Gender as Performance, Ann Arbor, MI: University of Michigan Press, 2010.

${ }^{79}$ Henry Rubin, Self-Made Men: Identity and Embodiment among Transsexual Men, Nashville, TN: Vanderbilt University Press, 2003, 145.

${ }^{80}$ Jason Cromwell, "Queering the Binaries: Transsituated Identities, Bodies, and Sexualities", in The Transgender Studies Reader, 509-20.
} 
siderations of the fluidity of masculinity itself, and of the value attached to sex and masculinity in butch and trans subjects. ${ }^{81}$

If some work takes for granted that the unstable signifier masculinity has no natural referent, it may also assume that masculinity is constituted through complicated forms of representation. Most of this work comes not out of social sciences, but out of the humanities, and is often directly or indirectly subtended by post-structuralist thought. An early example of theoretically-informed work, Victor Seidler's Rediscovering Masculinity took a discourse-centered perspective to masculinity and aimed in part to "reclaim language as a facet of experience". ${ }^{82}$ Under the influence of the French philosopher Jacques Derrida's notions of deferral, some thinkers cast masculinity as an unending, ultimately un-definable phenomenon, composed not so much of social constructs per se but of an unending series of questions. As the cultural critic Homi Bhabha writes in an essay on masculinity: "my own masculinity is strangely separating from me, turning into my shadow, the place of my filiation and my fading. My attempt to conceptualize its conditionality becomes a compulsion to question it." 83 My own Masculinities in Theory takes a systematic and comprehensive approach to masculinity as movement-centered, not as a fixed object of inquiry, and discusses how select post-structuralist theories that do not take masculinity as an object of inquiry can nonetheless be brought to bear on its analysis. Although, for instance, the French philosopher Michel Foucault's theoretical models on power and discourse do not refer to masculinity per se, and have been considered with respect to women, homosexuality, and other non-hegemonic categories, masculinity can be taken in Foucauldian terms as discursively constructed. ${ }^{84}$ One can argue that there is no original form of masculinity, and that its inherent diffuseness means that it cannot ultimately be located in a single place and that it needs to be considered as a fragmented phenomenon a priori. Work on masculine anxiety is also, in a different way, part of a movement-centered approach since it

${ }^{81}$ See Halberstam, Female Masculinity, Chapter 5; Gayle Rubin, "Of Catamites and Kings: Reflections on Butch, Gender, and Boundaries", in The Transgender Studies Reader, 471-81.

${ }^{82}$ Victor J. Seidler, Rediscovering Masculinity: Reason, Language, and Sexuality, London: Routledge, 1989, 5.

${ }^{83}$ Homi K. Bhabha, “Are You a Man or a Mouse?”, in Constructing Masculinity, eds Maurice Berger, Brian Wallis and Simon Watson, New York: Routledge, 1995, 58.

${ }^{84}$ See Reeser, Masculinities in Theory, 29-35. 
assumes masculinity has to respond, perhaps constantly, to anxiety in order to be, or to give the impression of being, stable and static. ${ }^{85}$

While there is often an academic split between these kinds of movement-centered approaches and social-science approaches in men's studies, the former approaches are politically engaged in the sense that they attempt to upend the perception of masculinity as universal and stable and allow for numerous other possibilities. If inherently unstable, hegemonic masculinity cannot maintain its dominance or the perception of dominance. As David S. Gutterman writes in his outline of postmodern interrogations of masculinity: "Postmodern theories of subjectivity, identity, and agency ... can be useful not only for rethinking governing cultural values but also as a framework for actively seeking social change." ${ }^{\prime 86}$ In his discussion, Gutterman makes a case for such approaches to be considered in political coalition building, which depends on gathering fractured constituencies together for a common goal: "the appreciation of difference enables a coalition ... not to try to figure out what $a$ new cultural script for masculinity ought to be. Instead, the coalition could focus on destabilizing and denaturalizing the scripts in place and create the space for a variety of different masculinities to be performed." ${ }^{, 87}$

If stable or movement-centered approaches are, however, taken as antithetical to each other, a possible compromise position between them would be to consider that the experience of masculinity (and of gender in a larger sense) is predicated on a movement between stability or essentialism on the one hand, and free play on the other. ${ }^{88}$ While masculinity itself may be essential or fluid, the experience of masculinity on a daily basis likely oscillates between the sense that it has a core or is natural, and the sense that it is fluid or fragmented. Or, as I have discussed with respect to what I call "a moderate approach to masculinity": "The essentialism that I experience might also place me

\footnotetext{
${ }^{85}$ See also Calvin Thomas who takes the writing of the male body as his topic, arguing that "the mechanisms of assuagement are ideologically embedded in cultural modes of representational containment that govern and restrict the visibility of male bodies and male bodily productions" (Calvin Thomas, Male Matters: Masculinity, Anxiety, and the Male Body on the Line, Urbana: University of Illinois Press, 1996, 3).

${ }^{86}$ David S. Gutterman, "Postmodernism and the Interrogation of Masculinity", in Theorizing Masculinities, 224.

${ }^{87}$ Ibid., 234.

${ }^{88}$ Eve Kosofsky Sedgwick, “'Gosh, Boy George, You Must Be Awfully Secure in Your Masculinity!'”, in Constructing Masculinity, 18.
} 
in a position in which essentialism is not exactly opposed to free play since essentialism might actually help me to understand that free play better." Or conversely, "because I focus on my masculinity as freefloating and non-essential, I might have moments in which I feel masculinity as a core". ${ }^{89}$ While a substantial body of work that takes such a moderate approach and seeks to destabilize the split between stability or essentialism and free-play has yet to appear, this theoretical approach gestures toward a theoretical apparatus that has the potential better to link together humanities-based and other types of work.

\section{Anthropology and the global turn}

A recent, growing body of research gestures toward a key future direction in the study of masculinity, namely the global and the transnational. In 1990, patterns of masculinity within the context of cultural difference were already the focus of anthropologist David Gilmore's Manhood in the Making: Cultural Concepts of Masculinity. Taking into account a number of western and non-western cultures, he studies what it means to be a man or to be a "real man" in selected cultures. The "regularity" that interests him "is the often dramatic ways in which cultures construct an appropriate manhood - the presentation or 'imaging' of the male role". 90 Among his material-based conclusions is the idea that "Manhood is the social barrier that societies must erect against entropy, human enemies, the forces of nature, time, and all the human weaknesses that endanger group life". ${ }^{91}$ A groundbreaking and innovative book at the time of its publication, Gilmore's book was subsequently viewed by some as lacking sufficient plurality in its view of masculinity. In his survey of anthropological approaches to masculinity up until the mid-1990s, Don Conway-Long, for instance, comments on Gilmore's failure to recognize "the plurality of masculinities within any of the cultures he analyzed". ${ }^{92}$ As Conway-Long also suggests, the anthropological work of Gilbert Herdt from the 1980s on South-Pacific-islander cultures and initiation ceremonies could be taken as part of the history of anthropological approaches to masculin-

\footnotetext{
${ }^{89}$ Reeser, Masculinities in Theory, 51.

${ }^{90}$ David D. Gilmore, Manhood in the Making: Cultural Concepts of Masculinity, New Haven: Yale University Press, 1990, 11.

${ }^{91}$ Ibid., 226.

92 Don Conway-Long, "Ethnographies and Masculinities", in Theorizing Masculinities, 61 (emphasis in the original).
} 
ity ${ }^{93}$ even if Herdt's work is not necessarily often imagined in that trajectory.

Despite the growing body of work on non-western masculinities, as Ronald Jackson II and Murali Balaji write, "masculinity studies has generally been ghettoized by a Eurocentric paradigm of whiteness and its Others, the latter most closely associated with the representations and assumed practices of black masculinity". ${ }^{94}$ Scholars are, however, increasingly working on how masculinity is constructed in cultures around the globe, but they are also increasingly interested in how masculinities travel or transition from one cultural zone to another.

Connell calls for work on global masculinities, and sketches out three major types of globalizing masculinity: masculinities of conquest and settlement, masculinities of empire, and masculinities of postcolonialism and neoliberalism. ${ }^{95}$ The small amount of work on the topic largely relates to transnational business or corporate masculinity or to global politics and militarism. Christine Beasley rethinks hegemonic masculinity for consideration of a global context, one aspect of her argument being that the term should focus "on its meaning as a political mechanism involving the bonding together of different masculinities in a hierarchical order". ${ }^{96}$ One might consider what happens to an Asian form of hegemonic masculinity when it encounters an African form, for example. Beasley also calls for thinking about "plural hegemonic masculinities" in a global context with "the language of 'supra' and 'sub' hegemonic" that allow for a range of masculinities to be placed in global dialogue. ${ }^{97}$ Connell and Messerschmidt call for hegemonic masculinities to be studied at the local, regional, and global level, but also to take the links between the three levels into account. ${ }^{98}$ As the world continues to become increasingly global and as the study of masculinity follows suit, scholars are likely to imagine what specific interactions between spatially-defined masculinities will

${ }^{93}$ Ibid., 66-70.

${ }^{94}$ Ronald Jackson II and Murali Balaji, Introduction, in Global Masculinities and Manhood, 21.

${ }^{95}$ R.W. Connell, "Masculinties and Globalization", Men and Masculinities, I/1 (July 1998), 12-16; see also Connell in this volume.

${ }^{96}$ Christine Beasley, "Rethinking Hegemonic Masculinity in a Globalizing World", Men and Masculinities, XI/1 (October 2008), 99.

${ }^{97}$ Ibid., 100.

${ }^{98}$ Connell and Messerschmidt, "Hegemonic Masculinity”, 849. 
take place, and in turn how those interactions will wash back onto the study of gender itself. ${ }^{99}$

99 This article is a shortened and thoroughly reworked version of Todd Reeser, "Englischsprachige Männlichkeitsforschung", in Handbuch Männlichkeit, eds Stefan Horlacher, Bettina Schötz and Wieland Schwanebeck, Stuttgart: Metzler, forthcoming. 


\title{
MAsCulinities: The Field OF KNOWLEdGe
}

\author{
RAEWYN CONNELL
}

\begin{abstract}
In the last twenty-five years a body of international research on masculinities has consolidated and important conclusions of this research are as follows: there are multiple masculinities, there are hierarchies of masculinities, often defining a hegemonic pattern for a given society; masculinities are collective as well as individual; masculinities are actively constructed in social life; masculinities are internally complex; masculinities change throughout history. Certain masculinities operate in global, not just local, arenas. We can trace this historically through the phases of imperialism, colonialism, de-colonization, and contemporary globalization. New masculinities are also emerging in global business. At the same time, movements that aim to reform masculinities have developed in many countries. While many men resist change because of the dividend they get from patriarchal gender systems, there are also important motives for men to change their gender practices. The article argues that such changes or reforms are most likely to be successful when they emphasize social justice as well as gender diversity or de-gendering.
\end{abstract}

\section{Conceptualizing gender and masculinity}

In the last four decades, there has been a huge growth of debate and investigation on men as gendered beings, on questions about masculinity. The main impulse for this was the women's movement and its problematization of gender. Most feminist research has, for good reasons, focused on the lives of women. But gender is inherently relational. Even if our understanding of gender is no more than sex differences, there must always be two terms in a difference. 
A closer look at gender shows the reality involves much more complex patterns than simple difference. Gender is also about relationships of desire and power, and these must be examined from both sides. In understanding gender inequalities it is essential to research the more privileged group as well as the less privileged. For good reasons, then, there has been a marked growth in gender-informed research about men and masculinities, ${ }^{1}$ which now comes from every region of the world. ${ }^{2}$

This project requires more than simply an examination of men as a statistical category. It requires an examination of men's gender practices; the ways the gender order defines, positions, empowers, and constrains men; and the consequences of those definitions in culture and in the lives of women. In short, it is necessary to study masculinity.

By "masculinity" I mean the pattern or configuration of social practices linked to the position of men in the gender order, and socially distinguished from practices linked to the position of women. Masculinity is not a pre-social category. Masculinity constantly refers to male bodies (sometimes symbolically and indirectly), but is not determined by male biology. One can, therefore, speak of masculine women, and feminine men; of gender ambivalences and contradictions. This is, indeed, an important theme in gender analysis, since the days of Sigmund Freud.

An understanding of masculinity starts with the gender orders in which masculinities are defined. There are different perspectives on this question. Perhaps the most widespread in the social sciences and in professional practices adopts the concept of "sex roles". Sex role theory explains gender patterns by appealing to the social customs that define proper behavior for women and for men.

${ }^{1}$ See Handbook of Studies on Men and Masculinities, eds Michael Kimmel, Jeff Hearn and Raewyn Connell, Thousand Oaks, CA: Sage, 2005.

${ }^{2}$ See, for example, From Boys to Men: Social Constructions of Men in Contemporary Society, eds Tamara Shefer et al., Lansdowne, South Africa: UCT Press, 2007; Masculinidades y Globalización: Trabajo y Vida Privada, Familias y Sexualidades, ed. José Olavarría, Santiago, Chile: Red de Masculinidad/es, Universidad Academia de Humanismo Cristiano (UAHC) and Centro de Estudios para el Desarrollo de la Mujer (CEDEM), 2009; Xingkui Zhang, Studies of Men and Masculinities in Contemporary China, PhD thesis, Faculty of Education and Social Work, University of Sydney, 2010 . 
Applied to men, the sex role approach emphasizes the way expectations about proper masculine behavior are conveyed to boys as they grow up, by parents, schools, mass media, and peer groups. This theory emphasizes the role models provided by sportsmen, military heroes, etc.; and the social sanctions (from mild disapproval to violence) that are applied to boys and men who do not live up to the role norms. This is a plausible approach to some issues about masculinity. But sex role theory has serious intellectual weaknesses. ${ }^{3}$ It gives no grasp on issues of power, violence, or material inequality. It misses the complexities within femininity and masculinity, and it offers very limited strategies of change.

Another widely used model of gender, which I call "categorical theory", treats women and men as pre-formed categories. In categorical thinking about gender, the focus is on some relation between the pre-determined categories - most often a relation of difference or inequality. This is, for instance, the logical structure underlying most discussions of gender equity policy, such as "Equal Opportunity" statistics contrasting men's employment with women's employment.

Compared with sex role theory, this approach more readily addresses issues of power. But categorical gender research too has difficulty grasping the complexities of gender, such as gendered violence within either of the two main categories. The categorical approach leaves little space for the interplay of gender with class and race, and misses such issues as the importance of unionism for working-class women, or community organizing for indigenous women.

Categorical thinking, in the form of gender essentialism, was the principal target of deconstructive gender theory and post-structuralist approaches that locate gender in the realm of discourse. This became the most popular approach to gender in the Anglophone academic world of the global North, especially in fields such as the humanities that normally deal with texts, documents and discourse. ${ }^{4}$ A large body of research now examines the discursive construction of masculinities in literature, mass media, and other cultural forms.

This approach, enormously productive in some fields, has little grip on others. It is not well suited to political economy, research on institutions, or questions of social dynamics, including most of the

\footnotetext{
${ }^{3}$ See Raewyn Connell, Gender and Power, Cambridge: Polity, 1987.

${ }^{4}$ See Rachel Alsop, Annette Fitzsimons and Kathleen Lennon, Theorizing Gender: An Introduction, Cambridge: Polity, 2002.
} 
urgent problems of policy and practice that concern masculinity in the developing world..$^{5}$ Researchers prioritizing fields such as these tend to emphasize that gender issues always concern a structure of social relations.

In a structural approach, gender is understood as a way in which social practice is ordered. In gender processes, the everyday conduct of life is organized in relation to a reproductive arena, defined by the bodily structures and processes of human reproduction. This arena includes sexual arousal and intercourse; childbirth and infant-care; bodily sex difference, and similarity. I call this a "reproductive arena" rather than a "biological basis" because biology does not determine what happens. Rather, bodies are participants in a historical process as both agents and objects of practice. ${ }^{6}$

Social practice is creative and inventive, but not formless. As social beings, we act in response to particular situations, within definite structures of social relations. Gender relations, the relations among people and groups organized through the reproductive arena, form one of the major structures of all documented societies. Practice that relates to this structure, generated as people and groups grapple with their historical situations, does not consist of isolated acts. Actions are configured in larger units, and when we speak of "masculinity" and "femininity" we are naming configurations of gender practice. Seen in terms of change through time, masculinities and femininities are best understood as gender projects, dynamic arrangements of social practice through time, in which we make ourselves and are made as particular kinds of human beings. ${ }^{7}$

Understanding gender as a fundamentally historical phenomenon means that we must understand gender, and masculinity, in their connection with the most important historical change in modern world history - the process of colonial expansion, conquest, resistance, and the subsequent neocolonialism and postcolonial globalization. It is increasingly recognized that these are crucial contexts for the making of masculinities, both in the colonizing powers and among the colo-

\footnotetext{
${ }^{5}$ See Men and Development: Politicizing Masculinities, eds Andrea Cornwall, Jerker Edström and Alan Greig, London: Zed Books, 2011.

${ }^{6}$ See Raewyn Connell and Rebecca Pearse, Gender: In World Perspective, 3rd edn, Cambridge: Polity, 2014.

${ }^{7}$ Raewyn Connell, Masculinities, 2nd edn, Cambridge: Polity, 2005.
} 
nized, and among the groups and movements and social struggles of the postcolonial world. ${ }^{8}$

\section{Crucial research findings}

Historians and anthropologists have shown that there is no one pattern of masculinity that is found everywhere. Different cultures, and different periods of history, construct masculinity differently. Some cultures regard homosexual sex as incompatible with true masculinity; others think no one can be a real man without having had homosexual relationships. Some cultures make heroes of soldiers, and regard violence as the ultimate test of masculinity; others look at soldiering with disdain and regard violence as contemptible. The masculinities of east Asia, for instance, have a different history and now exist in different configurations from those of, say, North America. ${ }^{9}$

It follows that in large-scale societies there are likely to be multiple definitions of masculinity. Sociological research shows this to be true, with differences of class, ethnicity and generation. Equally important, more than one kind of masculinity can be found within a given cultural setting. Within any workplace, neighborhood or peer group, there are likely to be different understandings of masculinity and different ways of "doing" masculinity. Quite complex negotiations of the meanings of masculinity occur in the flow of everyday life, as shown in ethnographic research. ${ }^{10}$

There are definite relationships between different patterns of masculinity. Typically, some masculinities are more honored than others. Some may be actively dishonored, for example homosexual masculinities in modern Western culture. Some are socially marginalized, for example the masculinities of disempowered ethnic minorities. Some are exemplary, taken as symbolizing admired traits, for example the masculinities of sporting heroes.

The form of masculinity which is culturally dominant in a given setting is commonly called "hegemonic masculinity". "The idea of

${ }^{8}$ See Changing Men in Southern Africa, ed. Robert Morrell, London: Zed Books, 2001.

${ }^{9}$ See Kam Louie and Morris Low, Asian Masculinities: The Meaning and Practice of Manhood in China and Japan, London: Routledge, 2003.

${ }^{10}$ See Matthew Gutmann, The Meanings of Macho: Being a Man in Mexico City, Berkeley, CA: University of California Press, 1996.

${ }^{11}$ For debate on this concept, see Raewyn Connell and James W. Messerschmidt, "Hegemonic Masculinity: Rethinking the Concept", Gender and Society, XIX/6 (De- 
hegemony signals a position of cultural authority and leadership, not total dominance; other forms of masculinity persist alongside. The hegemonic form need not be the most common form of masculinity. A hegemonic masculinity is, however, likely to be highly visible. Hegemonic masculinity is hegemonic not just in relation to other masculinities, but in relation to the gender order as a whole. It is an expression of the privilege men collectively have over women. The hierarchy of masculinities is an expression of the unequal shares in that privilege held by different groups of men.

The gender structures of a society define particular patterns of conduct as "masculine" and others as "feminine". At one level, these patterns characterize individuals. Thus we say that a particular man (or woman) is masculine, or behaves in a masculine way. But these patterns also exist at the collective level. Masculinities are defined and sustained in institutions such as corporations, armies, and governments or schools. Masculinities are defined collectively in the workplace, as shown in industrial research; and in informal groups like street gangs, as shown in criminological research.

Masculinity also exists impersonally in culture. Video games, for instance, not only circulate stereotyped images of violent masculinity. They require the player to enact this masculinity (symbolically) in order to play the game at all. Sociological research on sport has shown how an aggressive masculinity is created organizationally by the structure of organized sport, by its pattern of competition, its system of training, and its steep hierarchy of levels and rewards. ${ }^{12}$ Images of this masculinity are circulated on an enormous scale by sports media, though most individuals fit very imperfectly into the cultural slots thus created.

Masculinities do not exist prior to social behavior, either as bodily states or fixed personalities. Rather, masculinities come into existence as people act. They are accomplished in everyday conduct or organizational life, as patterns of social practice. Close-focus research has

cember 2005), 829-59; Richard Howson, Challenging Hegemonic Masculinity, London: Routledge, 2006; Christine Beasley, "Problematizing Contemporary Men/Masculinities Theorizing: The Contribution of Raewyn Connell and Conceptual-Terminological Tensions Today", British Journal of Sociology, LXIII/4 (December 2012), 747-65.

${ }^{12}$ See Michael A. Messner, Out of Play: Critical Essays on Gender and Sport, Albany: State University of New York Press, 2007. 
shown how we "do gender" in everyday life. ${ }^{13}$ A similar insight has thrown new light on the link between masculinity and crime. This is not a product of a fixed masculine character being expressed through crime. Rather, the link results from a variety of men from impoverished youth gangs on the street to white-collar criminals at the computer using crime as a resource to construct particular masculinities. ${ }^{14}$

A great deal of effort can go into the making of masculinities, hegemonic or non-hegemonic. Research on homosexual men's lives shows that for these men too, identity and relationships involve a complex and sustained effort of construction. ${ }^{15}$ One reason why masculinities are not fixed is that they are not simple, homogenous patterns. Close-focus research on gender often reveals contradictory desires and logics. A man's active heterosexuality may exist as a thin emotional layer concealing a deeper homosexual desire. A boy's identification with men may co-exist or struggle with identifications with women. The public enactment of an exemplary masculinity may covertly require actions which undermine it. The complexity of desires, emotions or possibilities may not be obvious at first glance. But the issue is important, because these complexities are sources of tension and change in gender patterns. ${ }^{16}$

From the fact that different masculinities exist in different cultures and historical epochs, we can deduce that masculinities are able to change. To speak of the "dynamics" of masculinity is to acknowledge that particular masculinities are composed, historically, and may also be de-composed, contested, and replaced. There is an active politics of gender in everyday life. Sometimes it finds public expression, more often it is local and limited. But there is always a process of contestation and change; and in some cases this becomes conscious and deliberate. This has happened, for instance, in the "men's movements" of North America in the 1980s and 1990s. ${ }^{17}$

\footnotetext{
${ }^{13}$ See Doing Gender, Doing Difference: Inequality, Power, and Institutional Change, eds Sarah Fenstermaker and Candace West, New York: Routledge, 2002.

${ }^{14}$ See James W. Messerschmidt, Masculinities and Crime: Critique and Reconceptualization of Theory, Lanham, MD: Rowman and Littlefield, 1993.

${ }^{15}$ See Gary Wayne Dowsett, Practicing Desire: Homosexual Sex in the Era of AIDS, Stanford, CA: Stanford University Press, 1996.

${ }^{16}$ See Connell, Masculinities.

${ }^{17}$ See Michael A. Messner, The Politics of Masculinities: Men in Movements, Thousand Oaks, CA: Sage, 1997.
} 


\section{Masculinities and world arenas}

The social sciences and humanities have given increasing attention to globalization, and the field of gender studies is no exception. ${ }^{18}$ To understand the relationship between globalization and the formation of masculinities we have to start with the history of colonialism and the structures of empire. Colonization itself was mostly carried out by a workforce of men, and had a profound effect on gender orders among the colonized. As the imperial social order stabilized, it created a hierarchy of masculinities, as it created a hierarchy of communities and races. The colonizers distinguished "more manly" from "less manly" groups among their subjects. In British India, for instance, Bengali men were supposed effeminate, while Pathans and Sikhs were regarded as strong and warlike.

At the same time, the emerging imagery of gender difference in European culture provided general symbols of superiority and inferiority. In the colonizer's mind, the conqueror was virile, while the colonized were dirty and sexualized, or effeminate, or childlike. In many colonial situations indigenous men were called "boys" by the colonizers. In the late nineteenth century, racial barriers in colonial societies were hardening rather than weakening, and gender ideology tended to fuse with racism in forms that the twentieth century has never untangled.

The power relations of empire meant that indigenous gender orders were generally under pressure from the colonizers, rather than the other way around. But the colonizers too might change. The barriers of late colonial racism were not only to prevent pollution from below, but also to forestall "going native", a well-recognized possibility. The pressures, opportunities, and profits of empire might also create changes in gender arrangements among the colonizers. For instance the work of married women changed in households with a large supply of indigenous workers as domestic servants. Empire might also affect the gender order of the metropole itself: through changing gender ideologies, divisions of labor, and the nature of the metropolitan state. For instance, empire figured prominently as a source of masculine imagery in Britain, in the Boy Scouts, and in the cult of "Lawrence of Arabia" as a national hero.

${ }^{18}$ See Esther Ngan-ling Chow, "Gender Matters: Studying Globalization and Social Change in the 21st Century", International Sociology, XVIII/3 (September 2003), 443-60. 
The world of empire created two very different settings for the modernization of masculinities. In the periphery, the forcible restructuring of economies and workforces tended to individualize social relations and rationalize economies. The specific form of masculinity might be local; for instance the Japanese "salary man", a social type first recognized in the first decade of the twentieth century, was specific to the Japanese context of large, stable industrial conglomerates. The result generally was middle-class masculinities defined around economic action and increasingly adapted to emerging market economies. But in recent years this pattern has come under increasing pressure and demands for change. ${ }^{19}$

In the metropole, the accumulation of wealth made possible a specialization of leadership in the dominant classes. Struggles for hegemony followed, in which masculinities organized around domination or violence were split from masculinities organized around expertise. Political contests between Fascism and liberalism, between "hardliners" and "soft-liners", showed these divisions. In the context of both first-wave and second-wave feminism, reform movements appeared, including the temperance movement, companionate marriage, and homosexual rights movements, leading eventually to the pursuit of androgyny in "men's liberation" in the Seventies. Not all reconstructions of masculinity, however, emphasized tolerance. The vehement masculinity politics of fascism, for instance, emphasized both dominance and difference, ${ }^{20}$ a pattern still found in contemporary racist movements.

The process of de-colonization disrupted the gender hierarchies of the colonial order. Some activists and theorists of liberation struggles celebrated masculine violence, as a necessary response to colonial violence and emasculation: women in liberation struggles were less impressed. ${ }^{21}$ However one evaluates the process, one of the consequences of de-colonization was further disruption of community-

\footnotetext{
${ }^{19}$ See Men and Masculinities in Contemporary Japan: Dislocating the Salaryman Doxa, eds James E. Roberson and Nobue Suzuki, London: Routledge, 2003.

${ }^{20}$ See Männlichkeitskonstruktionen im Nationalsozialismus, eds Anette Dietrich and Ljiljana Heise, Frankfurt am Main: Peter Lang, 2013.

${ }^{21}$ See Amina Mama, "Sheroes and Villains: Conceptualizing Colonial and Contemporary Violence against Women in Africa", in Feminist Genealogies, Colonial Legacies, Democratic Futures, eds M. Jacqui Alexander and Chandra Talpade Mohanty, New York: Routledge, 1997, 46-62.
} 
based gender orders, and another step in the re-orientation of masculinities towards national and international contexts.

With the collapse of Soviet Communism, the decline of postcolonial Socialism, and the ascendancy of the new right in Europe and North America, world politics is more and more organized around the needs of transnational capital and the creation of global markets. The neo-liberal agenda has little to say, explicitly, about gender. It speaks a gender-neutral language of "markets", "individuals", and "choice". But the world in which neo-liberalism is ascendant is still a gendered world, and neo-liberalism has an implicit gender politics.

The individual of neo-liberal theory has the attributes and interests of a male entrepreneur. The attack on the welfare state usually weakens the position of women, while the increasingly unregulated power of transnational corporations places strategic power in the hands of particular groups of men. It is not surprising, then, that the installation of capitalism in Eastern Europe and the former Soviet Union has been accompanied by a reassertion of dominating masculinities, a trend that has been turned to advantage by Vladimir Putin.

Among the business executives who operate in global markets, the owners of big capital, and the political executives who interact (and in many contexts merge) with them, we are likely to see the hegemonic masculinities of contemporary globalization. Among the very rich, a defensive masculinity, produced by a conscious toughening education and marked by distrust, seems to prevail. ${ }^{22}$ Among executives, we are more likely to see a masculinity marked by increasing egocentrism, conditional loyalties (even to the corporation), and a declining sense of responsibility for others, seen in neoliberal attacks on welfare recipients and the public sector. Management textbooks portray the manager as a person with no permanent commitments, except (in effect) to the idea of accumulation itself. Contemporary corporate masculinity differs from traditional bourgeois masculinity by its increasingly libertarian sexuality, with a growing tendency to commodify relations with women. In many parts of the world there is a well-developed highlevel prostitution industry catering for international businessmen. Corporate masculinity does not require bodily force, since the wealth on which it rests is accumulated by impersonal, institutional means. But corporations increasingly use the exemplary bodies of elite

${ }^{22}$ See Mike Donaldson and Scott Poynting, Ruling Class Men: Money, Sex, Power, Bern: Peter Lang, 2007. 
sportsmen as a marketing tool (note the phenomenal growth of the corporate sponsorship of sport), and indirectly as a means of legitimation for the whole gender order.

\section{Changing masculinities}

In the days of the small but active Men's Liberation movement in the 1970 s, it was assumed that feminism was good for men, because men too suffered from rigid sex roles. As women broke out of their sex role, men would be enabled to break out of theirs, and would have fuller, better, and healthier lives as a result.

Few men actually followed this path, at least in the short term. Men's dominant position in the gender order has a material pay-off, which I call the "patriarchal dividend" for men, and this dividend is not withering away. The gender segregation of the workforce in the rich countries has declined little in recent years. Men's representation in parliaments worldwide has risen, not fallen, over the last five years. As corporations have gone multinational under the aegis of transnational business masculinity they have increasingly escaped the national-level political structures through which women press for gender equality. International industries such as garment manufacturing and microprocessor assembly are arenas of rampant sexism. Violence against women has not measurably declined.

What might change men's attachment to a patriarchal society? There are several possibilities. First, the appeal of justice itself; men can support change simply because they believe it is right. Statements of human rights, however often they are evaded, do have some force in the long run. Second, though men in general gain the patriarchal dividend, specific groups of men gain very little of it. For instance, working-class youth, economically dispossessed by structural unemployment, may gain no economic advantage at all over the women in their communities. Other groups of men pay a price, alongside women, for the maintenance of an unequal gender order. Gay men are frequently made targets of prejudice and violence, and effeminate men are constantly abused. Indigenous men often experience extremely high rates of unemployment and imprisonment.

Third, men have interests which are not purely egotistic. Most men have relational interests that they share with particular women. Men's lives frequently involve dense networks of relationships with women: with mothers, wives, partners, sisters, daughters, aunts, grandmothers, friends, workmates, and neighbors. Each of these relationships can be 
the basis for men's relational interest in reform. For instance, a father has an interest in his daughter being free of sexual harassment at school, in her having access to education and training, in her growing up a confident and autonomous person.

Which of these interests is actually pursued by particular men is a matter of politics in the quite familiar sense, of organizing in the pursuit of programs. A complex terrain of masculinity politics has emerged in the last generation, which as Messner observes, involves conflicting agendas of change. ${ }^{23}$ It involves a variety of rhetorics and political strategies, visible in comparative studies. ${ }^{24}$ In the Nordic countries, for instance, changes in state policy have been crucial in masculinity politics, such as the funding of paternity leave for new fathers, the famous "father's month". ${ }^{25}$ A crucial fact is that progressive masculinity politics, together with masculinity research, have now emerged in all regions of the world, from Latin America ${ }^{26}$ to south Asia. ${ }^{27}$

This has provided a basis for global initiatives. One of these was undertaken by UNESCO, an attempt to consolidate knowledge about masculinities, violence and peacemaking. ${ }^{28}$ A second was an initiative through the United Nations secretariat, leading to the first worldwide policy document about these issues, the Agreed Conclusions of the 2004 United Nations Commission on the Status of Women on "The Role of Men and Boys in Achieving Gender Equality". ${ }^{29}$ A third is the recent creation of a global network of NGOs and other agencies concerned with change among men, MenEngage.

${ }^{23}$ See Messner, The Politics of Masculinities.

${ }^{24}$ See Bob Pease and Keith Pringle, A Man's World? Changing Men's Practices in a Globalized World, London: Zed Books, 2006.

${ }^{25}$ See Oeystein Gullvag Holter, Can Men Do It? Men and Gender Equality - the Nordic Experience, Copenhagen: Nordic Council of Ministers, 2003.

${ }^{26}$ See Masculinidades y equidad de genero en America Latina, eds Teresa Valdés and José Olavarría, Santiago, Chile: FLACSO-Chile, United Nations Fund for Publication Activities (UNFPA), 1998.

27 See Reframing Masculinities: Narrating the Supportive Practices of Men, ed. Radhika Chopra, New Delhi: Orient Longman Private, 2007.

${ }^{28}$ Male Roles, Masculinities and Violence, eds Ingeborg Breines, R.W. Connell and Ingrid Eide, Paris: UNESCO, 2000.

29 James Lang, Alan Greig and Raewyn Connell, in collaboration with the Division for the Advancement of Women, "The Role of Men and Boys in Achieving Gender Equality", Women 2000 and Beyond series, New York: United Nations Division for the Advancement of Women / Department of Economic and Social Affairs, 2008: http.www.un.org/womenwatch/daw/w2000.html. 
Gender relations involve different spheres of practice, as well as different geographies, so there is an unavoidable complexity in gender politics. The days of simple solutions are long past. As reform agendas develop around the world, ${ }^{30}$ the field of knowledge will be extended and its value, already evident in scientific terms, will be tested more and more in practice. ${ }^{31}$

${ }^{30}$ See Chopra, Reframing Masculinities; Men and Gender Equality: Towards Progressive Policies, eds Jouni Varanka, Antti Närhinen and Reetta Siukola, Helsinki: Ministry of Social Affairs and Health, 2006; Lang, Greig and Connell, "The Role of Men and Boys in Achieving Gender Equality".

${ }^{31}$ This article draws on the framework proposed in my book Masculinities, and on my contribution, "Gender, Men and Masculinities", to Quality of Human Resources: Gender and Indigenous Peoples, ed. Eleanora Barbieri-Masini, Encyclopedia of Life Support Systems, I, UNESCO, 2009, 140-55. I am grateful to the many people who have offered criticisms and extensions to the argument of Masculinities; the real development of social-scientific knowledge is a collective work. 



\title{
On ReAding Men, LAW AND Gender: Legal Regulation and the New Politics of MASCULINITY
}

\author{
RICHARD COLLIER
}

\begin{abstract}
This essay has two aims. First, drawing on themes in the book Men, Law and Gender: Essays on the 'Man' of Law (2010) it explores how an engagement with masculinity has developed in the field of legal studies. The essay argues that particular ideas about men and masculinity have been constituted as distinctive kinds of "social problems" for law at different historical moments, in ways that have served to shape debates about law and gender across a range of areas of social policy in the UK.

Second, building on a recently completed study of fathers' rights groups and on the book Fragmenting Fatherhood: A Socio-Legal Study (2008), the article explores these issues about law and masculinities in the context of debates about fathers' rights politics. It argues, via examples, that studies of fathers' rights and masculinities have much to gain from incorporating a more complex and multilayered account of the gendered male subject and the interconnected nature of the personal lives of women, children and men.
\end{abstract}

A rich body of interdisciplinary theoretical and empirical research has explored, from a variety of perspectives, the gender of men in an explicitly pro-feminist manner. ${ }^{1}$ The depth of contemporary work on

${ }^{1}$ See, for example, R.W. Connell, Masculinities, 2nd edn, Cambridge: Polity, 2005; R.W. Connell, The Men and the Boys, Cambridge: Polity, 2000; R.W. Connell, Gender and Power, Cambridge: Polity, 1987; The Handbook of Masculinity Studies, eds R.W. Connell, Jeff Hearn and Michael Kimmel, London: Sage, 2004; Stephen White- 
masculinities is illustrated by the number of books, articles and research reports on the topic as well as by the existence of dedicated encyclopedias and bibliographic databases. ${ }^{2}$ As the author of one recent study has observed, "issues surrounding men and masculinities have become 'hot politics' in late capitalist societies". ${ }^{3}$ The interaction of structural change and the social and political effects of feminism, in particular, has prompted a new focus on questions about men's identities and practices in what has been referred to as a "new politics of masculinity". ${ }^{4}$

How does law relate to this work? In contrast to developments in English literature, history, sociology and social policy, as well as many other disciplines, there is a distinct sense in which law has lagged behind other fields of study. In 1995 writing Masculinity, Law and the Family, I noted how, at the time, few texts had sought to explore the relationship between masculinity and law. This is no longer the case, however, and over the past fifteen years or so, a picture has emerged of the "man" or, rather, more accurately, the "men" of law. Certainly, this work remains marginal to much mainstream legal study. At international conferences and symposia in the sub-field of law, gender and sexuality studies, it is rare to find workshops focused on law and masculinity. Nonetheless, a now substantial body of scholarship has sought to address the way in which ideas about men and gender have been understood, constructed or otherwise depicted in law.

This essay explores how a critical study of law can inform understanding of the relationship between men and gender in other disciplines, including English literature. ${ }^{5}$ Work on law and masculinity has

head, Men and Masculinities: Key Themes and New Directions, Cambridge: Polity, 2002; The Masculinities Reader, eds Stephen Whitehead and Frank Barrett, Cambridge: Polity, 2001; Jack S. Kahn, An Introduction to Masculinities, Oxford: WileyBlackwell, 2009; Michael Kimmel and Michael Messner, Men's Lives, 8th edn, Boston: Allyn and Bacon, 2010.

${ }^{2}$ See The International Encyclopaedia of Men and Masculinities, eds Michael Flood et al., London: Routledge, 2007, I.

${ }^{3}$ Fidelma Ashe, The New Politics of Masculinity: Men, Power and Resistance, London: Routledge, 2007, 1.

${ }^{4}$ See ibid.; see also Bob Pease, Recreating Men: Postmodern Masculinity Politics, London: Sage, 2000; Alan Petersen, Unmasking the Masculine: Men and Identity in a Sceptical Age, London: Sage, 1999.

${ }^{5}$ This article presents a revised version of material contained in Richard Collier, Men, Law and Gender: Essays on the 'Man' of Law, London: Routledge, 2010 and selected 
raised important questions about the variable and contested meanings that attach to gender and the structures of feeling that shape our lives. Gender struggles involving law have a long and well-documented history. Yet, I shall argue, an amalgam of social, economic and cultural change, alongside the embedding in law, across Western countries, of models of formal equality and ideas of gender neutrality, has reshaped legal-political and cultural terrains based on a particular set of beliefs about men and masculinities. The result is a far-reaching, complex and contradictory politicization of masculinity within and beyond the legal arena, a development that has become a key, if often overlooked, site of conflict around contemporary gender relations.

\section{A brief history: masculinities, law and feminist legal studies}

The interrogation of masculinities within legal studies has occurred at a nexus of developments that, although interconnected, draw on distinct theoretical and political trajectories. The most significant influence has been feminism; or, in legal studies, work sometimes referred to as legal feminism (or, more accurately, legal feminisms ${ }^{6}$ ). The roots of the engagement with masculinity in feminist work in law can be found in the distinction between sex and gender ${ }^{7}$ and, more specifically, post-war social psychological research concerned with sex roles and gender identity. Feminist critiques of the broadly functionalist analyses of masculinity of the 1950s and 1960s revealed an implicit methodological individualism that served to negate any questioning of the social structure, the gendered nature of a contingent, legally constituted public/private divide ${ }^{8}$ and, importantly, the crucial issue of the social power of men. Within feminist texts that began to impact on the discipline of law throughout the 1970s and 1980s, in contrast, a challenge to the structural power of men involved a reframing of how the relationship between masculinity and law was understood.

themes discussed in Richard Collier, "Masculinities, Law and Personal Life: Towards a New Framework for Understanding Men, Law and Gender", Harvard Journal of Law and Gender, XXXIII/2 (Summer 2010), 431-75. I am grateful to the publishers for permission to revise and republish this work here. If not further indicated, references to arguments "elsewhere" or "in other works" are to these two texts.

${ }^{6}$ See Transcending the Boundaries of Law: Generations of Feminism and Legal Theory, ed. Martha Fineman, New York: Routledge, 2011.

${ }^{7}$ See also Wendy Cealey Harrison and John Hood-Williams, Beyond Sex and Gender, London: Sage, 2002.

${ }^{8}$ See Katherine O'Donovan, Sexual Divisions in Law, London: Weidenfeld and Nicolson, 1985. 
In the development of feminist legal scholarship, masculinity has been deployed in different ways in seeking to account for the relationship between women, men and the power of law. There are, I have argued elsewhere, three principal areas in which an engagement with masculinity has featured in feminist legal studies. In relation to each, there exist similarities and differences in how masculinity has been conceptualized, revealing ambiguities about the meaning of the term as it has been used more generally in the study of law and gender.

First, masculinity has been deployed extensively within analyses of institutions and practices relating to diverse aspects of law and legal regulation. Ideas about masculinity have informed, for example, studies of the work of solicitors, barristers and the judiciary. ${ }^{9}$ There exists a rich literature on gender and the courts, police, prisons and criminal justice systems (see below), legal education, the law school and the legislature ${ }^{10}$ as well as the administration of criminal and civil justice. In some accounts of these institutions of law, men's practices, taken together and cumulatively, have been understood to reproduce distinctive cultural forms and belief structures, an ideology of "masculinism" "11 that has deleterious consequences for women and, depending on the reading, some categories of "subordinated" men. ${ }^{12}$

In challenging the gendered cultures of law, feminist scholarship questioned how the masculinity of law's institutions and practices has been linked to the reproduction of discriminatory beliefs and practices. Feminist work has unpacked, for example, the homosocial and homophobic aspects of legal cultures and the gendered perceptions of authority at play within the legal field. ${ }^{13}$ Of particular significance for the argument to follow, feminist work in law has challenged an elaborate silencing of the contingency and structurally grounded nature of men's private lives, not least in relation to social practices of care and

9 See Hilary Sommerlad and Peter Sanderson, Gender Choice and Commitment: Women Solicitors in England and Wales and the Struggle for Equal Status, Aldershot: Ashgate, 1998.

${ }^{10}$ See Margaret Thornton, "Hegemonic Masculinity and the Academy", International Journal of the Sociology of Law, XVII (1989), 115-30; Richard Collier, "Nutty Professors', 'Men in Suits' and 'New Entrepreneurs': Corporeality, Subjectivity and Change in the Law School and Legal Practice", Social and Legal Studies, VII/1 (March 1998), 27-53; Richard Collier, "Masculinism, Law and Law Teaching", International Journal of the Sociology of Law, XIX (1991), 427-51.

${ }^{11}$ Arthur Brittan, Masculinity and Power, Oxford: Basil Blackwell, 1989, 4.

${ }^{12}$ Connell, Masculinities; Connell, Gender and Power.

${ }^{13}$ See Thornton, "Hegemonic Masculinity and the Academy". 
relations of dependency within families. ${ }^{14}$ Feminist scholarship has further identified the persistent benchmarking of women in law against a normative ideal figure, a "man of law". This is an individual seen as both gendered (as male/masculine: assertive, rational, competent, unemotional and so on) and, equally, gender-neutral, notably in relation to commitments associated with caring relationships and practices that fall out with the field of paid employment. ${ }^{15}$

Second, feminist work has explored the connections between masculinity and legal methods and reasoning - the very ways of studying and doing law as a discipline. Questioning the conceptual and political limitations of liberal-progressive feminist legal scholarship, a different strand of feminist work has sought to interpret the relationship between law and masculinity in a rather different way. Far from seeing otherwise gender-neutral legal systems somehow skewed by gendered (that is, masculine) assumptions that resulted from the empirical dominance by men of law's institutions, at issue was precisely the inherent masculinity or maleness of law and global patriarchal legal systems. Within this work, a link was made explicit between law's status as an androcentric, positivist discipline and the masculine nature of law's governance, institutions and jurisprudence. Concepts central to liberal legal thought, such as individualism, reason, autonomy, justice, freedom, were themselves refigured as somehow quintessentially masculine values. ${ }^{16}$

Third, and finally, challenging the essentialism and reductionism of each of the above two approaches, later engagements with masculinity in feminist legal studies were, by the late 1980s and early 1990s, increasingly shaped by the impact of postmodernism and poststructuralism. ${ }^{17}$ This development was taking place across the social sciences, arts and humanities. In the context of law, however, and aligned to the rejection of categorical thinking underway within socio-

\footnotetext{
${ }^{14}$ See Martha Fineman, Autonomy Myth, New York: New Press, 2004; Martha Fineman, The Neutered Mother, The Sexual Family and Other Twentieth Century Tragedies, New York: Routledge, 1995.

${ }^{15}$ See Kathryn Abrams, "Cross Dressing in the Master's Clothes", The Yale Law Journal, CIX/4 (January 2000), 745-82.

${ }^{16}$ See Robin West, "Jurisprudence and Gender", University of Chicago Law Review, LV/1 (Winter 1988), 1-72; Catherine A. Mackinnon, Feminism Unmodified: Discourses on Life and Law, Cambridge, MA: Harvard University Press, 1987.

17 Note, for example, Carol Smart, Feminism and the Power of Law, London: Routledge, 1989; Drucilla Cornell, Beyond Accommodation: Ethical Feminism, Deconstruction and the Law, New York: Routledge, 1991.
} 
logical studies of masculinity, ${ }^{18}$ it served to refigure how law was seen to link to masculinity and the power of men.

Drawing on concerns about anti-essentialism ${ }^{19}$ and intersectionality, ${ }^{20}$ feminist work in law increasingly began to focus on the question of whether, given that men might not have equal access to cultural, symbolic or economic capital, all men might still be seen as the beneficiaries of patriarchal legal systems. In this third-wave feminist legal scholarship, a key concern related to whether earlier feminist work had ascribed to the category "Woman" an essential, ontological status, negating the discursive construction of the feminist subject Woman (the "Woman of law"). ${ }^{21}$ In so doing, however, such work had also sidestepped the diverse positionality of, and differences within, men's lives.

Feminist legal scholars thus began to question an approach to masculinity that had, at times, embraced a depiction of a seemingly omnipotent male sexuality and which had failed to engage with questions of heterosexuality. ${ }^{22}$ Raising broadly similar questions to those being asked in the sociological studies of masculinity at the time, what became of issue were the "significant overlaps" or "mutual resonances" between how "both law and masculinity are constituted in discourse". How, that is, "challenging legal discourse" also entailed unpacking the "naturalistic assumptions about masculinity" to be found in law. ${ }^{23}$ Linking to engagements with rhetoric, interpretation and hermeneutics informing critical legal scholarship by the late 1980s and early $1990 \mathrm{~s},{ }^{24}$ this approach opened up to analysis the plurality and contingency of those discourses which speak of men and masculinity across diverse institutional and cultural contexts. Turning attention to the construction of the "Woman" of legal discourse, ${ }^{25}$ in short, brought

\footnotetext{
${ }^{18}$ See Connell, Gender and Power.

${ }^{19}$ Feminist Legal Theory: An Anti-Essentialist Reader, eds Nancy Dowd and Michelle S. Jacobs, New York: New York University Press, 2003.

${ }^{20}$ Intersectionality and Beyond: Law, Power and the Politics of Location, eds Emily Grabham et al., Abingdon: Routledge-Cavendish, 2009.

${ }^{21}$ See further on this idea Carol Smart, "The Woman of Legal Discourse", Social and Legal Studies, I/1 (March 1992), 29-44.

${ }^{22}$ See Lynn Segal, Is the Future Female? Troubled Thoughts on Contemporary Feminism, London: Virago, 1994; Lynn Segal, Straight Sex: The Politics of Pleasure, London: Virago, 1994.

${ }^{23}$ Smart, Feminism and the Power of Law, 86-87.

${ }^{24}$ See Peter Goodrich, Legal Discourse, Oxford: Blackwell, 1987.

${ }^{25}$ Smart, "The Woman of Legal Discourse".
} 
into question, inescapably, the nature of the "Man" of legal - and, indeed, of feminist - discourse.

\section{Exploring the "man" of law}

It is impossible to summarize all the themes contained within the rich and varied literature on law that has engaged with the analysis of masculinities in legal cases, statutes, utterances and representations in relation to such areas as family, criminal, health care law, jurisprudence, crime and criminology. ${ }^{26}$ I have sought to chart these principal areas of study and key arguments contained in this scholarship in more detail elsewhere. For the purposes of this essay, concerned with reading the masculinities of law, three themes emerge as of particular importance in delineating the contours of the "man of law" in legal study.

First, work on gender and law has explored how an individualized notion of autonomy, central to liberal conceptions of the self, ${ }^{27}$ has been associated with a particular set of beliefs about masculinity. ${ }^{28}$ Work in family law, for example, has questioned a model of autonomy based upon a historical separation of men from areas of social life connected to the affective domain, to relations of care and caring. ${ }^{29}$ In accounts of heterosexuality, parenthood and family practices, sociolegal scholars have challenged the political, practical consequences of assumptions in law and policy about men's physical and emotional distance from children, childcare and associated ideas of dependency and vulnerability. An increasingly pressing issue, with resonance across political-legal systems and evident in contemporary cultural debates in both the United Kingdom and Germany, concerns how this masculine ideal of gendered autonomy may itself, in important respects, increasingly ill-fit many aspects of dominant political and cul-

\footnotetext{
${ }^{26}$ See further, for examples of recent work, Nancy Dowd, The Man Question: Male Subordination and Privilege, New York: New York University Press, 2010; Masculinities and the Law: A Mutlidimensional Approach, eds Frank Rudy Cooper and Ann C. McGinley, New York: New York University Press, 2012; Exploring Masculinities: Feminist Legal Theory Reflections, eds Martha Albertson Fineman and Michael Thomson, Farnham: Ashgate, 2013.

${ }^{27}$ See further on this idea Joseph Raz, The Morality of Freedom, Oxford: Oxford University Press, 1986; Ronald Dworkin, Life's Dominion: An Argument about Abortion and Euthanasia, London: Harper Collins, 1993.

${ }^{28}$ See further Stephen Whitehead, Men and Masculinities: Key Themes and New Directions, Cambridge: Polity, 2002.

${ }^{29}$ See Fineman, Autonomy Myth.
} 
tural assumptions about masculinity and men's social practices. I have argued elsewhere, with Sally Sheldon, that the emergence in England and Wales of a new normative model of responsible fatherhood in law has embodied a particular kind of heterosexual masculinity markedly different from the ideas about men, gender and autonomy that informed earlier beliefs about fatherhood. ${ }^{30}$

Second, interlinked to this model of the gendered autonomous subject, studies in law and society have explored aspects of the embodied nature of masculinity. ${ }^{31}$ Work has drawn on sociological studies of the body and feminist philosophical engagements with corporeality that emerged in the wake of postmodernism and queer theory. ${ }^{32}$ In studies of family and criminal law, for example, the liberal rational individual has been seen not simply as a sexed, autonomous, masculine subject, as above, but also as a peculiarly disembodied being. This is a figure bounded, constituted as male in ways dependant on a separation from other men and, crucially, on the establishment of hierarchical differences from women. ${ }^{33}$ Women's bodies in law have frequently appeared as incomprehensible, fluid, unbounded. The bodies of men, in contrast, Sheldon has suggested, more often appear marked by ideas of bodily absence and physical disengagement than any sense of corporeal presence. ${ }^{34}$ In particular, an association has been made between ideas of men's bodies as safe, stable and bounded, and a culturally, and legally, tangential and contingent relation to gestation, fertility and reproduction. ${ }^{35}$

Third, and finally, alongside engagements with the gendered nature of autonomy and embodiment, a questioning of masculinity has also occurred at the interface of social policy and legal practice, with a growing body of work exploring how lawyers and other legal actors

\footnotetext{
${ }^{30}$ Richard Collier and Sally Sheldon, Fragmenting Fatherhood: A Socio-Legal Study, Oxford: Hart, 2008.

31 See Michael Thomson, Endowed: Regulating the Sexed Male Body, London: Routledge, 2007; Collier, "Nutty Professors', 'Men in Suits' and 'New Entrepreneurs"”.

32 See Elizabeth Grosz, Volatile Bodies: Towards a Corporeal Feminism, St Leonards, NSW: Allen and Unwin, 1994; Moira Gatens, Imaginary Bodies: Ethics, Power and Corporeality, London: Routledge, 1996.

${ }^{33}$ See Ngaire Naffine, "Possession: Erotic Love in the Law of Rape", Modern Law Review, LVII/1 (January 1994), 10-37.

${ }^{34}$ See Sally Sheldon, "Reconceiving Masculinity: Imagining Men's Reproductive Bodies in Law", Journal of Law and Society, XXVI/2 (June 1999), 129-49.

${ }^{35}$ See further Collier and Sheldon, Fragmenting Fatherhood, Chapter 3.
} 
"talk about men" across areas of legal regulation. In the case of the legal profession, for example, I have argued elsewhere that, with regard to cultural representations of young trainee lawyers and policy debates about gender and work-life balance, significant political shifts have transformed how gender relates to the benchmarking of the normative ideal legal professional as masculine. ${ }^{36}$ Far from deploying a monolithic ideal of the masculine culture of legal practice, the position is much more complex. Thus, whilst "circles of social embodiment constantly involve the institutions on which ... privileges rest", ${ }^{37}$ the differential commitments individual men have to dominant modes of masculinity, mediated by race, ethnicity, class, sexual orientation and so forth (see below), suggest it is too simplistic to say that law is in any straightforward way masculine without at least noting how the normative nature of masculinity has changed significantly.

I have conveyed thus far something of the way masculinity has been approached in the discipline of law. An important question remains unanswered, however, one that I address in the remainder of this article. How adequate has the conceptualization of masculinity been underscoring studies of law and gender?

\section{(Re)conceptualizing masculinity: lessons from law}

In other works, I have traced in depth the strengths, and weaknesses, of the principal sociological and social-psychological perspectives that have shaped the study of masculinity within Anglophone jurisprudence. What marks these engagements out as different from the functionalist, positivist approaches that informed the earlier sociological accounts discussed earlier is a two-fold rejection of the once influential sex role theory and an attempt to take seriously the insights of feminism and engage with the social power of men. The first perspective, central to feminist work and the critical study of men and masculinities, evolved around hegemonic masculinity, a recurring, and seemingly ubiquitous concept associated with a structured model of

\footnotetext{
${ }^{36}$ See Collier, Men, Law and Gender, Chapters 4 and 6; on transnational business masculinities in law, see also Richard Collier, "Rethinking Men and Masculinities in the Contemporary Legal Profession: The Example of Fatherhood, Transnational Business Masculinities and Work-Life Balance in Large Law Firms", Nevada Law Journal, XIII/2 (Winter 2013), 410-37.

${ }^{37}$ R.W. Connell and James W. Messerschmidt, "Hegemonic Masculinity: Rethinking the Concept", Gender and Society, XIX/6 (December 2005), 852.
} 
gender power. ${ }^{38}$ The second concerns the interconnections between the discursive production of masculinity and the contingency of the male subject, what has been termed, in some accounts, a psychosocial approach to masculinities.

The concept of hegemonic masculinity, developed notably in R.W. Connell's book Gender and Power (1987) and elaborated on in later work, presents a systematic sociological theory of gender. ${ }^{39}$ Masculinities are defined by Connell as configurations of practice structured by gender relations, inherently historical in their making and remaking, enmeshed with questions about the balance of interests in society and the direction of social change.$^{40}$ Hegemonic masculinity has prompted a sub-field of study within the masculinities scholarship ${ }^{41}$ and has been seen by some critics as a problematic concept. ${ }^{42}$

In the analyses in legal studies discussed earlier we find numerous references to how law "reproduces", "asserts" or "privileges" a distinctive hegemonic masculine form interlinked, within Connell's schema, with the interests of all men whilst at the same time embracing recognition of the diversity and heterogeneity of men's lives. Various associations have been made between "doing law" and "doing (hegemonic) masculinity". ${ }^{43}$ In the field of crime, law and criminology, for example, men have been seen as "accomplishing" masculinity

\footnotetext{
${ }^{38}$ See Whitehead, Men and Masculinities, 84-99.

${ }^{39}$ See Connell, Gender and Power; Connell, The Men and the Boys; Connell and Messerschmidt, "Hegemonic Masculinity"; R.W. Connell, Masculinities, 1st edn, Cambridge: Polity, 1995. See further Richard Howson, Challenging Hegemonic Masculinity, London: Routledge, 2005; Christine Beasley, "Rethinking Hegemonic Masculinity in a Globalizing World", Men and Masculinities, XI/1 (October 2008), 86-103.

${ }^{40}$ See Connell, Gender and Power; and Masculinities, 2nd edn. See further Peter Middleton, The Inward Gaze: Masculinity and Subjectivity in Modern Culture, London: Routledge, 1992, 153; Segal, Is the Future Female?, 288.

${ }^{41}$ See Mike Donaldson, "What is Hegemonic Masculinity?", Theory and Society, XXII/5 (October 1993), 643-57; Tony Jefferson, "Subordinating Hegemonic Masculinity", Theoretical Criminology, VI/1 (February 2002), 63-88.

${ }^{42}$ See, for example, Beasley, "Rethinking Hegemonic Masculinity in a Globalizing World"; Stephen Whitehead, "Hegemonic Masculinity Revisited", Gender, Work and Organization, VI/1 (January 1999), 58-62; Demetrakis Z. Demetrious, "Connell's Concept of Hegemonic Masculinity: A Critique", Theory and Society, XXX/3 (June 2001), 337-61; Richard Collier, Masculinities, Crime and Criminology, London: Sage, 1998.

${ }^{43}$ See Smart, Feminism and the Power of Law, 18.
} 
by engaging in crime. ${ }^{44}$ Yet, some critics suggest, there has been a failure here to engage with and theorize the subjectivity of individual men and explore why some men engage in certain kinds of behavior, or invest in particular masculine subject positions, whilst others do not.

Thus, if masculinities are offered up for all men within specific socio-cultural, structural locations, for example, why do men choose one, and not another, masculine identity ${ }^{45}$ Why, say, might one father in the process of a painful separation from his partner come to identify with a strand of fathers' rights activism and commitment to values associated with hegemonic masculinity, whilst another man does not? ${ }^{46}$ How adequate is hegemonic masculinity in explaining the emotional, psychological complexity of men's engagements with law in this context?

It can be argued in response that all men benefit from the "patriarchal dividend" resulting from those who relate to, embody and reproduce hegemonic masculine values. ${ }^{47}$ However, it has been argued that it is difficult to see within structured action theory an account of why this should be the case, and whether hegemonic masculinity necessarily, as Dowd has asked in the context of law, benefits men. ${ }^{48}$ What tends to be deployed, rather, is a model of men as inherently reflexively rational, self-interested beings; men whose social action relates, in a distinctly deterministic way, to the legal and cultural norms associated with hegemonic masculinity. Connell and Messerschmidt, writing in 2005, have recently noted how "the internal complexities of masculin-

\footnotetext{
${ }^{44}$ See James W. Messerschmidt, Masculinities and Crime: Critique and Reconceptualization of Theory, Lanham, MD: Rowman and Littlefield, 1993. For further discussion, see Collier, Masculinities, Crime and Criminology; Adrian Howe, Sex, Violence and Crime: Foucault and the 'Man' Question, Abingdon: Routledge-Cavendish, 2009.

${ }^{45}$ See Tony Jefferson, "Masculinities and Crimes", in The Oxford Handbook of Criminology, eds Mike Maguire, Rod Morgan and Robert Reiner, 2nd edn, Oxford: Clarendon Press, 1997, 341.

${ }^{46}$ See Richard Collier, "Fathers' Rights, Gender and Welfare: Some Questions for Family Law", Journal of Social Welfare and Family Law, XXXI/4 (December 2009), 357-71.

${ }^{47}$ See Connell, Gender and Power; Connell and Messerschmidt, "Hegemonic Masculinity".

${ }^{48}$ Nancy Dowd, "Masculinities and Feminist Legal Theory: An Antiessentialist Project", SSRN.com, Social Sciences Research Network, University of Florida Legal Studies Research Paper, 19 August 2008: http://papers.ssrn.com/sol3/papers.cfm? abstract_id=1238070.
} 
ities have only gradually come into focus as a research issue". Further, that "without treating men as objects of pity, we should recognize that hegemonic masculinity does not necessarily translate into a satisfying experience of life". ${ }^{49}$ If we look to accounts of masculinity in autobiographical, empirical and theoretical work in the fields of sociology, psychology, history and literature, it is precisely this emotional complexity of the relationships that individuals have to gendered categories which comes to the fore. It is often difficult to see this complexity in accounts of masculinities and law.

In a way that connects to developments at the interface of feminist philosophical work and queer theory ${ }^{50}$ and a heightened engagement across disciplines with emotion and affect, ${ }^{51}$ there has emerged a move to explore the relationship between the social and psychological processes that inform men's experience of masculinity. ${ }^{52}$ This work has rejected, in suitably postmodern fashion, the idea of a unitary rational male subject. The stated aim of what has been termed, in the context of criminology, a psychosocial approach to masculinity, rather, has been to develop a social understanding of the masculine psyche: one that might shed light on men's behavior across diverse contexts, including in relation to law and legal practice.

For advocates of this position, integrating questions of individual biography and life history, and addressing the contingency and conflicted dimensions of lived experience, gives a handle on the question, noted earlier, of why some men do, and others do not, invest or engage in certain kinds of behavior or subject positions. The focus of analysis shifts, however, away from social structure to how a nonunitary inherently contradictory subject comes to invest, whether consciously or unconsciously, in socially empowering discourses around masculinity. An overarching masculine gender norm, embodied in or reproduced through law, is not seen as accounting for what men do. It is in the interaction between the social realm and the individual psyche, rather, that the disposition or motivation towards particular action

\footnotetext{
${ }^{49}$ Connell and Messerschmidt, "Hegemonic Masculinity", 851-52.

${ }^{50}$ See Intersections between Feminism and Queer Theory, eds Diane Richardson, Janice McLaughlin and Mark Casey, London: Palgrave Macmillan, 2006.

${ }^{51}$ See, for example, Kathryn Abrams, "Legal Feminism and the Emotions: Three Moments in an Evolving Relationship", Harvard Journal of Law and Gender, XXVIII/2 (Summer 2005), 325-45; Martha Nussbaum, Hiding From Humanity: Disgust, Shame and the Law, Princeton, NJ: Princeton University Press, 2004.

${ }_{52}$ Kahn, An Introduction to Masculinities, Chapter 10.
} 
is located. Social action is depicted, in one strand of writing, as the product of biographically contingent anxieties and desires. ${ }^{53}$

In turning towards the implications of this work for law and legal regulation, however, it remains unclear how accounts of the taking up of masculine subjectivity can ever be tested or proven in any meaningful way. ${ }^{54}$ Indeed, within some accounts we would seem to be reduced to a wholly semiotic understanding of the subject whereby, as Connell has put it, "with so much emphasis on the signifier ... the signified tends to vanish". ${ }^{55}$ What is lost in these discursive readings of masculine subjectivity is precisely the original focus of Connell's attempt to engage with the concrete, material, grounded institutional spaces of masculinities, the social sites in which ideas about gender take on meaning (such as specific locations around law).

The implications in terms of politics, policy and practice in relation to law are similarly uncertain. It is unclear how theorizing subjectivity at the level of the individual can ever be an effective strategy in facilitating social change in a broader sense. ${ }^{56}$ In one recent feminist sociolegal study of this strand of work on masculinity, focused on how it has developed in the area of crime and criminology, Howe has argued that the psychosocial approach does more than simply misread feminism and feminist work informed by postmodernism. She identifies a troubling, profoundly regressive development here. ${ }^{57}$ Howe argues that the psychosocial approach, within criminology at least, has been informed by "an extraordinary anti-feminist animus". ${ }^{58}$ This has resulted in the silencing of the violence(s) of men and the harms that men do. Howe identifies in much of this psychosocial work something more akin to an individualistic focus on the "insecure, vulnerable, anxious" man. ${ }^{59}$ How, therefore, might it be possible to move this debate forward?

\footnotetext{
${ }^{53}$ See Jefferson, "Masculinities and Crimes"; Challenging Subjects: Critical Psychology for a New Millennium, ed. Valerie Walkerdine, London: Palgrave Macmillan, 2002.

${ }^{54}$ See Collier, Men Law and Gender.

${ }^{55}$ Connell, Masculinities, 1 st edn, 50-51.

${ }^{56}$ See Connell, Masculinities, 1st edn; Connell, The Men and the Boys.

${ }^{57}$ Howe, Sex, Violence and Crime, 136-42.

${ }^{58}$ Ibid., 139.

${ }^{59}$ Ibid., 140.
} 


\section{Sex, gender and the "masculinity" of law}

The critique of masculinity that has developed across disciplines in recent years has been based, in part, on questioning the analytic utility and coherence of concepts premised on the epistemic frame of sex/gender, outlined earlier in this chapter. This work has raised a number of theoretical and political questions particularly relevant to legal studies that can be grouped around two key themes. First, an engagement with the gendered binary divisions that have shaped legal regulation; and, second, a rethinking of what it means to speak of gender, law and "personal life". I will address each of these issues in turn.

First, within work variously termed a "new corporeal" or "sexed bodies" approach to law and gender, there has been a forceful critique of the dualism between sex and gender. ${ }^{60}$ Within this approach the idea of the "sexed body" is seen to be neither inherently masculine active, rational, reasonable, bounded, non-permeable and so forth nor feminine - as passive/vulnerable, irrational, unreasonable. It is, rather, positioned as an object interwoven with and constitutive of a heterogeneity of systems of meaning, signification and representation that vary across social contexts, including, in this case, different areas of law and legal regulation. Far from presuming a body as the passive recipient of gender roles or messages (for example, the messages conveyed by the law, media or peer groups), this perspective integrates an appreciation of the sexed specificity of the bodies of women and men in determining consciousness. Rather than seeing the body as a tabula rasa upon which social lessons are inscribed by law/society, what becomes an issue is the materiality of gender in/of bodies, the significance of embodiment and, importantly, the contingent, always socially grounded nature of these processes in relation, for example, to race, ethnicity, class.

This approach stands in marked contrast to the broadly constructionist perspectives that have underscored so much gender and law scholarship to date, where the object has been to unpack or reveal the meanings of masculinity that circulate within law. Far from negating the complexity of men's subjectivity, a theme central to the psychoso-

${ }^{60}$ See Gatens, Imaginary Bodies; and Moira Gatens, "A Critique of the Sex/Gender Distinction", in Beyond Marxism? Interventions after Marx, eds Judith Allen and Paul Patton, Sydney: Intervention Publications, 1983, 143-60. See also Cealey Harrison and Hood-Williams, Beyond Sex and Gender; Kathleen Daly, "Different Ways of Conceptualising Sex/Gender in Feminist Theory and their Implications for Criminology”, Theoretical Criminology, I/1 (February 1997), 25-51. 
cial critique of hegemonic masculinity considered earlier, an attempt is made here to see sex (difference), like gender, as something itself constituted in discourse. This does not occur, however, by means of any essentialist fixing of meaning about what constitutes a male/female, masculine/feminine body, experience, identity, culture and so forth. It is, rather, through reference to cultural and historically specific discourses and practices that women and men come to have differential relationships to reproduction and gestation, parenting and employment, caring, crime and so forth.

This critique can be located within the context of broader attempts in legal studies to transcend binary oppositions that have informed understandings of gender. Other dualisms singled out for attention include nature/nurture, the public/private and, within a body of queer legal theoretical work, the binary between hetero- and homosexuality. An interrogation of the latter, I've already intimated, is of particular potential significance to discussions of masculinities and law, raising questions about how assumptions about heterosexuality encode and structure many aspects of everyday life, whether in relation to law's regulation of the family, the workplace, health care and so on. In exploring the active processes involved in becoming a gendered subject, and recognizing how the body can, and does, intervene to confirm or to deny social significances, this literature also connects to recent sociological attempts to address the realities of gendered experiences.

Second, these debates about masculinity and law connect to and, I have argued elsewhere, have much to gain from developments taking place at the interface of sociological work on gender and what Carol Smart has termed in her book of the same name "Personal Life". ${ }^{61}$ In the words of a call for papers for a conference held in September 2009 in the UK, Turning Personal: An Interdisciplinary Conference (16-17 September 2009, University of Manchester), this personal turn in sociology constitutes an attempt to explore how social research can incorporate more complex and multi-layered accounts of personal lives into academic writings and analyses. It constitutes, in part, an attempt to bring to sociology an appreciation of the complexity, texture, richness and contradictory nature of social relations. These are issues, in a sense, central to studies of masculinities and English literature. Importantly for law however, highlighting the deficiencies of grand theories of sociology, this work involves reappraising the place of affect

${ }^{61}$ Carol Smart, Personal Life, Cambridge: Polity, 2007. 
and emotion, memory, love and commitment in understandings of gender and law. What is called for is a renewed engagement with the significance of social class, race, ethnicity, intimacy, relationality and kinship. In so doing, questioning the long-standing neglect of feelings within the social sciences, and gendered conceptions of human nature and divisions of labor in which this perspective has its roots, such developments bear upon the relationship between law and masculinities in a number of intriguing ways.

Approaching the gendered dimensions of social experience in such a way as not to lose track of the issues of power raised by feminism entails integrating an appreciation, at both a theoretical and political level, of the complexity and often contradictory nature of "personal life". Such an engagement interlinks to the accounts of the social and psychological processes informing men's experiences of masculinity discussed earlier in this chapter. It differs, however, in not losing sight of the sociological grounding of these processes. It also leads to some intriguing questions about how previous social constructionist accounts of masculinity have interpreted legal policy agendas pitched at changing masculinity. One result of focusing policy on masculinity as a social problem was to divert attention from individual men's actions so that the responsibility for particular actions shifts from individual men to society and gender relations. This can lead to an evacuation of questions about responsibility and agency. ${ }^{62}$ The experience of the individual, Whitehead has suggested, can be lost when what is privileged is an "ideological apparatus" of masculinity, a reification of a gender category that results, paradoxically, in an erasure of men's practices. ${ }^{63}$ Put simply, if masculinity - existing prior to its production through social agency ${ }^{64}$ - appears as the problem, then the embodied and inter-subjective dimensions of gender experience are effaced.

In a similar manner, Jeff Hearn has argued that what is required is a move away from these debates about masculinities and back to men in an attempt to distinguish between hegemonic masculinity from

\footnotetext{
${ }^{62}$ See also Howe, Sex, Violence and Crime; Anthony McMahon, Taking Care of Men: Sexual Politics in the Public Mind, Cambridge: Cambridge University Press, 1999; Wendy Hollway, The Capacity to Care: Gender and Ethical Subjectivity, London: Routledge, 2006.

${ }^{63}$ Whitehead, Men and Masculinities, 94.

${ }^{64}$ See Ashe, The New Politics of Masculinity, 155.
} 
what he terms the hegemony of men. ${ }^{65}$ This is a subtle but important difference in rethinking the place of power in analyses of masculinities and law, although to what extent it avoids the essentialism of earlier accounts is open to question. ${ }^{66}$ For Hearn, at issue is how "men are both a social category formed by the gender system and dominant collective and individual agents of social practices". ${ }^{67}$ Such concerns connect to how the psychodynamic dimensions of social experience as a man may be marked, as we have already seen, by emotional ambivalence and contradiction as much as any notion of straightforward hegemonic masculine identification. Emotions and experiences, moreover, can themselves be seen as effects of power that have the potential not just to reinforce dominant masculinities but also, importantly (and possibly at the same time) generate oppositional practices and resistances. This can be seen in the field of fathers' rights politics for example where, I have argued elsewhere, cultural, social and economic transformations around equality and gender neutrality have altered men's expectations of law and practices in the legal field. ${ }^{68}$ Particular discursive positioning and gender categories can thus be understood as products of a matrix of social and legal relations shaped by historically specific ideas about power and subjectivities not necessarily held out or available to all individuals in the same way. With this point in mind, moving towards conclusions, it is necessary to look closer at what in law the term "masculinity" has been seen to involve.

\section{On masculinities and legal study}

Masculinity remains a primary reference point within studies of law and gender as well as a key concept within contemporary cultural conversations about gender and social change more generally. The concept cannot be wished away. It has cultural resonance and meaning(s) and a resonance across diverse legal and policy debates. Yet, whether understood as embedded within and reproduced through the interaction of social structure and individual/collective practice, or

65 Jeff Hearn, "From Hegemonic Masculinity to the Hegemony of Men", Feminist Theory, V/1 (April 2004), 49-72.

${ }^{66}$ See Beasley, "Rethinking Hegemonic Masculinity in a Globalizing World".

${ }^{67}$ Hearn, "From Hegemonic Masculinity to the Hegemony of Men", 59.

${ }^{68}$ See Collier, "Fathers' Rights, Gender and Welfare". See also Collier and Sheldon, Fragmenting Fatherhood; Sandy Ruxton and Helen Baker, "Father's Rights, Fatherhood and Masculinity/ies", Journal of Social Welfare and Family Law, XXXI/4 (December 2009), 351-55. 
else discursively constituted by the contingencies of psyche and society, I have suggested that masculinity has been used within legal scholarship in some very different ways involving diverse attributes and ideas.

Masculinity has been deployed in work on law and gender, we have seen, to describe the psychological characteristics of men and particular aspects of men's gendered experiences and identities. It has also been used to describe an array of gendered cultural practices, rationalities and ways of thinking about law, legal norms and legal values. It has been pivotal to psychoanalytic, psychological and power-based readings of men and gender, as well as to analyses of men's gendered behavior within specific institutional settings relating to law. Masculinity has appeared as both the cause and, curiously, the consequence of hierarchical, oppressive gender relations, structurally embedded in societies, interconnected, in often ill-defined ways, to the sexed bodies of men.

For others, masculinity is no more, or less, than a fluid performative practice, the having, obtaining, taking up of masculine identity "a public process of power relations in which everyday interactions [are seen to] take place between actors with sexual identities in sexualized locations". ${ }^{69}$ In the case of law these locations potentially encompass numerous and diverse areas, although, curiously, it would also appear there is no one model of "masculinity" at play in the legal arena. ${ }^{70}$ Bodies, cultures, discourses, practices, emotions, modes of thought, sexual practices, discrete areas of law and even political views, therefore, each have been described, in different contexts, as "masculine". At times, masculinity has been conceptualized in different ways, drawing on different theoretical traditions, even within the same piece of writing or research project. In the light of such diversity, however, it is profoundly unclear just what masculinity entails.

As Peter Middleton has asked, what is masculinity? "Is it a discourse, a power structure, a psychic economy, a history, an ideology, an identity, a behavior, a value system, an aesthetic even?" Or is it "all these and also their mutual separation, the magnetic force of repulsion

${ }^{69}$ David Bell and Gill Valentine, "The Sexed Self: Strategies of Performance, Sites of Resistance", in Mapping the Subject: Geographies of Cultural Transformation, eds Stephen Pile and Nigel Thrift, London: Routledge, 1995, 146.

${ }^{70}$ See Jonathan Scourfield and Mark Drakeford, "New Labour and the 'Problem of Men'”, Critical Social Policy, XXII/4 (November 2002), 619-40; Collier, Men, Law and Gender. 
which keeps them apart ... a centrifugal dispersal of what are maintained as discrete fields of psychic and social structure?"71 To speak legitimately within a diverse body of work on law and gender of a coherent "discourse of masculinity" it would be necessary to show that these usages of the term were located structurally within "a clearly defined institution with its own methods, objects and practices". ${ }^{72}$ It is possible one could argue this in relation to law, although the heterogeneity of the legal contexts discussed in this essay suggests otherwise. In which case, accounts seeking to reveal a discourse of, say, "hegemonic masculinity in law" are really simply referring to repeated patterns of linguistic usage within the parameters of a legal field that is itself contested. It is far from clear, in short, that, in talking about masculinity, legal scholars have been talking about the same thing. In relation to work on masculinities and law emerging from North America and Europe, for example, contrasting welfare regimes and distinctive legal-political systems shape these engagements with masculinity in a number of ways. Different social, economic and policy contexts inform the way studies of masculinities and law integrate discussion of issues such as class, race and ethnicity.

For some, it is the concept of masculinity itself that is problematic. Hearn, writing in 1996, charged masculinity with being more than just analytically imprecise: "it is as if [it] ... exemplifies [a] field of concern and even, possibly, distils the aggregation of activity of men in the social world into one neat word." 73 The general use of the term across disciplines, he suggests, has all too often been premised on heterosexist, ethnocentric assumptions mediated by ideas about class and disadvantage (see below); he finds it to be the product of a particular historical moment that is, in some cultural contexts at least, at best "irrelevant or misleading" ${ }^{74}$ These points have significance for law as masculinity has been viewed as potentially yielding high explanatory returns for critical studies of law and gender. ${ }^{75}$ However, I shall suggest, by way of concluding remarks, these engagements with law may themselves have been bound up with a form of thinking about men and masculinity for which the time has now passed.

${ }^{71}$ Middleton, The Inward Gaze, 152; see also Pease, Recreating Men.

${ }^{72}$ Middleton, The Inward Gaze, 142.

${ }^{73}$ Jeff Hearn, "Is Masculinity Dead?", 202.

${ }^{74}$ Ibid., 209. Contrast Connell, Masculinities, 1st edn, 30-34.

${ }^{75}$ See further, Gatens, Imaginary Bodies. 


\section{Concluding remarks}

In this article, I have traced diverse political, intellectual and institutional influences that have shaped the study of masculinities and law. These developments constitute part of what has been, within legal studies, a broader "discursive attempt ... to stop the depiction of women as "the problem".

The aim has rather been to deflect "the objectifying gaze" to "benchmark masculinity and heterosexuality ... [and] to disrupt the conventional orderings of modernity within legal texts" ${ }^{76}$ Yet masculinity is not, I have suggested, a fixed, homogenous or unchanging concept. ${ }^{77}$ Far from taking for granted what is meant by the term, locating its meaning within any grand political narrative or big debate within law, sociology or any other discipline, it is more helpful to look at how it has been deployed in different contexts, in different ways, and at different moments, as a particular kind of (inter)discursive construction.

Both studies of law and gender and feminist legal scholarship have much to gain from incorporating a more complex account of the gendered male subject and, with it, an appreciation of the interconnected, interrelated and interdependent nature of the lives of women, children and men. Work emerging at the interface of sociological studies of personal life $^{78}$ and anti-essentialist and materialist feminist scholarship, ${ }^{79}$ for example, is leading to a reappraisal of precisely what it means to speak of, perform or do a masculine gender. In some respects this can be located as part of a wider shift within the social sciences to develop a self-reflective "science of the subject", focusing on how social experiences and gender categories are "offered to thought" as social problems requiring attention. ${ }^{80}$ Importantly, this raises questions about the role of legal mechanisms, legal arenas, functionaries and forms of reasoning within late modern forms of governance. It is also important not to lose sight of the political and

\footnotetext{
${ }^{76}$ Margaret Thornton, "Neoliberal Melancholia: The Case of Feminist Legal Scholarship", Australian Feminist Law Journal, XX (June 2004), 12.

${ }^{77}$ See Collier, Men, Law and Gender.

${ }^{78}$ See Smart, Personal Life.

${ }^{79}$ See Materialist Feminism: A Reader in Class, Difference and Women's Lives, eds Rosemary Hennessy and Chrys Ingraham, London: Routledge, 1997; Rosemary Hennessy, Materialist Feminism and the Politics of Discourse, London: Routledge, 1993. ${ }^{80}$ Nikolas Rose and Mariana Valverde, "Governed by Law?", Social and Legal Studies, VII/4 (December 1998), 541-51.
} 
policy dimensions of debates about law and social order that have tended to be pitched at certain categories of men and not others in ways mediated by assumptions about class, race and ethnicity.

What is required, I have argued in more detail elsewhere, is a retheorizing of men's identities by looking critically at, and beyond, the term "masculinities" in ways that might produce a richer, more nuanced conceptual framework in which both men's, and women's, practices, subjectivities and bodies can be approached. ${ }^{81}$ Locating questions about men's agency within networks of power entails, following Ashe, challenging simplistic male positive and anti-male standpoints alike, and recognizing the politically open-ended nature of practices that people socially categorized as men reproduce through their agency within contexts of power. Reducing developments in an area such as fathers' rights activism around law, for example, ${ }^{82}$ to no more than an anti-feminist animus on the part of men offers little "in terms of conceptual clarity or theoretical usefulness". ${ }^{83}$ Importantly, the concept of hegemonic masculinity is itself insufficient to account for the complexity of these developments in law and the politically open-ended nature of the debates that have resulted.

Where does this leave us? At national and cross-national levels, a critical engagement with masculinity should no longer be seen as marginal to debates about law. In the UK, as in Germany, it is important to note the influence of European Union agendas around diversity and the mainstreaming of gender equality. In the UK, certainly, this issue of men and masculinities has itself become an explicit, rather than implicit, feature of high profile policy debates, research agendas and political contestations across a wide range of topics. ${ }^{84}$ These debates about masculinities are occurring in the slipstream of the embedding in law of ideals of egalitarianism and gender neutrality, part of a broader social process transforming normative understandings of many aspects of men's and women's lives. ${ }^{85}$

\footnotetext{
${ }^{81}$ See Collier, Men, Law and Gender.

${ }^{82}$ See Collier and Sheldon, Fragmenting Fatherhood.

${ }^{83}$ Ashe, The New Politics of Masculinity, 159.

${ }^{84}$ Note, for example, Coalition on Men and Boys (COMAB), Man Made: Men, Masculinities and Equality in Public Policy, London: COMAB, 2009; also "Critical Research on Men in Europe" Network (CROME). See Jeff Hearn and Keith Pringle, European Perspectives on Men and Masculinities, Basingstoke: Palgrave Macmillan, 2006.

${ }^{85}$ See Fineman, Autonomy Myth, 195.
} 
In rejecting the idea that there exist essential male identities amongst those people identified, within particular societies, as "men" ${ }^{86}$ developments at the interface of feminist theory, thirdwave/anti-essentialist feminism and queer theory question aspects of both pro-feminist studies of masculinities and feminist accounts of law, men and gender. At the same time, contemporary sociological work is raising important questions about how emotion and affect, intimacy and memory, love and commitment interrelate with ideas of social class, race, ethnicity, relationality and kinship. The result is a redrawing of the theoretical terrain around masculinities and law, a development that opens up new possibilities for a more nuanced and multi-layered engagement with the gendered subject. In following Thornton's call for a refocusing on "political engagement, rather than introspection", this rethinking of masculinities can be seen as part of the constitution of "a new episteme of feminist legal theory that is linked to the political". ${ }^{87}$

There has been a tendency in legal studies, as in sociological accounts of masculinity, to categorize a vast range of men's activities by "treat[ing] ... them as if they were all subject to the same laws". ${ }^{88}$ What may be more productive, however, I have argued, is an attempt to re-theorize men's identities beyond the term masculinities in such a way as to produce "a more multi-conceptual framework for examining men's subjectivities, bodies and practices" ${ }^{89}$ In reconsidering how a political terrain around law and masculinity has itself been reshaped by a complex amalgam of social, legal, cultural and technological developments, it is necessary to recognize the emergence of a new constellation of ideas about the relationship between law, men and gender. It is necessary to challenge, with it, what it means to speak of masculinity and law.

\footnotetext{
${ }^{86}$ See Ashe, The New Politics of Masculinity.

${ }^{87}$ Thornton, "Neoliberal Melancholia", 22.

${ }^{88}$ Carol Smart, "Feminist Approaches to Criminology or Postmodern Woman meets Atavistic Man", in Feminist Perspectives in Criminology, eds Lorraine Gelsthorpe and Anne Morris, Buckingham: Open University Press, 1990, 77.

${ }^{89}$ Ashe, The New Politics of Masculinity, 158.
} 


\title{
MASCUlinity In ThOMAS MALORY's MoRTE DARTHUR
}

\author{
CHRISTOPH HOUSWITSCHKA
}

\begin{abstract}
Thomas Malory's Arthurian tale recurrently refers to the male body, and both the knights' physical and spiritual integrity are of crucial significance in maintaining masculinity. The male body represents power but is also threatened by physical violence and "fleshly lusts". Representing ideals of chivalry, masculinity in Morte Darthur oscillates between scenes of male power and experiences of anxiety. While Gareth represents moderation as a way of stabilizing the destructive forces of masculinity, Lancelot is determined to remain the strongest and most powerful knight, a position beyond control or condemnation. By avoiding the question whether Lancelot slept with the Queen, Malory transforms his gradual downfall into an epiphany of chivalric prowess. In a time of social disintegration the social acceptance of a knight's masculinity determines whether his personal individuality is to the benefit or to the destruction of the Arthurian fellowship.
\end{abstract}

Malory's Morte Darthur undoubtedly belongs among the most influential Arthurian stories in English Literature - kept alive by the best of British writers from Spenser to Tennyson and classics of the twentieth century such as T.H. White's The Once and Future King. Many more lovers of the Arthurian matter have almost invariably read and adopted the lengthy prose narrative of this - for quite some time - mysterious knight. ${ }^{1}$ Thomas Malory, who found himself in prison towards the end of the War of the Roses, summarized all the major Arthurian tales

\footnotetext{
${ }^{1}$ For the search after the true Thomas Malory, see, for example, Christina Hardyment, Malory: The Knight Who Became King Arthur's Chronicler, New York: Harper and Collins, 2005.
} 
of his time, both Old French and Middle English. Malory was looking for a new language that would drop the courtly tone of some of his sources, deliberately searching for words to match the world he lived in, a world of war and male codes of behavior, rewriting more or less any gendered narrative to a male perspective. Communication seems hardly to take place between the two sexes unless it maps out the intricacies of male power and anxieties signifying - generally speaking - anything but a genuine interest in women. ${ }^{2}$ With the exception of Guinevere, Isolde, or the Lady of Astolat, none of the female characters retains the complexities present in Malory's sources, none but Elaine of Astolat, who seems to be conceptionalized as an agent acting independently in the center of the subplot to which she belongs. ${ }^{3}$

Quite a few critics have suggested that Malory tampered so much with some of the subtle love stories in his sources because he had no interest in female characters such as Guinevere or Isolde. For Malory, one woman seems to have been as good as any other one. Unless he could represent differences in male characters by doing so, Malory's approach did not allow him to recognize individual differences among female characters, differences which he must have found in his sources. In the best case women are saved to bring honor to a knight; in the worst case women are sacrificed to save a man whose chivalric status or life is in jeopardy. The overruling question Malory tried to answer was whether the relationship between a given knight and his

\footnotetext{
${ }^{2}$ There are exceptions to this, such as the Lady of Astolat, who becomes the victim of Lancelot's unforgiving male principles. Elaine establishes a counter position that collapses Lancelot's fragile visions of perfectibility which are eventually jeopardized by his love to Queen Guinevere. I would argue, however, that Elaine of Astolat does not establish a female stance in the narrative, but rather in sacrificing herself stabilizes Lancelot's precarious masculinity for a little longer.

${ }^{3}$ Hodges refers to Armstrong who argues that the Pentecostal Oath's definition of chivalric manhood is dependent on vulnerable women: "Armstrong's analysis is important for revealing how chivalry constructs ideals of femininity even while it seems to dictate masculine behavior, and she is right that the two are interdependent" (Kenneth Hodges, Forging Chivalric Communities in Malory's Le Morte Darthur, New York: Palgrave Macmillan, 2005, 36). Marion Wynne-Davies claims that some women in Morte Darthur are less passive than this oath suggests (see Marion WynneDavies, Women and Arthurian Literature: Seizing the Sword, New York: St Martin's, 1996, 70-71). See also Dorsey Armstrong, Gender and the Chivalric Community in Malory's Morte d'Arthur, Gainesville: University Press of Florida, 2003; and Dorsey Armstrong, "Gender and the Chivalric Community: The Pentecostal Oath in Malory's 'Tale of King Arthur'", Bibliographic Bulletin of the International Arthurian Society, 51 (1999), 293-312.
} 
damsel or queen could inform the values of men in situations that might weaken their positions of power.

In her studies about Menacing Virgins, which also include chapters on male virginity in Morte Darthur, Kathleen Coyne Kelly voices a truism with regard to Malory when she confirms that "the female body has figured prominently as site, as meeting-place for ideological conflict. The male body, on the other hand, has been often and emphatically constructed literally, a thing in and of itself." ${ }^{4}$ Kelly argues that "when the male body is threatened ... a feminine and feminized body takes its place within the narrative frame". Substitution, then, is only one way of protecting the male body, where another one is "transformation of the masculine into the feminine for precisely the same reason - the feminized masculine body preserves the body chivalric from any real critique". ${ }^{5}$

This reading is based on R.W. Connell's assumption that gender relationships in patriarchal societies are defined by "body-reflective practices". ${ }^{6}$ These practices are inscribed into the body, which, being both agent and object, stabilizes hegemonial masculinity. In this understanding, gender "is a social practice that constantly refers to bodies and what bodies do, it is not social practice reduced to the body". ${ }^{7}$ Connell's concept emphasizes the connection between gender identity and social identity. Masculinity then assumes the hegemonic position by "the configuration of gender practices which embodies the currently accepted answer to the problem of the legitimacy of patriarchy which guarantees (or is taken to guarantee) the dominant position of men and the subordination of women". ${ }^{8}$

For Morte Darthur this means that, whenever Malory cannot avoid telling stories of gender relations, he almost exclusively reflects aspects of manhood referring to "a man in power, a man with power, and a man of power". ${ }^{9}$ The central concept containing these aspects in

\footnotetext{
${ }^{4}$ Kathleen Coyne Kelly, "Menaced Masculinity and Imperiled Virginity in Malory's Morte Darthur", in Menacing Virgins: Representing Virginity in the Middle Ages and the Renaissance, eds Kathleen Coyne Kelly and Leslie Marina, Newark: University of Delaware Press, 1999, 97.

${ }^{5}$ Ibid., 99.

${ }^{6}$ R.W. Connell, Masculinities, Berkeley: University of California Press, 1995, 27.

${ }^{7}$ Ibid., 71 .

${ }^{8}$ Ibid., 77.

${ }^{9}$ Michael S. Kimmel, "Masculinity as Homophobia", in Privilege: A Reader, eds Michael S. Kimmel and Abby L. Ferber, Boulder, CO: Westview, 2003, 57.
} 
the Arthurian narrative is that of chivalric prowesse. Masculinity in Malory's Morte Darthur is represented by the precarious rivalries in male relationships that define war and peace, fellowship and civil strife, or more generally, power and anxiety. Following Todd W. Reeser, I would not like to define masculinity as a set of positive social values that are either observed or not. It is not an arbitrary dichotomy of ideal and reality as represented in fiction, but rather the instability of masculinity as a hegemonic effect in social and gender hierarchies - in Reeser's words: "Despite the various instabilities of the power theoretically engendered by moderation, masculinity should not be viewed as simply powerless either, for patriarchy and male power were in large terms still the norm in the period, particularly within the intellectual context of humanism." Reeser takes into account two aspects of masculinity, "its hegemonic, dominating aspects and its 'anxiety' or its 'neurosis". ${ }^{10}$ This tension is also found in Morte Darthur.

Being revised and printed in 1485 by William Caxton, Thomas Malory's Morte Darthur is informed by humanistic ideas in spite of the fact that it appears in many ways to be a strangely archaic text partially imitating old-fashioned styles of writing. The politics represented in this fashion, however, are nothing but archaic. They discuss Arthur's power in a highly versatile political environment in which magnates were as strong as the king himself or even stronger and the feudal order was based on a system of patronage. King Arthur's domination is not imposed by an overpowering warlord, but accepted to the mutual benefit of powerful men who want to avoid an all devouring war as Malory would have experienced himself during the Wars of the Roses. This contemporaneity of Malory's traditional Arthurian narratives has been described by Roberta Krueger for romances that "are remarkable for their authors' capacity to remake their shared stories anew in different contexts and to reposition their ethical systems as they respond to particular audiences, in distinct geographic locations and social contexts". ${ }^{11}$

Arthurian power is negotiated in the framework of hegemonic masculinity. Lacking legitimation in a military, dynastic, economic

\footnotetext{
${ }^{10}$ Todd W. Reeser, Moderating Masculinity in Early Modern Culture, Chapel Hill: University of North Carolina Press, 2006, 30.

${ }^{11}$ The Cambridge Companion to Medieval Romance, ed. Roberta L. Krueger, Cambridge: Cambridge University Press, 2000, vi.
} 
sense, not to speak of constitutional legitimation, late medieval power relations were personalized. For this reason Malory could identify each powerful knight with an aspect of order in the Arthurian world. Masculinity in Malory's world is constructed on the basis of a codified system of values and beliefs, laid out in the Pentecostal Oath that is either observed and defended as a legal framework of Arthurian Order or violated by individual knights performing acts of chivalric prowesse on their own terms. A knight's service for the common good, as represented in his protection of the weak, becomes the touchstone of this chivalric order's validity:

... the kyng stablysshed all the knyghtes and gaf them that were of londes not ryche, he gaf them londes, and charged hem neuer to doo outragyousyte nor mordre, and alweyes to flee treason. Also by no meane to be cruel, but to gyue mercy vnto hym that asketh mercy, vpon payn of forfeture of their worship and lordship of Kyng Arthur foreuermore, and alweyes to doo ladyes, damoysels, and gentylwymmen socour vpon payne of dethe. Also that no man take noo batails in a wrongful quarel for noo lawe, ne for no worldes goodes. Vnto this were all the knyghtes sworne of the Table Round, both old and young, and euery yere they sworne at the hyghe feest of Pentecost. ${ }^{12}$

The Pentecostal Oath is Malory's own invention. While the idealism of this oath is obvious, the reasons for its failure are assessed quite differently. While Dorsey Armstrong believes that both earlier episodes in the text and the Grail Quest in particular demonstrate "the full scope of the inadequacy of the Oath as a means of social order", ${ }^{13}$ one could also argue that it is not the oath but the chivalric code of prowesse which is doomed to collide with any legislative effort on the side of the King. ${ }^{14}$

${ }^{12}$ A New Edition of Thomas Malory's Le Morte Darthur. Based on the Pierpont Morgan Copy of William Caxton's Edition of 1485, eds James W. Spisak and William Matthews, Berkeley: University of California Press, 1983, 92, 11. 30-38. All quotations from Le Morte Darthur are from this edition.

${ }^{13}$ Dorsey Armstrong, "The (Non-)Christian Knight in Malory: A Contradiction in Terms?", Arthuriana, XVI/2 (Summer 2006), 30.

${ }^{14}$ For love and power in Malory, see Christoph Houswitschka, Politik und Liebe in der Literatur des englischen Spätmittelalters am Beispiel von Thomas Malorys Morte Darthur, Frankfurt am Main: Peter Lang, 1991, and for the flaws of idealistic knights, Christoph Houswitschka, "From Vision to Vainglory: Malory as a Critic of Idealism in the Morte Darthur", in Of Remembraunce the Keye: Medieval Literature and its Impact through the Ages, ed. Uwe Böker, Frankfurt am Main: Peter Lang, 2004. 
Through the regulations of the Pentecostal Oath, Arthur keeps his knights in check, as Karen Cherewatuk explains: "The annual Pentecostal celebration, at which the knights renew this oath, reinforces the hierarchical bonds of love, loyalty, and fear that both Aristotle and Malory advocate, for the king is head of all knighthood." 15

The Pentecostal Oath also talks about male obligations to women of high rank. ${ }^{16}$ Robeson points out that the behavioral restraints for men embodied in the Pentecostal Oath pave the way to achieve "worship by honouring that [that is, worship] of women; certainly women maintain their worship more easily when not threatened by rape or abduction". While any knight "who violates a woman's worship by raping or abducting her automatically sacrifices his own" ${ }^{17}$ women must follow the rules that define fifteenth-century sexual mores. ${ }^{18}$

The oath is a well established form of social contract binding together individuals in a consensual group based on shared interests, values and norms. Otto Gerhard Oexle points out that such oaths bind together persons who do not find their own people in pre-existing relationships such as kinship, but choose to create the group they belong to. Oexle asks what this distinction means in terms of our understanding of individuality in medieval society. This form of sworn federation of co-operating groups had some common roots in feudalism (lord and vassal), but is more typical of civic communities. ${ }^{19}$

\footnotetext{
${ }^{15}$ Karen Cherewatuk, "Sir Thomas Malory's 'Grete Booke",, in The Social and Literary Context of Malory's Morte Darthur, Arthurian Studies 42, eds D. Thomas Hanks Jr. and Jessica Gentry Brogdon, Cambridge: D.S. Brewer, 2000, 54.

${ }^{16}$ Women also show "loyalty to their obligations and (perhaps surprisingly) to the ideals of the Round Table set out in the Pentecost Oath. It is often said that ladies are obliged to remain virgins before marriage and faithful to their husbands afterwards, that that is the equivalent of a knight's obligation to show courage in battle, and that knights have no more obligation to chastity than ladies to courage in combat" (ReViewing Le Morte Darthur: Texts and Contexts, Characters and Themes, eds K.S. Whetter and Raluca L. Radulescu, Woodbridge: Brewer, 2005, 5).

${ }^{17}$ Lisa Robeson, "Women's Worship: Female Versions of Chivalric Honour", in ibid., 110.

${ }^{18}$ The Winchester Manuscript is clearer in this respect explicitly condemning rape as a crime: "and allwayes to do ladyes, damesels, and jantilwomen and wydowes socour: strengthe hem in hir ryghtes, and never to enforce them, uppon payne of dethe" (The Works of Sir Thomas Malory, ed. Eugène Vinaver, 3 vols, 2nd edn, Oxford: Clarendon Press, 1971, 120.

${ }^{19}$ Otto Gerhard Oexle, "Konsens-Vertrag-Individuum: Über Formen des Vertragshandelns im Mittelalter", in Das Individuum und die Seinen: Individualität in der okzidentalen und in der russischen Kultur in Mittelalter und früher Neuzeit, eds Jurij
} 
Malory places the Pentecostal Oath in his work in the tradition of similar oaths in orders of knighthood. ${ }^{20}$ These chivalric communities help administer and police King Arthur's realm and offer "valuable perspectives on the way in which late-fifteenth-century communities were imagined". Kenneth Hodges convincingly shows that these communities also provided "the common core of proto-nationalist sentiment" as the number of readers of chivalric literature grew. ${ }^{21}$ Oexle explains that this kind of oath could be found in both a civic coniuratio and in aristocratic groups of persons who are bound together in a community of different and unequal rights and duties. For lords and vassals, the oath defines a whole new way of acting among one another, what Max Weber calls the making of a "sworn brotherhood" (Verbrüderung). ${ }^{22}$

While the conflicts in Malory's Morte Darthur, especially those between the main representatives of the two most powerful families in Arthur's kingdom, can be approached from the perspective of competing communities within the Round Table, the battles among the descendants of Lot and Pellinore are carried out between individuals who are guided by their ideas of chivalric prowesse. ${ }^{23}$ Prowesse is the

L. Bessmertnyj and Otto Gerhard Oexle, Göttingen: Vandenhoeck und Ruprecht, 2001, 15-16.

${ }^{20}$ In Boulton's understanding, these orders offered "a form of reciprocal relationship" (D'Arcy Jonathan Dacre Boulton, The Knights of the Crown: The Monarchial Orders of Knighthood in Later Medieval Europe 1325-1520, Woodbridge: Boydell and Brewer, 1987, 15). The most common term was "companion (socius, compaignon, compagno)" (ibid., 458) who would have "to take a special oath of love and loyalty to their fellow companions, very similar to that undertaken by brothers-of-arms" defining "mutual obligations" (ibid., 467).

${ }^{21}$ Hodges, Forging Chivalric Communities in Malory's Le Morte Darthur, 7. In his popular handbook, The Book of the Order of Chivalry, written probably between 1279 and 1283, Ramon Llull "specifically urges the body of right-thinking knights to act as a policing agency themselves, admonishing them even to be willing to kill those knights who dishonour the order of chivalry, as in the case (which so obviously troubles him) of knights who are thieves and robbers, wicked and traitorous" (Richard W. Kaeuper, Chivalry and Violence in Medieval Europe, Oxford: Oxford University Press, 1999, 278).

${ }^{22}$ Oexle, "Konsens-Vertrag-Individuum", 16.

${ }^{23}$ See Hodges' analysis of the conflicting loyalties towards the family and the Pentecostal Oath: "Blood-feud ... persists even as other, newer styles of chivalry come into being. It is during Balin's adventures that Pellinore kills Lot in battle, and through the rest of Le Morte Darthur Lot's sons, Gawain and his brothers, pursue their feud with Pellinore's sons, Lameroke in particular. And Mordred, the living reminder of the dangers of not recognizing family, lurks to bring down Arthur in the 
chivalric aspect of masculinity representing a given knight's individuality. Masculinity then is gendered individuality, embedded in a specific social, cultural and historical context and at the same time expressing a person's individual development. ${ }^{24}$ Max Fuchs describes individuality in the context of "personality", a term that describes a natural being with reason and responsibility within a social system of norms. ${ }^{25}$ Fuchs explains that the concept of individuality as a person's property is not a Renaissance invention. In the Middle Ages a person is an individual who is endowed with reason and a moral sense that gives to him the power of choice. ${ }^{26}$ This claim places Fuchs in line with Jan A. Aertsen and the majority of medievalists. ${ }^{27}$

Fuchs shares this position with historians such as Oexle, who is also critical of the fact that our understanding of the relationship between individuals and groups is still very much determined by two grand narratives of the nineteenth century. In his classic Die Kultur der Renaissance in Italien: Ein Versuch (1860), Jacob Burckhardt suggests that the Renaissance marks the beginning of modernity because the individual has liberated him - or herself from the bonds of faith and social groups such as family, social status et cetera. This narrative of social progress was counterpoised with Ferdinand Tönnies' narrative of decline in Gemeinschaft und Gesellschaft (1887), who defined society (Gesellschaft) as mechanistic and consisting merely of rational contractual relations among individuals as opposed to the organic bonds that exist among people gathered in a community (Gemeinschaft). In Tönnies' reading the history of individuality was one of emancipation, replacing a feeling of belonging and protection with the isolation and fragmentation the individual would encounter in anonymous masses.

Both these narratives share the belief that there was no concept of individuality in the Middle Ages and that there were no contractual

end. These two enduring elements of the book are engendered at precisely the time chivalry has added the honoring of reciprocal obligations to its celebration of prowess, resulting in an ideal of blood feud that never goes away" (Forging Chivalric Communities in Malory's Le Morte Darthur, 48).

${ }^{24}$ See Max Fuchs, Persönlichkeit und Subjektivität: Historische und systematische Studien zu ihrer Genese, Opladen: Leske und Budrich, 2001, 9.

${ }^{25}$ Ibid., 27.

${ }^{26}$ See ibid., 129.

${ }^{27}$ Individuum und Individualität im Mittelalter, eds Jan A. Aertsen and Andreas Speer, Berlin: de Gruyter, 1996, xvi. 
relations. Oexle points out that Burckhardt's and Tönnies' narratives still have a tremendous impact on our debates about the individual or individuality and about the self or subjectivity. ${ }^{28}$ Although medievalists have long since established the presence of a concept of individuality in medieval thinking, many scholars continue to deny the concept's applicability to the period.

Malory lived in a time when many ideas of the Italian Renaissance had already found their way to England via Burgundy and such translators and publishers as William Caxton. Therefore, individuality, whether in the medieval or renaissance sense, plays a major role in defining the contractual relations in the Arthurian community of the Round Table. Malory's Pentecostal Oath tries to balance out the contractual relations against the interests of individual knights who are more likely to strengthen their masculinity or, in chivalric terms, their prowesse.

The narratives about King Arthur's knights and the prowesse they earn are based on a concept of masculinity which illustrates the delicate balances that keep the power relations in the world of Camelot gradually moving from rise to climax and up to its fall. Malory's concept of masculinity keeps both patriarchal hegemony and its anxieties in a precarious balance. Malory's stories of love and marriage, of bonds of friendship and family, keeping peace and waging war, and showing loyalty and committing treason, illustrate these conflicting forces of masculinity. Malory's language of masculinity represents those aspects of power that keep the Arthurian order together.

The education he received as a member of the lower gentry formed the basis of Malory's rhetoric of masculinity. Had he been the Malory of Newbold Revel, he would have been educated as a lay aristocrat of later medieval England:

The grammar education of the son of a gentle or aristocratic family usually took place in the home and lasted approximately six years, from the age of six or seven until fourteen. The instruction was the re-

\footnotetext{
${ }^{28}$ See Oexle, "Konsens-Vertrag-Individuum", 22-23. The endurance of Burckhardt's assessment of individuality in the Middle Ages is criticized throughout medieval studies (see Henryk Anzulwicz, "Grundlagen von Individuum und Individualität in der Anthropologie des Albertus Magnus", in Individuum und Individualität im Mittelalter, 125; and Klaus Jacobi, "Einzelnes-Individuum-Person: Gilbert von Poitiers' Philosophie des Individuellen", in ibid., 3) and has become a common place (cf. Fuchs, Persönlichkeit und Subjektivität, 128).
} 
sponsibility of professional schoolmasters, most with university education in grammar, others possessing at least the highest level of their most advanced students .... Rhetoric was an essential and primary element in the artes liberates and, as such, was at the heart of the educational curriculum. ${ }^{29}$

Malory uses this rhetoric "in such a way as to bring about certain preferred interpretations". "In doing so", we learn from Hanks, "he interprets chivalry as giving meaning, value, and even triumph to the individual male life". ${ }^{30}$ The rhetoric of masculinity is associated with recurrent references to the male body in metaphors and phrases. Both the knights' physical and spiritual integrity are of crucial significance in maintaining masculinity. The male body, representative of power, encounters threats to its integrity.

These threats, coming from outside the body, take the form of the weapons of adversaries as well as the temptations of the flesh, what Malory calls "lycours lustes". ${ }^{31}$ In his famous passage likening love to May, "he defines virtuous love as being based on restraint and balanced priorities". ${ }^{32}$ Such "hote lustes", 33 as Dame Lyones' feelings for Sir Gareth are called, threaten the integrity of the male body from outside. The body is described as a container of certain qualities capable of endangering a person from within, just as he might be destroyed from without. Lancelot acknowledges this when he talks about traitorous knights around King Mark and Tristram: "hard hit is to take oute of the fleshe that is bred in the bone" ${ }^{34}$ he says, trying to explain why some knights cannot live up to the high standards of Arthurian knighthood.

Power and anxiety cannot be separated since power cannot be achieved without danger. When Pellinore, who takes on the quest of pursuing the "Questing Beast", meets Arthur and asks him for a horse, he explains to the King: "I haue folowed this quest this xii moneth, and other I shal encheue hym, or blede of the best blood of my

${ }^{29}$ Ann Dobyns and Ann Laskaya, "Introduction: Rhetorical Approaches to Malory's Morte Darthur", Rhetorical Approaches to Malory's Le Morte Darthur, eds Ann Dobyns and Ann Laskaya, Arthuriana, XIII/3 (Fall 2003), 4.

${ }^{30}$ D. Thomas Hanks Jr, "The Rhetoric of the Folk Fairy Tale in Sir Thomas Malory's 'Tale of Sir Gareth'”, Arthuriana, XIII/3 (Fall 2003), 58.

${ }^{31}$ Spisak and Matthews, New Edition of Malory's Le Morte Darthur, 573, 1. 32.

${ }^{32}$ Hodges, Forging Chivalric Communities in Malory's Le Morte Darthur, 130.

${ }^{33}$ Spisak and Matthews, New Edition of Malory's Le Morte Darthur, 181, 1. 14.

${ }^{34}$ Ibid., 287, 1. 17. 
body." 35 This quotation shows that the tension between power and anxiety is not exclusive. The knight does not fear his vulnerability but rather sees it as a consequence of any loss of power. Therefore Merlin explains elsewhere that "it is Gods wyll, youre body to be punysshed for your fowle dedes". ${ }^{36}$ A knight's body represents his chivalric prowesse. It is the identification of the two, however, that Malory emphasizes so strongly in language that creates masculinity as an ideological concept. Whatever truth a knight wants to prove, he must be willing to "preue it on his body" ${ }^{37}$ This and similar expression appear frequently. "He is a passyng good man of his body", ${ }^{38}$ we learn, or "for he was a good man named of his body". 39

Consequently, violence and combat, in so far as they threaten the male body to be destroyed or disfigured, are the only proof of a knight's valiance and nobility. The body is a vessel protecting the specific virtues that define chivalric prowesse. Some wounds may be healed, but others damage the body so severely that the knight perishes both physically and as a male capable of protecting his masculinity. Expressions such as "the hauberk perysshed, and so percyd thurgh his body and the hors croppe" 40 establish an image of the total disfiguration and destruction of the male body. This signifies the annihilation of a knight's masculinity, not only the destruction of his body.

This difference is explained in an early provocation young King Arthur faces when he is challenged by the messenger of King Ryons who had "a mantle with kynges berdes". ${ }^{41}$ When the messenger asks for Arthur's beard, the King is outraged. The beard symbolizes Arthur's and the other Kings' masculinity. Although the loss of the beard would not threaten a man's life, the beard here represents the integrity of the male body, which is to be defended at all costs. Therefore, King Arthur replies to King Ryons' messenger:

... also thow mayst see my berd is ful yong yet to make a purfyl of hit. But telle thow kynge this: I owe hym none homage, ne none of myn elders, but or it be longe to he shall do me homage on bothe his kneys,

\footnotetext{
${ }^{35}$ Ibid., 54, 11. 31-32.

${ }^{36}$ Ibid., 55, 1. 24.

${ }^{37}$ Ibid., 56, 1. 6.

${ }^{38}$ Ibid., 61, 1. 2.

${ }^{39}$ Ibid., 63, 11. 23-24.

${ }^{40}$ Ibid., 66, 11. 37-38.

${ }^{41}$ Ibid., 60, 1. 29.
} 
or els he shall lese his hede, by the feith of my body, for this is the most shamefullest message that euer I herd speke of. ${ }^{42}$

The beard stands here pars pro toto for the entire body: honor, not the body itself, is forfeited with the loss of the beard.

This explains why Bagdemagus refuses to "retorne vnto the courte ageyne tyll he had wonne a knyghtes body of the Round Table, body for body". ${ }^{43}$ Only then will "men speke of me grete worship and that I be worthy to be a knyghte of the Rond Table", ${ }^{44}$ Bagdemagus explains. Expressions such as "to fyghte for the lyuelode, body for body" ${ }^{45}$ show that a knight's honor is represented by the integrity of his body. From our modern perspective the exchange value of bodies might be compared to that of money in a capitalist society. The difference, however, is shown with King Ryons. To accumulate a large number of beards only for the sake of completing "a mantle with kings' beards" does not honor the construction of masculinity as an essentialist category any longer. The beard only symbolizes the exchange value of the body. Therefore the formula that one can draw from this and that defines masculinity is - somewhat simplified "body for body", not "beard for beard".

One of the most moving of Malory's episodes exploring the significance of the male body is that of Balyn. Balyn kills a knight whose mistress cannot bear her loss:

O Balyn, two bodyes thou hast slayne in one herte, and two hertes in one body, and two soules thow hast lost. And therwith she toke the swerd from her loue that lay ded and fylle to the ground in a swowne, and whan she aroos she made grete dole out of mesure, the whiche sorowe greued Balyn passyngly sore. And he wente vnto her for to haue taken the swerd oute of her hand, but she helde it so fast, he myghte not take it oute of her hand onles he shold haue hurte her, and sodenly she sette the pomell to the ground, and rofe herself thorow the body. When Balyn aspyed her dedes he was passynge heuy in his herte and ashamed that so fair a damoysell had destroyed herself for the loue of his deth. Allas, said Balyn, me repenteth sore the deth of

\footnotetext{
${ }^{42}$ Ibid., 60, 11. 33-37.

${ }^{43}$ Ibid., 97, 11. 21-22.

${ }^{44}$ Ibid., 97, 11. 24-25.

${ }^{45}$ Ibid., 99, 1. 1.
} 
this knyght for the loue of this damoysel, for ther was moche true loue betwixe them bothe, and for sorowe myght not lenger behold hym. ${ }^{46}$

Chivalric prowesse is demonstrated on the basis of a specific understanding of masculinity and the integrity of the male body. In this episode, however, we are introduced to more complex aspects of masculinity that cannot be constructed on the level of rhetoric any longer. In order to present the more intricate dangers and dilemmas any knight must face using violence as a cultural practice, more complex symbolical structures of narrative art are required. These more subtle social conflicts go beyond combat encounters. Balyn regrets the killing of the knight because both, the knight and his mistress, were united in a relationship of true love. This true love is the most honored bond between men in Camelot.

By killing this knight Balyn damages the very foundation of the political order in King Arthur's realm. His repentance proves him to be a knight who acknowledges the fact that the other knight's true love was a valid one in spite of the fact that he became the adversary of his own prowesse. Balyn's reckoning shows that any ideology based on the defense of individual masculinity must conflict with its own assumptions the moment obligations towards the community conflict with personal goals. Being defined by masculinity, the knight's individuality precedes any chivalric code of behavior or sense of community. While the knight's sense of his own individuality takes precedence over his chivalric duties, the fellowship of the Round Table is required to stabilize the difficult concept of community.

The Pentecostal Oath tries to civilize masculinity in order to avoid collision with the interests of community. If it were for a mere honorand-shame culture as was suggested in the Seventies and Eighties, ${ }^{47}$ this masculinity would have a strong element of social control to it. However, Malory's Morte Darthur introduces us into a world of strong individual rights where the honor of a knight's prowesse ought to earn a lady's love. The obvious problem that remains is whether this is done in a way that is not destructive to the community. The ideal is voiced in various places in Morte Darthur. When, for exam-

\footnotetext{
${ }^{46}$ Ibid., 67, 11. 3-13.

${ }^{47}$ See Mark H. Lambert, Malory: Style and Vision in Le Morte Darthur, New Haven, CT: Yale University Press, 1975, 178; Lisa Robeson,"Noble Knights and Mischievous War': The Rhetoric of War in Malory's Le Morte Darthur", Arthuriana, XIII/3 (Fall 2003), 29.
} 
ple, Sir Kay smote a king "so hard on the helme that the stroke clafe the helme and the hede to the erthe", ${ }^{48}$ King Arthur is delighted:

That was wel stryken ... and worshipfully hast thow hold thy promesse; therefor I shal honoure the whyle that I lyue .... Quene Gweneuer praysed Syr Kay for his dedes and sayd, what lady that ye loue, and she loue yow not ageyne she were gretely to blame. And amonge ladyes, said the quene, I shalle bere youre noble fame, for ye spak a grete word and fulfylled it worshipfully. And therwith the quene departed. ${ }^{49}$

Honor is established by the King's praise and recognition; however, its social consequences are expressed differently. No lady with whom Sir Kay would fall in love could possibly reject a knight of such honor without losing hers. Guinevere's statement is important, since, by the same reasoning, she is not permitted to reject Lancelot's love. This, however, indicates that masculinity empowers the male individual to a degree that his chivalric prowesse may collide with his social loyalties at any time.

In Malory's interpretation of the tradition of Lancelot's character, masculinity seems to be a concept that brings a knight's social responsibility into jeopardy. The more Lancelot's masculinity - or, rather, one should rather say, his body - is threatened in combat or by seduction, the more difficult it gets for the knights of the Round Table to tolerate his exceptional prowesse. The uniqueness of his prowesse is the mark of an individual who cannot be controlled: masculinity cannot be a concept respecting social restrictions unless a knight sacrifices himself or is defeated. Quite inevitably, Lancelot cannot offer to yield to either of these solutions. For the same reason it is inevitable that he would love the Queen, and indeed, possessing at least as much prowesse as King Arthur, he deserves her love. Therefore Merlin warns Arthur "that Gweneuer was not holsome for hym to take to wyf, for he warned hym that Launcelot shold loue her, and she hym ageyne". ${ }^{50}$

At the beginning of Morte Darthur, Lancelot's relationship to King Arthur and his specific role in Camelot is determined by his explicit intention to serve Arthur without claiming land or power for himself.

\footnotetext{
${ }^{48}$ Spisak and Matthews, New Edition of Malory's Le Morte Darthur, 95, 11. 35-36.

${ }^{49}$ Ibid., 95, 11. 36-42.

${ }^{50}$ Ibid., 80, 11. 19-20.
} 
This is markedly different from the members of Arthur's kinship, particularly Gawain who claims power in Arthur's realm, his brother Gareth who becomes a feudal lord in the provinces, or those very few knights who achieve spiritual knighthood and serve God such as Galahad and Perceval.

In spite of their differences, the leading knights of Camelot share the same prowesse. Masculinity, however, is defined differently. While all of them must prove to be excellent soldiers, the point of departure is represented in their sexual conduct. Galahad's masculinity is defined by male virginity; Gawain's masculinity, on the other hand, is traditionally defined by the opposite. That Lancelot neither remains a virgin nor (later on) endures chastity in his relationship to Guinevere illustrates specific aspects of his masculinity. Male virginity or chastity signifies the absence of any claim for political power. The more Lancelot engages in sexual adventures, the less likely it is that his power will be tolerated by Gawain and other suspicious Arthurian knights. This is a singular threat to Arthur's power. The moment Lancelot is tricked into a sexual encounter and loses his virginity his downfall begins, along with that of Camelot as a whole. Eventually, he will be suspected of having slept with the Queen. In other words, Lancelot's adversaries regard his prowesse as a threat to the kingdom, because the strongest knight's masculinity collides with his contractual responsibilities.

Why is sexual love such a destructive power in chivalric society? Sexual love in Thomas Malory's Morte Darthur carries that meaning for religious reasons. Even in the Queste del Saint Gral, Malory takes the destructive power of sexual love from his sources without conveying any major sense of chivalric achievement which can be found there. ${ }^{51}$ Following the Governance of England by Sir John Fortescue,

${ }^{51}$ See Ferguson: "The idea of the Christian knight could lead to the life of chastity and selfdenial exemplified in Galahad and aspired to somewhat overoptimistically by Launcelot. And among the earnest apologists for the chivalric ideal in the fifteenth century there is especially discernible a suspicion of wine and women and of selfindulgence in any form. But this is the asceticism of the dedicated soldier" (Arthur B. Ferguson, The Indian Summer of English Chivalry: Studies in the Decline and Transformation of Chivalric Idealism, Durham, NC: Duke University Press, 1960, 97). 
however, one could argue that a lack of chastity leads to pride,${ }^{52}$ this being one of the reasons why Fortescue deplores the decay of the aristocracy. ${ }^{53}$ Focusing on masculinity one comes to the conclusion that sexual love represents an aspect of masculinity that causes an individual knight's prowesse to turn against the community as a whole. Following the norms of his age, Fortescue identifies pride as the prime deadly sin.

In modern terms one could compare this with egotistic individualism. I do not want to do away with the significant historical differences and, moreover, would find it quite difficult to apply the term "individualism" to a late medieval society. A knight's individuality is represented by his chivalric prowesse, which is not a bad thing as such. However, this prowesse is rooted in a concept of masculinity that is almost exclusively represented by the male body and therefore it is very likely to defy all social restrictions that limit a knight's power or provoke anxieties of loss. It is the extreme gendering of this masculinity in a knight's individual personality that leaves no space to define the social other in the narrative.

For this reason, the significance of Lancelot's love affair with Elaine has been explored in gender studies. Lancelot's refusal of Elaine should not be seen as being "motivated by a fear that she might claim the feminine within him, which his life dedicated to male bonding denies", as Donavin suggested. ${ }^{54}$ This would exclusively identify love with the feminine as opposed to "his masculine strength" (in Donavin's definition) ${ }^{55}$ Rather, sexual desire shows the uncontrolled individuality of the masculine destroying the ideals of chivalric prowesse. Masculinity should not be reduced to military strength nor should love be exclusively identified with the feminine. In Malory's text, love or sexual desire is an aspect of masculinity characterizing the social acceptance of chivalric prowesse. Therefore, Donavin's evasive explanation that even "Lancelot's affair with Guinevere, an unattainable woman who often requires him to demonstrate his masculine strength, distances him from knowledge of and relationship to

\footnotetext{
${ }^{52}$ See John Fortescue, The Governance of England: Otherwise Called the Difference between an Absolute and a Limited Monarchy (1885), ed. Charles Plummer, Oxford: Oxford University Press, 1926, 79-81.

${ }^{53}$ See ibid., 104.

${ }^{54}$ Georgiana Donavin, "Elaine's Epistolarity: The Fair Maid of Ascolat's Letter in Malory's Morte Darthur", Arthuriana, XIII/3 (Fall 2003), 71.

${ }^{55}$ Ibid., 78.
} 
the feminine" ${ }^{, 56}$ fails to contextualize Malory's use of masculinity in the work as a whole. In the context of Malory's Morte Darthur, femininity is absent as a signifying concept describing the social other. Malory does not, as Donavin suggested, advance "Elaine's feminist voice" to any extent and does not even try to "dramatize the difficulty of establishing a feminine subject position in the male-dominated Arthurian world". ${ }^{57}$

The male subject positions in Malory's Morte Darthur allow for hardly any feminine subject position or social commitment. The fellowship of the Round Table functions on the basis of a contractual community that acknowledges the right of each knight to strengthen his masculinity so long as in doing so, he does not intentionally damage this community. The acceptance into the fellowship of the Round Table implies the solemn promise to acknowledge the other knight's chivalric prowesse as much as it is possible to do so. Malory confronts his readers with a vision of masculine individuality in a group of equal males who celebrate their unique achievements.

How is this contractual community kept together under such premises? The answer is by mutual consent, as represented by love. In the context of sexual love, these contractual relations based on mutual consent occur in two cases, in Gareth's marriage and in Lancelot's agreement with Guinevere not to consummate their love. In both cases sexual love is an exclusive aspect of these contractual relationships. In the case of Gareth, sexual love is not mentioned after marriage, and in Lancelot's case it ought never to have been mentioned. It is the absence of any communication about sexual love that shows that the contractual community of the Round Table is still unharmed. As soon as sexual love is mentioned, it means that social responsibilities are defeated by a knight's individuality. That sexual love goes unmentioned does not necessarily mean it is absent - an absurd assumption in Malory's understanding. It is rather the case that the knights do not worry about it, as it could violate their own interests, that is, those of the contractual community. Such a contractual community or "fellowship" is a compact of equals based on a mutual concession of individual freedom and requiring an oath of commitment. In the Pentecostal Oath Arthurian knights remind themselves each year of their holy duties.

${ }^{56}$ Ibid., 71.
${ }^{57}$ Ibid., 77. 
The wedding of Arthur and Guinevere marks the first occasion of the ratification of this oath. The contractual obligations laid out in the oath define the boundaries of individual masculinity. Significantly, this is done in negative terms, defining what is absolutely forbidden rather than what is allowed. There is no female subject position in Thomas Malory's narrative because the concept of masculinity among Arthurian knights does not acknowledge any restrictions of chivalric prowesse unless the integrity of the male body is in danger. This is illustrated by an episode which is told in the context of Gareth's search for a bride. When Gareth is invited into Persante's castle, the host's daughter is sent to Gareth's bed chamber:

When Beaumayns was abede, Syr Persaunt had a lady, a faire doughter of xviiii yere of age. And there he called her vnto hym and charged her and commaunded her vpon his blessynge to go vnto the knyghtes bedde, and lye doun by his syde, and make hym no straunge chere, but good chere, and take hym in thyne armes and kysse hym; and loke that this be done, I charge you, as ye wil haue my loue and my good wil. So Syr Persants doughter dyd as her fader bad her. ${ }^{58}$

Gareth, however, rejects the damsel when he learns that she is a virgin in order not to treat his host dishonorably:

Be ye a mayde or a wyf? said he. Sir, she said, I am a clene maiden. God defende, sayd he, that I shold defoyle you to doo Syre Persaunt suche a shame. Therfore, fayre damoysel, aryse oute of this bedde, or els I wille .... I were a shameful knyghte and I wold do your fader ony disworship. And so he kyst her. ${ }^{59}$

When she tells her father about Gareth's words, Sir Persant is satisfied: "whatsomeuer he be, he is comen of a noble blood." one's daughter to a visiting knight is a stock motive in medieval literature. Malory uses it neither to tell us about the role of women in his times nor about the significance of female virginity, but rather about

\footnotetext{
${ }^{58}$ Spisak and Matthews, New Edition of Malory's Le Morte Darthur, 170, 11. 26-31.

${ }^{59}$ Ibid., 11. 34-39.

${ }^{60}$ Ibid., 1. 41.
} 
the "godelye comynycacyon bytwene Syr Persaunt and Beaumayns", ${ }^{61}$ as we learn from the title of this episode.

In Lancelot's case masculinity reaches a maximum of individual fulfillment that transcends all social boundaries. After his death Ector describes Lancelot in the following words:

... thou were hede of al Chrysten knyghtes ... thou were neuer matched of erthely knyghtes hande. And thou were the curtest knyght that euer bare shelde; and thou were the truest frende to thy louar that euer bestrade hors; and thou were the trweste louer of a synful man that euer loued woman; and thou were the kyndest man that euer strake wyth swerde; and thou were the godelyest persone that euer cam emonge prees of knyghtes; and thou was the mekest man and the ientyllest that euer ete in halle emonge ladyes; and thou were the sternest knyght to thy mortal foo that euer put spere in the reeste. ${ }^{62}$

All these various aspects of Lancelot's superior knighthood reflect his unmatched masculinity that is honored outside any other normative framework of the defining social order. Liberated from the forces of social loyalties, Lancelot embodies an ideal of masculinity unmatched by any other knight and venerated independently of the social consequences of his chivalric prowesse. Lancelot's masculinity is that of a knight created by Thomas Malory in times of social disintegration. Masculinity becomes the ultimate expression of individual personality. Malory's concept of masculinity shares only a few features with that of the literature of the Italian Renaissance: it is masculinity hardly controlled by moderation or the anxieties of jealousy. While masculinity in the Italian Renaissance is modified by the acknowledgement of the other, for instance, empowering female characters by attributing knowledge to them which then threatens masculinity, ${ }^{63}$ Malory speaks mainly of the anxieties of being wounded in an act of violence. Malory's knights belong to a time of social disintegration in which the social acceptance of a knight's masculinity determines whether his per-

${ }^{61}$ Title of Chapter 13 of "The Tale of Sir Gareth of Orkeny That was Called Bewmaynes", which can be found in the contents (ibid., 12).

${ }^{62}$ Ibid., 599, 11. 5-13.

${ }^{63}$ See, for example, Breitenberg's interpretation of Othello: Mark Breitenberg, Anxious Masculinity in Early Modern England, Cambridge: Cambridge University Press, 1996. 
sonal individuality is to the benefit or to the destruction of the Arthurian fellowship. 


\title{
From Antisocial to Prosocial Manhood: SHAKESPEARE'S RESCRIPTING OF MASCULINITY IN AS YOU LIKE IT
}

\author{
MARK BRACHER
}

\begin{abstract}
Cognitive psychologists have established that people's internalized gender scripts, which play a large role in constituting people's identity, or sense of self, and thus in motivating and directing their behaviors, are to a significant degree internalizations of the gender scripts circulating in one's culture. Shakespeare's plays offer a rich array of masculinity scripts for examination and either rejection or adoption. More specifically, by revealing the respective motives and consequences of various masculinity scripts, the plays embody a tacit but powerful critique of dominant masculinity (most obviously in the tragedies and histories) and an embrace of alternative masculinities, most notably in the comedies. As You Like It stands out among the comedies as offering the most cogent critique of dominant masculinity together with a strong case for embracing alternative masculinity scripts that are at once "truer to nature", less harmful to others, and more fulfilling to their bearers themselves.
\end{abstract}

Why should scholars, teachers, and students concern themselves with exploring representations of masculinity in literary texts, particularly when those texts were produced in times and places quite distant and different from their own? The only defensible answer - that is, the only answer that can justify the expenditure of human and economic resources on such explorations - is that such endeavors can in some way be of benefit to us today. The key question concerning a text's representations of masculinity, therefore, is can they function in any 
way to help current audiences negotiate more effectively the vexed issue of masculinity that is implicated in so many personal and social problems afflicting people today?

Prima facie evidence that Shakespeare's As You Like $I t^{1}$ might be capable of providing such assistance comes in two forms. First is the fact that the play offers exemplars of multiple alternative masculinities for its audiences to reflect on, identify with, and respond to. Bruce R. Smith notes in Shakespeare and Masculinity that "At least five ideal types offer themselves for emulation in Shakespeare's scripts: the chivalrous knight, the Herculean hero, the humanist man of moderation, the merchant prince, and the saucy jack", ${ }^{2}$ and he points out that these representations provide Shakespeare's audiences with the opportunity to alter their understanding of and/or their identity as men. ${ }^{3}$

A second body of evidence for the play's potential to assist us with our current struggles regarding masculinity lies in the fact that during Shakespeare's time there was a fierce debate in the royal court and the wider public sphere over the relative virtues of the heroic and the humanist models of masculinity. In Shakespeare on Masculinity Robin Headlam Wells, noting that "all [Shakespeare's] tragedies and most of [his] comedies and histories inevitably concern themselves in one way or another with the question of "manhood and honour", 4 observes that during the time Shakespeare was writing, opposing political alliances and public policies in England, including conflict over whether to wage war against Spain, were determined to a significant degree by opposing forms of masculinity. The anti-war side of this political divide was motivated by the Renaissance humanist ideal of masculinity, espoused by figures such as Erasmus and More, which valorized learning, public service, and the pursuit of a just society. ${ }^{5}$ The pro-war side, which included men such as Sidney and Essex, was motivated by the heroic ideal of masculinity, which valorized physical courage,

${ }^{1}$ All citations and references to acts, scenes, lines and verses refer to The Arden Shakespeare edition (3rd series) of As You Like It, ed. Juliet Dusinberre, London: Bloomsbury, 2007.

${ }^{2}$ Bruce R. Smith, Shakespeare and Masculinity, New York: Oxford University Press, $2000,44$.

${ }^{3}$ See ibid., 120-22, 148.

${ }^{4}$ Robin Headlam Wells, Shakespeare on Masculinity, New York: Cambridge University Press, 2000, 6.

${ }^{5}$ See ibid., 14. 
competitive assertiveness, military prowess, and a politics of violence. $^{6}$

The stakes of this conflict between opposing masculinities were high: "the conflicting political positions signaled by such coded phrases as 'courage-masculine' and 'manly virtue' caused deeper divisions in Elizabeth's and James' Privy Councils than any other topic of public debate in late-Elizabethan and early-Stuart England", Wells reports: "Those conflicts very nearly resulted in the deposition of a reigning monarch, and later provoked a bitter and embarrassing public rift between her successor and the crown prince." "Four hundred years later, this conflict between opposing masculinities has by no means been settled, and the continued presence in our era of swaggering, bellicose politicians demands that we continue to address it. The question, then, is how As You Like It might help us do so in a productive manner.

In order to answer this question I will not only argue that a) Shakespeare's plays offer a rich array of masculinity scripts for examination and either rejection or adoption and that b) these plays - by revealing the respective motives and consequences of various masculinity scripts - embody a tacit but powerful critique of dominant masculinity (most obviously in the tragedies and histories) and an embrace of alternative masculinities (most notably in the comedies), but also that c) As You Like It stands out among the comedies as offering the most cogent critique of dominant masculinity together with a strong case for embracing alternative masculinity scripts that are at once truer to nature, less harmful to others, and more fulfilling to their bearers themselves. These alternative, more feminine scripts, I shall argue, are not only less harmful and more fulfilling, they are also truer to nature, in that they acknowledge and enact, rather than repress, a broader range of the human needs, vulnerabilities, and capabilities that are inherent in all men as well as all women.

\section{Masculinity scripts}

\section{Nature, function, and consequences}

The first step in answering the question of how literature, and especially Shakespeare's As You Like It, might help us to overcome opposing and outdated scripts of masculinity is to understand the effects that

\footnotetext{
${ }^{6}$ See ibid., 11-12, 15.

${ }^{7}$ See ibid., 6.
} 
Shakespeare's theatrical script can have on the cognitive scripts that variously constitute and determine readers' definition, understanding, evaluation, and enactment of masculinity. Cognitive scripts are structures of general knowledge that serve as "blueprints for behavior and thus guide both our actions and our understandings of events and behaviors". 8 They "provide us with a general idea of how we are supposed to behave and what is supposed to happen". "A script incorporates both procedural and declarative knowledge and suggests what events are to happen in the environment, how the person should behave in response to these events, and what the likely outcome of those behaviors would be." 10 Gender scripts are structures of knowledge concerning the specific behaviors through which various forms of masculinity and femininity are constituted, performed, and recognized. Our gender scripts thus play a major role in determining those of our behaviors that imply a certain gender identity as well as in our perception and judgments regarding the gender identities of other people. ${ }^{11}$

In performing these functions, gender scripts can produce serious psychological and social problems, and masculinity scripts are major causes of both types of harm. One way gender scripts cause psychological harm is by conflicting with people's experiences of themselves and the world. As second-wave feminists convincingly documented, the gender scripts for women that held sway prior to the 1960s caused considerable psychological suffering for huge numbers of women by prescribing certain behaviors (for example, those of the dutiful wife, mother, and homemaker) and proscribing others (for example, those of an autonomous, assertive career woman and sexual agent). More recently, psychologists have documented that certain masculinity scripts take a severe psychological toll on many men. Terence Real, for example, has explained how masculinity scripts of toughness and

\footnotetext{
${ }^{8}$ Joan D. Atwood, "Social Construction Theory and Therapy Assumptions", in Family Scripts, ed. Joan D. Atwood, New York: Taylor and Francis, 1996, 13.

${ }^{9}$ Joan D. Atwood, Introduction, in ibid., xvi.

${ }^{10}$ L. Rowell Huesmann, "The Role of Social Information Processing and Cognitive Schema in the Acquisition and Maintenance of Habitual Aggressive Behavior", in Human Aggression: Theories, Research, and Implications for Social Policy, eds Russell G. Geen and Edward Donnerstein, San Diego, CA: Academic Press, 1998, 89.

${ }^{11}$ See Laura M. Carpenter, "From Girls into Women: Scripts for Sexuality and Romance in Seventeen Magazine, 1974-1994", The Journal of Sex Research, XXXV/2 (May 1998), 158-68.
} 
impassivity cause considerable psychological pain for the great majority of men and their families by shaming them into denying their feelings of tenderness and vulnerability. ${ }^{12}$

Gender scripts also produce serious social problems in a more direct manner, by prescribing antisocial behaviors and proscribing prosocial ones. Masculinity scripts are particularly culpable on this count. Scripts of competitiveness (do anything to win), honor (never back down or walk away from a fight), control (always be in control of yourself and of the situation), toughness (boys do not cry), and impassivity (never let them see you sweat) continue to lead men to engage in actions that are harmful and unjust - to themselves as well as to others. One team of psychotherapist researchers has identified seven contemporary masculinity scripts that they have found to be common among their male patients. Each of these scripts emanates from and supports the heroic ideal of masculinity as monolithic, inflexible, penetrating, impenetrable, and unyielding. While these scripts can have beneficial effects for self and others when they are enacted in certain circumstances and with the right degree of intensity, they are also often a significant cause not only of the interpersonal and emotional difficulties that lead men to seek help in psychotherapy ${ }^{13}$ but of various social problems as well.

These scripts include the following: a) the tough-guy script, which suppresses or represses tender feelings and awareness of vulnerability and promotes violent behavior; b) the give-'em hell script, which underwrites interpersonal and intergroup forms of physical violence and abusive behaviors; c) the winner script, which promotes competitiveness and the aggression that often accompanies it; d) the strong and silent script, which contributes to fear of intimacy and depression; e) the independent script, which leads men to undervalue relationships and collective endeavors and to see other people as challenges and threats rather than potential sources of comfort and fulfillment; f) the playboy script, which validates exploitation of women and militates against feelings and behaviors of empathy, caring, and attachment, g) the homophobic script, which not only proscribes affectionate feelings and behaviors toward other men but also promotes anti-gay violence

\footnotetext{
${ }^{12}$ Terence Real, I Don't Want to Talk about It, New York: Scribner, 1998.

${ }^{13}$ See James R Mahalik, Matt Englar-Carlson and Glenn E. Good, "Masculinity Scripts, Presenting Concerns, and Help Seeking: Implications for Practice and Training”, Professional Psychology: Research and Practice, XXXIV/2 (April 2003), 124.
} 
by forcing externalization of men's affectionate feelings for other men.

\section{Altering harmful masculinity scripts}

The personal, interpersonal, and social problems produced by these scripts of heroic, dominant masculinity motivate the search for and development of alternative scripts through which one can be a man. As You Like It can be seen as both a product of this search for alternatives on Shakespeare's part and a means of facilitating audience members' discovery and development of alternative, more productive scripts. The play can help its audiences alter their own harmful masculinity scripts by engaging them in some of the same cognitive and emotional processes through which scripts are constructed and reconstructed by socialization, education, and psychotherapy.

As You Like It can help audience members discontinue the use of harmful scripts and replace them with more beneficial scripts by engaging its audiences in the same basic processes that psychotherapists have identified as key to script alteration. These processes include the following: a) providing a safe environment; b) identifying the harmful scripts; c) spelling out the benefits that these scripts produce for the client; d) enumerating the costs incurred through enacting these harmful scripts; e) helping the client become more flexible in enacting these harmful scripts; f) generating alternative, less problematic scripts, and g) reflecting on the implications and consequences of these alternative scripts..$^{14}$

Watching, reading, and performing plays can activate each of these processes. In the first place, reading or watching a play is safe, much less emotionally threatening than directly confronting one's own psychological issues - a fact that has led some therapists to have their patients read literary works that deal with the same problems the patients are facing. Second, plays can represent problematic behavioral scripts that audience members enact or accept, and they can expose the benefits as well as the costs of these scripts to the audience. Plays can also demonstrate for their audiences more flexible, less compulsive ways of enacting these problematic scripts. And finally, and per-

\footnotetext{
${ }^{14}$ For points b) to e), see Mahalik, Englar-Carlson and Good, "Masculinity Scripts, Presenting Concerns, and Help Seeking", 126; for points a) and f), see Atwood, "Social Construction Theory and Therapy Assumptions", 25; and for point g), see ibid., $15-17,25$.
} 
haps most importantly, plays can generate alternative, less problematic scripts for their audiences and help them reflect on their consequences.

How is this done? New scripts are acquired by observing other people enacting certain behaviors in response to particular types of situations. Such acquisition of behavioral scripts occurs as a result of observing their enactment not only in real life but also in media representations, ${ }^{15}$ which includes watching performances of plays on stage or on screen, and even reading the script of the play. Behavioral scripts are solidified by being rehearsed, and this rehearsal can take the form not only of real-life enactment but also of play-acting (as in rehearsing or performing a play), fantasizing the enactment, or simply recalling the enactment. ${ }^{16}$ Solidification of behavioral scripts is promoted by positive reinforcement, including vicarious reinforcement that is, witnessing the positive outcomes of these scripts when they are enacted by other people or characters.

\section{As You Like It's interventions in masculinity scripts}

As You Like It promotes the development of more beneficial and prosocial masculinity scripts by engaging its audiences in all of these script-changing practices. First, the play operates on numerous fronts to expose and undermine its audiences' harmful, antisocial masculinity scripts. It does so by demonstrating the costs of these dominant scripts, which include various harms both to those who attempt to enact the scripts and to those who are the objects of those enactments. Second, the play reveals the positive functions of these harmful scripts and indicates how these positive effects can be maximized and the harmful effects minimized by the selective and judicial restriction of the harmful scripts' enactment to certain specific modes and situations. And finally and most importantly, As You Like It represents less harmful, more beneficial scripts of masculinity, demonstrates their positive consequences, and engages its audiences in constructing and rehearsing these alternative, prosocial scripts.

\footnotetext{
${ }^{15}$ See Huesmann, "The Role of Social Information Processing and Cognitive Schema in the Acquisition and Maintenance of Habitual Aggressive Behavior", 97.

${ }^{16}$ See ibid., 95, 98 .
} 


\section{Costs of heroic masculinity scripts}

Costs of heroic masculinity scripts include social, political, material, and physical harm to self and others as well as various kinds of psychological harm, including vulnerability, insecurity, anxiety, transience, inauthenticity, self-deception, and hyper-defensiveness. As You Like It engages its audiences in vicariously experiencing multiple episodes in which enactments of heroic masculinity scripts produce such harm. The most brutal episodes involve violent physical competition that is in some cases lethal and that is motivated by scripts in which men achieve or preserve honor through competing with and gaining dominance over other men.

The play begins with a physical struggle between Orlando and his older brother Oliver, who has deprived Orlando of the support he promised their dying father he would provide. That struggle is followed by Oliver's enlisting Duke Frederick's professional wrestler Charles - the quintessence of masculine virility, toughness, and brutality - to permanently disable Orlando, if not kill him, in the next day's wrestling competition. In the following scene, the negative consequences of this masculinity script are driven home to the audience when Le Beau reports to Rosalind and Celia that Charles has just wrestled three brothers and left them dying:

The eldest of the three wrestled with Charles, the Duke's wrestler, which Charles in a moment threw him, and broke three of his ribs, that there is little hope of life in him, So he serv'd the second, and so the third. Yonder they lie, the poor old man, their father, making such pitiful dole over them that all the beholders take his part with weeping.

The weeping of the father and the spectators cues Shakespeare's audience as to their proper response to the harm inflicted by the script of violent masculinity. Later in the same scene, it is Charles himself who is victimized by this Herculean script, when, after threatening Orlando with the same fate he visited on the brothers ("Come, where is this young gallant that is so desirous to lie with his mother earth", I.ii.19192), he is thrown by Orlando and rendered speechless and unable to walk.

Such episodes can work to make audience members less inclined to enact or condone the Herculean masculinity script and the physical violence it entails. One major reason people (mainly boys and men) 
engage in physical violence is because their dominant masculinity scripts connect such behavior with positive outcomes (for example, security, honor, wealth). As L. Rowell Huesmann explains, "more aggressive individuals have encoded in memory more extensive, well connected networks of social scripts emphasizing aggressive problem solving". ${ }^{17}$ Such individuals often "misperceive the likely consequences of aggressive acts simply because their scripts are inaccurate in predicting consequences for the present situation". ${ }^{18}$ The presence and power of such scripts derive in significant measure from observing them in mass media:

Research on media violence and aggression provides ... compelling evidence of that process [of encoding violence scripts in memory]. Copycat crimes and the well-known contagion of suicide ... provide some of the clearest examples of specific aggressive scripts being acquired by adults through observation from media. More importantly from a scientific standpoint perhaps, numerous laboratory and field experiments ... have demonstrated the encoding of specific scripts from such observations. ${ }^{19}$

If observation of fictional representations of violence scripts with positive outcomes enhances their encoding, accessibility, and retrieval, the same is no doubt true of observations of violence scripts with negative outcomes, such as those with which As You Like It begins. Repeated encounters with such episodes in which physical violence produces disablement, suffering, and death should enhance the strength and accessibility of audiences' competition $\rightarrow$ violence $\rightarrow$ negative consequences scripts vis-à-vis their competition $\rightarrow$ violence $\rightarrow$ positive consequences scripts and thus make them more cognizant of the negative consequences of such scripts and hence less likely to enact, honor, or even condone them when they encounter them.

In addition to promoting the establishment of a competition $\rightarrow$ violence $\rightarrow$ negative consequences script in readers, As You Like It also works to extend this script backwards, through envy and pride, to masculine honor, and to incorporate violence by proxy as a goal and negative consequence, thus connecting masculine honor to multiple forms of injustice, suffering, and death. The dominant masculinity $\rightarrow$

\footnotetext{
${ }^{17} \mathrm{Ibid} ., 91$.

${ }^{18}$ Ibid., 92-93.

${ }^{19}$ Ibid., 97.
} 
honor/pride $\rightarrow$ competition $\rightarrow$ envy $\rightarrow$ treachery script is presented first in statements made by Duke Frederick and Oliver. When Oliver soliloquizes at the end of the opening scene that he hates Orlando but does not know why, his subsequent ruminations indicate clearly to the audience that the reason is envy:

I hope I shall see an end of him; for my soul, yet I know not why, hates nothing more than he. Yet he's gentle, never schooled and yet learned, full of noble device, of all sorts enchantingly beloved; and indeed so much in the heart of the world, and especially of my own people, who best know him, that I am altogether misprized. But it shall not be so long.

That Frederick is following the same dominant masculinity $\rightarrow$ honor/pride $\rightarrow$ competition $\rightarrow$ envy $\rightarrow$ treachery script is indicated in the following scene, when he says to Orlando, "The world esteemed thy father honorable, / But I did find him still mine enemy" (I.ii.214-15). Shortly thereafter Duke Frederick enacts this script on Rosalind, whom he banishes and threatens to kill because he is envious that she is more admired and beloved by the people than his daughter Celia. This envy is made clear by Le Beau, who informs Orlando and the audience that

... of late this Duke

Hath ta'en displeasure 'gainst his gentle niece,

Grounded upon no other argument

But that the people praise her for her virtues,

And pity her for her good father's sake;

Duke Frederick confirms that envy is motivating his treachery when, in response to Celia's objection, he explains:

She is too subtle for thee, and her smoothness,

Her very silence, and her patience

Speak to the people and they pity her.

Thou art a fool. She robs thee of thy name,

And thou wilt show more bright and seem more virtuous

When she is gone. 
Frederick then turns to Rosalind and, invoking the masculine honor that is motivating him, repeats his lethal threat:

You, niece, provide yourself;

If you outstay the time, upon mine honour, And in the greatness of my word, you die.

(I.iii.87-89)

The dominant masculinity $\rightarrow$ honor/pride $\rightarrow$ competition $\rightarrow$ envy $\rightarrow$ treachery script is repeated one short scene later in Oliver's scheme against Orlando. Adam warns Orlando that his elder brother, enraged over the accolades Orlando is receiving after having defeated Charles, intends to kill him:

Your brother ...

Hath heard your praises, and this night he means

To burn the lodging where you used to lie,

And you within it. If he fail of that,

He will have other means to cut you off;

(II.iii.19-25)

Act III begins with Duke Frederick following this same script issuing an ultimatum to Oliver:

Find out thy brother, wheresoe'er he is;

Seek him with candle; bring him dead or living

Within this twelvemonth, or turn thou no more

To seek a living in our territory.

This script of dominant masculinity $\rightarrow$ honor/pride $\rightarrow$ competition $\rightarrow$ envy $\rightarrow$ treachery is further reinforced in Act II by Duke Senior and his men, whose exile is a result of Duke Frederick's enactment of it. The Act begins with Duke Senior reflecting,

Now, my co-mates and brothers in exile, Hath not old custom made this life more sweet Than that of painted pomp? Are not these woods More free from peril than the envious court? 
Later Amiens echoes the sentiment in a song that ends, "Here shall he see no enemy / But winter and rough weather" (II.v.6-7), a refrain that is repeated later in the scene by the Duke's entire entourage. And Amiens concludes the act with another song contrasting the treachery of the court with its absence in the forest:

Blow, blow, thou winter wind,

Thou art not so unkind

As man's ingratitude:

Thy tooth is not so keen,

Because thou art not seen,

Although thy breath be rude.

Hey-ho, sing hey-ho, unto the green holly.

Most friendship is feigning, most loving mere folly.

Then hey-ho, the holly!

This life is most jolly.

Freeze, freeze, thou bitter sky,

That dost not bite so nigh

As benefits forgot:

Though thou the waters warp,

Thy sting is not so sharp

As friend remembered not.

(II.vii.175-90)

Such repeated reminders of the treachery, injustice, and suffering entailed by heroic masculinity and its envious quest for dominance, combined with the repeated enactments of such treachery by the envious Oliver and Duke Frederick, promote the establishment of the dominant masculinity $\rightarrow$ honor/pride $\rightarrow$ competition $\rightarrow$ envy $\rightarrow$ treachery script in audiences and thus reduce their inclination to either pursue or approve the pursuit of dominance. That is, whenever audience members think of or feel drawn to pursue honor through the dominance of someone else, they are more likely to be aware not only of the positive consequence of honor but also of negative consequences such as envy, enmity, treachery, suffering, and injustice, and this awareness will make them less inclined to enact or approve the enactment of the script of masculine dominance - either in interpersonal relations or in collective social actions, including politics. 
Heroic masculinity as defensive masquerade

In addition to promoting the development of cognitive scripts connecting heroic, dominant masculinity with multiple negative outcomes, $A s$ You Like It also induces the formation of inferential scripts for recognizing dominant, heroic masculinity as a cover, façade, or masquerade disguising an impotent, "unmasculine" core. This script is developed most centrally through the audience's multiple and extended experiences of Ganymede in full cognizance that "he" is really Rosalind (and the further awareness in Shakespeare's original audiences that Rosalind was really a boy actor). The audience is instructed early on that Ganymede's swagger and bluster, rather than being a manifestation of an underlying masculine self, are efforts to disguise and thus protect the vulnerable feminine self that is enacting them. And at the same time, Shakespeare tells his audience explicitly, through Rosalind's continued musings, that this is precisely the case with many hypermasculine men:

Were it not better,

Because that I am more than common tall, That I did suit me all points like a man?

A gallant curtle-axe upon my thigh, A boar-spear in my hand, and - in my heart Lie there what hidden woman's fear there will We'll have a swashing and a martial outside, As many other mannish cowards have

That do outface it with their semblances.

(I.iii.112-19; emphasis added)

This masquerade, we are further shown, may itself be responsible, through the defense of reaction formation, for any actual qualities of heroic masculinity that a person, whether male or female, may develop. This point is made when Rosalind says to the fatigued and flagging Celia: "I could find it in my heart to disgrace my man's apparel and to cry like a woman, but I must comfort the weaker vessel, as doublet and hose ought to show itself courageous to petticoat. Therefore courage, good Aliena" (II.iv.4-8). Thus primed, Shakespeare's audience is more capable of seeing all instances of "a swashing and a martial outside" - both in the play and in life - as at least potentially mere "semblances" covering for "mannish cowards". And we are guided to this conclusion with various degrees of explicitness. When 
Orlando accosts Jaques and Duke Senior with sword drawn demanding food, Duke Senior recognizes that this aggression is a function of his vulnerability rather than a manifestation of his true nature. "Art thou thus boldened, man, by thy distress?" (II.vii.92), he asks Orlando, and Orlando replies in the affirmative: "The thorny point / Of bare distress hath ta'en from me the show / Of smooth civility" (II.vii.9597).

Touchstone's belligerence is also revealed to be a bluff, and even Oliver's and Frederick's violence turns out, at the end of the play, to have been hiding a more authentic vulnerable self. By witnessing multiple instances of heroic, dominant masculinity being little more than a defensive disguise of an underlying vulnerability, audience members begin to acquire a masculinity script that inclines them, whenever they encounter or think of bluster, bravado, belligerence, or other dominating behavior, to infer or suspect that this behavior is not a manifestation of the man's substance or true self but rather a façade beneath which lies a "girl" - that is, a vulnerable, "non-masculine" self. In promoting the development of this vulnerability $\rightarrow$ dominantmasculinity façade script, As You Like It performs a valuable function for us today, for this same disguise is still much in operation, ${ }^{20}$ and we would be better off if we could recognize the frequent instances in which male bravado and aggression - whether in interpersonal relations or in the pubic posturing of a president - are a sign of and defense against an underlying vulnerability: essentially, a frightened "feminine" self.

\section{Touchstone: more flexible enactments of the dominant script}

In addition to undermining the audience's script of dominant, heroic masculinity by interpolating negative consequences, vulnerability, and defensiveness into it, As You Like It also scripts a more flexible, less destructive mode of enacting dominance. This is accomplished through the character of Touchstone, who renounces overt, physical aggression - apparently because he is aware of its potential negative consequences, in the form of physical harm, for himself - and engages instead in sublimated aggression in the form of insults and threats. Touchstone's mode of dealing with his envy is through sublimated aggression, aggression expressed verbally rather than physically. That envy lies behind his aggression is supported by the suggestion that he

\footnotetext{
${ }^{20}$ See Real, I Don't Want to Talk about It.
} 
is unattractive (see III.iii.3), ${ }^{21}$ as well as by the ubiquity of his aggression. This verbal aggression takes four forms. First there is his verbal abuse and manipulation, which he directs against those of less nimble wit than he. He outduels the modest and gentle shepherd Corin with nonsensical verbal gymnastics until Corin surrenders, stating, "You have too much courtly wit for me, I'll rest" (III.ii.67), and then tells Corin he will be damned for breeding sheep (see III.ii.80-82). He corners the naïve country girl Audrey with his sophistries, demeaning her for lack of learning (see III.iii.10-14), calling her a "foul slut" (III.iii.33), declaring that he will marry her, and then indicating to Jaques that a sham marriage would suit him fine insofar as it would enable him to use Audrey sexually and then abandon her (see III.iii.73-85). Later, as he is anticipating his marriage to Audrey the following day, he gratuitously criticizes the singing of Duke Senior's pages after they have performed a song at his request (see V.iii.40-47). Such verbal putdowns allow the envious, competitive man to achieve a form of dominance without doing actual physical harm.

Touchstone's second mode of verbal aggression is the threat, which, like his insults, he is careful to deliver only to individuals who will not respond with physical violence. When William, who is in love with Audrey, appears, Touchstone first confuses him with a sophisticated declaration that he cannot have Audrey (see V.i.40-44) and then pedantically, condescendingly, and bombastically threatens to kill him if he does not withdraw his suit:

Therefore, you clown, abandon (which is, in the vulgar, 'leave') the society (which in the boorish is 'company') of this female (which in the common is 'woman'); which together is: 'abandon the society of this female', or, clown, thou perishest! Or to thy better understanding, diest. Or (to wit) I kill thee, make thee away, translate thy life into death, thy liberty into bondage. I will deal in poison with thee, or in bastinado or in steel. I will bandy with thee in faction; I will o'errun thee with policy. I will kill thee a hundred and fifty ways! Therefore tremble and depart.

${ }^{21}$ Dusinberre notes that Touchstone's unattractiveness would have been prominent if he was played by "Shakespeare's clown Robert Armin, a man of diminutive stature and grotesque appearance" (Shakespeare, As You Like It, ed. Dusinberre, 265, n.3). 
Like insults, such bullying enables envious, competitive men to dominate without doing physical harm, as long as their victims accede to their demands as William does.

In other cases, where the targets of his verbal abuse and threats might be less docile, Touchstone manages to avoid physical violence by obliquely criticizing them through their appearance or actions but not directly impugning their character. In bragging to Jaques that he has been a courtier, Touchstone declares, "I have had four quarrels and like to have fought one" (V.iv.46-47). When asked how he managed to avoid fighting in that instance, he responds, "Faith, we met and found the quarrel was upon the seventh cause" (V.iv.49-50), or, as he explains:

Upon a lie seven times removed $-\ldots$ as thus, sir. I did dislike the cut of a certain courtier's beard. He sent me word if I said his beard was not cut well, he was in the mind it was. This is called the 'retort courteous'. If I sent him word again it was not well cut, he would send me word he cut it to please himself. This is called the 'quip modest'. If again it was not well cut, he disabled my judgment. This is called the 'reply churlish'. If again it was not well cut, he would answer I spake not true. This is called the 'reproof valiant'. If again it was not well cut, he would say, I lie. This is called the 'countercheck quarrelsome' - and so to the 'lie circumstantial' and the 'lie direct'.

(V.iv.68-81)

When Jaques asks him, "And how oft did you say his beard was not well cut?" Touchstone responds, "I durst go no further than the lie circumstantial, nor he durst not give me the lie direct; and so we measured swords and parted" (V.iv.82-86). Violence is avoided in this case because neither Touchstone nor his adversary directly impugns the other's character: just as Touchstone restricts his criticism to the courtier's beard, so the courtier restricts his criticism to Touchstone's judgment and behavior ("You lie") and refrains from assailing his character by directly calling him a liar.

One can even call the other a liar and still avoid violence, Touchstone says, if one frames the accusation as a conditional. He recalls a quarrel that an entire panel of judges was unable to resolve: "but when the parties were met themselves, one of them thought but of an 'if': as, 'if you said so, then I said so'; and they shook hands and swore brothers. Your 'if' is the only peacemaker; much virtue in 'if'" (V.iv.97101). This use of the conditional accusation helps to avoid violence in 
two ways. First, it avoids the kind of direct accusation that often results in violence. It allows one to assume a position of dominance vis$\grave{a}$-vis the other without actually besmirching the other's character and thus risking severe retaliation. And second, the conditional prevents one from simply assuming that the other person has in fact done what the conditional posits. This move is a basic technique of aggressionreduction programs, which teach hyper-aggressive individuals to resist assuming that the other's actions are a product of hostile intentions. ${ }^{22}$ Instead of assuming, "Your comment (or action) implies that I am such and such; therefore I must attack you in order to defend my self", subjects are taught to think, "If your intentions were hostile, they implied that I am such and such, and therefore I would need to attack you to defend my self, my honor". While this and Touchstone's three other modes of verbal aggression are by no means admirable, his basic masculinity script (pridelenvy $\rightarrow$ verbal aggression $\rightarrow$ verbal putdown $\rightarrow$ psychological dominance) is nonetheless preferable to the heroic, chivalric masculinity scripts of Oliver, Duke Frederick, and Charles, which result in physically harming people and even killing them.

\section{Alternative scripts: empathic, relational masculinity}

As You Like It not only moderates, transvalues, and renders ineffectual our scripts of heroic, dominant masculinity; it also offers alternative masculinity scripts that are more beneficial both personally and socially - personally because they involve acceptance rather than repression of vulnerability and other qualities inherent in all humans, and socially because they entail accord and peace rather than conflict and violence. At the core of this alternative masculinity script is the quest to actualize an open relational self of love, empathy, and altruism instead of the closed monadic self of self-sufficiency, selfishness, and dominance. ${ }^{23}$ The initial, and paradigmatic, instance of this script in the play is the relationship between Rosalind and Celia - a fact indicating that the relational self and its scripts are traditionally coded as feminine and that women are more adequately socialized to embrace and enact their relatedness, empathy, and selflessness than men are. Celia

\footnotetext{
${ }^{22}$ See Cynthia Hudley and Sandra Graham, "An Attributional Intervention to Reduce Peer-directed Aggression among African-American Boys", Child Development, LXIV/1 (February 1993), 124-38.

${ }^{23}$ For a detailed account of the play's exposition of these two types of self, see Mark Bracher, "Contrary Notions of Identity in As You Like It", Studies in English Literature, XXIV/2 (Spring 1984), 225-40.
} 
articulates the empathy experienced by the relational self when she chides Rosalind for feeling despondent over the exile of her father: "If my uncle, thy banished father, had banished thy uncle, the Duke my father, so thou hadst been still with me I could have taught my love to take thy father for mine. So wouldst thou, if the truth of thy love to me were so righteously tempered as mine is to thee" (I.ii.9-14). Thus instructed, Rosalind replies, "Well, I will forget the condition of my estate to rejoice in yours" (I.ii.15-16). In the following scene, Celia enacts the relational self when she responds to her father's banishment of Rosalind by telling him, "Pronounce that sentence then on me, my liege; / I cannot live out of her company" (I.iii.82-83), and declaring to Rosalind, "thou and I am one" (I.iii.94).

But the play indicates in several ways that the need for relationship is not just a feminine characteristic but a universal human one that is absent only when it is overridden by the unnatural contrivances of civilization, epitomized by the court. Many of the men in the play who are not associated with the court are more interested in peacefully coexisting with others than in dominating them. Three men of the forest - Corin, Silvius, and William - are gentle and peaceful. The shepherd Corin (the feminine version of which, Corinne, means maid) responds to Touchstone's insults and arrogance with dignity and equanimity and declares himself to be a man of modesty and empathy rather than pride and envy: "Sir, I am a true labourer. I earn that I eat, get that I wear; owe no man hate, envy no man's happiness; glad of other men's good, content with my harm; and the greatest of my pride is to see my ewes graze and my lambs suck" (III.ii.70-74).

The other shepherd, Silvius, likewise shows himself to be a man of love and self-effacement rather than pride and aggression. When Phoebe, the unreciprocating object of his love, condescends to allow him in her company, he responds:

So holy and so perfect is my love,

And I in such a poverty of grace,

That I shall think it a most plenteous crop

To glean the broken ears after the man

That the main harvest reaps. Loose now and then

A scattered smile, and that I'll live upon.

(III.v.100-105) 
And when the country youth William (perhaps played by Shakespeare himself) is threatened with death by Touchstone if he does not abandon his suit of Audrey, rather than enacting the script of chivalric, heroic masculinity and responding to the attack on his honor with violence, to Audrey asking him to depart, he simply replies "God rest you merry, sir", and exits (V.i.59).

In addition to these scripts of pastoral masculinity, the play valorizes relational masculinity in the form of service and interdependence. This script is embodied most prominently in the relationship between Adam and Orlando. When Orlando at first refuses to flee from Oliver, explaining that he has no honest means of supporting himself, Adam gives Orlando his life savings and offers to be his servant and to face his end with no regrets:

Master, go on and I will follow thee

To the last gasp with truth and loyalty

... fortune cannot recompense me better

Than to die well and not my master's debtor.

(II.iii.69-70, 75-76)

That Adam bears the name of the male (and human) prototype may be taken to suggest that his empathy, altruism, and generosity are inherent masculine (and human) qualities. Orlando reciprocates this selflessness when he declines Duke Senior's offer of food until he has provided for Adam (see II.vii.131-33).

Duke Senior and his men also evince a relational masculinity based on empathy, mutuality, kindness, and generosity. Duke Senior is the antithesis of the competitive, aggressive, monadic self typified by Oliver and Duke Frederick. Senior's relational self is first announced by Rosalind, who confides that her father "loved Sir Rowland as his soul" (I.ii.224), and Senior defines himself as a relational, loving self rather than a prideful, competitive one when he says to Orlando, "I am the Duke / That loved your father" (II.vii.199-200). Senior enacts the empathy and altruism of the relational self in a number of ways. When Orlando accosts him and his men with sword drawn demanding food, the Duke empathizes with him and responds with kindness and generosity rather than reciprocating Orlando's aggression. His reprimand of Jaques for his failure to do likewise promotes the same script of responding to others' faults with kindness: 
Most mischievous foul sin in chiding sin.

For thou thyself hast been a libertine,

As sensual as the brutish sting itself,

And all th'embossed sores and headed evils

That thou with licence of free foot hast caught

Wouldst thou disgorge into the general world.

(II.vii.64-69)

Duke Senior's comments here suggest that, unlike Jaques (and most other men as well), he is aware of his own negative qualities - aware that he harbors within himself - if only in potentia, or in highly attenuated form - the same negative qualities that he observes in others.

He also realizes, like Jaques, that the world is full of suffering and injustice, about which he feels deeply, but he avoids depression and fatalism and tries to do what he can to mitigate the suffering and injustice (as in "the uses of adversity" speech), even as he recognizes that he is himself implicated in it, as he indicates when he expresses profound empathy for the suffering and death of the deer he kills for food:

Come, shall we go and kill us venison?

And yet it irks me the poor dappled fools, Being native burghers of this desert city, Should in their own confines with forked heads Have their round haunches gored.

This deep and capacious empathy of Duke Senior, together with his opposition to splitting and projection (as indicated by his reprimand of Jaques for projecting his own licentiousness) and his desire to reduce the suffering of others (as he does in helping Orlando and Adam), are indicative of a form of selfhood that in Kleinian psychoanalysis is referred to as the depressive position. Individuals operating from what is called the paranoid-schizoid position are unable to deal with the fact that all people, both oneself and others, are composed "of many parts" (as Orlando says of Rosalind, III.ii.146), both good and bad, and as a consequence they rely heavily on the psychological defense mechanisms of splitting and projection, whereby they split off their own negative qualities from awareness and attribute them instead to certain other individuals or groups, whom they then perceive as all bad. 
This is what Jaques does when he wishes to attribute to others (that is project) the negative qualities that he himself possesses, what the treacherous Duke Frederick does when he accuses Rosalind of treachery and banishes her, and what belligerent politicians often do today. ${ }^{24}$ The depressive position, in contrast, is based on the acknowledgement that no one has a monopoly on either good or evil. In the terms of $A s$ You Like It, everyone is "motley": both oneself and others are composed of many heterogeneous parts, some good and others not so good. The depressive position also involves the recognition that human nature and the human condition are far from ideal but avoids fatalism or wallowing in depression, choosing instead to find a reason to go on living and to help others do the same, as Senior does at the conclusion of his opening speech:

Sweet are the uses of adversity,

Which, like the toad, ugly and venomous,

Wears yet a precious jewel in his head;

And this our life, exempt from public haunt,

Finds tongues in trees, books in the running brooks,

Sermons in stones, and good in everything.

Where many people would see only bad in (literal and metaphoric) "ugly and venomous" toads, and seek to do them harm, Duke Senior seeks and finds some good in them and in everything else as well.

The masculinity of the depressive position embodied by Duke Senior entails social behaviors that are profoundly different from those of the paranoid-schizoid position. From the depressive position it is no longer possible to separate persons into good and evil, since everyone is recognized as containing both kinds of qualities. This means that it is more difficult to do violence to others, or to try to dominate them, when one recognizes that one is inherently no better than they are. In addition, one recognizes that violence in others comes from basic human needs and impulses that oneself harbors, and that in similar cir-

\footnotetext{
${ }^{24}$ For example, it is what George W. Bush did when he accused the perpetrators of the 9/11 attacks as being cowardly and hating freedom, when he himself was missing in action following the attacks and subsequently perpetrated a massive assault on civil liberties. For a more detailed exposition of this point, see Mark Bracher, Social Symptoms: Why We Have Failed to Solve Our Social Problems, and What to Do about It, London: Karnac, 2009.
} 
cumstances one might be inclined to engage in similar behaviors (as Duke Senior recognizes when accosted by the desperate Orlando). And finally, the realization that one has oneself caused harm to others, even if only by living and consuming resources that others also need (or that others are, in the case of food such as the slaughtered deer), leads one to try to make reparations by helping and supporting others rather than trying to dominate them, a switch that both Frederick and Oliver make near the end of the play.

The depressive position thus entails a basic masculinity script that runs directly counter to the basic script of dominating, heroic, chivalric masculinity. In place of the latter's honor/pride $\rightarrow$ competition $\rightarrow$ envy $\rightarrow$ treachery/violence script, Duke Senior's motley, relational masculinity entails the basic script of humility $\rightarrow$ responsibility $\rightarrow$ empathy $\rightarrow$ reparation (generosity, self-sacrifice) $\rightarrow$ atonement, $m u$ tual flourishing.

\section{Scripts for overcoming aggressive, dominating masculinity}

Epiphany and conversion: Oliver and Frederick

In addition to scripting this alternative, reparative masculinity, As You Like It also scripts three basic paths by which one can move away from the paranoid-schizoid position of heroic, aggressive, dominating masculinity and toward the empathic, reparative atonement of relational masculinity. The first and quickest route to reparative masculinity is by way of epiphany and conversion. This is the path taken by Oliver and Frederick. Oliver's epiphany occurs when his life is saved by Orlando, the very man he has been trying to kill, who is wounded in the process. Orlando's selflessness demonstrates to Oliver that his own hatred and violence are "unnatural" (IV.iii.123), and that altruism and kindness are both more noble and more natural than aggression and revenge:

... kindness, nobler ever than revenge, And nature, stronger than his just occasion, Made him give battle to the lioness, Who quickly fell before him, in which hurtling From miserable slumber I awaked.

(IV.iii.127-31)

Oliver's slumber here is metaphorical as well as literal, referring to his earlier envy and aggression, which rendered his more authentic em- 
pathic and altruistic impulses dormant. He now realizes that this previous self of heroic, dominating masculinity was not his truest, deepest self:

'Twas I but 'tis not I. I do not shame

To tell you what I was, since my conversion

So sweetly tastes, being the thing I am.

(IV.iii.134-36)

Thus enlightened, Oliver falls in love with Aliena/Celia, makes reparation to Orlando by giving him their father's estate, and vows to remain in the forest and "here live and die a shepherd" (V.ii.12).

Duke Frederick's epiphany and conversion come when, on his way to attack Duke Senior in the forest, he comes upon "an old religious man" and, "after some question with him, was converted / Both from his enterprise and from the world" (V.iv.158-60). Following this epiphany and conversion, Frederick, like Oliver, makes reparation,

His crown bequeathing to his banished brother, And all their lands restored to them again

That were with him exiled.

(V.iv.161-63)

This act, together with Oliver's similar one, provides audience members with an envy/aggression $\rightarrow$ epiphany $\rightarrow$ conversion $\rightarrow$ empathy $\rightarrow$ reparation script through which they can move beyond the paranoid-schizoid position of splitting, projection, and violence.

\section{Orlando: training in perspective taking and relationship}

Like Oliver and Frederick, Orlando begins the play enacting the dominant masculinity $\rightarrow$ honor/pride $\rightarrow$ competition $\rightarrow$ envy $\rightarrow$ aggression masculinity script. But his first aggressive actions - his struggling with Oliver over his inheritance and his wrestling with Charles - suggest that in addition to being envious, he is also depressed. As he indicates to Rosalind and Celia when they try to dissuade him from wrestling Charles, he feels alienated, unworthy, and unloved and doesn't really care if he lives or dies:

... if I be foiled there is but one shamed that was never gracious, if killed, but one dead that is willing to be so. I shall do my friends no wrong, for I have none to lament me; the world no injury, for in 
it I have nothing. Only in the world I fill up a place which may be better supplied when I have made it empty.

Orlando's wrestling with Charles thus enacts aggression not only against Charles but against himself, expressing a barely disguised suicide wish that is not only a result of depression but a defense against it as well. The same is true of his initial determination to ignore Adam's warning of Oliver's plot to kill him and remain on Oliver's estate nonetheless - an action that would almost certainly result in his death, according to Adam.

Fortunately, through falling in love with Rosalind, experiencing the generosity, first, of Adam and then of Duke Senior, and finally being trained in perspective taking by Rosalind (posing as Ganymede), Orlando is enabled to overcome the paranoid-schizoid position and the envy, depression, and aggression it entails and embrace instead the depressive position and its reparative action. Orlando's transformation is initiated when he is smitten by Rosalind as she congratulates him on his victory over Charles. At this point, the script of masculine dominance no longer has dominance over him: his victory over the Herculean hero Charles is followed closely by the defeat of the Herculean masculinity script within himself. His love for Rosalind renders him hopelessly inadequate for himself, leading him to realize that he can become whole or strong not through domination of others but only through relationship to them. "O poor Orlando, thou art overthrown!" he declares as Rosalind departs: "Or Charles or something weaker masters thee" (I.ii.248-49). The overthrow of the chivalric ideal of dominant masculinity is further signaled by Celia when she reports to Rosalind that she saw Orlando lying beneath a tree "like a wounded knight" (III.ii.233-34), indicating that his heroic, chivalric masculinity is moribund.

Orlando therefore abandons his quest for heroic, indomitable masculinity and seeks instead to be united with his better half, which requires first of all connecting with his better internal half: extricating himself from his self-involvement and attuning himself to the nature and needs of the other. This process, in turn, requires his recognizing and accepting the other's, and his own, multiplicity and heterogeneity - that is, recognizing and accepting that neither he, nor his love, nor anyone else is simply one thing, either all good or all bad. The encomium to Rosalind that Orlando disseminates in the forest demon- 
strates, however, that he has still not integrated the good and bad aspects of both self and object.

Thus Rosalind of many parts

By heavenly synod was devised,

Of many faces, eyes, and hearts

To have the touches dearest prized.

Heaven would that she these gifts should have,

And I to live and die her slave.

(III. ii.146-51)

These lines indicate that Orlando is still splitting the good qualities off from himself and projecting them onto his love object, whom he idealizes as possessing only wonderful qualities, while rendering himself an abject object, worthy only of being her slave. Such splitting is nonetheless an improvement over the splitting that attributes only negative qualities to the other, for unlike this latter splitting, which facilitates hatred and violence toward the other, Orlando's form of splitting is a provisional way of maintaining awareness of the other's good qualities and thus facilitates the pursuit of relationship and reparative action. ${ }^{25}$

Orlando requires training and practice in order to enter fully into the relationship and reparative action of the depressive position. As contemporary relational therapists emphasize, men who have spent their lives practicing the heroic, Herculean, chivalric scripts of aggression and dominance cannot easily switch into a relational, reparative mode when they encounter the impasse that the former scripts inevitably entail. Rather, they must work to understand and attune themselves to those others with whom they want a meaningful relationship. ${ }^{26}$ This point is made clear by the fact that Orlando is struck dumb by Rosalind's presence and is incapable of responding to her overtures at first (see I.ii.246-47). Hence before he can enter into a fulfilling relationship with her, he must first receive instruction on how to be an adequate partner. "I am he that is so love-shaked", he says to Ganymede/Rosalind: "I pray you tell me your remedy" (III.ii.353-54). Ganymede/Rosalind obliges by training Orlando to be

\footnotetext{
${ }^{25}$ John Steiner, "The Equilibrium between the Paranoid-Schizoid and the Depressive Positions", in Clinical Lectures on Klein and Bion, ed. Robin Anderson, New York: Routledge, 1992, 46-58.

${ }^{26}$ See Real, I Don't Want to Talk about It.
} 
attentive to her wishes, to take her perspective regarding his own actions, and to recognize and feel guilty when he has failed to do so (see IV.i.35-65, 175-84). She also trains him to recognize her negative qualities and integrate them with the positive, warning him that after they are married she will lose the luster produced by his current idealization of her (see IV.i.138-46).

By the end of the play, Orlando has accomplished the most crucial task of psychological integration: his aggression has been integrated with and subordinated to his love, empathy, and altruism. This point is made clear by Oliver's report of Orlando's actions in saving Oliver's life. When Orlando encounters the sleeping Oliver about to be attacked by the hungry lioness, part of him is inclined to abandon Oliver to his fate as just revenge for Oliver's treachery, but this impulse is subordinated to his empathic, reparative impulses:

Twice did [Orlando] turn his back and purposed [to abandon me to the lioness];

But kindness, nobler ever than revenge,

And nature, stronger than his just occasion,

Made him give battle to the lioness.

(IV.iii.126-29)

Orlando's defeat of the lion, which is a companion and hence metonym of Hercules, symbolizes his overcoming of his own dominating, Herculean masculinity, just as his scaring away of the serpent that is about to enter Oliver's open mouth symbolizes his defeat of his own wicked impulses. His ability to subordinate his own aggressive impulses to his altruistic, reparative impulses can be seen as the result of his encounter with good external objects, in the form of Rosalind, Adam, and Duke Senior, which contribute to and help him own and consolidate his good internal objects ${ }^{27}$ and integrate their qualities into his sense of self. The script for this route that Orlando takes to achieve the depressive position is the following: splitting/idealization of the other (falling in love) $\rightarrow$ encounter with good external objects $\rightarrow$ relationship training $\rightarrow$ integration of empathy and subordination of aggression $\rightarrow$ reparation and relational commitment (marriage).

\footnotetext{
${ }^{27}$ This consolidation includes also his father, of whom he says to Oliver at the beginning of the play, "I have as much of my father in me as you" (I.i.46-47).
} 
Jaques: achieving the depressive position

In Jaques, Shakespeare presents a third script for attaining the relational, reparative masculinity of the depressive position. Instead of repressing his vulnerability and externalizing it onto others by dominating them either physically or verbally, Jaques struggles to acknowledge not only his vulnerability but also his imperfections. This struggle is evident in his vacillation between melancholy and aggression, and this vacillation indicates that both states are responses to vulnerability and imperfection of both self and world.

When he first appears in the play, Jaques is immersed in melancholy, importuning Amiens to keep singing so that he can extend his melancholy state (see II.v.8-12). As they part, he indicates to Amiens, "I'll go sleep if I can; if I cannot, I'll rail against all the first-born of Egypt" (II.v.53-54). Both the desire to sleep and the inability to do so are symptoms of depression (which is a function of the paranoidschizoid position rather than the depressive position), while his fallback position of aggression (in verbal form, against either gypsies or Duke Senior's band of metaphorical gypsies) is a form of manic defense against the depressive position. ${ }^{28}$ And indeed, when he reappears a few minutes later, he is well immersed in this manic alternative. Having just witnessed Touchstone railing against the "miserable world" (II.vii.13), he has resonated with Touchstone's sublimated verbal aggression, which has lifted him out of his depression. Thinking he has found a solution to his angst, he is determined to emulate Touchstone and, by assuming the manner (and motley attire) of the fool, unleash his aggression with impunity: "cleanse the foul body of th'infected world" (II.vii.60).

This plan to defend against his own vulnerability and imperfection by projecting it into "the foul body of th'infected world" is cut short, however, by a decisive intervention from Duke Senior, who, operating much like a psychoanalyst, confronts Jaques with his projection and the personal failings that it is defending against:

Most mischievous foul sin in chiding sin.

For thou thyself hast been a libertine,

As sensual as the brutish sting itself,

And all th'embossed sores and headed evils

${ }^{28}$ See Shakespeare, As You Like It, ed. Dusinberre, 214, n.54. 
That thou with licence of free foot hast caught, Wouldst thou disgorge into the general world.

Jaques protests that his verbal attacks will be entirely just and deserved, but he is interrupted by the sudden entrance of Orlando, and when he resumes his ruminations some mere fifty lines later in his Seven Ages of Man speech, after having witnessed Duke Senior's kindness to the belligerent Orlando, he has ceased his manic externalizing defense and is in the process of possessing his own multiplicity, imperfections, and vulnerability (ultimately, mortality). Jaques has moved from the paranoid-schizoid position, which sees both self and others in black/white, either/or terms as either purely good or purely bad, toward the depressive position, which realizes that both self and others are composed of many possibilities and that who or what they are changes as they live their lives.

Jaques does not immediately abandon his aggression once and for all. He returns to verbal aggression when he tells Orlando to stop posting his verses, invites Orlando to join him in railing against the world and their misery, and says it is a fault to be in love (see III.ii.252-74). However, several scenes later, when he is severely chided by Rosalind for being once again immersed in melancholy, he explains that unlike some forms of melancholy, which function in various ways as simply another means of self-aggrandizement, his depression derives from his broad experience of the world. When Rosalind glibly dismisses his travels as folly, he corrects her, asserting that the experience he gained from them is invaluable, despite the fact that it makes him sad. Most tellingly, when Rosalind continues to mock him, he does not respond with verbal aggression of his own, but simply retires upon the entrance of Orlando, as Rosalind's mockery of him continues (see IV.i.19-34). And at the end of the play, on hearing that Duke Frederick has renounced ambition and dominance and withdrawn into a life of solitude, Jaques determines that he will join him in a life of contemplation: "To him will I; out of these convertites / There is much matter to be heard and learned" (V.iv.182-83). Hence, after wishing the others well, he declares: "I am for other than for dancing measures" (V.iv.191), and departs to begin the contemplative life that will presumably enable him to attain the depressive position and the awareness of moral complexity and engagement in reparative action that it entails. The character of Jaques thus offers audiences a mascu- 
linity script of vulnerability $\rightarrow$ depression $\rightarrow$ (verbal aggression) $\rightarrow$ contemplation ( $\rightarrow$ depressive position $\rightarrow$ reparation).

\section{Conclusion}

As You Like It thus undermines the dominant paranoid-schizoid masculinity script by exposing its negative consequences and its defensive function, and it offers several scripts, through the actions of Touchstone, for enacting this aggressive, dominating masculinity more flexibly and benignly: pride $\rightarrow$ envy $\rightarrow$ verbal aggression (insult, threat, oblique criticism, or conditional accusation) $\rightarrow$ verbal putdown $\rightarrow$ psychological dominance. Most importantly, the play provides, in the actions of Duke Senior and others, a basic script for enacting the empathy and reparation of the depressive position (humility $\rightarrow$ responsibility $\rightarrow$ empathy $\rightarrow$ reparation $\rightarrow$ atonement, mutual flourishing), as well as three scripts for moving beyond paranoid-schizoid masculinity to the empathy and reparation of the depressive position. These scripts include: a) Oliver and Frederick: envy/aggression $\rightarrow$ epiphany $\rightarrow$ conversion $\rightarrow$ empathy $\rightarrow$ reparation; b) Orlando: splitting/idealization of the other (falling in love) $\rightarrow$ encounter with good external objects $\rightarrow$ relationship training $\rightarrow$ integration of empathy and subordination of aggression $\rightarrow$ reparation and relational commitment (marriage), and c) Jaques: vulnerability $\rightarrow$ depression $\rightarrow$ (verbal aggression) $\rightarrow$ contemplation $(\rightarrow$ depressive position $\rightarrow$ reparation).

These alternative scripts not only offer escape from the personal suffering and interpersonal violence produced by the scripts of dominant masculinity, they also constitute necessary and sufficient prerequisites for overcoming much of the collective violence perpetrated by social and political structures, institutions, policies, and actions, including war, poverty, and inequality. In Shakespeare's day, these masculinity scripts constituted an alternative to the belligerent, warmongering masculinity of men like Sidney and Essex. In our day, these same scripts offer an alternative not only to the belligerent, warmongering masculinity of politicians such as Bush, Cheney, and Rumsfeld, but also to the massive indifference toward the suffering of the underclass in the United States and around the world. For as Neil Altman has observed, the widespread abandonment of social responsibility in American society is the result of a collective defense "against precisely the depressive guilt that ... leads to reparative con- 
cern for others". ${ }^{29}$ Our entire society, Altman argues, has embraced the paranoid-schizoid position, splitting people into groups of good and bad, deserving and undeserving, and externalizing all negative qualities onto the latter groups, thus inviting and justifying the perpetration of various forms of violence (physical, institutional, structural, cultural) against them. Social responsibility demands that we eschew this paranoid-schizoid behavior and instead embrace the depressive position, recognizing our own complicity in the suffering of others at home and around the world and engaging in reparative action to ameliorate that suffering. ${ }^{30}$

Literary texts such as As You Like It can promote this movement to the depressive position and prosocial action, provided they are consumed in the right way. Simply reading or watching As You Like It will rarely result, in and of itself, in the acquisition by audience members of the more benign relational, reparative masculinity scripts. For such acquisition to occur, teaching must play a key role. Some may object that it is not the role of teachers to help students acquire alternative behavioral scripts. ${ }^{31}$ Recent developments in learning theory, however, suggest otherwise. Roger Schank, for one, argues that helping students acquire such scripts should be the central purpose of education: "We should teach cross curricularly with a focus on what we want students to actually be able to do in the real world", ${ }^{32}$ he advises, and this means that "we need to teach relevant scriptlets", ${ }^{33}$ by which he means specific scripts for cognition and action. Indeed, in Schank's view, "a curriculum ought to be no more than a collection of scriptlets to be acquired". ${ }^{34}$

Recalling that scripts are acquired by rehearsing them in multiple contexts in any of several various ways (for example, reading, recalling, imagining, performing), we can identify a number of basic pedagogical activities by which such acquisition can be maximized, including a) re-reading, remembering, and/or performing key scenes

${ }^{29}$ Neil Altman, "Manic Society: Toward the Depressive Position", Psychoanalytic Dialogues, XV/3 (June 2005), 330.

${ }^{30}$ See ibid., 329-31.

${ }^{31}$ See, for example, Stanley Fish, Save the World on Your Own Time, New York: Oxford University Press, 2008.

32 Roger C. Schank, Dynamic Memory Revisited, New York: Cambridge University Press, 1999, 180.

${ }^{33}$ Ibid., 184.

${ }^{34}$ Ibid., 185. 
from the play with attention focused on the relational, reparative masculinity scripts; b) rehearsing the relational, reparative scripts by viewing and reading other Shakespeare plays, and other literary texts, in which they are present; c) searching for and identifying the relational, reparative scripts in other texts, so that when one reads these texts, one is simultaneously consciously rehearsing these scripts; d) writing the relational, reparative scripts into other characters and circumstances, and e) imagining performing the relational, reparative scripts in real life. By engaging students in such activities, teachers can help them acquire alternative masculinity scripts that will not only enhance their chances for personal well being but will also contribute significantly to the general welfare. 



\title{
Sentimental Masculinity: HENRY MACKENZIE'S THE MAN OF FEELING (1771)
}

\author{
RAINER EMIG
}

\begin{abstract}
Sentimental fiction is nowadays often seen as the province of a femininity slowly asserting itself against all patriarchal odds. Pamela and Clarissa have become the heroines in this one-sided story. However, sentimental fiction and the philosophy that goes hand in hand with it also had important effects on the reformulation of acceptable modes of masculinity. Harley, the protagonist of Mackenzie's seminal short novel, is such a transitional figure who is torn between privilege and individual virtue, rationality and feeling, expected strength and appropriate weakness. In him we can see a trial run of modern masculinity - or rather of the various acceptable shapes of modern masculinities. He also offers a suitable illustration of the transition from Neoclassical to Romantic to bourgeois masculinity. The fact that he does not survive his own story but is torn apart by his contradictions points towards impasses in masculine roles with which we are still struggling today.
\end{abstract}

The term "sentimental" and the concept of sentimentality are nowadays firmly associated with femininity. An emphasis on emotions and their entanglement with the body and its affects fits into modern stereotypes of the weaker sex. Victor J. Seidler's painfully sweeping study Transforming Masculinities reproduces this cliché: "emotions are interpreted as 'feminine' and so as a threat to male identities, and partly because masculinities are identified with self-control as a mode of dominance in which reason supposedly silences inner emotions, feel- 
ings and desires." "Yet when Sentimentalism emerged as a philosophical and aesthetic tendency in the eighteenth century, it was originally a universal concept. In fact, when one studies the ideas of the foremost British exponent of sentimental philosophy, Anthony Ashley Cooper, Earl of Shaftesbury (1671-1713), one cannot say whether his descriptions refer to male or female observers or if they describe masculine or feminine qualities. In this vein, he states that the moral sense of the mind

... feels the soft and harsh, the agreeable and disagreeable in the affections, and finds a foul and fair, a harmonious and a dissonant, as really and truly here, as in any musical numbers or in the outward forms or representations of sensible things. Nor can it withhold its admiration and ecstasy, its aversion and scorn, any more in what relates to one than to the other of these subjects. ${ }^{2}$

In another, later passage, he goes even further:

No sooner the eye opens upon figures, the ear to sounds, than straight the beautiful results and grace and harmony are known and acknowledged. No sooner are actions viewed, no sooner the human affections and passions discerned (and they are most of them as soon discerned as felt) than straight an inward eye distinguishes and sees the fair and shapely, the amiable and admirable, apart from the deformed, the foul, the odious or the despicable. ${ }^{3}$

Chester Chapin indeed sees Cooper's life and career as a mirror of that of many failed sentimental heroes. ${ }^{4}$ Janet Todd's seminal study of Sensibility also upholds the non-gendered status of sentimental writing. In its introduction she writes:

The sentimental work reveals a belief in the appealing and aesthetic quality of virtue, displayed in a naughty world through a vague and

${ }^{1}$ Victor J. Seidler, Transforming Masculinities: Men, Cultures, Bodies, Power, Sex and Love, London: Routledge, 2006, 25.

${ }^{2}$ Anthony Ashley Cooper, Characteristics of Men, Manners, Opinions, Times, ed. Lawrence E. Klein, Cambridge Texts in the History of Philosophy, Cambridge: Cambridge University Press, 1999, 172-73.

${ }^{3}$ Ibid., 326.

${ }^{4}$ See Chester Chapin, "Shaftesbury and the Man of Feeling", Modern Philology, LXXXI/1 (August 1983), 47-50. 
potent distress. This distress is rarely deserved and is somehow in the nature of things; in later sentimental works it even overshadows virtue, which may in fact be more manifest in the sympathy of the observer than in the sufferer. The distressed are natural victims, whose misery is demanded by their predicament as defenseless women, aged men, helpless infants or melancholic youths. ${ }^{5}$

The idea that emotions were not only linked to moral ideas of virtue but also explicable in rational terms shows that Sentimentalism is not a simple opposition to Enlightenment rationality. Another important philosophical influence in the context of Sentimentalism, David Hume, had already declared in his Treatise of Human Nature (17391740): "A propensity to the tender passions makes a man agreeable and useful in all the parts of life; and gives a just direction to all his other qualities, which otherwise may become prejudicial to society." Sentimentalism therefore indeed paved the way for the transition of rationalist Neoclassicism to the ideologies and aesthetics of Romanticism. The merger of Romanticism and bourgeois pragmatism, one could argue, in turn prepared the path for the modern thinking to which, in terms of gender and sexuality, we still adhere. This makes it all the more necessary to understand Sentimentalism in terms of gender.

The literary manifestations of Sentimentalism were also to a considerable degree male: Sarah Fielding's The Adventures of David Simple (1744), Henry Brooke's, The Fool of Quality (1766-1772), Oliver Goldsmith's The Vicar of Wakefield (1766), Laurence Sterne's A Sentimental Journey (1768) and Henry Mackenzie's The Man of Feeling all feature men as their protagonists. ${ }^{7}$ That these are unusual heroes becomes evident in the strong ambivalence that many of them exerted even in their own time and all the more so today: are they comic fig-

\footnotetext{
${ }^{5}$ Janet Todd, Sensibility: An Introduction, London: Methuen, 1986, 2-3.

${ }^{6}$ David Hume, A Treatise of Human Nature, ed. P.H. Nidditch, 2nd edn, Oxford: Clarendon Press, 1978, 603-604.

${ }^{7}$ Patricia Meyer Spacks believes this to be the result of the eclipsing of female authored texts by male authored ones. Yet even she has to admit, in a critical aside on Janet Todd, that an easy gendering of sensibility as feminine is problematic: "Janet Todd observes that the 'cult of sensibility stressed those qualities considered feminine in the sexual psychology of the time,' specifying 'intuitive sympathy, susceptibility, emotionalism and passivity.' But the attribution of sensibility to women did not seem so bland a matter to eighteenth-century female writers" (Meyer Spacks, quoted in Todd, Sensibility, 110).
} 
ures, or are we supposed to take them seriously? Only Sterne's Parson Yorick is clearly marked as a comic hero. At the time of the novels' first publication, Goldsmith's tragic vicar and Mackenzie's equally doomed hero in particular were taken very seriously. In a letter by Lady Louisa Stuart from 1826 she describes her surprise at the reaction of a group of country-house readers to the novel she, her mother and sisters had been weeping over when it first appeared: "Nobody cried, and at some passages, the touches that I used to think so exquisite - oh dear! They laughed."

The present essay will try to link the multiple borderlines on which sentimental fiction is located: serious versus comical, Enlightenment rationalism versus proto-Romantic emotionality, and masculinity versus its supposed binary opposite, femininity. It will attempt to prove that sentimental heroes, such as Mackenzie's Harley, represent trial runs of a new masculinity, one whose legacy is still with us when we debate for instance "new men". At the same time, such eighteenthcentury attempts to redefine the dominant gender of patriarchy will be employed to show that masculinity - already in its early "conceptual" manifestations - was a far cry from essentialist, and therefore probably superior to some contemporary backlashes that try to tie masculinity to the body and psyche in naïve and simplistic fashions.

The "Man of Feeling", a country gentleman called "Harley", is clearly not the norm when the reader encounters him posthumously for the first time in Mackenzie's novel. His very first introduction by a narrator already calls him "whimsical", an adjective that implies a simultaneous lack of relevance and predictability, two qualities that a man of his rank ought to possess. In fact, Harley is in many ways a failure. He lacks integrity, a fact that is already aptly demonstrated by the medium in which he has managed to manifest himself. What he has left behind are incoherent notes that do not amount to a history or a sermon. Neither do they represent philosophical aphorisms, another acceptable genre for a male writer. These notes are further fragmented by their present owner, who uses them to clean his hunting gun:

"Some time ago," said he, "one Harley lived there, a whimsical sort of man I am told, but I was not then in the cure; though, if I had a turn

\footnotetext{
${ }^{8}$ Stephen Bending and Stephen Bygrave, Introduction, The Man of Feeling, ed. Brian Vickers, Oxford World's Classics, Oxford: Oxford University Press, 2001, xv. All quotations from Henry Mackenzie's The Man of Feeling are from this edition.
} 
for those things, I might know a good deal of his history, for the greatest part of it is still in my possession."

"His history!" said I. "Nay, you may call it what you please," said the curate; "for indeed it is no more a history than it is a sermon." ....

"Soon after I was made curate, he left the parish, and went no body knows whither; and in his room was found a bundle of papers, which was brought to me by his landlord. I began to read them, but I soon grew weary of the task; for, besides that the hand is intolerably bad, I could never find the author in one strain for two chapters together; and I don't believe there's a single syllogism from beginning to end."

Harley does not fit into masculine patterns of self-representation through his loose ends and unacceptable openness. ${ }^{10}$ This also affects his behavior, for he cannot control himself and lets his feelings run away with him. Here is a description of how he behaves in the company of a maiden aunt who might leave him a fortune:

... notwithstanding the instructions he daily received, his visits rather tended to alienate than gain the good-will of his kinswoman. He sometimes looked grave when the old lady told the jokes of her youth; he often refused to eat when she pressed him, and was seldom or never provided with sugar-candy or liquorice when she was seized with a fit of coughing: nay, he had once the rudeness to fall asleep, while she was describing the composition and virtues of her favourite cholicwater. In short, he accommodated himself so ill to her humour, that she died, and did not leave him a farthing. ${ }^{11}$

Within the framework of eighteenth-century politeness, his behavior is unacceptable. Within the framework of eighteenth-century Sentimentalism, however, his conduct is honest and therefore virtuous. Virtuousness clashing with the demands of his gender and class is a shorthand description of Harley's problem. This goes as far as making him incapable of proposing marriage to a wealthy heiress who not only lives nearby, but clearly likes him. Believing himself to be beneath her in terms of wealth, but more importantly feeling far too much for her

\footnotetext{
${ }^{9}$ Mackenzie, The Man of Feeling, 4.

${ }^{10}$ See Rainer Emig, "Madness, Eccentricity, Sociability: Henry Mackenzie's The Man of Feeling (1771) and the Trials of Modernising the British Subject", in Einsamkeit und Geselligkeit um 1800, ed. Susanne Schmid, Regensburger Beiträge zur Gender Forschung 3, Heidelberg: Winter, 2008, 163-75.

${ }^{11}$ Mackenzie, The Man of Feeling, 11.
} 
to be able to put this into the mercenary terms of a marriage contract, he dies after declaring his love for her.

Why is Harley so different from the norms of his class in terms of his gendered attitudes? The text rather weakly tries to explain this through the early loss of his father and his insufficient replacement as a role model by a group of guardians:

He lost his father, the last surviving of his parents, as I have already related, when he was a boy. The good man, from a fear of offending, as well as a regard to his son, had named him a variety of guardians; one consequence of which was, that they seldom met at all to consider the affairs of their ward; and when they did meet, their opinions were so opposite, that the only possible method of conciliation, was the mediatory power of a dinner and a bottle, which commonly interrupted, not ended, the dispute; and after that interruption ceased, left the consulting parties in a condition not very proper for adjusting it. ${ }^{12}$

Yet this is a fairly common situation for a man of his time. Patriarchy never needed to manifest itself in the direct transmission of knowledge and power from father to son. It could always rely on substitutes, such as institutions or abstract ideologies, to perform its task. Yet in The Man of Feeling neither of these seems to work. Harley refuses to accept his inherited role of country gentleman. He shows himself remarkably immune and even reluctant concerning the worldly things that were considered appropriate for a man of his standing.

The long introduction to the important Chapter XII of the novel makes this abundantly clear:

\section{CHAPTER XII - OF WORLDLY INTERESTS}

There are certain interests which the world supposes every man to have, and which therefore are properly enough termed worldly; but the world is apt to make an erroneous estimate: ignorant of the dispositions which constitute our happiness or misery, they bring to an undistinguished scale the means of the one, as connected with power, wealth, or grandeur, and of the other with their contraries. Philosophers and poets have often protested against this decision; but their arguments have been despised as declamatory, or ridiculed as romantic.

${ }^{12}$ Ibid., 10. 
There are never wanting to a young man some grave and prudent friends to set him right in this particular, if he need it; to watch his ideas as they arise, and point them to those objects which a wise man should never forget. Harley did not want for some monitors of this sort. He was frequently told of men whose fortunes enabled them to command all the luxuries of life, whose fortunes were of their own acquirement: his envy was invited by a description of their happiness, and his emulation by a recital of the means which had procured it.

Harley was apt to hear those lectures with indifference; nay, sometimes they got the better of his temper .... ${ }^{13}$

Mackenzie's text clearly positions Harley on the romantic rather than the materialist side. More than that, it shows him rejecting the homosocial influence that made men in the eighteenth century as much as it makes them nowadays. In practical terms, this means that he foregoes the chance of gaining the title to a significant property. In fact, he allows himself to be tricked out of it. The text had, in fact, hinted at such an outcome when introducing the sub-plot concerning crownland with the mention of "interest with the great, which Harley or his father never possessed". ${ }^{14}$

Harley's "interests" are not possessions. Harley defines his happiness through himself, through his passions, his feelings, as the title of the novel emphasizes. ${ }^{15}$ Their litmus test lies in the affects that literally affect his body. The body was meant to be the medium on which true sentiments expressed themselves: as blushing and turning pale, as smiling and yawning, in extreme cases as tears or even fainting fits. Once again, we see things through a modern or at least Victorian lens when we identify these bodily symptoms with femininity. Indeed Harley is the prime example of the violation of the modern rule "boys don't cry", for he indeed cries forty-nine times in the roughly hundred-and-fifty pages of the slim novel. Later editors even indexed his tears, so central did they appear to an understanding of the protagonist. $^{16}$

${ }^{13}$ Ibid., 9-10.

${ }^{14}$ Ibid., 11.

${ }^{15}$ In an often problematic attempt to describe Harley as the focus of the novel's sexualization of reality, George E. Haggerty also concludes that "His desire is merely selfdirected after all" (George E. Haggerty, Men in Love: Masculinity and Sexuality in the Eighteenth Century, Between Men - Between Women: Lesbian and Gay Studies, New York: Columbia University Press, 1999, 90).

${ }^{16}$ See Mackenzie, The Man of Feeling, 110-11. 
Bodily integrity, masculinity studies generally agree, is a major test of masculinity, and its only legitimate violation is bloodshed in situations of attack or defense. It is all the more fascinating that, despite this link between weeping and non-masculine behavior, Mackenzie's text at no time calls Harley's attitude "effeminate". Indeed, it makes clear that Harley not only cries frequently, but that he also believes honest tears to be a thing of beauty. He is not merely sentimental, he is also a believer in Sentimentalism: "A blush, a phrase of affability to an inferior, a tear at a moving tale, were to him, like the Cestus of Cytherea, unequalled in conferring beauty." ${ }^{17}$ A "cestus", interestingly enough, is both a woman's belt or girdle, fastened beneath the breast, and a leather strap for the hand of a boxer in ancient Greece and Rome. The support that affects provide can be feminine or masculine.

The same is true for tears. Tears have a moral value in Sentimentalism and thus also for Harley, as becomes clear when the narrative comments on his reaction to the sad tale of a love-struck young gentlewoman who is now in Bedlam, the infamous London mental asylum: "he had given it the tribute of some tears." 18 A little later he comments on the tears of a young woman who has had to resort to prostitution by exclaiming: "there is virtue in these tears." ${ }^{19}$ Virtue, as the name implies, originally a masculine quality, shifted to a feminine one in the time of Shakespeare. Indeed the first recorded use of "virtue" for a woman is in Shakespeare's Much Ado About Nothing. ${ }^{20}$ While it had signified integrity, honor, and bravery for men, it increasingly came to mean chastity for women. Virtue in The Man of Feeling, however, is non-gendered and can be applied to men and women alike. It can even be mediated between the sexes through sympathy in its original sense: joint suffering. In a manner already prefiguring Wordsworth's emotion recollected in tranquility, Harley cries again when he remembers the tears he and the young woman have shed during their encounter:

He rose, uncertain of his purpose; but the torpor of such considerations was seldom prevalent over the warmth of his nature. He walked

\footnotetext{
${ }^{17} \mathrm{Ibid} ., 12$

${ }^{18}$ Ibid., 26.

${ }^{19}$ Ibid., 38.

${ }^{20}$ See Rainer Emig, "Terror und Verstummen: Gewalt und Widerstand in Shakespeares Komödien", in Shakespeare Jahrbuch 143, eds Ina Schabert et al., Bochum: Kamp, 2007, 92.
} 
some turns backwards and forwards in his room; he recalled the languid form of the fainting wretch to his mind; he wept at the recollection of her tears. ${ }^{21}$

This places the depiction of emotions in The Man of Feeling in an interesting connection with eighteenth-century debates on passion and interest. Susan Kingsley Kent argues that "Transforming passions into interest emptied them of their feminine content .... In transforming the passions - rendered as feminine - into the interests - depicted as masculine - these thinkers [David Hume and Adam Smith] also brought about a transformation of virtue." 22 There is indeed an economy of tears, as becomes evident when Harley hears the sad story of old farmer Edwards who exchanges himself for his press-ganged son and weeps uncontrollably as a result, while the teller of the tale, though directly affected by it, has told it so often that it only provokes a single tear from him: "The old man now paused a moment to take breath. $\mathrm{He}$ eyed Harley's face; it was bathed with tears: the story was grown familiar to himself; he dropped one tear, and no more. ${ }^{, 23}$ At the end of the tale, Harley expends himself once again: "at last he pressed him in his arms, and when he had given vent to the fulness of his heart by a shower of tears, 'Edwards,' said he, 'let me hold thee to my bosom, let me imprint the virtue of thy sufferings on my soul'."

Sympathy and empathy enable not only suffering to be shared and exchanged, but also the transfer of virtue from the victim of circumstances to the sympathetic onlooker. Ideally this also includes the reader. This is where The Man of Feeling doubles up on itself: it depicts its protagonist anxiously consuming passions and transforming them into sympathetic interests - and it encourages its readers to do the same with the help of the novel as a commodity of passion, interest, and virtue. Here it even works backwards, so to speak, by making Edwards lose his reserve: "Edwards, from whom the recollection of his own suffering had scarced forced a tear, now blubbered like a boy." ${ }^{24}$ Markman Ellis, in his study The Politics of Sensibility, describes this in unsentimental terms:

\footnotetext{
${ }^{21}$ Mackenzie, The Man of Feeling, 41.

${ }^{22}$ Susan Kingsley Kent, Gender and Power in Britain, 1640-1990, London: Routledge, 1999, 65 .

${ }^{23}$ Mackenzie, The Man of Feeling, 67.

${ }^{24}$ Ibid., 71.
} 
Sensibility was one of the tools of a thorough-going and selfconscious analysis of the emergent consumer-economy of British society and culture. Sensibility was drawn into, and helped define, an increasingly open debate that identified and analysed these problems, and created spaces within public opinion for imagining and creating responses of individual and institutional reform.

The nexus of individual, public and institutional explains the involvement of masculinity. Quoting Paul Langford, Ellis views the cult of sensibility as the expression of "the middle-class need for a code of manners which challenged aristocratic ideals and fashions", in short, as "part of the reformation of the code of genteel contact necessary for the middle class to purchase gentility". ${ }^{25}$

Harley, the upper-class failure who cannot even look after his own interests when it comes to property and income ${ }^{26}$ is indeed very capable of creating interest in others, of affecting them. Here we approach the real reason for Harley's failure in terms of his own class and its increasingly outmoded views of gender: his interests are the wrong ones for them. Yet they are the right ones in terms of a different class who would soon dominate not only the economy of Britain, but also its ideology. Harley's failure as country gentleman endeared him to a bourgeois readership. Their sympathies derive not so much from his anti-materialism - this would indeed disqualify him as a bourgeois tradesman or entrepreneur. What they applauded was his individualism and his idea of virtue that was a far cry from the hollow forms of upper-class honor and politeness. J.G.A. Pocock indeed claims that the new middle-class ideal of the entrepreneur departed from traditional masculine principles embodied by the landed gentry: eighteenth-century economic man, he claims, "was seen as on the whole a feminised, even an effeminate being, still wrestling with his own passions and hysterias and with interior and exterior forces let loose by his fantasies and appetites ... in the eighteenth-century debate over the new relations of polity to economy, production and exchange are

${ }^{25}$ Markman Ellis, The Politics of Sensibility: Race, Gender and Commerce in the Sentimental Novel, Cambridge Studies in Romanticism 18, Cambridge: Cambridge University Press, 1996, 17.

${ }^{26}$ See Maureen Harkin, "Mackenzie's Man of Feeling: Embalming Sensibility”, ELH: English Literary History, LXI/2 (Summer 1994), 324. 
regularly equated with the ascendancy of the passions and the female principle." 27

If Harley consistently refuses to learn from men of his fellow class, he is indeed more influenced by the middle-class ideas of a misanthrope whom he also encounters in Bedlam and who becomes a mouthpiece for the novel's argument against empty formality and in favor of honest sentiment:

"Honour," said he [the misanthrope], "Honour and Politeness! this is the coin of the world, and passes current with the fools of it. You have substituted the shadow Honour, instead of the substance Virtue; and have banished the reality of Friendship for the fictitious semblance which you have termed Politeness: politeness, which consists in a certain ceremonious jargon, more ridiculous to the ear of reason than the voice of a puppet. You have invented sounds, which you worship, though they tyrannize over your peace: and are surrounded with empty forms, which take from the honest emotions of joy, and add to the poignancy of misfortune." - "Sir," said Harley - His friend winked to him, to remind him of the caution he had received. He was silenced by the thought ..... ${ }^{28}$

Harley himself is quite capable of making pronouncements in favor of an anti-aristocratic masculinity that goes hand in hand with an emerging middle-class ethos:

"Perhaps," said Harley, "we now-a-days discourage the romantic turn a little too much. Our boys are prudent too soon. Mistake me not, I do not mean to blame them for want of levity or dissipation; but their pleasures are those of hackneyed vice, blunted to every finer emotion by the repetition of debauch; and their desire of pleasure is warped to the desire of wealth, as the means of procuring it. The immense riches acquired by individuals have erected a standard of ambition, destructive of private morals, and of public virtue. The weaknesses of vice are left us; but the most allowable of our failings we are taught to despise. Love, the passion most natural to the sensibility of youth, has lost the plaintive dignity he once possessed, for the unmeaning simper of a dangling coxcomb; and the only serious concern, that of a dowry,

27 J.G.A. Pocock, "The Mobility of Property and the Rise of Eighteenth-Century Sociology", in Virtue, Commerce, and History: Essays on Political Thought and History, Chiefly in the Eighteenth Century, Cambridge: Cambridge University Press, $1985,114$.

${ }^{28}$ Mackenzie, The Man of Feeling, 30. 
is settled, even amongst the beardless leaders of the dancing-school. The Frivolous and the Interested (might a satirist say) are the characteristical features of the age; they are visible even in the essays of our philosophers. They laugh at the pedantry of our fathers, who complained of the times in which they lived; they are at pains to persuade us how much those were deceived; they pride themselves in defending things as they find them, and in exploding the barren sounds which had been reared into motives for action. To this their style is suited; and the manly tone of reason is exchanged for perpetual efforts at sneer and ridicule. This I hold to be an alarming crisis in the corruption of a state; when not only is virtue declined, and vice prevailing, but when the praises of virtue are forgotten, and the infamy of vice unfelt."

Harley argues against repression, the repression of honest and individual feelings, not of the desires imposed by imitation and peer-pressure. What he has in mind are the homosocial environments of public schools and Oxbridge, which were well known to be degraded into upper-class gathering places without any claim to education, moral or otherwise. What is interesting is that he calls for love as the guiding passion and devalues wealth. It is also noteworthy that he does not see a conflict between his model of positive affection and masculinity or rationality, as his ideal of a "manly tone of reason" 29 demonstrates.

Rather than attacking other countries, Harley's ideal young men defend their ideas of virtue and even explode empty reification. Mackenzie employs the martial rhetoric of masculinity of his time, yet manages to translate it into terms that fit the sentimental ideas of his novel as much as they agree with an emerging middle-class ethos of individual virtue - rather than class-based honor.

That this virtue is here applied to men is important. Men are still considered the sex in charge of society's welfare. Kent indeed reminds us that

... virtue occupies a central place in eighteenth-century English and Scottish political and moral theory. Drawn from the Aristotelian and renaissance republican traditions of citizenship, which saw in participation in civic life the sole means through which men (and it was only men and men of independent wealth) could achieve their full human

${ }^{29}$ Ibid., 61-62. 
potential, virtue signified the capacity of human beings to govern themselves. $^{30}$

Yet the manifestations of this virtue in Mackenzie's novel are remarkably ungendered. There is not a single mention of "masculine", "feminine", or "effeminate" in the text. Not once is Harley compared to a fop - the anti-masculine caricature of earlier decades of the late seventeenth and early eighteenth centuries. "Manly" is indeed employed several times, yet virtue is also possible for women, even the fallen woman whom Harley encounters. The sentimental body, the medium and litmus test of this new concept of a rational as well as emotional virtue, is ungendered. Blushes and tears belong to either sex, and their value is not determined by the body of those who display them, but by the contexts they inhabit. Mackenzie's model of sentimentality is thus a discursive one, and one should not be fooled into believing that an excess of bodily symptoms signals an essentialist attitude of the text.

In fact the text is in many ways wiser than some recent returns to essentializing masculinity. After having abandoned the notion of the male body as determining, for example, aggression and dominance, this essentialism has migrated into the psyche. There, specific psychic dispositions that are themselves mere helpless constructions, such as Asperger Syndrome, are now supposed to be able to explain masculine behavior. ${ }^{32}$ That matters are a good deal more complicated, that we need to see the body as a writing board of historical discourses and gender as one among several of these is what a text like The Man of Feeling upholds. In this respect, too, it still has a lot to teach us.

\footnotetext{
${ }^{30}$ Kent, Gender and Power, 55.

${ }^{31}$ See Michael S. Kimmel, "The Contemporary 'Crisis' of Masculinity in Historical Perspective", in The Making of Masculinities: The New Men's Studies, ed. Harry Brod, London: Allen and Unwin, 1987, 134-35.

${ }^{32}$ See Berthold Schoene, "Serial Masculinity: Psychopathology and Oedipal Violence in Bret Easton Ellis' American Psycho", Modern Fiction Studies, LIV/2 (Summer 2008), 378-97.
} 



\title{
"JOSEPH THE DREAMER OF DREAMS": JUdE FAWLEY's CONSTRUCTION OF MASCULINITY IN THOMAS HARDY'S JUDE THE OBSCURE
}

\author{
STEFAN HORLACHER
}

\begin{abstract}
Jude the Obscure is not only Thomas Hardy's last but probably also his bleakest novel. Even the epigram on the frontispiece - "The letter killeth [but the spirit giveth life]" - can be read as having negative forebodings; it can, however, also be interpreted as a commentary on the "nature" of language and on the absolute necessity of understanding its founding mechanisms such as absence, difference and deferral if one is to lead a happy and meaningful life and if one endeavors to claim the freedom and the responsibility to construct one's gender identity. This essay thus centers on the extent to which Hardy's protagonist Jude Fawley, a man who desperately clings to the illusion of a transcendental signified, is able to understand and put into practice Hardy's epigram when constructing his masculinity. Therefore, the focus of inquiry will be the hitherto largely neglected discursive construction of an ill-fated male gender identity in a discursive universe where "nobody did come, because nobody does" and where taking words literally has lethal consequences.
\end{abstract}

It is certainly surprising that a closer look at the hundreds of articles, essays and monographs about Jude the Obscure reveals that most of these publications tend to ignore the eponymous hero of the novel and concentrate instead on Sue Bridehead, "perhaps the most remarkable feminine portrait in the English novel". One eminent critic, Mary

\footnotetext{
${ }^{1}$ Frank Rodney Southerington, Hardy's Vision of Man, London: Chatto and Windus, $1971,145$.
} 
Jacobus, even speaks of "Sue the Obscure", 2 and in a letter Thomas Hardy himself called his novel "the Sue story". ${ }^{3}$ Given this evident neglect of, or even discrimination against, the male protagonist in Hardy studies, it seems appropriate to shift the focus of critical attention. Not, however, back to the humanist phallic and integrated self, ${ }^{4}$ but to a male gender identity which is insecure, fractured and fraught with problems.

Considering the norms and social codes of the nineteenth century, there can be no doubt that Jude Fawley leads a very unconventional and even progressive life. In contrast to a character such as Michael Henchard in the Mayor of Casterbridge, Jude appears to consist of a complex blend of traditionally male and female attributes and continues to seek a semblance of security throughout his life in a world which clearly "has become unmoored from natural certitude" and in which "to the unappeased spirit in search of articulate paradigms, nothing - not even the body's native stresses - can be reliably categorized".

Lured primarily by the enigmatic Sue Bridehead, Jude is propelled into a kind of obscurity which renders his identity as well as his sexuality highly problematic. If this is an extremely unhappy situation for Hardy's male protagonist, it does have the advantage that it puts the reader in a position first to realize and then to further explore the fact that "all labels that 'ticket' a person, especially the most common ones of gender and class, are false". 6

\footnotetext{
${ }^{2}$ Mary Jacobus, "Sue the Obscure", Essays in Criticism, XXV/3 (July 1975), 305.

${ }^{3}$ Penny Boumelha, Thomas Hardy and Women: Sexual Ideology and Narrative Form, Brighton: Harvester, 1982, 138.

4 See Toril Moi, Sexual/Textual Politics: Feminist Literary Theory, London: Routledge, 1990, 8.

${ }^{5}$ Philip M. Weinstein, The Semantics of Desire: Changing Models of Identity from Dickens to Joyce, Princeton, NJ: Princeton University Press, 1984, 139. See also: "Life is a something foreign to the classificatory demands made by the spirit. In its utterances, its values, and even its bodily grounding, life is a phenomenon of stain, illogic [sic], and obscurity" (ibid., 139).

${ }^{6}$ Margaret Randolph Higonnet, Introduction, in The Sense of Sex: Feminist Perspectives on Hardy, ed. Margaret Randolph Higonnet, Urbana, IL: University of Illinois Press, 1993, 4.
} 
Applying traditional male and female stereotypes, ${ }^{7}$ there can be little doubt that the two main protagonists in Jude the Obscure are characterized by an odd combination of what Linda Dowling calls "male effeminacy and female mannishness". ${ }^{8}$ The overriding consensus in the secondary literature is that "Sue assumes the attitudes of the decisive Victorian male", while "Jude appears to take on the qualities of the submissive Victorian wife". 9 And in Hardy's novel, Jude is indeed depicted as "a ridiculously affectionate fellow", ${ }^{10}$ as "thin-skinned", "horribly sensitive" 11 and as the born victim; he even complains about being a man and is looking for a partner on whom "he can lean on and look up to". ${ }^{12}$

In the following, I do not intend to offer yet another analysis of male and female stereotypes, which Hardy's novel effectively questions and transgresses anyway, but shall instead adopt a psychoanalytically inspired masculinity studies approach before asking to what extent Jude's failure is caused by his desperate clinging to the illusion of a transcendental signified, and in particular by a defective understanding of writing.

\section{Masculinity studies and the discursive construction of identity}

Although there has been an increase in interest in masculinity studies during the last decades, ${ }^{13}$ work on masculinity is still an almost negli-

\footnotetext{
${ }^{7}$ See Doris Grimm-Horlacher, Weiblichkeitsmuster und Geschlechtsrollenstereotype im Spätwerk von D.H. Lawrence: The Plumed Serpent, Fantasia of the Unconscious und Psychoanalysis and the Unconscious, St Ingbert: Röhrig, 2002, 42-58.

${ }^{8}$ Linda Dowling, "The Decadent and the New Woman in the 1890's", NineteenthCentury Fiction, XXXIII/4 (March 1979), 445.

9 Anne Z. Mickelson, Thomas Hardy's Women and Men: The Defeat of Nature, Metuchen, NJ: Scarecrow, 1976, 5.

10 Thomas Hardy, Jude the Obscure (1895), ed. Dennis Taylor, London: Penguin Classics, 1998, 85 (all quotations from Thomas Hardy's Jude the Obscure are from this edition).

${ }^{11}$ Ibid., 286.

12 Mickelson, Thomas Hardy's Women and Men, 138.

${ }^{13}$ See Stefan Horlacher, "Charting the Field of Masculinity Studies: or, Toward a Literary History of Masculinities", in Constructions of Masculinity in British Literature from the Middle Ages to the Present, ed. Stefan Horlacher, New York: Palgrave Macmillan, 2011, 3-18; Stefan Horlacher, "Überlegungen zur Theoretischen Konzeption Männlicher Identität: Ein Forschungsüberblick mit Exemplarischer Vertiefung", in "Wann ist die Frau eine Frau?" - "Wann ist der Mann ein Mann?": Konstruktionen von Geschlechtlichkeit von der Antike bis ins 21. Jahrhundert, ed. Stefan Horla-
} 
gible quantity in comparison to the amount of research being done on women and femininity in the field of gender studies. What Peter F. Murphy argued twenty years ago is, at least to a certain degree, still valid today: men are only just beginning "to articulate a critical analysis of masculinity in contemporary culture and in modern literature. More recent, and sometimes more radical, books have been written by sociologists, psychologists, and historians, not literary or cultural critics." 14

If we leave aside the more sociologically oriented branch of masculinity studies and concentrate on approaches inspired by deconstruction, post-Freudian psychoanalysis and discourse analysis, we have to state that the majority of these studies support the approach that male as well as female gender identities are to be thought of as subject positions and as relational, performative and linguistic constructs. However, if gender identities are subject to the structures of language, this does not necessarily mean that they are totally bereft of any possibility of agency or that the body becomes irrelevant.

Whereas medical research has demonstrated that bodies are not always unambiguously sexed and that one should probably speak of a continuum and not of a dichotomy as far as femininity and masculinity are concerned ${ }^{15}$ cultural anthropology makes clear that bodies are always gendered and that this gendering is oriented towards the creation or exaggeration of difference. ${ }^{16}$ If there is no denying that there is a body, we can, as Jacques Lacan, Judith Butler and others have

cher, Würzburg: Königshausen und Neumann, 2010, 195-238; Susan Bassnett and Gisela Ecker, Editorial, in Journal for the Study of British Cultures, III/2 (1996), 100.

${ }^{14}$ Peter F. Murphy, "Introduction: Literature and Masculinity", in Fictions of Masculinity: Crossing Cultures, Crossing Sexualities, ed. Peter F. Murphy, New York: New York University Press, 1994, 4.

${ }^{15}$ See Stefan Horlacher, "Men's Studies and Gender Studies at the Crossroads (I): Überlegungen zum aktuellen Stand von Geschlechterforschung und Literaturwissenschaft", Literatur in Wissenschaft und Unterricht, XXXVII/2 (2004), 169-88; Stefan Horlacher, "Men's Studies and Gender Studies at the Crossroads (II): Transdisziplinäre Zukunftsperspektiven der Geschlechterforschung", Literatur in Wissenschaft und Unterricht, XXXVII/3 (2004), 267-86; Karin Christiansen, "Biologische Grundlagen der Geschlechterdifferenz", in Konstruktion von Geschlecht, eds Ursula Pasero and Friederike Braun, Pfaffenweiler: Centaurus, 1995, 15; Wolfgang Mertens, "Männlichkeit aus psychoanalytischer Sicht", in Wann ist der Mann ein Mann? Zur Geschichte der Männlichkeit, eds Walter Erhart and Britta Herrmann, Stuttgart: Metzler, 1997, 45; R.W. Connell, Masculinities, Cambridge: Polity, 1995, 21-22, 46-47.

${ }^{16}$ See David D. Gilmore, Mythos Mann: Rollen, Rituale, Leitbilder, Munich: Artemis und Winkler, 1991, 25. 
shown, nevertheless not be sure whether we can ever have access to a "natural" body, that is a body outside language and culture, and to what extent this "natural" body is really important as far as the construction of identity - which is always a gender or gendered identity ${ }^{17}$ - is concerned. ${ }^{18}$

In the following, I am mainly interested in the way the individual, in this case the "fictional entity", Jude Fawley, is positioned within the different fields of discourses and sign systems which constitute culture and which, by offering different subject positions, influence and shape (gender) identity. In accordance with Elizabeth Deeds Ermarth, language is thereby not conceived of as a "prison-house" 19 but as "a site of liberation from the restrictions ... imposed upon subjectivity" 20 and as the major means for a creative construction of identity.

If, as Ermarth argues, it is in the gap between the potential capacities of a differential code and any particular specification of it, that is between language (langue) and enunciation (parole), that the arena of subjectivity and freedom resides, then it should be possible a) to demonstrate that Jude's identity as a man is the result of linguistic constructs, and b) that this identity (nevertheless) can be conceived of as "multiplied" and as a kinetic process. From this perspective Jude's masculine subjectivity would become a

particular expression of systemic value, 'above all, an accomplishment, a particular work, a particular act,' the 'very expression' of responsibility, not something independent of it. Identity ... has nothing to do with reducing difference .... Rather, identity appears only in the act of specifying sets of rules. And as we operate simultaneously in several sets at once, identity appears as the series of constantly multiplied specifications of the potential provided by those rule regimens. ${ }^{21}$

To reformulate 'the subject' as an element of such differential systems, that is, as a function of discourse, means to accept the multiplicity of what used to be called 'the subject': because subjectivity al-

\footnotetext{
${ }^{17}$ This does also comprise agender or gender-neutral identities.

${ }^{18}$ See Bruce Fink, The Lacanian Subject: Between Language and Jouissance, Princeton, NJ: Princeton University Press, 1995, 105, 123.

${ }^{19}$ Frederic Jameson, The Prison-House of Language: A Critical Account of Structuralism and Russian Formalism, Princeton, NJ: Princeton University Press, 1972.

${ }^{20}$ Elizabeth Deeds Ermarth, "Beyond 'the Subject': Individuality in the Discursive Condition”, New Literary History, XXXI/3 (Summer 2000), 408

${ }^{21}$ Ibid., 411.
} 
ways operates simultaneously in several discursive systems, whether their grammars and elements are verbal languages or other sign systems composed of gender relations, or fashion, or politics. ${ }^{22}$

Jude's singularity would then not exist in some essential "subject" but "in the unique and unrepeatable sequence of a life", while his "palimpsestuousness" would derive "from the multiplied discursive condition in which each moment involves a complex subjective specification of multiple codes". This conception, moreover, allows for "a kinetic subjectivity-in-multicoded-process", that is for a subjectivity which is thought of as

... the moving nexus or intersection at which a unique and unrepeatable sequence is constantly being specified from the potentials available in the discursive condition. Such a subjectivity is individual in its sequence, not in some irreducible core. Its uniqueness lies in its trajectory: the lifelong sequence, impossible to anticipate, within which an unpredictable series of specifications are made from among the languages available. The volatility of language - its resonance, its power of poetic, associative linkage - provides precisely the varied opportunities for selective specification that constitute the unique and unrepeatable poetry of a life. ${ }^{23}$

The application of this approach to Jude the Obscure leads to an interpretation which endeavors to demonstrate that Hardy's novel conceives of masculinity primarily as a medial (in the sense of linguistic) construct and that Jude's "tragic" fate - if it is tragic at all ${ }^{24}-$ is not the result of Hardy's alleged negativity and pessimism but can be read as the consequence of Jude's desperate clinging to the illusion of a transcendental signified.

With its epigram, "The letter killeth [but the spirit giveth life]", which is echoed later in the text by Jude's desperate "we are acting by

${ }^{22}$ Ibid., 410.

${ }^{23}$ Ibid., 411-12.

${ }^{24}$ See Ulrich Broich, "Der 'negative Bildungsroman' der neunziger Jahre”, in Die 'Nineties: Das englische Fin de Siècle zwischen Dekadenz und Sozialkritik, eds Manfred Pfister and Bernd Schulte-Middelich, Munich: UTB, 1983, 221; Ulrike Mühlheim, "Thomas Hardys 'Tess of the D'Urbervilles' und 'Jude the Obscure", in ibid., 188; Hans-Dieter Gelfert, Die Tragödie: Theorie und Geschichte, Göttingen: Vandenhoeck und Ruprecht, 1995, 74; Cedric Thomas Watts, Thomas Hardy: Jude the Obscure, London: Penguin, 1992, 80. 
the letter; and 'the letter killeth'!", ${ }^{25}$ Hardy's novel not only refers to the Bible but also obliquely to its own textuality as well as to the relation between society, language and the law. And it is exactly this relation which is of prime importance in the novel as well as in the interior psychic space of its protagonist. Hence, Jude the Obscure can be read as a book about the importance of internalized laws and the linguistic or semiotic construction of gender identity. Therefore we must ask whether Jude's failure as a man and as a human being cannot best be explained by his deficient understanding of how signs work. From this it follows that the negativity and bleakness of Jude the Obscure would not reside in a hostile social environment shaped by the law, but in Jude's catastrophic failure to recognize the sign-based constructedness of personal identity as well as of culture and society.

One could even go so far as to read the novel in a positive light, since Jude's failure is an important example of how not to construct one's identity and since other characters, who are in a way less "monumental", inflexible or petrified than Jude the "stonemason" - I need only refer to Vilbert and Arabella - demonstrate that survival and even a limited degree of happiness are possible. Maybe Jude's failure can even be regarded as proof not only of the freedom of the individual but also of the necessity to comprehend the constructedness of society and culture in general and of gender identity in particular.

\section{Narrativity, or, master narratives of masculinity}

If we consider the question of who Jude Fawley really is, we have to realize that at the outset of the novel he is a little boy whose mother committed suicide and whose father is dead too. As an orphan, Jude wishes not to have been born at all, feels isolated and is brought up unloved by his aunt: "It would ha' been a blessing if Goddy-mighty had took thee too, wi' thy mother and father, poor useless boy!"26 Shortly after this scene, Jude's male idol and substitute father figure, Phillotson, the schoolmaster, leaves him in order to study in Christminster. Jude remains behind as a little boy, "who could not himself bear to hurt anything" and who "was born to ache a good deal before the fall of the curtain upon his unnecessary life should signify that all was well with him again". ${ }^{27}$ Given these facts, it is hardly surprising

${ }^{25}$ Hardy, Jude the Obscure, 388.

${ }^{26}$ Ibid., 13.

${ }^{27}$ Ibid., 17. 
that Jude does not want to engage with life and sexuality: "If he could only prevent himself growing up! He did not want to be a man." 28

However, Jude does not remain passive but very soon follows well-established models regarding the construction of identity. Although Hardy's protagonist comes from an impoverished social background, there is never the question of Jude becoming "merely" a butcher, a baker or a farmer. Instead, Jude emulates Phillotson ${ }^{29}$ and sets out to become a scholar. What is significant is that throughout Hardy's novel, Jude not only tries to enact or perform certain "narrations of masculinity" but that these fail one after the other.

Jude, cast as the "young lover" and later as the "honest and knightly husband" of Arabella, is first tricked into marriage and then left behind when Arabella decides to emigrate to Australia. Although Jude really labors to learn Greek and Latin, he never enters Christminster University - and the story of "Jude the scholar" is one of failure, too. Underlying Jude's desire to flee from his social sphere is the dream of "Jude the self-made man". When he sets out to follow Phillotson to Christminster, he walks "the remaining four miles rather from choice than from necessity, having always fancied himself arriving thus .... He went along the outlying streets with the cautious tread of an explorer." ${ }^{30}$

After his project to enter Christminster as a "self-made man" has failed, Jude embraces a further prototypically masculine discourse by praising the dignity of manual labor: "[The] stone yard was a center of effort as worthy as that dignified by the name of scholarly study within the noblest of colleges." 31 That this discourse, which finds its incarnation in Tetuphenay, the head of Biblioll college, who advises Jude to remain in his sphere and to stick to his trade, ${ }^{32}$ glorifies manual labor only to keep up a rigid class system, is, of course, not realized

\footnotetext{
${ }^{28}$ Ibid., 18.

${ }^{29}$ For reasons of space I can only allude to the erotic component inherent in Jude's relation to Phillotson.

${ }^{30}$ Hardy, Jude the Obscure, 77-78.

${ }^{31}$ Ibid., 85.

32 "BiBlioll COllEge. 'SiR, - I have read your letter with interest; and, judging from your description of yourself as a working-man, I venture to think that you will have a much better chance of success in life by remaining in your own sphere and sticking to your trade than by adopting any other course. That, therefore, is what I advise you to do. Yours faithfully, T. Tetuphenay. 'To Mr. J. FAwLEy, Stone-cutter.”'
} 
by Jude who, somewhat naïvely, believes in the truth of the spoken or written word: "He had known all that before. He knew it was true." 33

Eventually, Jude's contact with Sue and their ensuing relationship triggers off a whole series of different concepts of male gender identity: "Jude the would-be lover of Sue", "Jude and the ideal of a devotional life in Melchester", "Jude the would-be husband of Sue and successful baker of Christminster cakes", "Jude the failed husband of Sue and would-be intellectual" (the "Christminster dream" again) and, last but not least, "Jude the disillusioned knightly and honor-bound husband of Arabella":

'Don't say anything against my honor!' enjoined Jude hotly, standing up. 'I'd marry the W---- of Babylon rather than do anything dishonorable! .... I am not a man who wants to save himself at the expense of the weaker among us! ${ }^{34}$

In this context, Elizabeth Langland correctly speaks of "Jude's alternating evasion and pursuit of manhood" ${ }^{\prime 3}$ and stresses the importance of "social practices and discourses that mock the idea of individual self-determination and locate self-fulfillment in death". ${ }^{36}$ If it is a point of controversy whether Hardy's novel actually endorses death as a solution, this ambiguity certainly does not apply to the reasons for Jude's problems. If Jude accepts narrative myths of traditional manliness as truths and wholly identifies with them, he falls prey to Lacanian méconnaissance ${ }^{37}$ without ever understanding what he is actually doing or what is happening to him.

Even when he realizes that the myths he tries to live by do not work, he shies away from facing the consequences so that finally Jude, the would-be scholar, refuses to learn and self-destructively, albeit unconsciously, propels himself from one méconnaissance into another: "It was better to love a woman than to be a graduate, or a parson; ay, or a pope!" 38 But no matter with which "of several ver-

33 Ibid., 117.

${ }^{34}$ Ibid., 381-82.

${ }^{35}$ Elizabeth Langland, "Becoming a Man in Jude the Obscure", in The Sense of Sex, 42.

${ }^{36}$ Ibid., 46.

${ }^{37}$ Jacques Lacan, "The Mirror Stage as Formative of the Function of the I", in Écrits: A Selection, trans. Alan Sheridan: New York: Norton, 1977, 1-7.

${ }^{38}$ Hardy, Jude the Obscure, 48. 
sions of the book of life typically invoked by Victorian fiction" Jude identifies, he is bound to fail, since, like its protagonist, the logic inherent in Hardy's novel

... invokes and finds untenable precisely those narratives which seek to reproduce most closely the shape of human existence: the spiritual journey; the story of individual vocation and education; the marriage plot. Its organization into curiously self-contained parts, a sort of episodic form writ large, follows the arrangement of Jude's life into distinct phases, each of which is overseen by an informing myth or masterplot. $^{39}$

From this it follows that both on the level of the individual, that is with regard to the narrative models of self-made man, family man or explorer, and on the level of the literary text, the narrative trajectory of the novel of development or Bildungsroman is being questioned. If novels of development are "stories of a boy's initiation into manhood, and ... rituals of masculine identity" $" 40$ and if masculinity is established by the fact that the protagonist, after a period of learning, proves his identity through his knowledge and education, his material wealth, his integration into society and his newly founded family, then the trajectory of Jude the Obscure is the exact opposite.

However, given the death of its protagonist, Jude the Obscure is not a negative Bildungsroman in the tradition of D.H. Lawrence either. ${ }^{41}$ With Tim Dolin, one could ask whether Hardy's novel does not serve as a deconstructive foil, foregrounding the implicit, unavowedly conservative ideological subtext of the English Bildungsroman. ${ }^{42}$ Or, even more radically, one could read Jude the Obscure as a "blueprint for the creation of self-destructive individuals", ${ }^{43}$ which would then

\footnotetext{
${ }^{39}$ Tim Dolin, "Jude Fawley and the New Man", in Jude the Obscure: Thomas Hardy, ed. Penny Boumelha, Basingstoke: Macmillan, 2000, 214-15.

${ }^{40}$ Ibid., 215.

${ }^{41}$ See Stefan Horlacher, Masculinities: Konzeptionen von Männlichkeit im Werk von Thomas Hardy und D.H. Lawrence, Tübingen: Narr, 2006.

42 "[They] need only to prove the self that they have always shared with the dominant class to which they belong, and it is duly restored to them as their rightful inheritance." In other words: "When David Copperfield speculates whether he will turn out to be the hero of his own life, he is questioning whether he can prove himself to be what he indubitably already is" (Dolin, "Jude Fawley and the New Man", 215).

${ }^{43}$ Eleanor C. Guetzloe and Ralph M. Cline, "Jude the Obscure: A Pathway to Suicide", in Youth Suicide Prevention: Lessons from Literature, eds Sara Munson Deats and Lagretta Tallent Lenker, New York: Plenum, 1989, 124-25.
} 
demonstrate that the socially propagated "master narratives of masculinity" are hardly more than a deception serving to secure social structures that guarantee class immobility and the persistence of the law.

\title{
The letter and the law
}

If one conceives of the notion of law in accordance with Lacan to be in the general sense a symbolic order or structure which coincides with language and determines the rules of society, ${ }^{44}$ one can argue that it is "the world of words that creates the world of things .... Man speaks, then, but it is because the symbol has made him man": ${ }^{45}$

\begin{abstract}
Symbols in fact envelop the life of man in a network so total that they join together, before he comes into the world, those who are going to engender him 'by flesh and blood'; so total that they bring to his birth, along with the gifts of the stars, if not with the gifts of the fairies, the shape of his destiny; so total that they give the words that will make him faithful or renegade, the law of the acts that will follow him right to the very place where he is not yet and even beyond his death; and so total that through them his end finds its meaning in the last judgment, where the Word absolves his being or condemns it - unless he attain the subjective bringing to realization of being-for-death. ${ }^{46}$
\end{abstract}

In other words, if the human being is the product of the sign, and if culture is the product of the symbolic order, then the question arises whether Jude's project of constructing a successful male identity does not fail because of his deficient understanding of how language and therefore society and the law work on a formal basis. ${ }^{47}$ One could even say that, anticipating Ferdinand de Saussure, Hardy's novel demonstrates that language - and even identity - is form and not substance. From this, two concomitant questions arise, namely how the law is presented in Jude the Obscure and how one should deal with it.

Though Jude's problems arise from his misunderstanding of different master narratives of masculinity and though Jude repeatedly

${ }^{44}$ Ordre symbolique, ordre du langage and ordre de la loi coincide (see Hermann Lang, Die Sprache und das Unbewusste: Jacques Lacans Grundlegung der Psychoanalyse, Frankfurt am Main: Suhrkamp, 1998, 155, 206, 236-37, 264; Horlacher, Masculinities, 264-69).

45 Jacques Lacan, "Function and Field of Speech and Language", in Écrits, 65.

${ }^{46}$ Ibid., 68.

${ }^{47}$ For a discussion of the relative (but often ignored) freedom which Lacanian psychoanalysis allows the subject, see Lang, Die Sprache und das Unbewusste, xii. 
blames society and the marriage law for his unhappiness, a closer look at the novel reveals that he is not presented as the victim of the semantic contents of the law. Despite Jude and Sue being afraid of the law, the law does not seem to care about them. As a matter of fact, no official institution ever expresses an interest in whether Jude is divorced from Arabella or not, or indeed takes any interest in whether Jude and Sue are married or not. In addition to this, Jude's divorce from Arabella and Sue's divorce from Phillotson are easily obtained and do not attract any attention at all:

The proceedings in the Law-Courts had reached their consciousness but as a distant sound, and an occasional missive which they hardly understood .... The same concluding incident in Jude's suit against Arabella had occurred about a month or two earlier. Both cases had been too insignificant to be reported in the papers, further than by name in a long list of other undefended cases .... "One thing is certain, that however the decree may be brought about, a marriage is dissolved when it is dissolved. There is this advantage in being poor obscure people like us - that these things are done for us in a rough and ready fashion. It was the same with me and Arabella. I was afraid her criminal second marriage would have been discovered, and she punished; but nobody took any interest in her - nobody inquired, nobody suspected it." ${ }^{48}$

If the "semantic side" or meaning (the signified) of the law does not harm Jude and Sue, this does not, however, hold true for the "formal side" of the law considered as a chain of signifiers. As has been shown, Hardy's novel consistently devalues the semantic side or structure of the law in order to stress its formal nature as an empty chain of signifiers. Moreover, Hardy's novel argues in favor of the ability to recognize and make use of interstices and soft spaces as a creative room for action. How this is enacted on the level of the histoire can, amongst other things, be shown with the help of writing, for example personal letters, as well as with the help of Arabella and her later lover Vilbert.

If we take a closer look at the large number of letters in Hardy's novel, we have to realize that these letters construe multiple realities

\footnotetext{
${ }^{48}$ Hardy, Jude the Obscure, 258-59. Marjorie Garson argues that Jude is "not a very good analysis of the divorce issue, if only because the divorces it depicts are so readily obtained" (Marjorie Garson, "Jude the Obscure: What Does a Man Want?", in Jude the Obscure: Thomas Hardy, 186); see also Patricia Ingham, "The Evolution of Jude the Obscure", Review of English Studies, XXVII/CVI (May 1976), 164.
} 
which have little to do with the reality actually experienced by the characters. In Hardy's own words: "nothing is as it appears." ${ }^{49}$ When Sue writes "a passionate letter .... She was quite lonely and miserable, she told him", Jude later realizes that she was not "quite the woman who had written the letter that summoned him". ${ }^{50}$ Thus a disappointed Jude tells Sue: "You are not so nice in presence as you are in your letters." ${ }^{51}$ But Jude never inquires further and never understands that basically he is "trapped within a linguistic worldview which holds that truth is external, is universally applicable, and has already been uttered". ${ }^{52}$ This is not only demonstrated by the often hapless interaction between Jude and Sue but is even made clear by the narrator, who stresses that "Jude was in danger of attaching more meaning to Sue's impulsive note than it really was intended to bear". ${ }^{53}$

Unfortunately, Jude is at no point able to transcend his naïve belief in the presence of truth, in the presence of the signified, in the contents of the law. And at no point is he able to gain insight into the functional mechanisms of this law. Although Jude realizes that Arabella has tricked him into marriage and that he does not love her, he never considers a divorce, "the law being the law". ${ }^{54}$ Phillotson even equates the law with cruelty and refuses "to be cruel to her [Sue] in the name of the law". ${ }^{55}$ But as has already been demonstrated, the law is totally indifferent towards Jude and Sue. Thus what causes their misery is not the law in itself, but a misunderstanding of it - and maybe one reason why the law gains such importance in Jude the Obscure is the sadomasochistic tendency in both, that is Sue and Jude's willingness to submit to any kind of authority. Maybe happiness and freedom are not even wished for. Sue, at least, seeks humiliation and penance when she returns to Phillotson in order to be sexually abused. And it was Sue, too, who started the relationship with a compliant Jude in "the selfish and cruel wish to make your heart ache for me without letting mine ache for you". ${ }^{56}$

${ }^{49}$ Florence Emily Hardy, The Life of Thomas Hardy 1840-1928, London: Palgrave Macmillan, 1962, 167, entry from 21 December 1885 (emphasis in the original).

${ }^{50}$ Hardy, Jude the Obscure, 132.

${ }^{51}$ Ibid., 165.

${ }^{52}$ Weinstein, The Semantics of Desire, 133.

${ }^{53}$ Hardy, Jude the Obscure, 156.

${ }^{54}$ Ibid., 182.

${ }^{55}$ Ibid., 235.

${ }^{56}$ Ibid., 353. 
If there is one character in Jude the Obscure who has a reason to fear the law, it is certainly Arabella. In the first place she does not tell her second husband about her son, and then she commits adultery with Jude - if indeed it can be called adultery at all, since at that point in time, Arabella is bigamously married to Cartlett as well as to Jude. She has a cool and relaxed way of interpreting the law - "Crime! Pooh. They don't think much of such as that over there! Lots of 'em do it ... "57 - and even gets away with it. Arabella, the unfaithful bigamist, neither fears nor openly opposes the law. Most of the time, she just ignores it or uses it and even goes so far as to accuse the lawabiding Jude of not respecting the institution of marriage: "You've no respect for marriage whatever, or its rights and duties!" ${ }^{58}$ Later, Arabella even expressly endorses the law and gives Sue the advice to marry Jude as soon as possible:

Then let him [take you before the parson], in Heaven's name. Life with a man is more businesslike after it, and money matters work better. And then, you see, if you have rows, and he turns you out of doors, you can get the law to protect you, which you can't otherwise. ${ }^{59}$

Although their actions are morally questionable, Arabella and Vilbert, the itinerant quack-doctor, do know how to deal with the law and how to survive. Vilbert, who calls himself "a public benefactor", is "well known to the rustic population, and absolutely unknown to anybody else, as he, indeed, took care to be, to avoid inconvenient investigations". ${ }^{60} \mathrm{He}$ is always one step ahead of the law and sells "golden ointment, life-drops, and female pills". ${ }^{61}$ Traversing enormous distances on foot and being constantly in motion, he, like no other character, symbolizes the deferral of meaning along the chain of signifiers. Whereas Arabella lives her passions and does not care much about justice, and whereas Vilbert gets away with selling perfectly useless

\footnotetext{
${ }^{57}$ Ibid., 185.

${ }^{58}$ Ibid., 385.

${ }^{59}$ Ibid., 270.

${ }^{60}$ Ibid., 26.

${ }^{61}$ Ibid., 27. "Jude had one day seen him selling a pot of coloured lard to an old woman as a certain cure for a bad leg, the woman arranging to pay a guinea, in instalments of a shilling a fortnight, for the precious salve, which, according to the physician, could only be obtained from a particular animal which grazed on Mount Sinai, and was to be captured only at great risk to life and limb" (ibid., 26).
} 
pills allegedly "warranted efficacious by the Government stamp", 62 Sue and Jude manage to adopt a similar lifestyle only for a very short period of time. They take advantage of Jude's "adaptive craftsmanship to enter on a shifting, almost nomadic, life, which was not without its pleasantness". ${ }^{63}$ Or, to quote Sue: "We gave up all ambition, and were never so happy in our lives." 64

But this nomadic lifestyle, which coincides with the only true happiness the couple ever experiences, remains an exception. Instead of analyzing the reason for their happiness, instead of actively inquiring into the mechanisms of the law, and instead of engaging with life, Jude and Sue remain in a state of limbo. They speak of their often body- and sexless love as "something too sublime for earth", and not only is Jude himself primarily interested in Greek and Latin, two dead languages, but he is also fascinated by Christminster's emblematic voices of dead philosophers:

Knowing not a human being here, Jude began to be impressed with the isolation of his own personality, as with a self-specter, the sensation being that of one who walked but could not make himself seen or heard. He drew his breath pensively, and, seeming thus almost his own ghost, gave his thoughts to the other ghostly presences with which the nooks were haunted. ${ }^{65}$

\section{The "order-loving man" and his refusal of responsibility}

In Hardy's novel, language, if incorrectly understood, seems to harbor a lethal quality. This becomes obvious when Jude's son Little Father Time takes the "learned doctors", "solemn stately figures in blood-red robes", to announce "Judgment Day"66 - and when, shortly after this, he takes Sue by her word, that is understands her literally and commits murder and suicide: "I said the world was against us, that it was better to be out of life than in it at this price; and he took it literally." ${ }^{, 67}$

On different occasions, Little Father Time is not only described as mechanical and impersonal but also equated with his father so that Jeffrey Berman calls him a "younger and more extreme portrait of

\footnotetext{
${ }^{62}$ Ibid., 294 (emphasis added).

${ }^{63}$ Ibid., 309.

${ }^{64}$ Ibid., 313.

${ }^{65}$ Ibid., 79.

${ }^{66}$ Ibid., 324.

${ }^{67}$ Ibid., 338.
} 
Jude" ${ }^{68}$ If Little Father Time's understanding of language is defective and causes his death and the demise of his siblings, it is no surprise that Jude faces a similar fate. As we know, Jude believes in the existence of a universal law of transmutation which would not only allow one language to be translated mechanically into another but would also equate natural with civil law. ${ }^{69}$ Jude assumes "that the words of the required language were always to be found somewhere latent in the words of the given language by those who had the art to uncover them". ${ }^{70}$ And indeed, Hardy's protagonist is continuously looking for meaning:

The mountain-weight of material under which the ideas lay in those dusty volumes called the classics piqued him into a dogged, mouselike subtlety of attempt to move it piecemeal. ${ }^{71}$

If Marcel Proust's protagonist in A la Recherche du temps perdu searches for hidden meanings in family names "in order to suggest their motivation and to gratify the obsession 'to discover some subject to which I could impart a philosophical significance of infinite value", ${ }^{72}$ Jude does not behave differently: "It had been the yearning of his heart to find something to anchor on, to cling to, for some place which he could call admirable. Should he find that place in this city if he could get there?"73 Throughout his life Jude keeps looking for deep structures and for a law of transmutation which would help him to understand the world, its rules and languages as well as Sue's "liquid" and - significantly - "untranslatable eyes". ${ }^{74}$ These untranslatable eyes - just as the dead languages - serve as metaphors for the fact that Jude's readings are severe misreadings, that they do not produce

${ }^{68}$ Jeffrey Berman, "Infanticide and Object Loss in Jude the Obscure", in Compromise Formations: Current Directions in Psychoanalytic Criticism, ed. Vera Camden, London, OH: Kent State University Press, 1989, 157.

${ }^{69}$ For a critical discussion of the relation between "civil law", "natural law" and allegory, see Horlacher, Masculinities, 324-37.

${ }^{70}$ Hardy, Jude the Obscure, 30.

${ }^{71}$ Ibid., 31.

${ }^{72}$ Stefan Horlacher, "Writing as Reading the Unreadable: A Reconsideration of the Medial Construction of Marcel Proust's A la Recherche du Temps Perdu", Paragraph: A Journal of Modern Critical Theory, XXV/1 (March 2002), 4-31.

${ }^{73}$ Hardy, Jude the Obscure, 25.

${ }^{74}$ Ibid., 89. 
knowledge about an exterior world but are much better understood as projections driven by lack and desire. ${ }^{75}$

And indeed, Jude recognizes neither Phillotson nor Arabella for what they are. In addition to this, he sticks to his construction of an ideal image of Christminster as "a city of light" "76 till the end, although the narrator tells us of "doorways of enriched and florid middle-age design, their extinct air being accentuated by the rottenness of the stones", and expressly concludes that "It seemed impossible that modern thought could house itself in such decrepit and superseded chambers". 77

Although "hardly a shred of the beliefs with which he had first gone up to Christminster [was] now remaining with him", and although he "was mentally approaching the position which Sue had occupied when he first met her", the death of his children and the fact that Sue leaves him make it impossible for Jude to live with the unbearable "sense of inconsistency between his former dogmas and his present practice". ${ }^{78}$ This keenly felt sense of difference and the absence of a supportive and freethinking Sue accelerate the loss of his flexibility and his final entry into the realm of the material, his petrifaction so to speak, and his death.

Jude's ability to construct his gender identity is much more flexible and progressive than any essentialist construction would allow for just compare him to the hopelessly phallic and ultimately failing Michael Henchard ${ }^{79}$ - yet Jude's construction of masculinity is, as has already been shown, repeatedly characterized by méconnaissance. Whether Jude constructs his male gender identity through identification with the "master narratives of masculinity" or whether he identi-

\footnotetext{
75 "There is no natural truth written anywhere that might be read without being somehow altered in the process. The text of associations Jude fabricates around him is already woven of interpretations and differences in which the meaning of dreams and the desire for illusions are unnaturally coupled" (Ramon Saldívar, "Jude the Obscure: Reading and the Spirit of the Law", in Jude the Obscure: Thomas Hardy, 43).

${ }^{76}$ Hardy, Jude the Obscure, 25.

${ }^{77}$ Ibid., 79.

${ }^{78}$ Ibid., 309-10.

${ }^{79}$ See Stefan Horlacher, "Negotiating Masculinity in Late Victorianism: Die Dekonstruktion phallischer Männlichkeit in Thomas Hardys Roman The Mayor of Casterbridge (1886) und die Frage nach dem New Man", in Der Verfasste Mann: Männlichkeiten in der Literatur und Kultur um 1900, ed. Gregor Schuhen, Bielefeld: Transcript, 2014, 179-228.
} 
fies with Sue's demands, ${ }^{80}$ in each and every case he takes something foreign or alien as his own. He identifies with external concepts, thereby eliminating the distancing of the symbolic and reverting to "Joseph the dreamer of dreams", 81 blithely embracing the imaginary. Only this identification seems to give him a kind of security, though it is a treacherous security that ultimately prevents him from understanding that his gender identity is hardly more than a shifting construct.

If Jude suspects that gender identity, and maybe identity in general, has to be produced and performed again and again, he also senses that this kind of identity does not harbor the security he craves but counteracts his logocentric desire for a transcendental meaning which would end his lack of being once and for all. Therefore, he prefers a form of méconnaissance, an identification with a supposedly pregiven subject position, a ready-made male gender identity - and it is exactly this stance which prevents him from learning and makes a second, albeit unwanted marriage with Arabella possible.

If Jude fails, it is because he is unable to accept the primacy of the signifier and because he opts for his fantasies of regression, that is a flight into the imaginary and a putative plenitude. This refusal of the multiple spaces which the symbolic order offers implies the refusal of responsibility and of a life which is not ruled by allegedly transcendental authorities. What Jude is looking for is plenitude in the sense of a fusion of the signifier and the signified; what he craves is the end of lack and desire. That this wish ultimately coincides with the wish to die is made clear by Jude's suicidal tendency: if, already during his youth, Jude undertakes an unsuccessful attempt to kill himself ${ }^{82}$ and "wish[es] himself out of the world", ${ }^{83}$ this early affinity to the realm of death is affirmed throughout the novel if we take into account that the narrator stresses that Jude is "more ghostly, less substantial" than even the voices of the dead philosophers who haunt Christminster, that the city itself is characterized as "a place full of fetishists and ghost-seers", that Jude admits "I am fearful of life, spectre-seeing always", ${ }^{84}$ that the "expression of Jude's corpselike face in the watery lamplight was indeed as if he saw people where there was nobody" 85

\footnotetext{
${ }^{80}$ See Hardy, Jude the Obscure, 239, 241.

${ }^{81}$ Ibid, 205.

${ }^{82}$ See ibid., 70.

${ }^{83} \mathrm{Ibid} ., 31$.

${ }^{84}$ Ibid., 151.

${ }^{85}$ Ibid., 392.
} 
and that he is metaphorically killed by the milestone in which, right at the beginning of his journey, he carved his hopeful "THITHER".

\section{The lethal aspects of writing, or, in search of origin(s) and truth}

Not without reason does Jude call himself a "monumental mason". He works on "the deadest and most intractable of materials" and sees himself "as in the business of supplying dead bodies, helping to provide "the carcasses that contained the scholar souls"". ${ }^{86}$ As a journeyman carver of tombstone epitaphs, he is a representative of fixation and death - and significantly enough, it is this job which ruins his health:

I was never really stout enough for the stone trade, particularly the fixing. Moving the blocks always used to strain me, and standing the trying draughts in buildings before the windows are in, always gave me colds, and I think that began the mischief inside. ${ }^{87}$

Jude develops pneumonia, but instead of clinging to Arabella, who at least stands for life, he embraces a sex- and bodiless Sue as well as his wishful projections of a Christminster in which he sees not only a mistress ${ }^{88}$ but also a clearly phallic "castle, manned by scholarship and religion". ${ }^{89}$ As a stonemason, Jude has always shunned speech, has happily carved and chiseled away in his endeavor to fix linguistic signs in stone and - in analogy to this - to reach a position where his identity and his masculinity, both so heavily undermined by Sue and Arabella, would be fixed once and for all.

Yet if chiseling epitaphs on tombstones promises to allow for a semblance of permanency and thereby the transcendence of time, it is still a form of writing and as such characterized not by the presence of any truth whatsoever but rather by absence and death. ${ }^{90}$ What Jude, the stonemason, does, is literally to petrify the signifiers in the vain

\footnotetext{
${ }^{86}$ Garson, “Jude the Obscure: What Does a Man Want?”, 183.

${ }^{87}$ Hardy, Jude the Obscure, 398.

88 "He was getting so romantically attached to Christminster that, like a young lover alluding to his mistress, he felt bashful at mentioning its name again" (ibid., 24).

${ }^{89}$ Ibid., 26.

90 "[The] symbol manifests itself first of all as the murder of the thing, and this death constitutes in the subject the eternalization of his desire. The first symbol in which we recognize humanity in its vestigial traces is the sepulture, and the intermediary of death can be recognized in every relation in which man comes to the life of his history" (Lacan, "Function and Field of Speech and Language", 104).
} 
hope that if only he could monumentalize and fix them once and for all, if only he could put an end to their play of deferral and unlimited semiosis, if only he could become part of the male scholarly society of Christminster, where he supposes a timeless, phallic truth to reign, and if only he could end his nomadic life and unstable relationships, this would guarantee the presence of a pre-given sense in life and therefore eventually stabilize his identity.

But instead of gaining access to a transcendental signified, he unknowingly turns himself into a "fetishist of the signifier", unreflectingly ${ }^{91}$ working with a medium of fixation and mortification which requires the transitory suspension of the process of dynamic development since only the complete emptying of the phenomenon, the sclerotic process of becoming a sign, the translation and transformation of plenitude into the obsession of writing can ever allow transferability. ${ }^{92}$ But, one has to ask, the transferability of what? At best of "untranslatable eyes" $" 93$ or of the dead languages Jude never really masters.

Any attempt to reach a final, monosemic truth is revealed to be lethal: Little Father Time and his siblings die because Sue tries to speak "the truth" - "It was that I wanted to be truthful. I couldn't bear deceiving him ... and he took it literally" " Phillotson, taking a masochistic, self-sacrificing and psychologically troubled Sue "at her word", knows all too well that there is much more than just "a touch of selfishness in it", ${ }^{95}$ and Jude, Little Father Time's double, finally dies because he has the same defective understanding of language and writing as his son. One last example should suffice to make this clear: what Jude feels during a moment of introspection at the beginning of his journey when he leaves Marygreen for Christminster is projected into his carving of the milestone and even rendered graphically in the novel: ${ }^{96}$

\footnotetext{
91 "Hardy dramatizes characters whose consciousness of what they want and why they want it remains continuously out of phase with the vagaries of their incarnate behavior. They have no terms for finding out what they are actually doing, and no way of actually doing what they want" (Weinstein, The Semantics of Desire, 138).

${ }^{92}$ See Horlacher, "Writing as Reading the Unreadable", 7.

${ }^{93}$ Hardy, Jude the Obscure, 89.

${ }^{94}$ Ibid., 338 (emphases added).

${ }^{95}$ Ibid., 365 (emphasis added).

${ }^{96}$ Ibid., 73.
} 
THITHER

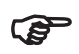

J.F.

At the end of his search for truth, Jude returns to this milestone to rediscover its fundamental message. A message which - significantly enough - does not possess a fixed meaning or signified but as an indexical sign is in itself nothing if not the mere display of the principle of deferral which underlies language and guarantees its functioning. If, in the beginning, Jude's "THITHER" stands for his aims and hopes in life, if it stands for the supposed presence of truth in Christminster, it appears in the end as a self-effacing, ironic commentary, inscribed on a stone which Hardy's text directly links to the gallows and thus symbolically transforms into Jude's tombstone.

If Jude's acts of almost desperately embodying an aim in a word, and cutting that word in stone, are emblematic of his logocentric desire, if he continuously endeavors to make the word real, that is to ensure its fulfillment by monumentalizing the signifier, ${ }^{97}$ it is exactly the opposite which happens. There is not only no fixed meaning but the signifier, although made of stone, vanishes too. Jude's inscription is "nearly obliterated by moss" hopeful indication of Jude's aims to an ironic comment on the mechanism of language, on Jude's failure and on the novel itself. Or, as Jan B. Gordon states: "In a curious way, Jude the Obscure seems to disappear as a book really, leaving language, texts, and their related activities as a kind of graveyard." 99

Where this "graveyard" and where Jude's defective understanding of language and writing come from and which semiotic doctrine Hardy's novel adamantly argues against becomes evident if one considers that Jude basically follows in the footsteps of St Paul and that he clings to his belief that "In the beginning was the Word, and the Word was with God, and the Word was God" (1 John 1). What Jude is ultimately looking for and what he is trying to write or to chisel is this very epistle "written not with ink, but with the Spirit of the living

${ }^{97}$ Cf. Saldivar, "Jude the Obscure: Reading and the Spirit of the Law"; Garson, "Jude the Obscure: What Does a Man Want?".

${ }^{98}$ Hardy, Jude the Obscure, 390.

99 Jan B. Gordon, "Gossip and the Letter: Ideologies of 'Restoration' in 'Jude the Obscure", Lore and Language, XVIII/1 (1989), 74. 
God; not in tables of stone, but in fleshy tables of the heart" (2 Cor. 3). ${ }^{100}$

If Jude could find this writing in his heart, his identity and meaning in life would forever be fixed and any fetishizing of the signifier, any hammering and chiseling would become unnecessary. But the kind of writing Jude is looking for is hard to find indeed, given that it would have supernatural, magic powers ${ }^{101}$ since it would be exactly that kind of writing which is not subject to the very foundation and rules which make writing - as well as speaking - possible, namely absence, difference and deferral.

That any kind of writing into the "fleshy tables" of the heart is characterized by several severe media-theoretical problems does not only become apparent if a) one considers Polycarp of Smyrna's "Wherefore, forsaking the vanity of many, and their false doctrines, let us return to the word which has been handed down to us from the beginning" ${ }^{102}$ which indirectly proves the very absence of exactly this word, but also if b) one takes into consideration Derrida's notion of arche-writing, c) the fact that the very idea of an arche-text/Urtext or arche-word/Urwort is most probably the metaleptical and retrospective effect of writing, ${ }^{103}$ and d) that neither oral nor literate cultures can allow for the existence of an arche-logos.

As Albert B. Lord has argued, in a world that conceives of itself orally no originary or arche-word is possible, let alone secondary words derived therefrom. Instead, there would be a plurality of "original words" - and precisely because of that no original word. If one were to take Lord's thesis seriously, which Bible exegeses has hardly done, it would indeed have a fateful effect upon the unending search

\footnotetext{
${ }^{100}$ See Saldivar, "Jude the Obscure: Reading and the Spirit of the Law", 50.

${ }_{101}$ See Paul Goetsch, Hardys Wessex-Romane, Tübingen: Narr, 1993, 303.

${ }^{102}$ Epistle to the Philippians (emphases added); see also W.H. Kelber, "Die Fleischwerdung des Wortes in der Körperlichkeit des Textes", in Materialität der Kommunikation, eds Hans Ulrich Gumbrecht and K. Ludwig Pfeiffer, Frankfurt am Main: Suhrkamp, 1988, 32.

${ }^{103}$ Ibid., 37; here Kelber also argues that because the visual objectification of words that takes place in the act of writing enables for the first time at all a distinction to be made between the original (Urschrift) and the copy (Abschrift), one can view the reduction of words to the original or arche-word as having been inspired by the shift towards written forms.
} 
for the ipsissima vox of Jesus, that is to say the ipsissima structura of his words. ${ }^{104}$

As Gordon has shown, Jude, "the dreamer of dreams", lives in a world in which "Origins are infinitely desired and therefore absent", so that "some kind of translation becomes necessary (because of the slipping of the Original) and impossible, because a sacred text ... would be untranslatable". ${ }^{105}$ Therefore, this "sacred text" or presence of meaning is clearly denounced by Hardy's novel as a figment of Jude's imagination: Sue's eyes remain forever unfathomable and untranslatable and her character incomprehensible to him, and his revered "city of light"106 and worshipped "new Jerusalem"107 is tellingly enough not characterized by authenticity but by "copying, patching, and imitating". ${ }^{108}$

Christminster and its cathedral are mainly marked by the fact that "numerous blocks of stone were lying about, which signified that the cathedral was undergoing restoration or repair to a considerable extent". ${ }^{109}$ Indeed, "the Cathedral repairs ... were very extensive, the whole fittings having been swept away, to be replaced by new". ${ }^{110}$ Ironically, as a stonemason Jude himself is a chief agent of this "copying, patching, and imitating", and the stone yard where he works is one of the most important places "where de-centering, the propagation of an historical supplement within a myth of restoration, is maintained for profit. It is a graveyard in some double sense, since the 'copy' speaks also to the death of any medieval scholasticism that could be recovered." "With Hardy, even this possibility of recoverability is

\footnotetext{
${ }^{104}$ Albert B. Lord, The Singer of Tales, Cambridge, MA: Harvard University Press, 1960. On the level of philosophy, Lord's thesis takes on significance with regard to Derrida's critique of the traditional dichotomy between speech and writing and the longing contained therein for the pure, logocentric origin. Speech, which in the Western tradition (according to Derrida) has become a symbol of our dreams of an eternal truth and a fundamental unity, is in Lord's view devoid of an arche-logos. In the beginning was not the word, in the beginning were words. See Kelber "Die Fleischwerdung des Wortes in der Körperlichkeit des Textes", 37.

${ }^{105}$ Gordon, "Gossip and the Letter", 74.

${ }^{106}$ Hardy, Jude the Obscure, 25.

${ }^{107}$ Ibid., 22.

${ }^{108}$ Ibid., 85.

${ }^{109}$ Ibid., 131.

${ }^{110}$ Ibid., 135. See also: "In his bewilderment Phillotson entered the adjacent cathedral, just now in a direly dismantled state by reason of the repairs" (ibid., 162).

${ }^{111}$ Gordon, "Gossip and the Letter", 57.
} 
negated, since "There is no natural truth written anywhere that might be read", since "Everything in Wessex 'begins' with repetition, with secondary images of a meaning that was never present but whose signified presence is reconstituted by the supplementary and belated word of Jude's desires". ${ }^{112}$

As a final look at Jude's beloved books reveals, these do not contain any original meaning either but are "amended by numerous correctors, and with variorum readings in the margin". ${ }^{113}$ Thus, "in a world where all knowledge is emendation and revision rather than recovery", ${ }^{114}$ texts, be they supposedly holy or not, are generally revealed to be palimpsests. But if meaning becomes a "function of progressive erasure", if the word "Bible" comes from the Greek ta biblia, that is "the books", ${ }^{115}$ if the Holy Text is not only from Sue Bridehead's deconstructive editorial perspective ${ }^{116}$ revealed to be "the reproduction of an arbitrary totalisation - the collection" 117 - and turned into a conglomeration of episodes, thus reflecting the narrative structure of Jude the Obscure, this implies that Hardy implicitly equates his novel with the Bible and - in analogy to D.H. Lawrence in his Study of Thomas Hardy - denounces the holy scripture as a fictional text, that is literature.

Moreover, the novel not only becomes the equivalent of Sue's edited version of the New Testament, it also coincides with Hardy's master narratives of masculinity and Jude's different versions of his male gender identity which both are revealed to be of an episodic nature. If, in addition to that, we also take Jude's homoerotic attachment to Phillotson, Arabella's earthy and earthly sexuality, Vilbert's emblematic function as Jude's successor, Sue's depiction as "sexless"

\footnotetext{
${ }^{112}$ Saldivar, "Jude the Obscure: Reading and the Spirit of the Law", 43.

${ }^{113}$ Hardy, Jude the Obscure, 43.

114 Gordon, "Gossip and the Letter", 50.

115 The Literary Guide to the Bible, eds Robert Alter and Frank Kermode, Cambridge, MA: Belknap Press, 1987, 11.

116 “'Jude,' she said brightly ... 'will you let me make you a new New Testament, like the one I made for myself at Christminster?' 'Oh yes. How was that made?' 'I altered my old one by cutting up all the Epistles and Gospels into separate brochures, and rearranging them in chronological order as written, beginning the book with Thessalonians, following on with the Epistles, and putting the Gospels much further on. Then I had the volume rebound. My university friend ... said it was an excellent idea. I know that reading it afterwards made it twice as interesting as before, and twice as understandable"" (Hardy, Jude the Obscure, 152 [emphasis in the original]).

${ }^{117}$ Gordon, "Gossip and the Letter", 50.
} 
and "boyish" and, finally, Jude's female attributes into consideration, it becomes clear that Hardy's novel vehemently a) questions the notion of a "natural" masculinity or femininity, b) emphasizes the constructedness, alterability and even multiplicity of gender identities, and c) calls upon the reader not to look for an original meaning but to engage critically with the text, with one's life, with one's identity. But if, as has been argued, it is in the gap between the potential capacities of a differential code and any particular specification of it that the arena of subjectivity and freedom lies, if one's identity is " above all, an accomplishment, a particular work, a particular act,' the 'very expression' of responsibility, not something independent of it", ${ }^{118}$ if therefore a discursive universe does not bereave us of personal responsibility and agency, this then is exactly what Jude, the "orderloving man", who takes "so much tradition on trust", 119 is not prepared to accept: "My dear one ... your will is law to me." ${ }^{120}$ In other words: "There were no brains in his head equal to this business; ... he wished he had never seen a book, that he might never see another, that he had never been born." 121

\section{The blessings of allegory}

Instead of offering a transcendental truth, "the direct, epileptic Word", the "cry that might abolish the night"122 or an "authentic" and unshakeable male gender identity, Hardy's novel offers only formal and dynamic "truths". It does not posit a simple negation of understanding but - in an almost postmodern turn - simply insists on the unverifiability of meaning and - equating Jude with Little Father Time - vehemently asks for an allegorical reading. As has been shown, taking words literally inevitably entails death. Thus, what Hardy's novel, albeit ad negativum, asks for is a metaphorical, even an allegorical reading and understanding of textuality, as has been suggested by critics such as Paul de Man. ${ }^{123}$

\footnotetext{
${ }^{118}$ Ermarth, "Beyond 'the Subject"”, 411.

${ }^{119}$ Hardy, Jude the Obscure, 153.

${ }^{120}$ Ibid., 239.

${ }^{121}$ Ibid., 31.

122 Thomas Pynchon, The Crying of Lot 49, Philadelphia and New York: Lippincott, 1966, 118.

${ }^{123}$ Paul De Man, Allegories of Reading: Figural Language in Rousseau, Nietzsche, Rilke and Proust, New Haven, CT: Yale University Press, 1979.
} 
If the character of Little Father Time has often been criticized as being deficient from the perspective of a traditional realist aesthetics, Jude's son becomes explicable if the episode involving his death is read as an allegory: What happens to Little Father Time also happens to Jude and - in a metaphorical sense - even to Hardy's novel, which the latter repeatedly claimed to have been largely misunderstood by the public. Hardy's complaint, however, should not be understood as the implicit postulation of the existence of the one and only "right" interpretation or of a stable, single and unitary meaning. Basically, the kind of reader Hardy attacks is his own protagonist, is Jude Fawley, a reader who ignores the figurative and allegorical dimension of writing, who looks for an "anchoring point" or "point de capiton" (Lacan) and the presence of sense in a literal meaning and who, just like Little Father Time, naïvely and anxiously "follow[s] his directions literally, without an inquiring gaze at anything". ${ }^{124}$

What Hardy asks for is an understanding of the figurative dimension of language, which on a metalevel demonstrates that any final understanding is impossible. In doing so, neither he nor the novel contradict themselves since the reader experiences together with Jude "that language itself, to the extent that it attempts to be truthful, necessarily misleads us about its own ability to take us outside its own structures in search of meaning". ${ }^{125}$ Therefore, "as an allegory of the breakdown of the referential system, Jude the Obscure continues to refer to its own chiastic operations. This new referentiality is one bounded strictly by the margins of textuality", and finally leads to the fact "that the resulting sociological, ethical, legal, or thematic categories" produced by the text "are undone by the very process that creates them". ${ }^{126}$

If Hardy's novel questions "the assurance of the truth of the referent", if there is simply nothing outside the symbolic order and the discursive universe of language which can fulfill the function of an unquestionable anchoring point, then the only presumably safe reference possible is, of course, a linguistic reference. That this reference is not unproblematic in itself becomes obvious if one considers that the novel also demonstrates that a one-sided, fixed and inflexible assignment of signifieds to signifiers - and this also holds true for the con-

${ }^{124}$ Hardy, Jude the Obscure, 278.

${ }^{125}$ Saldivar, "Jude the Obscure: Reading and the Spirit of the Law", 44.

${ }^{126}$ Ibid., 47. 
struction of gender identity - is lethal and has to give way to the infinite chain of semiosis, that is to the potentially never-ending interpretation of signs through other signs.

\section{Conclusion}

With regard to its meaning, Hardy's novel must be seen as an (in principle) unlimited play of signification, which, contrary to all attempts at controlling meaning through logic and clarification, ultimately leads to indeterminacy and indecision - and it is exactly by these very means that the text gains in fascination, depth and open-endedness. From this it follows that Jude the Obscure is not, as literary critics have often argued, a realist novel about the New Woman in the form of Sue Bridehead but an allegory of patriarchal laws, symbolic systems and the illusion of a metaphysics of presence. For Hardy's novel, meaning is always produced, dynamic, unstable and contextual. Meaning - just as one's (gender) identity - cannot be found or fixed but has to be constructed.

If Jude fails in the construction of his male gender identity and of a happy and meaningful existence, he mainly does so because he stubbornly continues to believe in the presence of a pre-given, and stable "truth" which can be located or discovered; if Jude fails, he does so because he ignores the fact that (gender) identity is not a biological given but to a large extent the product of a metaphorical act of writing which retrospectively creates the subject's supposed unity, the illusion of an essence, an origin or a presence which does not exist outside language but must be regarded as its very product.

This does not mean, however, that on a philosophical level Hardy's novel leaves us with a bleak and simple negative "truth". Jude's failure neither suggests nor implies that Hardy's novel denies the possibility of a meaningful existence. Quite the contrary: in an existential and linguistic turn, Jude the Obscure vividly and dramatically illustrates that "l'existence précède l'essence", ${ }^{127}$ that it is absence which founds the symbolic order as well as the conditio humana and that it is exactly this lack which ultimately guarantees our freedom. ${ }^{128}$

If Hardy's narrator explicitly states that "nobody did come, because nobody does", ${ }^{129}$ this implies that individuals as "subjects-in-

${ }^{127}$ Jean-Paul Sartre, L'existentialisme est un humanisme, Paris: Gallimard, 1996, 26.

${ }^{128}$ See Lang, Die Sprache und das Unbewusste.

${ }^{129}$ Hardy, Jude the Obscure, 31. 
process" ${ }^{\prime 30}$ have to create - or better: are allowed to create their own identity and meaning in life, that this work of construction is never finished and that - in contrast to Jude's hopes and wishes but in analogy to Proust's $A$ la Recherche du temps perdu - the price for this freedom resides in the fact that we cannot return to any kind of internal, "essential" or "natural" truth, be it gendered or not, at the core of the subject. ${ }^{131}$

${ }^{130}$ Cf. Julia Kristeva, Polylogue, Paris: Seuil, 1977; see also Ermarth, "Beyond 'the Subject"”.

131 This article is based on earlier versions, i.e. Stefan Horlacher, "From a Metaphysics of Presence to the Blessings of Absence: The Medial Construction of Masculine Identity in Thomas Hardy's Novel Jude the Obscure", Journal of Men, Masculinities and Spirituality, I/2 (June 2007), 116-36; Stefan Horlacher, "'The letter killeth but the spirit giveth life' - Masculinity in Thomas Hardy's Jude the Obscure", in Proceedings: Anglistentag 2004 Aachen, eds Lilo Moessner and Christa M. Schmidt, Trier: WVT, 2005, 171-82. 


\title{
From ANGRY Young SCHOLARShIP Boy to MALE Role MOdel: THE RISE OF THE WORKING-Class HERO
}

\author{
SEbAstian MÜLLER
}

\begin{abstract}
"Working-Class Hero is something to be", John Lennon sings, and he might mean: "at least something." Thus it becomes understandable that the "original angry young men" Jimmy Porter (John Osborne's Look Back in Anger) and Joe Lampton (John Braine's Room at the Top) fall back on this mythologically charged mode of subcultural subject formation. And a closer look reveals that both are not only in a class, but also a gender conflict. Both of them produce themselves as typical working-class heroes, a subcultural male subject form that gains further influence through protagonists like Alan Sillitoe's Arthur Seaton (in his bestselling Saturday Night and Sunday Morning). As a consequence, the working-class hero slowly but unstoppably steps out of the depths of his former realms into the light of social attention, becoming a male role-model to believe in, and thus becoming something to really be. In a modern or postmodern world of shifting identities, the working-class hero provides a very simple but effectively reaffirming mode of male identity formation; a mode of subject formation that, as we shall see, even gains global influence through one outstanding and very specific product of mass media representation: James Bond.
\end{abstract}

When John Osborne's Look Back in Anger was first performed at the Royal Court Theatre in London on May 8th, 1956, and Kenneth Haigh hit the stage as a "working class Hamlet" Jimmy Porter, a new era for

${ }^{1}$ This phrase is used on the back cover of the current Penguin paperback edition. Analogously, a 1962 Centre 42 National Youth Theatre performance of Hamlet in 
English literature began: fostered not so much by a consistent literary movement but mainly by considerable media attention and an extraordinary publicity campaign, "angry young men" conquered theatre stages, cinema screens and bestseller lists. ${ }^{2}$ In this essay, I will argue that Jimmy Porter and the "post-Osborne revolution" 3 not only set the stage for upcoming vital theatre productions and became a role-model for a series of angry texts, but that they also provided an effective mode of male identity formation, that is the "working-class hero", as a model of male identity that is still effective in our time. I intend to show that Jimmy Porter as well as Joe Lampton - the protagonist of John Braine's Room at the Top and one of the many other original angry young men - fall back on this mythologically charged mode of subcultural subject formation when they are trapped between the brave new world of the aspiring middle class and their ambiguous working-class origins.

A closer look will reveal that both are not only in class trouble, but also in a gender conflict. With their pride and masculinity at stake, Joe and Jimmy strive for compensations for their frustration: Jimmy by attacking and intimidating upper-class prigs, Joe by materially extending his working-class physicality through financial potency and status symbols. Yet both of them produce themselves as typical workingclass heroes, since this subcultural male subject form serves as a very simple but effectively reaffirming mode of male identity formation. Moreover, it develops into a male role model that, as we shall finally see, even gains global influence today through one outstanding and very specific product of mass media representation: James Bond.

\section{The post-war years and the 1950s: from euphoria to the "angry decade"}

Revolutionary though he might have been, Jimmy Porter was still a product of his time, the "angry decade", as the 1950s were called by Kenneth Allsop. ${ }^{4}$ A short summary of the socio-cultural changes of

Nottingham was billed as "Shakespeare's Jimmy Porter" (see Alan Sinfield, Literature, Politics and Culture in Postwar Britain, Oxford: Blackwell, 1989, 265).

2 See Stuart Laing, Representations of Working-Class Life, 1957-1964, London: Macmillan, 1986, 62.

${ }^{3}$ Ibid., 87.

${ }^{4}$ Kenneth Allsop, The Angry Decade: A Survey of the Cultural Revolt of the NineteenFifties, Wendover: Goodchild, 1985. 
the time might be helpful to understand the character of Jimmy Porter and his tremendous success among contemporary theatre-goers.

The 1940 Blitz, the German attempt to invade Britain via aircraft attacks, ended in a triumphant victory for the British military services and the whole British nation: though hopelessly outnumbered, Britain's Royal Air Force fought back the German attacks in less than half a year. The result of this heroic "Battle of Britain" was a never known feeling of coherence and community within British society. Even today veterans and older people look back on the war not in anger, but remember it as "the brief period when the English people felt that they were a truly democratic community". ${ }^{5}$ As a result of this feeling of coherence and community, the 1945 general election provided the Labour Party under Prime Minister Clement Attlee with its biggest ever majority in parliament. ${ }^{6}$ Even if the respective "postwar hope for socialism in Britain now seems to have been amazingly hubristic", ${ }^{7}$ the Labour ideal of a classless society seemed realistic in the euphoria of both the war and the election victory. And indeed, with the establishment of the welfare state (with National Insurance, National Assistance and the National Health Service) the government seemed to be able to overcome traditional British class divisions, and the new form of "welfare-capitalism implied that now all the people were to share in those good things that the upper classes had generally secured to themselves". ${ }^{8}$ Moreover, the 1944 Butler Education Act with its "free secondary education for all" had been hailed as "a great advance towards a unified modern society" even before the Labour government was elected. ${ }^{9}$

However, even if the economic boom of the post-war years and the early 1950s turned Britain into an affluent society ${ }^{10}$ in which even the tabloid Daily Express rejoiced in 1955 that the "British people never had it so good. Shops are fuller than ever ... higher pay packets, lower

${ }^{5}$ Angus Calder, The People's War: Britain, 1939-45, St Albans: Granada, 1969, 400.

${ }^{6}$ See Laing, Representations of Working-Class Life, 5.

${ }^{7}$ Sinfield, Literature, Politics and Culture in Postwar Britain, 307.

${ }^{8}$ Ibid., 44-45.

${ }^{9}$ Harry Hopkins, The New Look, London: Secker and Warburg, 1963, 143.

${ }^{10}$ However, Britain still remained a debtor nation, especially to the United States. British economy, though booming, was still lagging behind other European and global competitors like France, West Germany, Italy and especially Japan (see The Age of Affluence, 1951-1964, eds Vernon Bogdanor and Robert Skidelsky, London: Macmillan, 1970, 57; see also Sinfield, Literature, Politics and Culture in Postwar Britain, 95, 105). 
taxes, full shops and nice new homes", ${ }^{11}$ and Charles Curran stated in June 1956 that, thanks to the Butler Education Act, "Britain, in fact, is now very close to the point where it will be true to say that there is a general correlation between social status and mental ability", ${ }^{12}$ traditional British class divisions were again in effect, albeit in a new form: Sinfield argues that "the retention of fee-paying schools and division of the rest into grammar and secondary modern, with an extension of 'intelligence' testing, continued prewar trends" ${ }^{\prime 13}$ and a class division in education that perpetuated traditional upper- and middle-class privileges for better career chances. ${ }^{14}$ If one follows Norbert Elias, this effort of the upper classes to maintain the dividing line was to be expected: according to Elias, such a phase of repulsion always occurs in the course of the "civilizing process" when a lower class has the chance to strive for affluence and social influence; with the help of social institutions, the upper class changes norms, values and mannerisms according to a new behavioral and institutional code that the aspirant lower class can no longer access nor copy. ${ }^{15}$

In fact, Sinfield states that most upward movement from the working classes ended in the new jobs created by the technological advance

\footnotetext{
${ }^{11}$ Quoted in Laing, Representations of Working-Class Life, 11.

${ }^{12}$ Charles Curran, "The Passing of the Tribunes", Encounter, XXXIII (June 1956), 21.

${ }^{13}$ Sinfield, Literature, Politics and Culture in Postwar Britain, 55-56.

${ }^{14}$ See Calder, The People's War, 627. According to Sinfield, "The Robins Committee found in the early 1960s that there were more lower-class students only because the number of students had doubled: the proportion was the same as in 1939" (Literature, Politics and Culture in Postwar Britain, 235).

${ }^{15}$ Elias distinguishes two phases of assimilation and repulsion between competing classes: "a phase of colonization or assimilation in which the lower and larger outsider class is still clearly inferior and governed by the example of the established upper group which, intentionally or unintentionally, permeates it with its own pattern of conduct, and a second phase of repulsion, differentiation or emancipation, in which the rising group gains perceptibly in social power and self-confidence, and in which the upper group is forced into increased restraint and isolation, and the contrasts and tensions in society are increased ... in the first phase, which is usually that in which people rise individually from the lower to the upper class, the tendency for the upper class to colonize the lower and for the lower to copy the upper is more pronounced. In the second phase, when the social power of the lower group is increasing while that of the upper group declines, the self-consciousness of both groups increases with their rivalry, with a tendency to emphasize differences and - as far as the upper class is concerned - to consolidate them. Contrasts between the classes increase, the walls grow higher" (Norbert Elias, The Civilizing Process, trans. Edmund Jephcott, Oxford: Blackwell, 1994, 507-508).
} 
of the new consumer society located in a rather narrow buffer zone between the middle and traditional working class: "The preoccupation with upward mobility through education was a story that society, or parts of it, wanted to tell itself, not a record of experience." 16 The result of this limited form of upward mobility is a new social group consisting of "people of indeterminate social class", 17 as George Orwell put it, and it remained disputable whether the new class signified the "embourgeoisement ... of the proletariat"18 or rather the "proletarianization' of large sections of the petty bourgeoisie". ${ }^{19}$ As this matter utterly and insolvably seems to depend on one's subjective class perspective, Charles Curran solves the issue by establishing a new category - and thus makes the new social group understandable: "the New Estate is a classless zone, neither proletarian nor bourgeois. It has turned its back on the first but does not wish to assimilate to the second." ${ }^{20}$ Even if the assumption that the new group refuses to assimilate to the bourgeois way of life remains doubtful, the "New Estate" signifies the paradox of Britain's post-war society: new social mobility combined with traditional class boundaries.

On the gender level, new affluence and opportunities also seemed to have led to a state of overall contentment. Sinfield argues that in the 1950s feminism "was believed to have been successful and hence no longer necessary (like trade unions). A central assumption of welfare capitalism was that the good state had in principle arrived, and only details needed attention." ${ }^{21}$ Yet underneath the "good-state" surface with the overall tendency to domesticity, the renegotiation of gender roles within society had already begun. New employment patterns and expectations within the home softened up traditional gender role allocations: the economic boom of the post-war years encouraged married women to gradually seize their opportunities on the labor market; ${ }^{22}$ while men were expected to contribute to household work and particu-

\footnotetext{
${ }^{16}$ Sinfield, Literature, Politics and Culture in Postwar Britain, 234-35.

${ }^{17}$ The Collected Essays, Journalism and Letters of George Orwell, eds Sonia Brownell Orwell and Ian Angus, Harmondsworth: Penguin, 1970, II, 97.

${ }^{18}$ Evan Durbin, The Politics of Democratic Socialism, London: Routledge, 1940, 119.

${ }^{19}$ John Westergaard and Henrietta Resler, Class in a Capitalist Society, Harmondsworth: Penguin, 1976, 76.

${ }^{20}$ Curran, "The Passing of the Tribunes", 21.

${ }^{21}$ Sinfield, Literature, Politics and Culture in Postwar Britain, 203; see also Lynne Segal, Slow Motion: Changing Masculinities, Changing Men, New Brunswick, NJ: Rutgers University Press, 1990, 2.

${ }^{22}$ See Sinfield, Literature, Politics and Culture in Postwar Britain, 206.
} 
larly to childcare. Both tendencies, however, were challenged by the still prevailing traditional gender role expectations. The male contribution within the household was considered as being "effeminate", ${ }^{23}$ and an increasing number of women in paid work seemed to threaten the natural notion of women as supporting wives and caring mothers so that conservative institutions and individuals tried to urge women back into the home. ${ }^{24}$ The result of these contradictory expectations was that the "boundaries of male and female roles became uncertain and disputable, problematizing marriage and the heterosexual relation in all aspects". ${ }^{25}$ This also affected the self-understanding of the formerly unquestionably dominant masculine gender, which now, subtly but effectively, found itself exposed to a new demand for change. It is therefore not surprising that Lynne Segal argues that "male anxiety was running deep at the time". ${ }^{26}$ It was during this time of class and gender renegotiations that Jimmy Porter hit British stages.

\section{Jimmy Porter: from angry young scholarship boy to working- class hero}

Being one of the many "original angry young men", Jimmy Porter is of alleged working-class background ${ }^{27}$ and a typical scholarship boy arguing that his university education was "not even red brick, but white tile", ${ }^{28}$ as his upper-middle-class wife Alison quotes him. He holds the mythological suffering and enthusiasm of the working class as his principal purposes in life but is not able to turn his ambitious spirit into a social position that corresponds to his university education. Remaining a social underachiever he runs a sweet-stall and he is now stuck between the classes: educated beyond working-class limits, he is still denied access into the inner circles of the middle classes as is signified by the hostile welcome he receives from his wife's family. Thus his anger can be traced back to the class hatred of the failing social climber who (like so many others) has to learn that certain promises of the welfare state remain unfulfilled and who now utters

\footnotetext{
${ }^{23}$ Segal, Slow Motion, 3-5.

${ }^{24}$ See Sinfield, Literature, Politics and Culture in Postwar Britain, 205-206.

${ }^{25}$ Ibid., 207.

${ }^{26}$ Segal, Slow Motion, 21.

${ }^{27}$ The play itself is ambiguous about Jimmy's class background, his father being a political activist and his mother having "pretty posh" relatives (see John Osborne, Look Back in Anger [1957], Harmondsworth: Penguin, 1982, 30).

${ }^{28}$ Ibid., 42.
} 
"the cry of the scholarship boy angrily knocking at the bolted door of the bourgeoisie". ${ }^{29}$ This class hatred accounts for the savage war that Jimmy, together with his friend Hugh, wages on his wife's family and their relatives and acquaintances.

However, it does not necessarily explain why Jimmy not only hates the establishment but is also such a fierce misogynist, who fears that "these women bleed us to death", ${ }^{30}$ and why the "play continually associates women with superficiality and inauthenticity ... [and] identifies the enemy as femininity". ${ }^{31}$ Sinfield and Segal have in fact discerned a correlation between the feminine, or rather the "effeminate", and the establishment that functions as a welcome target for anger resulting from frustration. ${ }^{32}$ Furthermore, the effeminate establishment functions as a "constitutive other" 33 for the identity formation of the male working-class protagonist. Jimmy Porter's specific family background helps us to understand how this equation of establishment and the effeminate and of the working class and masculinity comes into effect.

It is not only Alison Porter's family that personifies the establishment; the specific history of Jimmy's parents, too, already suggests a class conflict that has been transferred into the character and psyche of Jimmy Porter: his father must have signified an idealized male working-class role model for Jimmy, as he fought for the Communist Brigades in the Spanish civil war during which deadly wounds were inflicted upon him. This idealization of the father hero is even strengthened by the fact that Jimmy was (according to his own reports) the only representative of his family who, at the age of ten, remained at his father's deathbed. It is crucial to note the massive impact that this experience must have had on young Jimmy's

${ }^{29}$ Paul Foot, The Politics of Harold Wilson, Harmondsworth: Penguin, 1968, 327-29.

${ }^{30}$ Osborne, Look Back in Anger, 84.

${ }^{31}$ Susan Brook, "Engendering Rebellion: The Angry Young Man, Class and Masculinity", in Posting the Male: Masculinities in Post-war and Contemporary British Literature, eds Daniel Lea and Berthold Schoene, Amsterdam: Rodopi, 2003, 25.

${ }^{32}$ See Sinfield, Literature, Politics and Culture in Postwar Britain, 66; Segal, Slow Motion, 13.

${ }^{33}$ For a detailed elaboration of the necessity of a "constitutive other" for the formation of an individual or a social group identity, see Andreas Reckwitz, Das hybride Subjekt: Eine Theorie der Subjektkulturen von der bürgerlichen Moderne zur Postmoderne, Göttingen: Velbrück, 2006, 45-47; Dan Zahavi, Self-Awareness and Alterity: A Phenomenological Investigation, Evanston, IL: Northwestern University Press, 1999, 160-62. 
psychological disposition: according to Freud, the attributes of a loved person lost in childhood are persistently internalized and become a part of one's own identity in order to overcome grief of loss. ${ }^{34}$ This is exactly what young Jimmy Porter experiences: he incorporates the idealized working-class hero characteristics into his own ego-structure and sustains them through acts of imitation. However, Jimmy thus is not only a representative of a time in which "English fathers seemed to be archetypally absent", ${ }^{35}$ he is at that stage already prejudiced and set against his bodily mother and thus, against "the female" per se: mother Porter not only deserted (again according to Jimmy's reflections ${ }^{36}$ ) the dying hero father alone on his deathbed, for Jimmy she also personifies a profound anxiety of the female, as we can see in the following central passage of the play, in which Jimmy describes his wife Alison (in her presence):

Oh, it's not that she hasn't her own kind of passion. She has the passion of a python. She just devours me whole every time, as if I were some over-large rabbit. That's me. That bulge around her navel - if you're wondering what it is - it's me. Me buried alive down there, and going mad, smothered in that peaceful looking coil. ${ }^{37}$

Even if these sentences have no direct reference to Jimmy's mother, the archetypal fear of being buried alive expresses a profound anxiety of the small male (rabbit) in front of, or rather inside the powerful female (python). ${ }^{38}$ The fact that Jimmy feels buried alive in a woman's womb is quite telling in many respects: first of all, Jimmy's anxiety reflects an unsolved mother conflict, in his fear he literally never really cut the cord to his mother. ${ }^{39}$ By thus never really growing be-

\footnotetext{
${ }^{34}$ See Sigmund Freud, "Mourning and Melancholia”, in General Psychological Theory, ed. Philip Rieff, New York: Macmillan, 1976, 170-72.

${ }^{35}$ Olivia Harris, quoted in Segal, Slow Motion, 9.

${ }^{36}$ It is almost obvious that Jimmy's idealization of his father and the condemnation of his mother would not hold true when tested by additional perspectives, since the father's heroic deed could also be interpreted as a simple escape from domestic responsibilities.

${ }^{37}$ Osborne, Look Back in Anger, 37-38.

${ }^{38}$ Here the Freudian archetypal female fear of the snake as a representation of aggressive male sexuality undergoes an inversion.

${ }^{39}$ However, Jimmy's yearning for motherly love (as expressed in the play by his utter dependency on women and his relationships with characters like lover-mother Madeline or foster-mother Tanner) shows that his hatred of his mother is counterbalanced
} 
yond the basic dependency of the child to its parents, Jimmy becomes a typical case of Freud's pathological (secondary) narcissism:

From the time of puberty onward the human being must devote himself to the great task of freeing himself from his parents; and only after this detachment is accomplished can he cease to be a child and so become a member of the social community .... In neurotics, however, this detachment from the parents is not accomplished at all; the son remains all his life in subjection to his father, and incapable of transferring his libido to a new sexual object. ${ }^{40}$

In his childlike egocentric narcissism Jimmy is not only unable to truly love another person, but he is also unable to see that this certain "bulge around her navel" is not he himself but his very own offspring: Alison's child, which Jimmy wants dead in order to bring his wife to an allegedly higher level of understanding for his own tragic fate. And it is a case of tragic irony that the unborn child will soon literally be buried (not alive but dead) in the womb of its mother, due to the circumstances of this domestic tragedy triggered by Jimmy's own childlike egocentrism that renders him unable to cope with parental responsibilities.

The reasons for Jimmy's pathological narcissism are quite obvious: he is a typical Freudian case of secondary narcissism caused by parental negligence. Due to the unsolved mother conflict and the archetypal absence of the father, Jimmy not only condemns his mother but also internalizes the idealized working-class hero attributes of his lost father, thus compensating for the lack of a male role model. This becomes obvious when the fragile self-esteem of the university graduate is later set to the test by the "bolted door of the bourgeoisie" that Jimmy expected to be wide open for him. The frustration triggered by the fierce rejection on the side of the Redfern clan ${ }^{41}$ is compensated by a reaction of defiance. Jimmy immediately retreats to a mode of identity

by an oedipal love for his mother, strengthened by the identification with his father and suppressed by the Freudian incest taboo.

${ }^{40}$ Sigmund Freud, "General Introduction to Psycho-Analysis: Twenty-First Lecture. Development of the Libido and Sexual Organisation", in The Major Works of Sigmund Freud, ed. William Benton, Chicago: Encyclopaedia Britannica, 1952, 584.

${ }^{41}$ If we may believe Colonel Redfern's statement on the case, this rejection of Jimmy's is pursued particularly by the female head of the Redfern clan, the Colonel's wife; a fact that probably helped little to ease Jimmy's profound misogyny (cf. Osborne, Look Back in Anger, 65-67). 
formation that is constructed in opposition to the expectations of the middle classes and already prefigured in his personal disposition: the simple but effective mode of the working-class hero. Mutually reaffirming themselves in their alleged role of the class victim, best friends Jimmy and Hugh now carry out attack after attack on Alison's upper-middle-class background.

My argument therefore is that Jimmy Porter does not "transcend class culture" as Susan Brook suggests ${ }^{42}$ but rather reinforces the given class boundaries by re-enacting a non-hegemonic mode of identity formation $^{43}$ in strict counter-definition to its constitutive other, the allegedly effeminate upper middle classes. This subcultural ${ }^{44}$ mode of identity formation, the working-class hero, serves two major purposes for the former scholarship boy: first, it reaffirms Jimmy's troubled class identity, caused by his being trapped in between classes and his rejection by the social circles he tried to gain access to. Yet this reaffirmation has to be evaluated as a step back into a stereotypical (and thus non-realistic) mode of working-class identity formation - a class that Jimmy no longer belongs to and most probably was never really rooted in. Second, as modes of identity formation are always already gendered and the concept of the working-class hero is connected to a subcultural - and in Jimmy's case paternal - male ideal, it serves to reaffirm his troubled masculinity, a very individual "masculinity in crisis" that is rooted in the still troubled relation to his parents as analyzed above.

The characteristics of the working-class hero mode of identity formation are thus easily summed up: it is the stereotypical "bluff, vigorous working-class male [whose] ruggedly heterosexual and rebellious masculinity ... [and] emotional honesty contrasts with the dominant culture, and whose masculinity dominates over inauthentic femininity". ${ }^{45}$ Furthermore, being a typical "underdog" phenomenon, the working-class hero always has to cope with a life that means suffering

\footnotetext{
${ }^{42}$ Brook, "Engendering Rebellion", 25.

43 For a detailed distinction between "hegemonic", "sub-hegemonic", "non-hegemonic" and "anti-hegemonic" modes of subject and identity formation, see Reckwitz, Das hybride Subjekt, 69-71.

${ }^{44}$ The concept of a "subculture" is here understood as Alan Sinfield defines it: "A subculture is a group collaboration to build a common story and establish it against rivals. This process is always in the making, and its strategy is characteristically appropriate" (Literature, Politics and Culture in Postwar Britain, 153).

${ }^{45}$ Brook, "Engendering Rebellion", 23-24.
} 
from and fighting against suppression from above. Therefore it is crucial for the hero to maintain a tough outward appearance through different forms of impression management, be it uncouth talk about having "no public school scruples about hitting girls" or the open display of the blokish or "savage" physicality of the "barbarian invader" at upper-middle-class dinner parties, "plundering them, wolfing their food and drinks, and smoking their cigars like ruffians". "Against women and the weak-kneed prigs of the upper middle classes, this rough physicality seems to function as an effective means of intimidation. However, Jimmy's display of blokish masculinity proves to be only a thin veneer of mere impression management: even if he made it doubly clear that he would "lay out" Helena and "lash back" at her when he found some woman "trying to cash in on what she thinks is my defenseless chivalry by lashing out with her frail little fists", ${ }^{47}$ in the later moment of escalation, when Helena actually slaps him savagely for his indignities, Jimmy's defense collapses like a house of cards. His only reaction is an "expression of horror and disbelief", ${ }^{48}$ and the alleged working-class hero is here unmasked as the little frightened boy he never ceased to be.

Thus Jimmy, through impression management mainly based on the exaggerated use of verbal violence (a capacity that he most probably acquired through his university education), only produces himself as a working-class hero in order to compensate for his class and gender frustration as well as the lack of his only pretended physicality. Maybe the weak basis for this kind of production accounts for the failure of Jimmy's futile striving for self-reaffirmation on both the class and the gender level: his masculine identity remains far from being affirmed, his fighting attitude towards women and the establishment is revealed as a frustrated boy's cry for attention, without higher aims or "good brave causes left" 49 to strive and even die for. Yet even if Jimmy fails in his own case, he establishes an ideal to be followed by others.

\footnotetext{
${ }^{46}$ Osborne, Look Back in Anger, 57; see also 43, 44.

${ }^{47}$ Ibid., 57.

${ }^{48}$ Ibid., 73-74.

${ }^{49}$ Ibid., 84.
} 


\section{Joe Lampton: the physical extension of man}

Whereas the outrageous Jimmy Porter certainly is the logical product of an obvious misogynist like John Osborne, ${ }^{50}$ John Braine's "original angry young man" Joe Lampton in Room at the Top follows a more rational, self-controlled strategy while trying to escape the class trap: coming from a true working-class background in the industrial parts of England - called "Dead Dufton" by the autodiegetic narrator Joe Lampton $^{51}$ - he now enjoys the new social mobility as an accountant for the local government in Warley, his new hometown with its promising prospects of affluence and a new consumerist lifestyle. His career outlook and financial opportunities being still rather limited due to his safe but dull work for the state, Joe develops aspirations to climb even higher and to step into the promising and exciting world of the free market system. His ambitions for even more are also reflected in Joe's relation to two contrasted women: with middle-aged and married Alice Aisgill, he finds both fulfilling sexuality and motherly care, adding up to something that Joe experiences as being real love. ${ }^{52}$ For Joe, however, twenty-year-old Susan Brown, daughter of Warley's most affluent business man, represents a ticket to prosperity and access to the circles of the posh society in which he eventually manages to settle due to his marriage with her.

With this remarkable achievement Joe Lampton is a typical representative of the post-war career model, a mode of subject formation that according to sociologists Niklas Luhmann and Andreas Reckwitz signifies the new hegemonic mode of identity formation in the middle of the twentieth century - replacing the self-controlled bourgeois subject and preceding the postmodern creative subject. ${ }^{53}$ The career model, originally stemming from the United States, the land of unlimited opportunities, enabled the individual to fulfill the myth of the "American Dream", the prototype career from rags to riches. ${ }^{54}$ The belief in

\footnotetext{
${ }^{50}$ See Segal, Slow Motion, 14; Alice Ferrebe, Masculinity in Male-Authored Fiction 1950-2000: Keeping It up, Houndsmill: Palgrave Macmillan, 2005, 17-18.

${ }^{51}$ John Braine, Room at the Top (1957), London: Arrow Books, 2000, 16.

${ }^{53}$ See ibid., 80-81, 105, 180.

53 See Reckwitz, Das hybride Subjekt, 282-84; see also Niklas Luhmann, Gesellschaftsstruktur und Semantik: Studien zur Wissenssoziologie der modernen Gesellschaft (1980), Frankfurt am Main: Suhrkamp, 1993, III, 232-33.

${ }^{54}$ Or, to put it in Anthony Crosland's terms: "Americans believe in the 'office-boy to president' mythology" (Anthony Crosland, The Future of Socialism, London: Cape, 1956, 251-52 [emphasis in the original]; see also Sinfield, Literature, Politics and Culture in Postwar Britain, 253-54).
} 
this philosophy of life was no longer limited to the US but was then among many other "American way[s] of doing things, of seeing things" 55 - adapted to the market systems of old class ridden Europe. Room at the Top is an excellent example that shows that this new way of life could not be transferred across cultures without major problems, because for Joe Lampton, the challenging step out of his working-class origin into the free market system requires various new faculties: Joe has to learn how to play different social roles, a capacity that he acquires quite quickly as a member of the local theatre group, the "Warley Thespians". At the same time, in Joe's view, the new world of Warley and its free market system seem to resemble Hobbes' state of nature rather than a civilized, social sphere: it is determined by a struggle to survive in the field of economic competition. Joe's feeling of being bound by a contract ${ }^{56}$ can thus not only be read as the traditional topos of a contract with the devil - Joe "loses his soul" when he ends up as a "successful zombie" of Hobbes' social contract: the new contract - which I would like to call the "market contract" - signifies the loss of social securities (represented by the stereotypical working-class solidarity of Joe's Dufton background) in exchange for the freedom and opportunity to climb to the highest step of the social ladder and thus to fulfill Joe's personal career dream.

It is clear that this market sphere is anything but a violence free zone; and even if the market system is still an inner social sphere that prohibits the use of physical violence, physicality is, at least in Joe's mind, a crucial factor in this field of competition. However, physicality is now understood in new, market contract compatible terms, as the following crucial passage suggests, in which Joe drives by Jack Wales' house, the home of his competitor for the hand of Susan Brown:

"Who lives there?" I asked; "Jack Wales," George said .... "Colossal, isn't it?" .... My spirits sank. For the first time I realized Jack's colossal advantages: I thought that I was big and strong; but there was a lot more to that house than there was of me. It was a physical extension

\footnotetext{
${ }^{55}$ Sinfield, Literature, Politics and Culture in Postwar Britain, 191.

${ }^{56}$ Braine, Room at the Top, 13.

${ }^{57}$ Ibid., 123.
} 
of Jack, at least fifty thousand pounds' worth of brick and mortar stating his superiority over me as a suitor. ${ }^{58}$

This passage shows that the primitive modes of hierarchical battles for position based on physical potency are still at work yet carried out by different means: bodily power is now substituted by financial potency. ${ }^{59}$ Joe has to realize that his strong working-class physicality (that is so much admired by Alice and other women and thus associated with the sexual sphere) is far from being equivalent to the extension of Jack Wales' material and financial powers.

At a later stage of the novel, however, Joe discerns this physical extension through status symbols not only in his opponents but also in himself, when the narrating Joe, looking back on his past, sums up:

I am like a brand-new Cadillac in a poor industrial area, insulated by steel and glass and air-conditioning from the people outside .... What has happened to me is exactly what I willed to happen. I am my own draughtsman. Destiny, force of events, fate, good or bad fortune - all that battered repertory company can be thrown right out of my story .... But somewhere along the line - somewhere along the assembly line, which is what the phrase means - I could have been a different person. ${ }^{60}$

This passage not only shows that Joe has lived up to his ideal of the American Dream (represented by the symbol of the American Dream, the Cadillac, as well as by the idea of having one's luck in one's own hands); it also signifies that Joe has now also extended his own physicality by material means such as steel and glass and a shiny, polished surface. This extension of the body is actually an application of Marshall McLuhan's understanding of the media as the extensions of man: McLuhan defines clothes, housing and money as nothing more than "media of communication, first of all, in the sense that they shape and rearrange the patterns of human association and community". ${ }^{61}$ Joe thus uses consumerist status symbols - from clothes over cars to

\footnotetext{
${ }^{58}$ Ibid., 66-67.

${ }^{59}$ In the course of the novel, this battle for positions is also reflected in the little social status game of who is allowed to pay a drink for whom (see ibid., 110, 113).

${ }^{60}$ Ibid., 124.

${ }^{61}$ Marshall McLuhan, Understanding Media: The Extensions of Man, London: Routledge and Kegan Paul, 1964, 127.
} 
women $^{62}$ - as a means of defining the hierarchical positions of himself and the people around him. The idea that these status symbols are thereby merely substitutes for or rather extensions of physical violence is also reflected in Elias" "civilizing process" theory, in which physical violence turns into "economic violence" in societies where state institutions are influential enough to secure and maintain the state's overall monopoly on physical force. ${ }^{63}$

However, Joe drives this extension of the self so far that - after his true love Alice is killed in a car accident - he finally cracks and turns into a split personality. At this point the former accountant has to sum himself up as follows: "I hated Joe Lampton, but he looked and sounded very sure of himself sitting at my desk in my skin; he'd come to stay, this was no flying visit." ${ }^{64}$ After this disastrous experience Joe is pursued by doubts about the sense of his new life, and ten years after the incidents represented in his narration, Joe Lampton, the firstperson narrator, now regards himself as a "zombie" who started his new career as a living corpse the moment Alice died. Significantly, after this enormous shock to his self-understanding, the young Joe Lampton falls back on stereotypical working-class behavior and seeks consolation in boozing, fighting and women. ${ }^{65}$

Yet in order to mend the split personality of the living dead, Joe Lampton requires more: he tries to overcome the split with the help of his autobiographical narration. The older Joe Lampton uses this mode of narration to reorganize the crucial incidents of his life into a chain of causes and effects and thus renders his destiny, his way of life, coherent and understandable again. ${ }^{66}$ It is crucial to note, however, that in this reconstructive identity narration, Joe Lampton idealizes his working-class origins - the formerly condemned "Dead Dufton" - as a real and authentic social network in contrast to the war-world of Warley that is ruled by disguise, deceit and ruthless competition. The working-class identity of Joe Lampton is thus again produced as a true kernel of the self beyond the split and shifting identities of the social

\footnotetext{
${ }^{62}$ See Ferrebe, Masculinity in Male-Authored Fiction, 49-51.

${ }^{63}$ See Elias, The Civilizing Process, 447-48.

${ }^{64}$ Braine, Room at the Top, 219. According to Luhmann, the diagnosis of the split personality is in fact a common result of the career model and the compulsion to fulfill different roles in different social contexts, as Joe Lampton has to do (see Gesellschaftsstruktur und Semantik, 227).

${ }^{65}$ See Braine, Room at the Top, 221-23.

${ }^{66}$ See Ferrebe, Masculinity in Male-Authored Fiction, 14-15.
} 
actor. By thus relating the "zombie" back to his origins, the autobiographical narration helps to mend the split personality of Joe Lampton, even if the original state of the uncorrupted self remains irretrievably lost.

One can thus discern a twofold application of the working-class hero concept in Room at the Top: stereotypical working-class physicality is a formative feature of the new identity-formation concept of the financial and material extension of the self. This new concept of physicality is required by the inner-cultural natural sphere of the market system that is seen as a battleground for affluence and a social position marked by status symbols. In contrast, the working-class hero concept, seen as an authentic and real representation of the "original self", helps to mend Joe Lampton's split personality after the overextension of the self by material means. The idealization of the working-class hero concept thus functions, as in the case of Jimmy Porter, as a mode of reaffirmation for a troubled male identity.

\section{Still fighting: new representations of the working-class hero con- cept}

Alice Ferrebe convincingly points out how repetitive narrations of simple modes of male identity formation not only helped to reaffirm troubled character identities but also to "emasculate" readers and recipients. ${ }^{67}$ And in fact, Jimmy Porter and Joe Lampton are only two of the many angry young men of the 1950s who establish the workingclass hero concept as a particular male style of being. Alan Sillitoe's Arthur Seaton is perhaps the most impressive and influential example of the time as both the novel and the film version of Saturday Night and Sunday Morning were highly successful vehicles that transported the working-class hero concept as a possible way of life to a huge crowd of male recipients. This perhaps exaggerated celebration of the concept leads Nigel Gray to suggest that "Sillitoe is too much taken with the working-class hero cult". ${ }^{68}$ However, different modifications of the working-class hero can also be found in Arnold Wesker's Trilogy as well as in the works of David Storey and later in the 1960s in the plays of Harold Pinter. Martin Amis' Money (1984) not only takes the physical extension of a male hero through status symbols to the extreme but also re-enacts the misogyny and fighting spirit of its an-

\footnotetext{
${ }^{67}$ Ibid., 14-15.

${ }^{68}$ Nigel Gray, The Silent Majority, London: Vision, 1973, 131.
} 
gry predecessors of the $1950 \mathrm{~s} .{ }^{69}$ Furthermore, the working-class hero's battle calls strongly echo in the Ladlit of the 1990s, and it is crucial to note that the connection of correspondent stereotypical class and gender virtues can thus still serve as an important means of subject formation in a British service sector society that has now undergone profound social change and witnessed - at least compared to the $1950 \mathrm{~s}$ - the success of feminism.

However, the concept of the working-class hero is nowadays by no means limited to Great Britain; in a postmodern world of shifting identities, the working-class hero provides a very simple but effectively reaffirming mode of male identity formation. It has become a subject model that nowadays gains even global influence through one outstanding and very successful product of mass media representation, namely James Bond. The sleek British secret agent is not only a matter of interest for cultural studies since, with his shifting identities, he represents the prototypical superhero for the postmodern age; his film episodes also always represent cultural anxieties and issues of the respective historio-cultural background, be it the 1960s race to the moon fostered by Cold War ideology in You Only Live Twice and Moonraker, the discussion of mass media power in Tomorrow Never Dies or the increasing influence of the world's dwindling freshwater supplies as represented in the recent Bond movie Quantum of Solace. The series has - beginning with Sean Connery and Ursula Andress always represented specific but influential ideals of masculinity and femininity; and with the advance of product placement, Bond movies have become the world's most expensive and influential advertisements. It would thus be a matter of unpardonable negligence to assume that James Bond was not one of the most important male media role models in at least Western societies.

A closer analysis of the 2006 film adaptation of Ian Fleming's first Bond novel Casino Royale (written in 1953, Bond was invented in the "angry decade") reveals that James Bond is not only a hero, but that he now also represents important characteristics of the working-class hero. Like Jimmy Porter, Bond is a misogynist; he, like Joe Lampton, commoditizes women and uses them for his own purposes. Like Braine's protagonist he uses gadgets, fancy clothes and cars as material extensions of his physicality. But does he reflect the most important characteristic of the working-class hero, namely a working- or lower-

${ }^{69}$ See Ferrebe, Masculinity in Male-Authored Fiction, 166. 
class background as a means of self-reaffirmation? The 2006 film version of Casino Royale is significant here due to the fact that its story is chronologically located at the very beginning of the Bond series. In this first episode, James Bond only becomes a double 0 agent and is still younger and less experienced than the slick agent that audiences used to know. This representation of a younger Bond is not only reflected by the change of the Bond actor from Pierce Brosnan to the younger and rougher Daniel Craig; it is also signified by a much stronger emphasis on Bond's physical brutality. Unlike former (or chronologically later) Bonds, the younger agent does not kill by pushing the buttons of Q's gadgets but by using his bare hands. Thus rejecting the technological artifacts of a modern material culture, Bond goes back to a very physical mode of fighting and killing, the man-toman fight.

Even more important than these changes in the style of being Bond is the glimpse into Bond's past that is exclusively provided during the movie's train dinner scene, ${ }^{70}$ in which Bond and his lover-to-be Vesper Lynd ruthlessly analyze the flaws and idiosyncrasies of each other's character. Here it is revealed to the audience that Bond does not come from an affluent background; he is an orphan and, according to Vesper Lynd's analysis:

... by the cut of your suit you went to Oxford or wherever and actually think human beings dress like that. But you wear it with such disdain, my guess is you didn't come from money, and your school friends never let you forget it, which means that you were at that school by the grace of someone else's charity. ${ }^{71}$

The "cold-hearted bastard" Bond feels "skewered" by this analysis of his past. Thus the film version of Casino Royale tells the story of how Bond becomes the sleek super agent we know: it is the narration of "angry young Bond", an orphaned scholarship boy who develops, like Jimmy Porter and Joe Lampton, a disdainful class hatred for the establishment. Moreover, Bond is also a case of parental absence and - as Casino Royale depicts in the later course of the movie as well as the novel - he suffers from an unsolved love frustration, as his trust in

\footnotetext{
${ }^{70}$ Casino Royale, dir. Martin Campbell, prod. Michael G. Wilson and Barbara Broccoli, perf. Daniel Craig and Eva Green, DVD, Columbia Pictures and Sony Pictures, $2006(0: 55: 31-0: 59: 40)$.

${ }^{71}$ Ibid. (00:58:07 - 00:58:22).
} 
women is fundamentally destroyed by what he perceives as Vesper Lynd's betrayal and unfaithfulness.

The Casino Royale movie of 2006 thus breaks with a long tradition of depicting Bond as a man without a past by emphasizing the innate fissures of the character stemming from his orphanage. Just like the working-class heroes of the angry decade this angry young Bond has to cope with the psychological challenges that come along with the frustrations of a social climber being unable to integrate in the circles of the upper classes. The methods of coping for both subject models follow the patterns of a "protesting masculinity" as Raewyn Connell described it. ${ }^{72}$ This mode of masculinity is essentially based on a traditional form of working-class manliness: Within the production processes, the hardened but worn-out body of the worker becomes proof of the worker's masculinity. Combined with the constant experience of limited access to power in early phases of the subject's development, the individual later shows a pronounced urge for power as well as an exaggerated display of bodily impression management. This aggressive form of masculinity serves as a mode of differentiation in two directions: first towards the upper middle classes and second against women. ${ }^{73}$ This form of a protesting masculinity explains Bond's misogyny as well as the class disdain he displays in the 2006 Casino Royale movie.

Even if it seems a bit overdone and constructed to ascribe a thorough working-class background to the character of the orphaned James Bond, my analysis shows that the authors of the 2006 version of Bond's story of origin chose to give the character some more edge and new psychological depth. They did this by shedding a new light on the character's origin and by ascribing Bond an aggressive mode of masculinity that stems from the time of his invention - the angry decade of the 1950 s. ${ }^{74}$

\footnotetext{
${ }^{72}$ See R.W. Connell, Der gemachte Mann: Konstruktion und Krise von Männlichkeit, 2nd edn, Opladen: Leske und Budrich, 2000, 55-57.

${ }^{73}$ Ibid., 96, 216.

${ }^{74}$ With Daniel Craig's angry young Bond the series thus also returns to its cinematic roots in the early 1960s, after a long intermediate period of Bond posing as gentleman-spy - embodied by Roger Moore and Pierce Brosnan in particular. Andrew Spicer's quote of producer Albert Brocoli's statement regarding the choice of Sean Connery as leading actor shows that the actor's working-class background and his raw physicality was deliberately chosen to attract not only a young audience in general, but also working-class viewers in particular: "Sean [Connery] had the balls for the part ... The whole point about having Sean in the role, with his strong physical mag-
} 
While the male role model James Bond thus aligns himself with social underdogs, the subcultural working-class hero concept steps up into the light of global media attention and becomes a simple but successful mode of subject formation for another generation of (angry?) young men in need of clear concepts of a stable male identity. Through repeated narration and production, the working-class hero thus develops into a typical case of gender identity formation through repetitive but potentially modifiable performative acts and practices. In the words of Judith Butler, it is a "repeated stylization of the body, a set of repeated acts within a highly rigid regulatory frame that congeal over time to produce the appearance of substance, of a natural sort of being", 75 and thus of a powerful ideal of how a "real man" should be and behave.

As this performative act is constituted by and directed against a stereotypical other, the effeminate establishment, it has to be defined as a former underdog phenomenon that seems to be gaining a growing mass appeal. My thesis is that this growing appeal to male recipients stems from the socio-cultural tendency that masculine identity is individually experienced as being in crisis, even if there is indeed no objective evidence for the much quoted "crisis of masculinity". However, I think that it is in fact a necessity that masculinity, or perhaps rather patriarchy, is experienced as being in crisis; otherwise one could easily argue that feminist thoughts and movements striving for a destabilization of a patriarchy maintaining the power structure of a compulsory heterosexual matrix would have to be dismissed as having had no effect at all. This is certainly not the case: a destabilization and thus a renegotiation of formerly sedimented gender roles has in fact taken place, and experiences of insecurity about gendered identities that are perceived as a crisis are a necessary result of such negotiations that erode the very essence of what generations believed to be unquestionable truths. However, signs of such a crisis and the means of its compensation should be alarming, as the success of the working-class hero concept signifies a propensity for a deeply rooted frustration which might easily turn into hostile aggression against the effeminate

netism and the overtones of a truck driver, was that it thrilled the women, but, more important, young men in the audience could feel there was a guy up there like them." (Quoted in Andrew Spicer, Typical Men: The Representation of Masculinity in Popular British Cinema, London: I.B. Tauris, 2003, 75).

${ }^{75}$ Judith Butler, Gender Trouble: Feminism and the Subversion of Identity, 2nd edn, New York: Routledge, 1990, 45. 
other - on the side of a still undoubtedly dominant male gender that clearly experiences itself as being under attack. Instead of denying the symptoms of such a crisis, a thorough analysis of its reasons should lead to a deeper understanding of anxieties on both sides; and thus hopefully to progress in the settlement of a still ongoing battle of the sexes that is arguably more than ever aggravated by media representations. 



\title{
"Filiarchy" AND MASCULinity IN THE EARLY NOVELS OF IAN MCEWAN
}

\author{
FATEMeH Hosseini
}

\begin{abstract}
The work of Ian McEwan is immensely relevant to the problematics of masculinity. The ambivalent quality of his fiction, which was first denounced as being misogynist and later acknowledged as being feminist, points to the challenging nature of his work with regard to gender issues. This transformation is, in fact, the effect of an obsessional, steady sketching and re-sketching of masculinities that have appeared as "resultants" of man-woman and child-parents relationships in his novels. This contribution deals with the portrayal of masculinity in a post-patriarchal era and the significant way it is inextricably intertwined with the recurrent motif of death in McEwan's work. Demonstrating the emergence of a new socio-cultural era in regard to gender identities, this article proposes a new term for the post patriarchal world (of his fiction), that is "filiarchy" - as distinct from its socioeconomic meaning. This term is meant to stand for the way modern men position themselves in relation to each other and to women.
\end{abstract}

Gender issues and relationships between the sexes have been of great significance in the context of Ian McEwan's fiction. ${ }^{1}$ His novels, especially the first four, depict a post patriarchal condition in which the concepts of gender identity, and therefore traditional gender roles, are greatly challenged. There is an agreement that McEwan's work has undergone a process of maturation and sophistication, which is also

\footnotetext{
${ }^{1}$ See Angela Roger, "Ian McEwan's Portrayal of Women”, Forum for Modern Language Studies, XXXII/1 (1996), 11-26.
} 
evident in the representation of gender identity in his fiction. ${ }^{2}$ This process of maturation is especially recognizable in his first four novels, which reflect an obsession with sketching and re-sketching of gender identities, especially masculinities. What this process of maturation and evolution suggests is a passage from patriarchy to a new condition.

As patriarchy has been challenged and questioned for at least a century by feminists, it is justifiable if we expect to see the outcome of feminist struggle in our time. If we believe that a limited patriarchal vision and its fixed and inflexible gender roles are still prevalent, we would have to admit that whatever has been done to remove sexual discrimination and injustice has been futile. However, we know that this is not true and changes that have taken place in gender relations in society are too prominent to be ignored. On the other hand, given the changing notion of masculinity in McEwan's fiction, the transformation of gender relations and the way they define and are defined by the social, historical, cultural and economic conditions of the sexes is undeniable. That is why the current condition of the world (within his fiction) should be considered as post patriarchal rather than patriarchal.

In fact, what has added to the significance of his novels is envisioning the emergence of a new condition in regard to gender issues, which is distinct enough to need a more specific term than post patriarchy. In other words, although this term embraces all diversities existing within feminist discourse, its inclusiveness has been achieved only at the expense of clarity. It is necessary to narrow down this meaning in order to avoid its ambiguities and different connotations, and to designate its peculiarities in the context of the novels. Therefore, I propose the term "filiarchy" as a term that has the capacity to better clarify the standpoints of McEwan's novels as far as gender issues are concerned.

It should be noted here that "filiarchy", as used in this article, is distinct from "filiarchy" in its socio-economic sense - a term first coined by James McNeal to refer to the crucial role of children in consumerist society. ${ }^{3}$ In my understanding, it literally means the reign of

${ }^{2}$ See ibid. and Jack Slay, "Vandalizing Time: Ian McEwan's The Child in Time", Critique, XXXV/4 (Summer 1994), 205.

${ }^{3}$ According to McNeal, children have become and should be regarded "as a market of influencers" whose decisions about their needs control their parents' decisions about 
sons, thus suggesting the end of patriarchy or the reign of the father. I should emphasize here that the reign of sons should not be confused with Freud's (and Darwin's) account of the evolution of human society from a primal herd in which the expelled sons killed their father and ended his tyranny in order to gain the right of mating with females. ${ }^{4}$ Even the startling similarity of the plots of The Cement Garden and The Comfort of Strangers to the primal horde and primal patricide should not be assumed as evidence of the sameness of "filiarchy" and Freud's hypothesis about the origin of human society. The primal patricide, as described by Freud in Totem and Taboo, the subsequent institution of matriarchy and the desperate need of the remorseful sons to have a father with whom they can identify are the first steps in giving the father his idealized image in Western culture, suggesting independence, self-sufficiency and authority. And it is "filiarchy" that, as introduced here, makes a stand against this very image and underlines the sons' determination to stop worshipping the father.

In fact, in spite of his minor role, if any at all, the father is not replaced by the mother in the filiarchal condition. In contrast with the two extremes of matriarchy and patriarchy, "filiarchy" enjoys a special balanced relationship with women, which proceeds from the childlike traits of sons and their interdependence with women. As neither dominant nor subordinate, women appear as sources of wisdom and affection, and contribute to this new condition exclusively in a maternal way. The filiarchal condition implies an inherent plurality and polyphony that patriarchy lacks: one can have only one father but several sons. Thus, it allows for the diversity of masculinities. It succeeds patriarchy and is affected by the feminist movement and its call for gender equality. Therefore, it is a reaction against patriarchal attitudes and order. Unlike patriarchy, "filiarchy" is not a repressive hegemonic condition, but is open to negotiation. However, "filiarchy", speaking for itself, also says that men, being in control of conceptual and social structures, are still the dominating class in society. Yet, their domination is only a legacy of patriarchy and its coercive tactics, which is in the process of being undermined by anti-totalitarian voices and forces that call for more inclusion and power-sharing.

how to spend their money (James McNeal, Kids as Customers: A Handbook of Marketing to Children, New York: Lexington Books, 1992, 73).

${ }^{4}$ See Sigmund Freud, Totem and Taboo (1913), trans. James Strachey, London: Routledge, 1990, 141-60. 
It seems that what has led to the advent of "filiarchy" in McEwan's fiction is the change that has taken place in its conception of masculinity, hence the transformation of power relations based on the superiority of men over women in the context of his novels. In fact, the crucial difference between patriarchy and "filiarchy" lies in their differing, even opposing, notions of masculinity. While hegemonic masculinity, as defined by R.W. Connell, is the bedrock of patriarchy, nonhegemonic masculinities construct "filiarchy". In the following, I attempt to trace the slow but steady formation of "filiarchy" by examining different types of masculinity in McEwan's first four novels - The Cement Garden (1978), The Comfort of Strangers (1981), The Child in Time (1987) and The Innocent (1990).

\section{Those falling men}

The first chapter of McEwan's 1997 novel, Enduring Love, ends with this sentence: "I have never seen such a terrible thing as that falling man." ${ }^{5}$ This sentence refers to the fatal fall of a man in a ballooning accident that serves as the central incident in the novel. Apart from the crucial role of the accident in the novel, the significance of this sentence extends to McEwan's other novels as well. In fact, at a symbolic level, it can be read as a brilliant condensation of the representation of masculinity and its association with death, murder and regression or with whatever can be called terrible. All the horrific things that are present in his fiction can be seen as inevitable consequences of the fall of a certain type of masculinity. It seems that this terrible fall is the essential first stage of the emergence of the new condition of "filiarchy". In McEwan's novels, this fall has taken three different forms: death, regression and murder.

The first form of the fall depicted in McEwan's early novels is death. Its recurrence along with the distinct way of its representation in McEwan's writing has given it a pivotal role in his fiction. It is the significance and functional presence of death that have been mainly responsible for the nightmarish effect of his fiction, as well as its multi-layered meaning. Among these four novels, The Cement Garden is the one that is most heavily resonant with death. It opens with a reference to the death of the narrator's father, which, in spite of what the narrator - the fifteen-year-old Jack - claims, proves very significant in the course of the novel:

\footnotetext{
${ }^{5}$ Ian McEwan, Enduring Love (1997), London: Vintage, 2006, 16.
} 
I did not kill my father, but I sometimes felt I had helped him on his way. And but for the fact that it coincided with a landmark in my own physical growth, his death seemed insignificant compared with what followed. ${ }^{6}$

These words not only signify an unresolved oedipal conflict underlying the narrator's relationship with his father, but - given the direction that the plot takes - also reveal a subtle resemblance to the primal herd as described by Freud. So it is no surprise that the father's characterization indicates a close correspondence with the jealous and cruel image of the primal patriarch who drives away his young sons to protect his position as the sole adult male member of the herd. The novel introduces the father as a faithful believer in the superiority of men like himself over women and other men. In fact, his attitudes and behavior speak of his belief in a culturally idealized form of masculinity known as "hegemonic masculinity".

According to R.W. Connell, hegemonic masculinity is "the configuration of gender practice which embodies the currently accepted answer to the problem of the legitimacy of patriarchy, which guarantees (or is taken to guarantee) the dominant position of men and the subordination of women". 7 Therefore, it "is not a personality type or an actual male character. Rather, it is an ideal or set of prescriptive social norms." 8 Jack's father exemplifies this definition; for although he cannot meet all requirements of hegemonic masculinity - as he is flawed by physical and intellectual deficiencies that have hindered him from living up to his ideal of masculinity - he supports it vigorously, simply because he benefits from it like most men. To give an example, he is against his daughter's wish to become a successful athlete. In his eyes, running fast is "daft" for a girl because he believes that it is an exclusively masculine activity: ${ }^{9}$ he supports what he is not and cannot be. Ironically, as a consequence of his heart condition which can also be read as his emotional death - he is not able to carry even one cement bag, let alone run fast. This distance between his ideal and his reality has made him insecure in his masculinity.

\footnotetext{
${ }^{6}$ Ian McEwan, The Cement Garden (1978), London: Vintage, 1997, 9.

${ }^{7}$ R.W. Connell, Masculinities, Cambridge: Polity, 1995, 77.

${ }^{8}$ Margaret Wetherell and Nigel Edley, "Negotiating Hegemonic Masculinity: Imaginary Positions and Psycho-Discursive Practices", Feminism and Psychology, IX/3 (August 1999), 336.

${ }^{9}$ McEwan, The Cement Garden, 19.
} 
This insecurity as the head of family has led to his excessive vulnerability, symbolized by his disability, and brought into sharp relief by his children when they return his mean comments with a caustic jibe at his garden. After the joke, he sulks for several days and then ceases working in his garden, a decision that coincides with his first heart attack. It should be added here that his secret admission of his disability and lack of the most integral part of idealized masculinity, that is working and bread winning, has increased his insecurity. Therefore, his dependence on his pipe is evidence of his attempt to compensate for his insecurity. He relies on it as a phallic object that functions as a symbol of the authority and castrating power he longs for. ${ }^{10}$ His pipe is what helps him feel confident and secure enough to impose his will on his wife and children:

While my mother talked my father used a penknife to scrape black shards from the bowl of his pipe on to the food he had barely touched. He knew how to use his pipe against her. She was telling him how little money we had and that Tom would soon be needing new clothes for starting at school. He replaced the pipe between his teeth like a missing section of his own anatomy and interrupted to say it was 'out of the question' sending the bags back and that was the end of it .... But how self-important and foolish he looked as he took the thing out of his mouth, held it by its bowl and pointed the black stem at my mother. ${ }^{11}$

His vulnerability, caused by an ideal far beyond his reach, and his acknowledgment of his failure in living up to it, has intensified his jealousy of his sons. Moreover, it is also responsible for his inability to communicate with his children, which has in turn led to their hostility. Jack's hostility towards his father is clearly reflected in his unwillingness to help him cement the garden, which brings the oedipal motive to the foreground. The significance of this motive is further confirmed by the coincidence between the father's death and Jack's first ejaculation as his first sign of puberty. His death as a patriarch symbolizes the failure and decline of hegemonic masculinity and patriarchy disguised as masculinity.

\footnotetext{
${ }^{10}$ See Laurenz Volkmann, "Extension of the Battle Zone: Ian McEwan's Cult Novel The Cement Garden", in Beyond Postmodernism: Reassessments in Literature, Theory, and Culture, ed. Klaus Stierstorfer, Berlin: de Gruyter, 2003, 316.

${ }^{11}$ McEwan, The Cement Garden, 11.
} 
The second form of the fall of masculinity in the novels is regression. Although it only ends with actual death in one case, it should be noted that regression in its extreme form becomes a radical renunciation of the symbolic order and one's identity as an individual. The symbolic order as the realm of differences and the recognition of otherness that constitutes language, law and culture is the site of constructing one's notion of self as a social being. In fact, while one's entrance into the symbolic order involves the experience of separation from others and the perception of one's identity, the exit from it in order to retrieve the preverbal world of idealized union with the mother is essentially an act of rejection of identity, hence a psychological death. ${ }^{12}$ In The Cement Garden and The Child in Time three characters who are traumatized by hegemonic masculinity go through regression. But only in the case of Charles Darke in The Child in Time does this eventually lead to his actual death.

The distance between the ideal and the actual self, which has caused Jack's father's feeling of insecurity and vulnerability in The Cement Garden, becomes a yawning abyss in the case of Charles Darke in The Child in Time. He is a well-established publisher and politician who is leading a very successful public life. He is married to an older physics professor, yet a prime minister, whose gender goes unmentioned throughout the novel, also loves him. After writing a childcare handbook with a strict disciplinary approach under the supervision of the prime minister, he leaves his political career and retreats to his country house to act out his childhood dreams, which he eventually ends with his suicide.

While Jack's father's awareness of his inability to live up to the ideal of hegemonic masculinity has resulted in his vulnerability in The Cement Garden, Charles Darke's faithful following of its norms and principles are responsible for his insecure identity in The Child in Time. His life seems to be an uncomfortable fluctuation between his relentless pursuit of the ideal of hegemonic masculinity and belated fulfillment of his childhood dreams. As his wife tells his friend, Stephen:

\footnotetext{
${ }^{12}$ See Sigmund Freud, "Introductory Lectures in Psychoanalysis", in The Standard Edition of the Complete Psychological Works of Sigmund Freud, trans. and ed. James Strachey, London: Hogarth, 1963, XVI, 344; Jacques Lacan, The Seminar of Jacques Lacan: Book I, Freud's Papers on Technique 1953-1954, trans. John Forrester, ed. Jacques-Alain Miller, New York: Norton, 1991, 230.
} 
... he wanted to be famous, and have people tell him that one day he would be Prime Minister, and he wanted to be the little boy without a care in the world, with no responsibility, no knowledge of the world outside. It wasn't an eccentric whim. It was an overwhelming fantasy which dominated all his private moments. ${ }^{13}$

The roots of this conflict can be traced back to his childhood:

... his mother died when he was twelve, so you could say he associated pre-pubescence with her. And he had a photograph, a horrid little picture taken when he was eight. It shows him standing next to his father who was fairly important in the city, a dull man ... but tyrannical. In the photograph Charles looks like a scaled-down version of his father - the same suit and tie, the same self-important posture and grown-up expression. ${ }^{14}$

According to his wife's account of his emotional and social confusion, that is of being denied a childhood, he was forced into early manhood. Apparently, he has had to follow his father's example and behave according to the principles of hegemonic masculinity without having the opportunity to fulfill his childhood, which led to his fixation on pre-pubescence. ${ }^{15}$

It seems that masculinity for him equates with steady social climbing and fulfilling those ambitions that mainly serve to marginalize, if not compensate for the losses he has experienced - the loss of his mother and his childhood. That is why his wife believes that "Charles's case [is] just an extreme form of a general problem" 16 which he shares with all other important men, who have to shout and win arguments so that they can hide the vulnerability and weakness they feel inside. Moreover, the masculine identity he performs, either as a publisher or as a politician, not only is meant to compensate for his inner insecurity but also involves control over the very structures and systems that have perpetuated men's dominance and promoted hegemonic masculinity: he is in search of the ultimate ascendancy

\footnotetext{
${ }^{13}$ Ian McEwan, The Child in Time (1987), London: Vintage, 1997, 200.

${ }^{14}$ Ibid., 202.

${ }^{15}$ In his "Introductory Lectures" Freud says about fixation: "I regard it as possible in the case of every particular sexual trend that some portions of it have stayed behind at earlier stages of its development, even though other portions may have reached their final goal" (Freud, "Introductory Lectures in Psychoanalysis", 340).

${ }^{16}$ McEwan, The Child in Time, 204.
} 
promised by this idealized form of masculinity. To gain the control that is essential for this ascendancy, he has to pursue its endless competitive goals, for hegemonic masculinity is "exclusive, anxietyprovoking, internally and hierarchically differentiated, brutal and ... crisis-prone". ${ }^{17}$ And the bigger the ambition, the more anxiety is provoked. So it is no surprise that for Charles trying to reach the unattainable status of "ideal" man is the same as digging out repressed and unsatisfied desires from the depth of his unconscious. That is why his extreme exhaustion, especially after his continuous social and political success, leads him to long more and more for a childhood. But the power-centeredness of this ideal of masculinity has made it irreconcilable with childhood and the powerlessness and irresponsibility that go with it. Therefore, unable to "bring his qualities as a child ... into his public life", ${ }^{18}$ tired of his manliness, his endless ambitions and responsibilities and his desire to "discipline" society, he regresses to childhood, to wander in the woods and be smacked and disciplined like a school boy by a prostitute. ${ }^{19}$ However, torn between a cultural ideal and an individual ideal, what he wishes for after sinking into his ideal state of childhood is returning to the adult world of politics and heavy responsibilities. When his wife, who has played the role of his mother during his regression, refuses to support him further and asks him to take responsibility for his own life, unable to reconcile or to bring into

\footnotetext{
${ }^{17}$ Mike Donaldson, "What Is Hegemonic Masculinity?", Theory and Society, XXII/5 (October 1993), 645.

${ }^{18}$ McEwan, The Child in Time, 204.

${ }^{19}$ Charles' regression along with his fetishism remind us of what Freud writes about regression in his "Introductory Lectures": "a regression of the libido without repression would never produce a neurosis but would lead to a perversion" (Freud, "Introductory Lectures in Psychoanalysis", 344). Moreover, Freud's definition of fetishism and its link to the "splitting of the ego in the process of defense" (the title of his 1938 essay) accounts for the ambivalence of Charles' life and the insecurity he feels within. On the other hand, in "On the Genesis of Fetishism" published in "Freud and Fetishism: Previously Unpublished Minutes of the Vienna Psychoanalytic Society", Freud asserts that a clothes fetishist "worships that which formerly prevented him from seeing: he becomes a clothes fetishist out of the repression of the desire to look" (Sigmund Freud, "On the Genesis of Fetishism", in "Freud and Fetishism: Previously Unpublished Minutes of the Vienna Psychoanalytic Society", trans. and ed. Louis Rose, Psychoanalytic Quarterly, LVII/2 [April 1988], 155 [emphases in the original]); a conclusion that leads us to read Charles' fetishism of being punished by a governess as evidence of his repression of his childhood desire to be free and not disciplined or forced to behave like a grown-up. As he does not repress this desire any more, his perverse regression begins and reveals his vulnerability.
} 
harmony the two poles of his problematic identity, he chooses to nullify it altogether and commits suicide. ${ }^{20}$

In comparison with the fatal outcome of regression in The Child in Time, The Cement Garden may seem to provide a milder image of regression. However, as it is categorized as Bildungsroman, the representation of regression and its interpretation play a very significant and central role in the novel. Tom is the youngest of four children in The Cement Garden. His excessive attachment to his mother, along with his excessive fear of his father and his father's jealousy of him, ${ }^{21}$ has made Tom unable to recognize and identify with the paternal authority in his Oedipal stage. Already six years old, he still demands his mother's constant attention and affection, a behavior that reveals he is still suffering from castration anxiety. ${ }^{22}$ Bullied at school, he is "tired of being a boy", which means he is tired of having to be afraid of castration. He also believes that he won't "get hit when [he is] a girl", ${ }^{23}$ meaning that he cannot lose what he lacks. Therefore, Tom's cross-

${ }^{20}$ Charles ends his life by sitting in the cold all day long. His choice of suicide, according to his wife when Stephen asks her about it - "I think he just sat down" (McEwan, The Child in Time, 196) - suggests some kind of passiveness and objectlike state that is in agreement with what Lacan has to say about anxiety. According to Lacan, as quoted in An Introductory Dictionary of Lacanian Psychoanalysis, "anxiety arises when the subject is confronted by the desire of the Other and does not know what object he is for the desire .... All desire arises from lack, and anxiety arises when this lack is itself lacking" (Dylan Evans, An Introductory Dictionary of Lacanian Psychoanalysis, London: Routledge, 1996, 12). In Charles' case, as long as he is acting out his desire he does not resort to suicide. But as soon as his playing in the woods becomes less interesting due to winter cold he starts to consider returning to his public life. His anxiety is provoked more when his wife decides he should return to politics which signifies her desire and his lack of the lack. Lacan distinguishes between the passage to the act and acting out as two defenses against anxiety: the passage to the act involves a flight from the Other and the symbolic order to the realm of the Real while acting out is only possible within the symbolic order. Exiting from the symbolic order, the subject becomes an object. Frustrated from acting out, passage to act or suicide here is the last resort of Charles against his deep anxiety.

21 "Julie had told me recently that now Father was a semi-invalid he would have to compete with Tom for Mother's attention. It was an extraordinary idea and I thought about it for a long time. So simple so bizarre, a small boy and a grown man competing. Later I asked Julie who would win and without hesitation she said, 'Tom of course, and Dad'll take it out on him.' And he was strict with Tom, always going on at him in a needling sort of way" (McEwan, The Cement Garden, 13).

${ }^{22}$ In his "Introductory Lectures" Freud defines castration anxiety as "the reaction to the threats against the child aimed at putting a stop to his early sexual activities and attributed to his father" (Freud, "Introductory Lectures in Psychoanalysis", 208).

${ }^{23}$ McEwan, The Cement Garden, 47. 
dressing appears as the first sign of his discontent with his identity and as the first step he takes to change his condition. It is also the starting point in the process of his emasculation, which actually signifies the total abandonment of his identity and all anxieties that go with it.

Furthermore, the loss of his object of desire, his mother, is a trauma that makes his condition more complicated. Tom's desperate desire for being mothered after their mother's death has made him decide that Julie is to take his mother's place. But it seems that the only aspect of motherhood that fascinates Julie is the power she has over her siblings. First, she refuses to provide Tom with the love and care he demands. But after a while, tempted by the power that abusing Tom's need promises, she finally agrees to play a maternal role for him only on the condition that he agrees to be a baby and act like one:

In the living room Julie was sitting by the table .... She was looking very pleased with herself. Tom was sitting on her lap with his thumb in his mouth and round his neck there was a napkin tied like a bib. He was staring across the room in a glazed kind of way and his head leaned against Julie's breasts. He did not seem to notice that I had come in and went on making small sucking noises with his thumb .... She smiled at me and I put my hand on the doorknob to steady myself. I felt as though I weighed nothing and might drift away. "Don't be so surprised," Julie said. "Tom wants to be a little baby." She rested her chin on his head and began to rock backwards and forwards slightly. "He was such a naughty boy this afternoon," she went on, talking more to him than to me, "so we had a long talk and decided lots of things." .... She had brought up from the cellar our old brass cot and put it right by her own bed. ${ }^{24}$

In fact, she forces Tom into the most helpless condition, which guarantees her the utmost power. ${ }^{25}$ Towards the end of the novel we witness his total regression to a state of miserable infanthood: we see him naked, lying in a baby cot and crying to attract Julie's attention, who is now more interested in exercising her power over the elder brother, Jack.

The teenage narrator of The Cement Garden, Jack, is in search of his identity. He is the elder son among his siblings, but even this fact has not made his father exempt him from his hostility. Nevertheless,

\footnotetext{
${ }^{24}$ McEwan, The Cement Garden, 107.

${ }^{25}$ See Kiernan Ryan, Ian McEwan, Plymouth: Northcote House, 1994, 23.
} 
due to the family's limited contact with the outside world, he has to model his male identity only on his father. ${ }^{26}$ But what he identifies as being masculine in his father are his gestures and his sexist views. In trying to prove himself a man, he then imitates his father's gestures and repeats his remarks and in doing so reproduces what seems to him more masculine. When playing a sexual game with his sisters, Jack is asked to be the next object of examination, and his reaction against being objectified by them is reminiscent of his father's behavior: “'Out of the question,' I said through an imaginary pipe. 'That's the end of it.", 27

But his father's death sweeps both him and his pipe away from Jack's life forever. Immediately after his dead body is taken away from their home, Jack goes to the cemented path in the garden and, using a plank, smoothes "away his [father's] impression in the soft, fresh concrete", ${ }^{28}$ a seemingly unconscious act that suggests his father's influence on shaping his character is undone forever. ${ }^{29}$ Now Jack has no one to identify with. For a while, however, a sense of guilt for his semi-conscious patricide induces him to consider the possibility of identification with his father, and in doing so he clings to his legacy that is a vague image of the values promoted by hegemonic masculinity. Searching for an image of himself, in a scene, he looks at a full length mirror and sees a falsified reflection of himself that encourages him to be tough and aggressive:

I frequently stared at myself in mirrors, sometimes for as long as an hour. One morning, shortly before my fifteenth birthday, I was searching in the gloom of our huge hallway for my shoes when I glimpsed myself in a full length mirror which leaned against the wall. My father had always intended to secure it. Colored light through the stained glass above the front door illuminated from behind stray fibers of my hair. The yellowish semi-darkness obscured the humps and pits of my complexion. I felt noble and unique. I stared at my own image till it

\footnotetext{
26 “... the family itself never was an intact family which would have fulfilled its social role of offering values and norms. Part of this is that Jack never had an adult role model. Little is told about his father, who appears as a distanced petty-bourgeois seeking to establish parental authority by means of ritualized gestures" (Volkmann, "Extension of the Battle Zone", 316).

${ }^{27}$ McEwan, The Cement Garden, 12.

${ }^{28}$ Ibid., 19.

${ }^{29}$ Ryan sees Jack's erasure of his father's impression in the cement as a patricidal act (Ryan, Ian McEwan, 21).
} 
began to dissociate itself and paralyzed me with its look. It receded and returned to me with each beat of my pulse, and a dark halo throbbed above its head and shoulders. "Tough," it said to me. "Tough." And then louder, "Shit ... piss ... arse."30

This passage, reflecting his search for an identity and indicating his resorting to the tough yet insecure form of masculinity as provided by what his father has left behind (that is, the mirror), reveals the power of hegemonic masculinity and its appeal to him. He tries to place himself beyond his mother's control, "abandons all the rituals of personal hygiene" and starts an irresolute idle life to show that he is not a child that can be disciplined. Furthermore, her docility reinforces his blind imitation of his father, an imitation that is characterized by a selfcenteredness and indifference to how others perceive him, especially his mother.

However, as the shaky and insecure mirror suggests, the fascination is only provisional. When his sister, Julie, challenges his notion of male superiority, he discards all those gestures and views he has inherited from his father in order to win her attention. The outset of this change of behavior is symbolically depicted in a kitchen cleaning scene. It seems that what Jack and Julie truly clear away are Jack's sexist views. ${ }^{31}$ But what is problematic here is that Jack's male identity is inextricably intertwined with such views. Therefore, what is discarded along with those beliefs is the male identity he has modeled on his father. This emasculation that suggests Julie's first success on her way to subjugate Jack and to break his resistance to her deeds and decisions is referred to in the same scene:

With an imaginary sten-gun at her hip she leapt into the kitchen and shot the place apart, all the mould-covered plates, the flies and bluebottles, the huge pile of rubbish that had collapsed and spread across the floor .... I stood by wondering whether I should join in this game. Julie whipped round and filled my belly with her bullets. I collapsed on the floor at her feet .... Julie took a handful of my hair and pulled my head back. She swapped her gun for a knife and as she pressed it against my throat she said, "Any more trouble and I'll stick it in here." Then she knelt down and pressed her fist near my groin. "Or here,"

\footnotetext{
${ }^{30}$ McEwan, The Cement Garden, 21 (emphasis added).

${ }^{31}$ Hossein Payandeh, Waking Nightmares: A Critical Study of Ian McEwan's Novels, Sussex: University of Sussex, 2001, 86-87.
} 
she whispered dramatically, and we both laughed. Julie's game was over very suddenly. ${ }^{32}$

Towards the end of the novel, envying Tom and his closeness to Julie, who seems more seductive to him in her new role as Tom's mother, ${ }^{33}$ Jack removes everything from his room and leaves it behind all empty to go nakedly to her room. First he sits on his brother's cot interrogating him about his feelings about their mother's death and the reason for his acting like a baby. Then he lies in it and thinks about his mother and staying there with Tom:

I liked it here in Tom's bed .... I felt like raising the cot's side and sitting all night. The last time I had slept here everything had been watched over and arranged. When I was four I had believed it was my mother who devised the dreams I had at night. If she asked me in the morning, as she sometimes did, what I had dreamt it was to hear if I could tell the truth. I gave up the cot to Sue long before that, when I was two, but lying in it now was familiar to me - its salty, clammy smell, the arrangement of the bars, an enveloping pleasure in being tenderly imprisoned. ${ }^{34}$

Stripped of his masculinity and all that reminds him of his father, Jack remembers his mother and her primacy and omnipotence in his childhood, especially her assumed control over his mind or rather his unconscious, which is less of an illusion than one may suppose. It is this primacy that accounts for his insistence on burying her in the basement as the only way he could think of for keeping her at home. Free from all the restraints of being an individual, he steps out of the symbolic order in an act of incest to return to and reunite with the mother, here replaced by Julie's body. ${ }^{35}$ Therefore, while his brother regresses into infanthood, Jack's regression, in spite of its lower visibility, is of a more grotesque nature. He regresses to a fetal stage signified by his slipping into incest and his return to the body of the

\footnotetext{
${ }^{32}$ McEwan, The Cement Garden, 84.

${ }^{33}$ Jack's envying his little brother highlights the very root of this fascination, which lies in Jack's unsatisfied incestuous desire for his mother.

${ }^{34}$ Ibid., 132.

35 "In quenching his lust for his sister, Jack consummates his desire for his mother, providing a suitably outrageous climax to the children's sustained assault on patriarchal law" (Ryan, Ian McEwan, 24).
} 
mother/Julie which coincides with the discovery of his mother's dead body by Derek. ${ }^{36}$

The last form of fall illustrated in these novels is murder. The significance of murder lies in the involvement of two persons or identities, and the conflict that exists between them. For the sake of brevity, my focus here is mainly on the victims. Nevertheless, there is no doubt that committing murder or resorting to violence is another form of fall that is in need of more attention. The murders depicted in the novels are of two different natures, a fact that is very significant in its own right. I am going to discuss The Comfort of Strangers and The Innocent here. Both novels are set outside England, with foreign characters playing central roles.

The first murder takes place in The Comfort of Strangers: Robert, a native macho with sadistic behavior kills a younger British tourist, Colin, who is a pro-feminist and intellectual man with left-wing views. Colin and his partner Mary have traveled to Robert's hometown for their holidays. ${ }^{37}$ They are not married and live separately, apparently because Mary has two children, while Colin does not like children at all. But the most unfortunate aspect of their relationship is Colin's subordinate and unequal status. Although they have long intellectual conversations on sexism and sexual politics with their impersonal detached way of talking, the way Colin behaves and is treated by Mary appears to be based on a feminist reversal of patriarchal views. The nature of their relationship is best reflected in their secret dreams, which are voiced after they learn about the sadomaso-

\footnotetext{
${ }^{36}$ Jack's and Julie's incestuous relationship, after all, underlines their father's inadequacy as far as their psychological development is concerned. It points to the absence of the prohibitive function of their super-egos. In his "The Ego and the Id" Freud writes, "the super-ego retains the character of the father, while the more powerful the Oedipus complex was and the more rapidly it succumbed to repression (under the influence of authority, religious teaching, schooling and reading), the stricter will be the domination of the super-ego over the ego later on - in the form of conscience or perhaps of an unconscious sense of guilt" (Sigmund Freud, "The Ego and the Id", in The Standard Edition of the Complete Psychological Works of Sigmund Freud, 1961, XIX, 34-35).

${ }^{37}$ Judith Seaboyer writes that the "unnamed yet unmistakable" city Colin and Mary are visiting is Venice, which "may be read as a figure for the Lacanian imaginary, but at the same time, it is a figure for the end of everything as it slowly loses the battle against time, pollution and rising water levels and returns to the Real of the Lagoon from which it was created" (Judith Seaboyer, "Sadism Demands a Story: Ian McEwan's The Comfort of Strangers", MFS: Modern Fiction Studies, XLV/4 [Winter 1999], 959, 961).
} 
chistic behavior of the Venetian couple. Mary reveals her secret desire for "hiring a surgeon to amputate Colin's arms and legs. She would keep him in a room in her house, and use him exclusively for sex, sometimes lending him out to friends." 38 She tends to objectify Colin as a mere male sex object, ${ }^{39}$ which goes against her own anti-sexist beliefs.

Therefore, the essence of Mary's dream is fulfilling a desire that apart from her self-centeredness, suggests her strong desire to deprive the opposite sex of its human capabilities in revenge for the objectification of women by patriarchy, no matter that she would be taking their revenge on her own pro-feminist partner. It seems that she has been partly able to fulfill this desire in reality: Colin admits his passiveness, which comes to light more in his own dream. He dreams of reducing Mary to the most passive sex object: however, the active part of his dream is not he himself, but rather a machine that has replaced him. In his dream, he is only there to watch the scene passively, as if he regards himself as inadequate, if not impotent. Therefore, it can be said that the voyeuristic nature of his dream has an undertone of emasculation. What is very striking here is the contrast that exists between his dream and that of Mary. In Mary's dream his maleness is taken for granted and the emphasis is on his mere sexual function, whereas the content of his own dream depicts a passive viewer who is involved in no sexual activity and therefore, his maleness is not relevant. It implies that Colin's uncertainty about his masculinity, which seems to stem from the dangerous equation of masculinity with hegemonic masculinity as the cornerstone of patriarchy, has resulted in the misrecognition of his identity as a gendered human being: he is either emasculated or objectified. When he, in his most private fantasy, replaces himself with a machine, it is no surprise that in Mary's dream he should appear as a sex object and become objectified by Robert's camera as well.

Colin's voyeuristic desire, which has also resulted from his passivity, has its own particular significance in the context of their relationship. Its significance is not limited to the realm of pleasure and sexual

\footnotetext{
${ }^{38}$ Ian McEwan, The Comfort of Strangers (1981), London: Vintage, 2006, 63.

39 This tendency to objectify Colin is also evident in the scene where Mary wakes up in Robert's apartment after a sleepless night and sits silently and looks at Colin's child-like or even woman-like naked body with a description that, as Seaboyer puts it, "could be of a classical sculpture" (Seaboyer, "Sadism Demands a Story", 969). See McEwan, The Comfort of Strangers, 39-40.
} 
satisfaction. Rather it draws our attention to the nature of Colin's masculine identity. As in The Cement Garden, there is a mirror scene in this novel, which testifies to Colin's obsession with Mary and accounts for his voyeurism:

Colin had brought the joint indoors for Mary, and she had refused it ... without turning in her seat. He lingered behind her, staring into the mirror with her, trying to catch her eye. But she looked straight ahead at herself and continued to brush her hair. He traced the line of her shoulder with his finger ... Colin turned to leave, and changed his mind. He cleared his throat and, rested his hand firmly on her shoulder ... but then, she was continuing to brush her hair, long after it was necessary, and it seemed she was waiting for Colin to leave ... and why? ... Miserably he ran his finger along the line of Mary's spine. She now held the handle of the brush in one hand and rested the bristles in the open palm of the other, and continued to stare ahead. Colin leaned forward and kissed her nape, and when she still did not acknowledge him, he crossed the room with a noisy sigh and returned to the balcony. ${ }^{40}$

It is evident that the function of the mirror in this scene is to direct Colin's eyes to Mary, who refuses to answer his gaze. Thus his voyeurism has its roots in his inability to see himself, as well as in his excessive insistence on satisfying Mary and her narcissism. He is so dependent on her that his identity becomes inseparable from hers. She is the only image he can (mis)recognize in the mirror. ${ }^{41}$ The centrality of seeing to his character is extended to his conception of desire and pleasure, hence the voyeurism he shares with Robert. At the end of the novel we see Colin bleeding and dying; but even then - although it seems that he is not able to see her anymore and is calling her name "like someone calling in a dark room" from her. This passage also explains why Mary should be forced to watch him die. In fact, by leaving her paralyzed in front of the dying Colin, the Venetian couple forces her to "look at" him for the first time in their relationship.

\footnotetext{
${ }^{40}$ McEwan, The Comfort of Strangers, 5.

41 "They often said they found it difficult to remember that the other person was a separate person. When they looked at each other they looked into a misted mirror .... It was precisely this collusion that made them vulnerable and sensitive to each other, easily hurt by the rediscovery that their needs and interests were distinct" (ibid., 7-8).

${ }^{42}$ Ibid., 96.
} 
Furthermore, a metaphor frequently used in the novel is "Colin is a child", which does not refer to the usual connotation of the word child. ${ }^{43}$ As an anti-sexist man, he has discarded all hegemonic notions of masculinity, but has not been able to replace it with an alternative version. That is why he has remained a child and has not grown up into a man. It is possible to see Colin and his passivity as an adult version of Jack and his confused identity. Even his unwillingness to father a child or to talk about it results from his being a child himself. $^{44}$ In fact, his ritualized murder by Robert as a self-appointed guardian of hegemonic masculinity suggests that Colin as a man who is not "identifiably male", has no place in this world. ${ }^{45}$ His dependence on his partner for realizing his own existence has made him too unfit to survive, especially in a world that, at least secretly, takes men like Robert as "real men".

While Colin is murdered by a native in a foreign country, Otto is murdered in his hometown by a foreigner in McEwan's fourth novel, The Innocent. Otto is one of those men who define masculinity as aggression, cruelty and toughness. Moreover, having been a soldier in the German army during the Second World War and now only a homeless drunk, he knows how to soften people's hearts to buy him beer by boasting about his bravery and sacrifice during the war. Although the miserable condition of his life is in sharp contrast to the culturally idealized form of masculinity, he tries to create a past image of himself that is in accordance with that ideal through inventing stories about his toughness and heroism in battle. At this he is successful, and even the police are impressed by his stories and regard him as a hero, though an unfortunate one.

Otto is the ex-husband of a German woman, Maria, who is regularly harassed by him and forced to pay for his expenses. She falls in

\footnotetext{
${ }^{43}$ See Charles Forceville, "The Metaphor 'Colin Is a Child' in Ian McEwan's, Harold Pinter's and Paul Schrader's The Comfort of Strangers", Metaphor and Symbol, XIV/3 (3rd quarter 1999), 179-98.

${ }^{44}$ Seaboyer asserts that in the description of Colin's nude body no genitals are mentioned, for he lies face down and therefore, they are not visible. This fact along with frequent references to his child-like beauty and feminine features produces an image of ambiguous sexuality (see Seaboyer, "Sadism Demands a Story", 969). But this ambiguity should not be interpreted as androgyny, since his passivity and his being the object of Mary's and Robert's gaze have obscured his masculine traits.

${ }^{45}$ John Haffenden, Novelists in Interview, London: Methuen, 1985, 165. Ian McEwan says in this interview: "Men's behavior is somehow invisible; we don't see ourselves as having a behavior that is identifiably male - we're just human."
} 
love with a younger British man, Leonard, who is an "innocent" English technician, working in Berlin during the Cold War. But even their relationship cannot stop Otto's harassments. He intrudes into Maria's apartment shortly after her official engagement to Leonard, to ask her to leave the apartment that he claims they have bought together. The confrontation that takes place afterwards goes against Leonard's pacifist principles, for as long as Otto has not attacked Maria, Leonard wants them to settle their problems without any form of aggression. However, what leads to Otto's murder in an act of self-defense is actually his attack on Leonard's manhood:

Hands were groping between his legs, and finding his testicles and closing round them. The grip that had been round Maria's throat. Burnt ochre blossomed in his vision and there was a scream. Pain was not a big enough word .... He would do anything, give anything to be free, or dead. ${ }^{46}$

Leonard loses control and savagely bites Otto's face, then crashing an iron rod down on his skull. Ironically, Leonard, the "innocent" murderer, has to resort to violence to defend and save his manhood while Otto's violence is integral to his notion of male identity. This domestic battle implies the conflict between different forms of masculinity in which hegemonic masculinity, finally, is the defeated one and the alternative masculinity should survive and develop. There is no doubt that the winner, as is evident in Leonard's case, has to go through immense suffering and judgments, because the very nature of this confrontation involves transgression and violation of sociocultural norms and therefore will be frowned at by society.

\section{Shall we die?}

So far I have focused on the representations of masculinity and its association with death, regression and murder as the three terrible falls of men as depicted in The Cement Garden, The Comfort of Strangers, The Child in Time and The Innocent. What comes next is an attempt to illustrate that these three fatal falls of male characters have a functional role in the problematization of masculinity in the post-patriarchal context of these four novels. For this purpose, answering a question asked in McEwan's oratorio, Or Shall We Die?, seems to be of great

${ }^{46}$ Ian McEwan, The Innocent (1990), London: Vintage, 2005, 145. 
significance. Although the oratorio is concerned with the turbulent state of a world threatened by nuclear wars and the increasing production of weapons of mass destruction, and the question "shall there be womanly times, or shall we die?" ${ }^{47}$ originally refers to the forking paths of the future of humanity, it seems that the dichotomy of "womanly times"/death proposed in this work has been extended in a more peculiar sense in McEwan's other novels and their approach to gender issues.

It is no exaggeration to claim that McEwan's novels in general, and these four novels in particular, are extended answers to this question. An overview of the representation of "womanly times" in The Cement Garden and The Comfort of Strangers indicates how "womanly times" - the matriarchal order in the former novel and the centrality of the pro-feminist protagonists in the latter one - tend to undermine masculinity and the gender identity of male characters, one with a matriarchal order and the other with pro-feminist protagonists. Both examples of "womanly times" provide pretexts for the emasculation of the male characters, either through regression (as in Jack and Tom's case) or through passiveness (as in Colin's case). But the correspondence of The Cement Garden and The Comfort of Strangers with the story of the primal herd puts an emphasis on the institution of matriarchy and its impact on male subjects, leading to the same conclusion.

In The Cement Garden, the father, whose death is semiconsciously wished by his son, dies and afterwards a matriarchal order with Julie as the head of the family develops. The new condition and the loss of the father make their construction of masculine identity for Jack and Tom more difficult than ever, as there is no father with whom the orphan sons can identify. Deprived of any model of masculinity, they become more and more dependent on Julie, their surrogate mother, who gives them the love and care they need, only in return for an unconditional obedience and absolute submission that can be acquired through regression only. In The Comfort of Strangers we see the image of the remorseful son, Robert, who had once wished his father's death. Now he regrets his patricidal feelings and his failure in living up to his father's expectations, especially his sterility and his inability to pass down his father's patriarchal values and views to the next generation. Regretting his oedipal conflict - his weakening desire

\footnotetext{
${ }^{47}$ Ian McEwan, Moving Abroad: Or Shall We Die and The Ploughman's Lunch, London: Pan Books, 1989, 23.
} 
for his mother and his rivalry with his father - Robert desperately needs to identify with his father.

However, this belated identification cannot be made easily. As his father is dead, the only way left to him is becoming a father himself, but he is sterile and can have no children. As a sterile man, he feels inadequate in his masculine identity. That is why his sadistic behavior begins when he learns about his problem. He has to detest women to reaffirm his masculinity and express his repentance. ${ }^{48} \mathrm{He}$ believes that his mission in life is to support and promote hegemonic masculinity and the superiority of men over women. Therefore, his misogyny does not only target women, but also those men who support them and criticize sexism. On the other hand, while his bisexuality tends to contradict heterosexuality and homophobia as "the bedrock of hegemonic masculinity", ${ }^{49}$ it paradoxically emphasizes his desire to gain control over women and men in his sexual activities. Among other things, this fact emphasizes his excessive need to control people around him, the extreme form of which is reflected in his murderous intentions towards his wife and then Colin, as the ultimate form of control that can be imagined is the ability to take others' lives. And Colin both is against the script of hegemonic masculinity and lacks all those masculine traits that in Robert's view a man should necessarily have.

Following the example of the orphan sons of the primal herd, and killing Colin as a sacrifice that he offers to the memory of his dead father, Robert tries to identify with his father to gain the masculine power and position he is deprived of. That is why Robert can be regarded not only as another falling man due to his firm clinging to hegemonic manhood, but also as another man that feels emasculated as a result of his sterility. Therefore, I suggest that these novels answer the question, "shall there be womanly times, or shall we die?" with death, rather than "womanly times". The cases represented in these novels speak of the inadequacy and insecurity caused by the ideal of hegemonic masculinity. It is responsible for the failure and frustration of both those male characters that have clung to it and those genderless figures with male bodies who, overshadowed by the increasing grasp of feminism, remain confused about their identity. Thus, their death is the essential first stage of the emergence of "filiarchy" and the birth of

\footnotetext{
${ }^{48}$ Freud, Totem and Taboo, 144.

${ }^{49}$ Donaldson, “What Is Hegemonic Masculinity?”, 644.
} 
a generation of men who, as the oratorio says, are "unafraid of gentleness", and can "have strength without aggression, without disgust". 50

Therefore, while The Cement Garden and The Comfort of Strangers shed light on the blight of stagnation, The Child in Time and The Innocent illustrate the difficulties of the rite of passage that is required for the initiation into filiarchal masculinity. In this context, The Child in Time is concerned with the growing insights of men who cannot be born again and develop a new identity, unless they die voluntarily and let their new identity rise from the ashes of either their genderlessness or their hegemonic masculine identity. In The Child in Time, Stephen has to go through a series of ordeals to gain the competence to give birth, both to his second child and to himself as a new man. It seems that what strengthens the link between his story and the story of masculinity told by the other three novels is the foiling function of his friend's character, Charles Darke who serves to depict the failure of hegemonic masculinity and its devastating influence.

This function gains more significance by focusing on the special script of hegemonic masculinity that he follows. As mentioned above, as a publisher and politician, he pursues control not only over women and other men but also over the very structure that validates such power relations. That is why his failing to gain control over his own life and existence seriously puts in question the validity of the ideal of hegemonic manhood and its ascendancy. At the same time, his story tends to sum up the stories of other falling men - Jack, Jack's father, Tom, Colin, Robert and Otto - with each of whom he shares similarities. ${ }^{51}$ This quality has worked to emphasize the contrast existing between him and Stephen, in order to draw our attention to the transformation undergone both by Stephen and the conceptualization of masculinity in McEwan's work. Stephen's radical change, which is due to his integration of childlike and feminine traits into his masculinity, appears as a turning point in the representation of masculinities. $\mathrm{He}$ is the first male character in McEwan's novels who experiences

\footnotetext{
${ }^{50}$ McEwan, Moving Abroad, 23.

${ }^{51}$ Similar to Robert's case, Charles' belief in the ideal of hegemonic masculinity is the outcome of his troubled childhood and of having a tyrannical father. As in the case of Jack's father, this belief has led to his excessive vulnerability and insecure male identity that, following Jack's and Tom's pattern, has resulted in his regression. His dependence on his wife resembles Colin's dependence on Mary. Finally, his dead body, that has dealt with hardship and should be carried by his friend, reminds one of Otto's body and how it becomes a problem in its own right.
} 
redemption and succeeds in introducing a masculine identity that is neither insecure nor affected by hegemonic masculinity.

While Stephen's transformation is closely linked to images of birth and delivery, Leonard's changes are associated with murder and dark womb-like images of the tunnel. He has to kill Otto in order to protect his fiancée, and more importantly, his own manhood. This experience and what he learns from his relationship with Maria, who is neither a dominant nor a submissive woman, provide him with new insights into his own identity. In both novels Stephen and Leonard eventually succeed in establishing a balanced relationship with female characters, in which the maternal role of these women, unlike in The Cement Garden and The Comfort of Strangers, does not lead to the regressive behavior or passiveness of male characters. The strength of the female characters, unlike in the earlier novels, does not leave the male characters in a disadvantaged status in their relationship.

Leonard Marnham in The Innocent, in contrast to Jack, Tom, Colin and Charles, is a young man who neither takes the path to regression (like Tom, Jack and Charles) nor remains a child (like Colin). Although at the outset, he is a grown-up innocent child who depends on an older German woman for his initiation into manhood, what happens in the course of the novel makes him a man whose identity is not flawed by hegemonic notions of masculinity. It should be noted that at one point, he tries to intensify his pleasure by defeating Maria's reluctance, a wild behavior that he mistakenly thinks is secretly wished by her. ${ }^{52}$ This misunderstanding has been caused by some wild fantasies that are influenced by movies and popular culture promoting an aggressive violent script of masculinity. However, Maria's reaction is strong enough to prove him wrong. Learning not to believe what he sees in movies, he begins to think and act independently from the norms set by popular culture and in doing so, he refuses to reproduce the image of a hegemonic man.

This is evident in the scene in which Leonard and Maria find Otto sleeping in their bedroom. Leonard, confused by the situation, wants him out of their apartment and at the same time does not wish to resort to the violence that Maria believes should be integral to his manliness:

"You want to throw him in the street, why don't you just do that? Do it! Why can't you just act? Why do you have to stand around and wait

\footnotetext{
${ }^{52}$ See McEwan, The Innocent, 77-84.
} 
for me to tell you what to do? You want to throw him out, you're a man, throw him out!"

His manliness again. He strode across the room and grabbed her by the front of her blouse. A button came off. He put his face up close to hers and shouted, "Because he's yours. You chose him, he was your husband, he got your key, he's your responsibility." His free hand was in a fist. She was frightened. ${ }^{53}$

Ironically, when Leonard wants to avoid behaving violently in accord with what is culturally expected from him as a man, he shows the very reaction that he tries to avoid. This ambivalence is created by the entangling web of the hegemonic script of masculinity, which has spread its influence so extensively, that even those who question its validity are affected by it. It becomes even more pronounced when Maria, who has been suffering from the outcome of this idealization of hegemonic masculinity in her own marital life with Otto, paradoxically provokes Leonard's aggression by insisting on the same notion of masculinity that demands men to be violent and aggressive. In this regard, Leonard's murder of Otto in self-defense should be considered as his attempt to defend the masculine identity that he has constructed, without referring to and reflecting the hegemonic masculinity the threat of which is constantly felt by alternative masculinities.

\section{Conclusion}

Ian McEwan's first four novels, The Cement Garden, The Comfort of Strangers, The Child in Time and The Innocent, can certainly be called "state-of-masculinity" novels. They do not only portray different images of masculinity in the post patriarchal era of our time, but also draw a connection between these images and the dark events taking place in these novels. As has been discussed, the male characters in McEwan's first four novels are entangled in the dark nets of death, regression and murder. These three morbid events, which frequently recur throughout the novels, are the fates of the male characters that are introduced in this article as "falling men". The fall of these male characters is essentially linked to and caused by the culturally idealized form of masculinity, known as hegemonic masculinity. This form of masculinity is recognized as the bedrock of patriarchy, both advocating and promoting the superiority of men and claiming to be the

${ }^{53}$ Ibid., 139 (emphasis added). 
only valid version of being a "real man". These novels demonstrate that both men who follow this ideal wholeheartedly, and men who have not chosen to or cannot follow it, inevitably go through these falls. Finally, the fourth novel, The Innocent, introduces a male character who is engaged in the process of learning how to be a man, without reproducing the hegemonic script of masculinity and without developing an insecure male identity. However, his resort to violence in his confrontation with hegemonic masculinity necessitates the presence of another male character that can perfectly epitomize filiarchal masculinity in the context of McEwan's novels.

This character appears in Saturday. McEwan's 2005 novel - which is in need of separate study in its own right - appears as the perfect example of "filiarchy". The novel is prologued by a passage from Herzog, in which the meaning of manhood is questioned. The protagonist, Henry Perowne, is a neurosurgeon whose city life adventure is supposed to answer the question about the meaning of being a man. He leads an easy life and is at peace with himself, with his family and with his world. He has been able to establish a successful relationship with his children and win their respect. His relationship with his wife is a symphony of mutual understanding, love and passion. But what makes him an epitome of the filiarchal man essentially lies in his treatment of hegemonic masculinity. The men representing hegemonic masculinity in Saturday are Baxter and his gang who have made a profession out of aggression. When Baxter and his mates intrude into Perowne's home, Perowne does not hesitate to defend himself and his family by knocking him unconscious. However, he is the one who performs an emergency operation on Baxter's brain afterwards. In his encounter with him, Perowne diagnoses Baxter's Huntington's disease. But, in spite of his wish, he cannot cure him of an illness he has inherited from his "father" and for which no treatment is known - a sad reality which symbolically represents that although hegemonic masculinity can be destructive, it is doomed and must eventually give way to alternative masculinities.

Today is Saturday, and therefore the fact that "filiarchy", like other socio-cultural orders, can be only a provisional stage should not be ignored. In the passage from patriarchy, we have reached "filiarchy" (in McEwan's fiction); what succeeds "filiarchy" in his novels, if it is succeeded by a new condition at all, should be an appropriate subject of further study. As the culmination of "filiarchy" has been represent- 
ed in Saturday, looking forward to the "Sunday" of McEwan's work and what it unfolds is of great significance. 


\title{
"WHAT IS A MAN?", OR THE REPRESENTATION of MASCUlinity In HaNif KUREIShi's SHORT FiCTION
}

\author{
BETTINA SCHÖTZ
}

\begin{abstract}
Based on Butler's concept of gender performativity and Connell's theory of the social construction of masculinity, this essay argues that Kureishi's "postethnic" short stories explore contemporary conceptualizations of masculinity: Love in a Blue Time (1997) depicts the disruption of masculine gender practices in the postfeminist era; Midnight All Day (1999) portrays the concomitant transformations of masculinity; The Body and Seven Stories (2002) emphasizes the performativity of masculine identity; and New Stories (2010) transcends traditional, patriarchal and hegemonic notions of masculinity, imagining alternative forms of masculine gender practice, such as the bisexual man or the "feminist house-husband". Since (gender) identity is as much a narrative artifice as literature, Kureishi's stories offer a specific savoir littéraire about the formation of masculine identity. Not only do they contribute to a better understanding of contemporary masculinities, but they also conceive of new forms of masculine identity.
\end{abstract}

Hanif Kureishi is considered one of the most eminent representatives of contemporary black British Literature by academia and public alike. ${ }^{1}$ Being the first widely acclaimed British-born writer of New

\footnotetext{
${ }^{1}$ I would like to thank Stefan Horlacher for this opportunity of discussing Hanif Kureishi's short fiction from a masculinity studies perspective. The essay has profited from the critical comments and constructive suggestions made by him and Ulrike Kohn.
} 
Commonwealth descent, Kureishi's particular, even "historic"2 importance is commonly attributed to both his pioneering role in the development of a specifically British Asian culture, and his articulation of the need for an inclusive and pluralistic ${ }^{3}$ understanding of British identity. ${ }^{4}$

Although such an acknowledgement of his impact on contemporary British culture appears to be highly justified, it is fraught with the concomitant danger of placing "the burden of being "representative" onto his work, ${ }^{5}$ expecting Kureishi to comply with the duty of a "minority" writer and "confine [himself] to questions of ethnicity". ${ }^{6}$ In fact, it appears to be mainly due to this expectation that his middle and recent works have been received less favorably than his early plays, his film scripts as well as the by now canonical novels, The Buddha of Suburbia (1990) and The Black Album (1995).

The short story collection introducing Kureishi's middle works, Love in a Blue Time (1997), has been taken to mark "something of a watershed". 7 Not only does it bespeak an increased concern with the short story form, ${ }^{8}$ but it also indicates a change in focus from the inherently political themes of ethnicity and class to the private difficul-

2 Bart Moore-Gilbert, Hanif Kureishi, Manchester: Manchester University Press, 2001, 190.

${ }^{3}$ In his autobiographical essay "The Rainbow Sign" (1986), Kureishi famously calls for "a new way of being British", arguing that "being British isn't what it was. Now it is a more complex thing, involving new elements. So there must be a fresh way of seeing Britain and the choices it faces" (Hanif Kureishi, "The Rainbow Sign", in Dreaming and Scheming: Reflections on Writing and Politics, London: Faber and Faber, 2002, 55).

${ }^{4}$ See Susie Thomas, Introduction, in Hanif Kureishi: A Reader's Guide to Essential Criticism, ed. Susie Thomas, Basingstoke: Palgrave Macmillan, 2005, 2.

${ }^{5}$ Kobena Mercer, Welcome to the Jungle: New Positions in Black Cultural Studies, New York: Routledge, 1994, 236.

${ }^{6}$ Thomas, Introduction, 4. Note Salman Rushdie's famous discussion of this problem in "Minority Literatures in a Multi-Cultural Society" (1987), which mentions Hanif Kureishi favorably (Salman Rushdie, "Minority Literatures in a Multi-Cultural Society", in Displaced Persons, eds Kirsten Holst Peterson and Anna Rutherford, Aarhus: Seklos, 1987).

${ }^{7}$ Moore-Gilbert, Hanif Kureishi, 152.

${ }^{8}$ Even though Kureishi's first collection of short stories was not published before 1997, Kureishi has been working in the genre since the mid-1980s (see Kenneth C. Kaleta, Hanif Kureishi: Postcolonial Storyteller, Austin: University of Texas, 1998, 148; Moore-Gilbert, Hanif Kureishi, 152). Once he saw an opportunity of publishing a collection, he began to work in the form more seriously between 1995 and 1996 (see Kaleta, Hanif Kureishi, 156). 
ties, worries and fears of predominantly white, middle-aged men. ${ }^{9}$ Since Kureishi's "postethnic" 10 middle works seem to render the postcolonial approach preferably applied to his writings less suitable, they have largely been ignored by critics. ${ }^{11}$ Additionally, the more Kureishi has appeared to divert his attention from issues of race or ethnicity and to refuse the burden of giving voice to the British Asian experience, the more severe and openly hostile criticism of his work has become. ${ }^{12}$ Jenny Turner's deprecating remark in The Independent,

${ }^{9}$ Ruvani Ranasinha is correct when she points out that this "shift from race to intimate relationships is", in fact, "not a new direction but a more explicit examination of Kureishi's latent preoccupations with diverse forms of masculinity and different kinds of relationship" (Ruvani Ranasinha, Hanif Kureishi, Tavistock: Northcote House, 2002, 19). On Kureishi's "private turn" see also ibid., 102-103; Moore-Gilbert, Hanif Kureishi, 152; Thomas, Hanif Kureishi, 164; Laurenz Volkmann, "Explorationen des Ichs: Hanif Kureishis post-ethnische Kurzgeschichten", in Self-Reflexivity in Literature, eds Werner Huber et al., Würzburg: Königshausen und Neumann, 2005, 138, 143; Bradley Buchanan, Hanif Kureishi, Basingstoke: Palgrave Macmillan, 2007, 69; and Rehana Ahmed, "Occluding Race in Selected Short Fiction by Hanif Kureishi", Wasafiri, XXIV/2 (May 2009), 28, 31. In fact, Kureishi's middle works in general and his short stories in particular illustrate McLeod's argument that contemporary black British writing is no longer exclusively concerned with black Britain. While McLeod therefore prefers the phrase "contemporary black writing of Britain" to Black British writing (John McLeod, "Extra Dimensions, New Routines: Contemporary Black Writing of Britain", Wasafiri, XXV/4 [November 2010], 46), I intend to convey this insight through not capitalizing "black" in "black British Literature".

${ }^{10}$ A number of critics have argued that Kureishi's middle works are "postethnic", borrowing the concept from the Berkeley historian David Hollinger (see Stein, Black British Literature: Novels of Transformation, Columbus: Ohio State University Press, 2004; Mark Stein, "Posed Ethnicity and the Postethnic: Hanif Kureishi's Novels", in English Literatures in International Contexts, eds Heinz Antor and Klaus Stierstorfer, Heidelberg: Winter, 2000; Volkmann, "Explorationen des Ichs"; and Sara Upstone, "Hanif Kureishi", in British Asian Fiction: Twenty-first-century Voices, Manchester: Manchester University Press, 2010).

${ }^{11}$ See Thomas, Hanif Kureishi, 5. The majority of academic criticism has focused on Kureishi's first two novels (see Buchanan, Hanif Kureishi, 147), which lend themselves most obviously to a postcolonial analysis and interpretation. With regard to Kureishi's short story ouvre it is noteworthy that Love in a Blue Time and, to a lesser extent, his second collection of short stories, Midnight All Day (1999), have been critically reviewed and have received some academic attention, while the short stories contained in The Body and Seven Stories (2002) as well as the New Stories have largely been ignored. All of the short stories mentioned are included in Kureishi's 2010 edition of Collected Stories (Hanif Kureishi, Collected Stories, London: Faber and Faber, 2010). If not indicated otherwise, references to any short story will be to this collection.

${ }^{12}$ See Buchanan, Hanif Kureishi, 147. 
"There are few sights in the world less appealing than the sort of men Kureishi writes about in this book [Love in a Blue Time]", ${ }^{13}$ exemplifies the kind of evaluative response his short fiction has elicited.

In what follows, I shall illustrate that Kureishi's short story æeuvre may be fruitfully approached from a masculinity studies perspective. While my analyses start from the premise that Kureishi's short stories are still concerned with questions of race, ethnicity and, ultimately, community,${ }^{14}$ they focus on the fact that a large proportion of the stories either implicitly or explicitly depict masculinities in crisis, or more precisely, the reasons for, ways of dealing with and effects of male characters' mid-life crises. While early stories "are riddled with instances of male depression, isolation and anxiety which are the consequence of failed negotiations of the demand for new forms of masculinity", ${ }^{15}$ later stories tend to emphasize the constructedness of gender identity and offer examples of new forms of masculinity, spanning from men eager to adapt to the demands of a relationship of equal power with their female partners to self-declared "feminist househusbands". ${ }^{16}$ Before my discussion of Kureishi's texts, I will make a few preliminary remarks about the underlying notion of masculine identity and the so-called "crisis of masculinity", and the specific knowledge that literature may convey about the formation of (gender) identity.

\section{Masculine identity and the crisis of the patriarchal gender order}

According to socio-psychological identity theory, identity may be defined as "the process of the construction and revision of selfconcepts that is constantly undertaken by the individual at the intersection of social interaction and individual biography". ${ }^{17}$ Rather than an essentialist substance, identity is thus considered a deliberate con-

\footnotetext{
13 Jenny Turner, "All about the babe they lack", The Independent, 13 April 1999: http://www.independent.co.uk/arts-entertainment/books/reviews/all-about-the-babethey-lack-737670.html.

${ }^{14}$ See Bettina Schötz, "The Exploration of Community in Hanif Kureishi's Short Fiction", Literary London Journal, X/2 (Autumn 2013): http://www.literarylondon. org/london-journal/autumn2013/schotz.html.

${ }^{15}$ Moore-Gilbert, Hanif Kureishi, 157.

${ }^{16}$ Kureishi, Collected Stories, 621.

${ }^{17}$ Stefan Glomb, Erinnerung und Identität im britischen Gegenwartsdrama, Tübingen: Gunter Narr, 1997, 27 (my translation).
} 
struction which the individual is forced to work at daily without the prospect of ever arriving at a final, fixed result. Although studies in the field of identity have usually refrained from specifying their findings with regard to gender, they have repeatedly emphasized the excessive demands the process of identity formation makes on the masculine and feminine - individual, underlining its concomitant propensity for identity crises. ${ }^{18}$

Accordingly, cultural anthropological findings suggest that all over the world masculine identity is conceived of as a problematic category which pressurizes the individual into confirming that it meets the high expectations the notion of masculinity raises and is, hence, worthy of being subsumed under it. To cultural anthropologists, masculinity is therefore inextricably linked with a fear of failure, ${ }^{19}$ which in turn may cause the masculine individual to suffer from an identity crisis.

In the field of gender studies, it is Judith Butler's influential concept of "gender performativity" 20 that offers a significant insight into feminine and masculine identity crises. According to Butler, gender is performative, that is produced through a ritualized repetition of "acts and gestures, articulated and enacted desires" 21 that comply with the

\footnotetext{
${ }^{18}$ See Thomas Luckmann, "Persönliche Identität, soziale Rolle und Rollendistanz", in Identität, eds Odo Marquard and Karlheinz Stierle, Munich: Wilhelm Fink, 1979, 293-313; Gertrud Nunner-Winkler, "Identitätskrise ohne Lösung: Wiederholungskrisen, Dauerkrise", in Identität: Entwicklungen psychologischer und soziologischer Forschung, eds Hans-Peter Frey and Karl Haußer, Stuttgart: Enke, 1987, 165-78; Lothar Krappmann, "Die Identitätsproblematik nach Erikson aus einer interaktionistischen Sicht", in Identitätsarbeit heute: Klassische und aktuelle Perspektiven der Identitätsforschung, eds Heiner Keupp and Renate Höfer, Frankfurt am Main: Suhrkamp, 1997, 66-92; Jürgen Straub, "Personale und kollektive Identität: Zur Analyse eines theoretischen Begriffs", in Identitäten: Erinnerung, Geschichte, Identität 3, eds Aleida Assmann and Heidrun Friese, Frankfurt am Main: Suhrkamp, 1998, 73-104; Heiner Keupp et al., Identitätskonstruktionen: Das Patchwork der Identitäten in der Spätmoderne, Reinbek bei Hamburg: Rowohlt, 1999.

${ }^{19}$ See Stefan Horlacher, "Überlegungen zur theoretischen Konzeption männlicher Identität aus kulturwissenschaftlicher Perspektive: Ein Forschungsüberblick mit exemplarischer Vertiefung", in "Wann ist die Frau eine Frau?" - "Wann ist der Mann ein Mann?": Konstruktionen von Geschlechtlichkeit von der Antike bis ins 21. Jahrhundert, ed. Stefan Horlacher, Würzburg: Königshausen und Neumann, 2010, 201203.

${ }^{20}$ Judith Butler, Bodies That Matter: On the Discursive Limits of "Sex", New York: Routledge, 1993, x.

${ }^{21}$ Judith Butler, Gender Trouble: Feminism and the Subversion of Identity, New York: Routledge, 1990, 136.
} 
gender norms prevalent in a heterosexual matrix. ${ }^{22}$ Butler defines performativity "as the reiterative and citational practice by which discourse produces the effects that it names". ${ }^{23}$ Moreover, she emphasizes that the notion of performativity applies to both "the effects of gender" and "the materiality of sex". ${ }^{24}$ Importantly, the citational repetition of gender norms opens up the possibility of modifying what is cited, and, thus, "proliferat[es] gender configurations outside the restricting frames of masculinist domination and compulsory heterosexuality". It ultimately implies that there is no "true or abiding masculinity or femininity":

If gender attributes and acts, the various ways in which a body shows or produces its cultural signification, are performative, then there is no preexisting identity by which an act or attribute might be measured; there would be no true or false, real or distorted acts of gender, and the postulation of a true gender identity would be revealed as a regulatory fiction. ${ }^{25}$

Consequently, Butler's notion of performativity entails that the masculine individual is, theoretically, free to perform its gender in an idiosyncratic way, a freedom that may easily pose a serious, overtaxing challenge and lead to a crisis of gender identity.

Within masculinity studies itself, Raewyn Connell's sociological analysis of masculinity proves extremely helpful in developing a thorough understanding of masculine crises. ${ }^{26}$ Theorizing gender as "a way of structuring social practice", ${ }^{27}$ Connell defines masculinity as "simultaneously a place in gender relations, the practices through which men and women engage that place in gender, and the effects of these practices in bodily experience, personality and culture". ${ }^{28}$ She stresses the processuality of masculinity, viewing the configuration of

\footnotetext{
${ }^{22}$ See Butler, Bodies That Matter, x; Hannelore Bublitz, Judith Butler zur Einführung, 3rd edn, Hamburg: Junius, 2010, 71-75.

${ }^{23}$ Butler, Bodies That Matter, 2.

${ }^{24}$ Ibid., x. See Bublitz, Judith Butler zur Einführung, 71, and especially 72.

${ }^{25}$ Butler, Gender Trouble, 141 (emphases added).

${ }^{26}$ The following remarks refer to Chapter Three of Connell's important study Masculinities, "The Social Organization of Masculinity" (R.W. Connell, Masculinities, Cambridge: Polity, 1995)

${ }^{27}$ Ibid., 75.

${ }^{28}$ Ibid., 71 .
} 
masculine practice as a "gender project", ${ }^{29}$ and points to its complex internal structure. ${ }^{30}$ Connell argues that one particular form of masculinity is "culturally exalted" at a specific time. This "hegemonic masculinity" constitutes "the configuration of gender practice which embodies the currently accepted answer to the problem of the legitimacy of patriarchy, which guarantees (or is taken to guarantee) the dominant position of men and the subordination of women". ${ }^{31}$ Importantly, Connell understands masculinity as "a configuration of practice within a system of gender relations". Accordingly, she points out that the term "crisis" cannot be applied to the category of masculinity, for: "As a theoretical term 'crisis' presupposes a coherent system of some kind." Therefore - and here I follow Connell rigorously - it is more accurate to "speak of the crisis of a gender order as a whole, and of its tendencies towards crisis", 32 and apply the terms "disruption" or "transformation" to the configuration of masculine practice. Hence, in order to analyze the construction of contemporary masculinities, it is necessary to examine the crisis tendencies of the prevalent gender order by scrutinizing the three kinds of gender relations in which men and women partake, that is power relations, production relations and relations of cathexis or emotional attachment.

Refuting assertions about an approaching "end of masculinity", 33 the above remarks appear to underpin Walter Erhart's argument that a notion of masculinity has emerged

... that regards masculinity as always and inevitably in crisis, a crisis which - according to Judith Butler - results from the continually performative and iterative status of the category of gender on the one hand, while it constitutes the symptom and effect of a rather coercive-

\footnotetext{
${ }^{29}$ Ibid., 72.

${ }^{30}$ Ibid., 73-74, 85.

${ }^{31}$ Ibid., 77. Connell classifies "the main patterns of masculinity in the current Western gender order" with regard to the relations among masculinities, distinguishing between a "hegemonic masculinity", a masculinity "subordinated" to the former, a masculinity "complicit" with the hegemonic one, and a pattern of "marginalized" masculinity (77-81).

${ }^{32}$ Ibid., 84.

${ }^{33}$ See John MacInnes, "The Crisis of Masculinity and the Politics of Identity", in The End of Masculinity: The Confusion of Sexual Genesis and Sexual Difference in Modern Society, Buckingham: Open University Press, 1998.
} 
ly and permanently imposed hegemonic masculinity that men find difficult to live up to on the other. ${ }^{34}$

\section{The significance of a specific savoir littéraire for masculine identity formation}

Since literature has the particular privilege not only to depict or criticize the existing extra-literary world, but also to create and explore new "realities", 35 it may be argued that Kureishi's short fiction goes beyond a mere representation of the crisis tendencies inherent in the contemporary British gender order, and their implications for a masculine configuration of gender practice. In fact, the stories additionally imagine new forms of masculinity in response to these crisis tendencies. In so doing, they offer a specific savoir littéraire ${ }^{36}$ in two respects: firstly, they contribute to a better understanding of masculine identity formation in the postfeminist era, and secondly, they conceive of and experiment with alternative forms of masculinity.

The unique potential of literature to provide such a thorough insight into the formation of gender identity results from the inextricable nexus between narration, identity and literature. ${ }^{37}$ Various recent studies emphasize that (gender) identity is produced through the act of narrating one's past with regard to one's prospective future - often in accordance with the narrative models a particular society provides at a certain historical moment, such as the "self-made man". ${ }^{38}$ Therefore,

${ }^{34}$ Quoted in Horlacher, "Überlegungen zur theoretischen Konzeption männlicher Identität", 196-97 (my translation).

${ }^{35}$ See Horlacher, "Literatur und die Überwindung der Dichotomien: Zum Verhältnis von Lebenswelt, Men's Studies, Gender Studies und savoir littéraire", in Literarische Gendertheorie: Eros und Gesellschaft bei Proust und Colette, eds Ursula Link-Heer et al., 2006, 46. See also Horlacher, Masculinities: Konzeptionen von Männlichkeit im Werk von Thomas Hardy und D.H. Lawrence, Tübingen: Narr, 2006, 117-18.

${ }^{36}$ A detailed discussion of savoir littéraire is provided in Horlacher, Masculinities, 109-19; and Horlacher, "Literatur und die Überwindung der Dichotomien".

${ }^{37}$ For an in-depth analysis of the connection between narration, identity formation and literature, see Horlacher, "Literatur und die Überwindung der Dichotomien", 48-51.

${ }^{38}$ See Norbert Meuter, Narrative Identität: Das Problem der personalen Identität im Anschlu $\beta$ an Ernst Tugendhat, Niklas Luhmann und Paul Ricoeur, Stuttgart: M und P Verlag für Wissenschaft und Forschung, 1995; Glomb, Erinnerung und Identität, 2325; Straub, "Personale und kollektive Identität", 93; Keupp et al., Identitätskonstruktionen, 56-59, 101-105, 269-70; Marion Gymnich, "Individuelle Identität und Erinnerung aus Sicht von Identitätstheorie und Gedächtnisforschung sowie als Gegenstand literarischer Inszenierung", in Literatur - Erinnerung - Identität: Theoriekonzeptionen und Fallstudien, eds Astrid Erll, Marion Gymnich and Ansgar Nünning, Trier: 
gender identity may be considered a linguistic construct, whose consistency and coherence result from the metaphorical act of writing that produces it. Gender identity is a narrative artifice and as such a cultural product similar to literature. ${ }^{39}$ Since literary texts not only create a fictional world, but also reflect on their contextualization and the linguistic constructedness of the illusions they produce, they are uniquely suited to reveal the rhetorical nature of (gender) identity. ${ }^{40}$ According to Stefan Horlacher, "the literary text is the place where an effect such as 'essentiality' or the illusion of a 'genuine femininity or masculinity,' a 'true personality core' and an 'authentic identity' is created", while it simultaneously depicts the production of these effects and illusions. ${ }^{41}$

In her essay "Beyond 'The Subject': Individuality in the Discursive Condition", the cultural theorist Elizabeth Deeds Ermarth addresses this interrelatedness between language, identity formation and literature, emphasizing the way in which literature may transcend the depiction of the extra-literary world and imagine new forms of being. ${ }^{42}$ In accordance with postmodernity's "turn toward language", Ermarth points out that "all systems operate like language" and are, hence, based on differential relationships. ${ }^{43}$ Therefore, she applies the Saussurean model of language as a differential system to the conceptualization of identity and concludes that personal identity may be understood metaphorically as an act of parole within the larger context of a langue.

Since "subjectivity always operates simultaneously in several discursive systems, whether their grammars and elements are verbal languages or other sign systems composed of gender relations, or fashion, or politics", ${ }^{44}$ Ermarth conceives of identity as "a kinetic subjectivityin-multicoded-process". ${ }^{45}$ This non-essentialist, mutable subjectivity

Wissenschaftlicher Verlag Trier, 2003, 38-39; and Dan P. MacAdams, "Narrative Identity", in Handbook of Identity Theory and Research, eds Seth J. Schwartz, Koen Luyckx and Vivian L. Vignoles, New York: Springer, 2011, I, 99-115.

${ }^{39}$ See Horlacher, "Literatur und die Überwindung der Dichotomien", 50.

${ }^{40}$ See ibid., 47-48.

${ }^{41}$ Ibid., 48 (my translation).

${ }^{42}$ See Elizabeth Deeds Ermarth, "Beyond 'The Subject': Individuality in the Discursive Condition”, New Literary History, XXXI/3 (Summer 2000), 405-19.

${ }^{43}$ Ibid., 409.

${ }^{44}$ Ibid., 410.

${ }^{45}$ Ibid., 412. 
is characterized by its sequence and its palimpsestuousness. The subject's singularity results from "the unique and unrepeatable sequence" of specifications made with regard to the multiple codes available in the discursive condition at any one moment. ${ }^{46}$ According to Ermarth, identity and gender identity are therefore not merely produced through the Butlerian citational performance of pre-existing, culture-specific narrative models or through the inverted reiteration of these models. ${ }^{47}$ Rather, gender identity is a sequence of metaphorical acts of parole. Consequently, "The arena of subjectivity and freedom lies in th[e] gap between the potential capacities of a differential code [langue] and any particular specification of it [parole]". ${ }^{48}$

Ermarth underpins the specific significance of literature when she argues: "If ... languages are above all systems, then literary texts are the most highly achieved specifications of those systems." Since literary language has the "particular power to turn convention aside, to reform the act of attention, to ground and limit the very formulation that is prior to any discussion at all", ${ }^{49}$ literary texts not only emphasize the freedom that results from the difference between langue and parole, but they may also illustrate new ways of using language and, hence, constructing realities such as gender identity. Accordingly, the diverse representations of masculinity in Kureishi's short fiction appear to "ope[n] new powers in our collective discursive potentials, in our power to revise social codes rather than merely to repeat the same old exclusions and emphases, the same, same, old stories over and over again". ${ }^{50}$

\section{The disruption of masculinity in Love in a Blue Time (1997)}

The male characters in Kureishi's first collection of short stories may roughly be divided into three groups: first and foremost, we encounter middle-aged men who are unhappily married, struggle to come to terms with their (impending) role as fathers and are either dissatisfied

\footnotetext{
${ }^{46}$ Ibid., 411-12.

${ }^{47}$ See Horlacher, "Literatur und die Überwindung der Dichotomien", 50-51.

${ }^{48}$ Ermarth, "Beyond 'The Subject"”, 411.

${ }^{49}$ Ibid., 406.

${ }^{50}$ Ibid., 415. With regard to the formation of a specific masculine identity, Peter F. Murphy accordingly argues that literature has played a significant role "in reinforcing the assumptions about masculinity and, at times, [in] helping to establish the norm of manhood" through offering "other images, other roles, other options for men and masculinity" (quoted in Stefan Horlacher's introductory article to this volume, p. 4).
} 
with their moderate professional success or suffer from the realization that they have pursued the wrong career. They question the life of commitments they have been leading so far. Second, there are a number of youngish and middle-aged protagonists or minor characters who have been living independent, antibourgeois vagabond lives but have come to crave settling down, founding a family and embarking on a career. Third, there is one instance of a previously married middle-aged man whose attempt to solve his mid-life crisis through divorcing his ex-wife has proved futile, exacerbating his sense of failure.

Following Connell, these stories may be taken to portray the disruptions of the configurations of masculine practice which result from the crisis tendencies inherent in the postfeminist gender order. MooreGilbert aptly remarks, albeit with regard to both Love in a Blue Time and Midnight All Day, that these short stories "testify to the pain and confusion entailed by the changing nature of gender relations in the contemporary period". 51

Concerning the first group of stories, ${ }^{52}$ this becomes especially apparent in "D'accord, Baby". In the heterodiegetic story, Billy's masculine identity appears to be severely unsettled by his wife Nicola, who may be argued to personify all the three kinds of change Connell has discerned in post-war gender relations.

In being employed at "a late-night TV discussion programme", ${ }^{53}$ Nicola epitomizes, first of all, women's increasing share in the workforce, rendering the traditional, patriarchal notion of the male breadwinner obsolete. ${ }^{54}$ She derives obvious satisfaction from her job, conscientiously preparing her interview of the ex-Maoist turned Catholic reactionary Vincent Ertel for two years and travelling back and forth between France and England. In the narrative, her professional success stands in stark contrast to Billy's mediocre career. Although he has won renown for directing commercials, he has failed to establish himself as a screenwriter.

\footnotetext{
${ }^{51}$ Moore-Gilbert, Hanif Kureishi, 156.

${ }^{52}$ Other male protagonists who belong into this group are: Eshan in "Blue, Blue Pictures of You", Roy in "In a Blue Time" and Parvez in "My Son the Fanatic". A slightly different case is Baxter in the surreal story "The Flies", for his sense of masculine identity is similarly disrupted but he is still "youngish" (Kureishi, Collected Stories, 182).

${ }^{53}$ Kureishi, Collected Stories, 51.

${ }^{54}$ See Connell, Masculinities, 85.
} 
The protagonist's position of inferiority is aggravated by his wife's infidelity, which demonstrates both a reversal of power relations and a change in relations of cathexis. ${ }^{55}$ Not only does Nicola follow her own sexual desires self-assuredly in an extramarital affair with Vincent, but she also refuses to offer her distressed husband an explanation for her absence when she eventually comes home. To his enquiries into how she has spent the night, she simply retorts: "What d'you think?" if conceding his wife's position of power within their marriage, Billy feels humiliated by Nicola but directs his aggression against his male rival Vincent. His acknowledgement of his wife's hegemonic position might also account for the striking void that the narrative focalized through Billy leaves in terms of the fatherhood of Nicola's unborn child.

Apart from his growing dissatisfaction with his chosen career and his wife's betrayal, his terror of becoming a father seems to disrupt Billy's sense of masculinity. Significantly, he appears to be aware of the specific savoir littéraire. He decides "not only to study the great books ... but to underline parts of and even to memorize certain passages", for they "surely represented the highest point to which man's thought had flown; they had to include guidance". ${ }^{57}$ In addition, the study of world literature provides him with the opportunity to prove himself as intellectually capable as his French rival, who threatens to force him into what Connell calls a relation of subordination. ${ }^{58}$ The middle-aged protagonist also intends to demonstrate his comparable virility by sleeping with Vincent's daughter Celestine. He is more than pleased to notice other men's lascivious stares at Celestine, for they suggest that he is even outdoing Vincent in this respect. He reflects: "This would not have happened with Nicola; only Vincent Ertel had taken an interest in her."

The short story takes a surprising and meaningful twist when young Celestine refuses to be used as a mere instrument of male revenge and an object of male desire. Not only does she transform an

\footnotetext{
${ }^{55}$ According to Connell, "Power relations show the most visible evidence of crisis tendencies" owing to "a historic collapse of the legitimacy of patriarchal power, and a global movement for the emancipation of women" (ibid., 84). On relations of cathexis see ibid., 74 .

${ }^{56}$ Kureishi, Collected Stories, 53.

${ }^{57}$ Ibid., 52.

${ }^{58}$ See Connell, Masculinities, 78-79.
} 
evening of simple "gratification" 59 into a romantic rendezvous involving a candlelight dinner and waltzing to Chopin, but she also illustrates that Billy really is an "Old man", ${ }^{60}$ who has not quite caught up with the changes the gender order has been undergoing.

Celestine rather than Billy decides about the course of their evening together, she is the one who leads their dance and their bed scene culminates in Celestine's seduction of Billy, being "on him vigorous$1 \mathrm{y}$ " 1 and making him do "everything she ask[s], for as long as she want[s]", including hitting her. ${ }^{62}$ She walks around her flat naked, while he freezes so much that he refuses to take off his scarf. She "looks into his eyes" domineeringly, when he only "glance[s] up" 63 or, at the end, attempts to leave "Without looking back". ${ }^{64}$ Finally, Celestine informs Billy that she hardly ever sees her father, thus rendering his attempt at revenge futile. The character of Celestine functions in the narrative to indicate vividly what Billy finds hard to accept with regard to his wife: the gender order has changed irrevocably and men are forced to adapt their notions of masculinity to the requirements of gender equality.

Having had his patriarchal world view seriously challenged, the protagonist concludes "that life could not be grasped but only lived" ${ }^{65}$ Nevertheless, this final emphasis on the activity of living one's life suggests that Billy will find a way out of his personal and professional dilemma. He will overcome the disruption of his configuration of masculine practice by fulfilling his "more "internal"" dreams, such as "travel[ing] overland to Burma while reading Proust". ${ }^{66}$

An integral part of the quandary in which the characters of the first group find themselves is their fear that they have taken on too many commitments too early - notably, to women who are actively reversing the traditional gender order - and are therefore "missing out on",

\footnotetext{
${ }^{59}$ Kureishi, Collected Stories, 54.

${ }^{60}$ Ibid., 59. Kureishi only added the phrase "old man" in the course of his revisions of the story draft, having "Middle age, not sexual revenge, ... becom[e] the story's theme" (Kaleta, Hanif Kureishi, 166).

${ }^{61}$ Kureishi, Collected Stories, 57.

${ }^{62}$ Ibid., 58 .

${ }^{63}$ Ibid., 57.

${ }^{64}$ Ibid., 58.

${ }^{65}$ Ibid., 59.

${ }^{66}$ Ibid., 56.
} 
what Billy terms, "life's meaner pleasures". ${ }^{67}$ The youngish and middle-aged characters belonging to the second group find themselves in the reverse situation. Late-twenties Brian's reflection in "Blue, Blue Pictures of You" summarizes their condition succinctly: "for a long time he had been part of everything new, living not for the present but for the next thing. He was beginning to see how little it had left him, and he was afraid." ${ }^{68}$ Like the autodiegetic narrator in the surreal story "The Tale of the Turd", these characters usually "dream ... of marriage and of putting the children to bed" ${ }^{69}$ However, they are frequently unable to transform their configurations of masculine practice in a way that enables them to enter a meaningful and lasting relationship of equal power with a woman. Their struggles to adapt to the contemporary gender order often fail due to their persisting immaturity and their concomitant difficulties in fulfilling "one's adult obligations". ${ }^{70}$

The protagonist in "Nightlight" represents the third category of male characters in Love in a Blue Time. The unnamed man in his late forties has recently entered an "inexplicable liaison" 71 with a considerably younger woman, whom he only meets on Wednesday nights to have sex with in his barely lit basement (note the metaphorical allusion to the Freudian $I d$ ). Although the focalizer of the heterodiegetic narrative falls deeply in love with the anonymous woman, he finds himself incapable of starting a conversation with her, for "he doesn't trust her, or any woman, not to let him down",72 and "he can't take any more disappointment". ${ }^{73}$

\footnotetext{
${ }^{67} \mathrm{Ibid} ., 54$.

${ }^{68} \mathrm{Ibid} ., \mathrm{106}$. In addition to Brian, the group comprises the unnamed narrator-focalizer in "The Tale of the Turd", young Rocco in "Lately", middle-aged Jimmy in "In a Blue Time", as well as Howard in "With Your Tongue down My Throat".

${ }^{69}$ Ibid., 131.

${ }^{70}$ Buchanan, Hanif Kureishi, 91. Buchanan argues more generally that the heroes of Love in a Blue Time, Midnight All Day and Intimacy are struggling to escape "from the torments of adulthood": "These books are sad, angry, despairing testaments to the difficulties that attend one's adult obligations, whether one accepts them fully or not." While this observation is certainly true for much of Kureishi's short fiction, it disregards that the male characters' fight with maturity is frequently interlinked with their struggle to come to terms with the changes that gender relations have been undergoing.

${ }^{71}$ Kureishi, Collected Stories, 135.

${ }^{72}$ Ibid., 136.

${ }^{73}$ Ibid., 137.
} 
He still suffers severely from the break-up of his marriage five years before, which apparently resulted from his inability to please his "liberated", successful wife without losing himself, his notion of masculine identity. Not without irony, the protagonist reflects:

For a while he did try to be the sort of man she might countenance. He wept at every opportunity, and communicated with animals wherever he found them. He tried not to raise his voice, though for her it was 'liberating' to get wild. Soon he didn't know who he was supposed to be. They both got lost. He dreaded going home. ${ }^{74}$

The fact that the woman for whose sake he eventually left his wife and children separated from the protagonist in turn "without explanation" ${ }^{, 75}$ suggests that the middle-aged character has been unable to transform his masculine identity to meet the needs of a self-assured female partner. While the protagonist holds women responsible for his unhappiness, the narrative therefore reveals that he is struggling with the requirements of a postfeminist gender order. However, his observation that London has become "A city of love vampires, turning from person to person, hunting the one who will make the difference", 76 signifies that the struggle to adapt to the demands of gender equality is a general rather than an individual phenomenon.

The protagonist's predicament is exacerbated by the impending insolvency of his business and the fact that his divorce has left him with nothing more than "a small flat, an old car and a shabby feeling". Having become the exact opposite of the "hegemonic man" he used to be "en route to somewhere called Success", ${ }^{77}$ his masculine identity is being reduced to the mere fact of his insatiable sexual drive. Strikingly, his enigmatic lover appears to share such an understanding of masculinity that equates masculine identity with virility, for she never addresses her sex partner by name and simply "calls him, when necessary, "man". 78

\footnotetext{
${ }^{74}$ Ibid., 136-37.

${ }^{75}$ Ibid., 135.

${ }^{76}$ Ibid., 138.

${ }^{77}$ See Connell, Masculinities, 77.

${ }^{78}$ Kureishi, Collected Stories, 135.
} 
However, the narrative ends on a positive note: to the extremely lonely ${ }^{79}$ protagonist, who is scared of "losing his hold" 80 and who harbors suicidal thoughts, the equally "wounded" and "hopeless" 81 anonymous woman in her early thirties comes to personify his new and "only hope", his metaphorical nightly light. She has him recognize that life is "worthwhile" 82 and "helps [him] kill the terrible fear he constantly bears that his romantic self has been crushed". ${ }^{83}$ In portraying a male character who has striven to solve the disruption of his masculine identity by divorcing his wife, that is actively changing his life, this short story fittingly leads on to the main concerns in Midnight All Day.

\section{The transformation of masculinity in Midnight All Day (1999)}

The majority of the stories collected in Midnight All Day focus on male protagonists who have sought to overcome the disruption of their masculine gender practices by leaving their wives and families, and entering relationships with, for the most part, younger women. They tend to consider this new start their last opportunity of achieving happiness - "the ordeal of their life" ${ }^{84}$ - and are acutely aware of their need to change their notions of masculinity. They contemplate "what men, and fathers, could become, having been released, as women were two decades earlier, from some of their conventional expectations". ${ }^{85}$ Applying Connell's terminology, these characters intend to effect a transformation of their masculinity in accordance with the post-war changes in gender relations of power, production and emotional attachment. The insight that women are adopting stronger, more powerful positions within the gender order is also reflected on the level of

\footnotetext{
79 The protagonist of "Nightlight" finds his loneliness all the more difficult to overcome since his ex-wife's recently developed depression makes him fear that he has a "toxic" effect on women $(135,136)$; however, this very thought grants him the satisfaction of believing that he, at least, possesses some power over women.

${ }^{80}$ Ibid., 134.

${ }^{81}$ Ibid., 137.

${ }^{82}$ Ibid., 140.

${ }^{83}$ Ibid., 139. Since "Nightlight" ends on a positive note, Liggins, Maunder and Robbins' statement that "the narrative is typical of Kureishi's portraits of the desires of middle-aged men, tired of their families but dissatisfied by what else remains", needs to be qualified (Emma Liggins, Andrew Maunder and Ruth Robbins, The British Short Story, Basingstoke: Palgrave Macmillan, 2011, 252).

${ }^{84}$ Kureishi, Collected Stories, 327.

${ }^{85}$ Ibid., 265.
} 
the discourse: in "Girl" and "Sucking Stones", we encounter the first two female protagonists in Kureishi's short fiction. ${ }^{86}$

Middle-aged Ian in the title story "Midnight All Day" may be taken to exemplify the depiction of masculinity in this collection. ${ }^{87}$ After six years of marriage, he has eventually left his wife Jane and their daughter for the sake of Marina, a woman in her late twenties who has made him "believe in romantic love" 88 and for whom he has yearned "for days and months and years". ${ }^{89}$ His decision to leave his family has been an extremely difficult one, one he has struggled with and continues to struggle with for some time. After their break-up, he finds himself unable to work in his film production company, taking tranquillizers, walking around London drunkenly and "talking only to the mad and derelict, people who did not know him". ${ }^{90}$ He suffers from the assumption that he will no longer be "the father he had wanted to be", that is, "Close, encouraging, generous, available". Thus, "he had failed without wanting to". 91

Ian is saved by his friend Anthony, who persuades him to spend some time with his pregnant girlfriend in Anthony's Parisian flat in order to find out whether they are actually able to live together. Here, in the City of Love, Ian resolves to make a conscious attempt at "be[ing] transformed from a man who could not do this with Jane, to a man who could do it with Marina", knowing that "the transformation had to be rapid, before he lost her". "If he could not get along with this woman", the protagonist reflects, "he couldn't get along with any of them and he was done for". ${ }^{92}$ Then, "not only had he broken up his

\footnotetext{
${ }^{86}$ While "With Your Tongue down My Throat" in Love in a Blue Time appears to be narrated by Nina, the story hinges on the final revelation that Howard has been pretending to speak with Nina's voice.

${ }^{87} \mathrm{He}$ is therefore representative of a group of characters comprising Morgan in "A Meeting, At Last", John in "Four Blue Chairs", Majid in "Girl", Alan in "Morning in the Bowl of Night", Marcia's unnamed husband in "Sucking Stones", Nick in "That Was Then", and, arguably, Archie in "Strangers When We Meet", who has not left his wife but realizes that he will lose her if he fails to "follow her" renewed, more selfassured personality (Kureishi, Collected Stories, 244).

${ }^{88}$ Ibid., 336.

${ }^{89}$ Ibid., 322.

${ }^{90}$ Ibid., 324.

${ }^{91}$ Ibid., 326.

${ }^{92}$ Ibid., 330.
} 
family for nothing, but he was left with nothing - nothing but himself". 93

The heterodiegetic narrative reveals that Ian's marriage with Jane has apparently failed because both partners used to demand an equally strong position in their relationship. Neither was ready to make any concessions to the other but fought to preserve their individual identity: "they had had to keep themselves apart, for fear of turning into someone they both disliked. He did not want to use her words; she did not want his opinions inside her." 94 That Ian used to be "afraid of her" ${ }^{95}$ suggests that his strong and self-confident wife even tended to overpower him. After they have separated, Jane reaffirms her selfassured, powerful position by stating that Ian "didn't try hard enough" to make their marriage work. ${ }^{96}$ In so doing, she challenges the traditional patriarchal view of women as "angels in the house", who are responsible for pleasing their husbands and providing them with a tidy, comfortable as well as peaceful home. Instead, she emphasizes that men are equally responsible for establishing a harmonious and lasting relationship.

Ian has to adapt his notion of masculinity quickly to these requirements of a relationship of equal power, rights and status because the story suggests that Marina is as strong a woman as Jane. She selfconfidently proclaims: "I've always supported myself", ${ }^{97}$ and knows that "she could get by without him". Marina even considers "returning to London, finding a small flat, getting a job, and bringing up the child alone". The protagonist contemplates: "Many women did that now; it seemed almost a matter of pride." $" 98$

However, Ian doubts that he will be able to transform his gender identity. He remembers that his mother used to regard him as too noisy and energetic: "His being alive at all seemed to alarm her." At the same time, he is aware of how deeply he has hurt Jane, who attempted to commit suicide after their marriage broke apart. Hence, Ian is worried that he might scare off Marina by "his own furies, ... his power, and ... the damage he believed that being a man might do". 99

${ }^{93}$ Ibid., 327.

${ }^{94}$ Ibid., 328.

${ }^{95}$ Ibid., 333.

${ }^{96}$ Ibid., 336.

${ }^{97}$ Ibid., 323.

${ }^{98}$ Ibid., 325.

${ }^{99}$ Ibid., 331. 
While Marina herself is anxious that Ian might be persuaded by others to end their relationship and return to his suicidal wife, the protagonist eventually finds motivation to try and "push against the world" 100 in art. When the couple visits the Musée d'Orsay, Ian is enthralled by a sculpture: "And yet, looking at Rodin's idea of Balzac now, he thought: rather a beast than a castrated angel." Ian takes the "forceful figure" of the French writer as an example and male role model, reflecting: "this was a man: someone who had taken action." 101 He decides to start anew and disregard the widely held expectation that a husband must stay with his wife in any circumstances. ${ }^{102}$ Longing "to be at home, in a house he liked, with a woman and children he liked", Ian seizes the opportunity to try and be happily "settled" for good. ${ }^{103}$ Thus, crucially, the protagonist is encouraged to transform his masculinity by means of the specific cultural knowledge offered by art in general and the visual arts in particular. ${ }^{104}$

\section{Emphasizing the constructedness and performativity of masculini- ty in The Body and Seven Stories (2002)}

The seven short stories collected alongside the novella "The Body" appear to combine the respective concerns of the two previous collections: not only do they portray what Connell calls the "disruption" of a male character's gender identity, but they also depict that this disruption may be overcome either by reaffirming the patriarchal notion of masculine identity or by transforming it. ${ }^{105}$

In these stories, the disruption of the middle-aged protagonists' configurations of masculine practice results from various factors: while in "Face to Face with You" Ed questions the relationship with his girlfriend Ann, Harry ("Goodbye, Mother"), the unnamed father in

\footnotetext{
${ }^{100}$ Ibid., 332.

${ }^{101}$ Ibid., 331.

${ }^{102}$ In response to the hostile reception of Intimacy, Kureishi has argued that the portrayal of "a man walking out on his partner" is still "a sacred taboo" (Kureishi quoted in Thomas, Hanif Kureishi, 134).

${ }^{103}$ Kureishi, Collected Stories, 326-27.

104 A remarkable example of a belief in a specific savoir littéraire can be found in "Morning in the Bowl of Night", where the divorced protagonist's hope for a happy future with his young, pregnant girlfriend is complemented by his reading of Charles Dickens' Great Expectations (see ibid., 356).

${ }^{105}$ Similarly, Connell has observed that the changed relations of power between men and women cause some men to revert to "cults of masculinity", while they induce others "to support feminist reforms" (Connell, Masculinities, 85).
} 
"Hullabaloo in the Tree" and Mal ("The Real Father") are struggling with the demands of their roles as fathers. Whereas Ed and Harry additionally doubt whether they have chosen suitable careers, Mal and Rick ("Remember This Moment, Remember Us") are dissatisfied with their moderate professional success. In "Straight", the protagonist Brett is even calling into question his entire lifestyle.

However, all male characters manage to solve their mid-life crises in the course of these stories. Some of them realize that they are "not so bad" 106 and merely lack hope as well as self-confidence (Ed, the father, Rick). Others become acutely aware of their need to "change" 107 their notions of masculinity. Therefore, they start "adjusting" 108 to the expectations of their female partners in order to save their relationships (Harry) or they begin to direct their attention from ephemeral to permanent pleasures (Brett). Living in relationships of equal power, rights and status, those protagonists who have children are increasingly concerned with the requirements of fatherhood (Harry, Rick, the father, Mal). They are striving to adapt to their bigger share in raising their children in a postfeminist society. In so doing, the male characters do not only question the best way of fatherhood, from authoritarian to permissive parent, but they also probe their relations of power with their children.

While Love in a Blue Time and Midnight All Day tend to explore notions of masculinity implicitly, The Body and Seven Stories conspicuously brings them to the fore. After fourteen-year-old Heather has run away from boarding school, one of the things she longs to discuss with her father in "Goodbye, Mother" is: "What is a man?" 109 While Harry contemplates his daughter's question, he comes to revise his initial materialistic understanding of masculinity: "Money was a way of measuring good things. The worth of a man had to be related to what he was able to earn." $110 \mathrm{He}$ eventually arrives at the conclusion that

... a man was someone who should know, who was supposed to know. Someone who knew what was going on, who had a vision of where

\footnotetext{
${ }^{106}$ Kureishi, Collected Stories, 505.

${ }^{107}$ See ibid., 540, 549, 551, 557.

${ }^{108}$ Ibid., 540.

${ }^{109}$ Ibid., 532.

${ }^{110}$ Ibid., 519.
} 
they were all heading, separately and as a family. Sanity was a great responsibility. ${ }^{111}$

The narrative reveals that Harry's wife Alexandra used to "run their lives, the house and the garden, with forethought, energy and precision", ${ }^{112}$ she has "kept them together and pushed them forward". ${ }^{113}$ Alexandra therefore seems to fit Harry's definition of a "man" better than he does. Hence, it may be argued that this short story highlights that masculinity - and, arguably, femininity - is a socio-culturally constructed and, following Butler, performative category rather than a biological given. In pointing out that women may possess masculine traits, the narrative indicates that women's performance of their gender identity is independent from their biological differences from men. The story refutes traditional stereotypes of gender roles and challenges women's inferior position in gender relations of power, production and cathexis. Therefore, "Goodbye, Mother" is one of many stories which may serve to invalidate the recurrent claim that Kureishi's middle works are misogynistic. ${ }^{114}$

The protagonist in "Hullabaloo in the Tree" appears to be an instructive example of the collection's increased emphasis on both fatherhood and the performativity of masculinity. The middle-aged man is primarily, and in fact exclusively, defined by his father role. He is referred to as "father" by the heterodiegetic narrator, his three sons as well as his young fiancée call him "Daddy", and he ultimately speaks of himself as "Daddy". Additionally, the protagonist remains unnamed throughout the narrative and thus lacks an individual identity apart from that relative to his children. Taking into consideration that ever since the Victorian Age it used to be women who were solely defined by their roles in relation to (male) others as daughters, wives and/or mothers, the protagonist may be argued to epitomize the changes gender relations have undergone in the wake of feminism.

The story sets in as the father and his seven-year-old twins of his first marriage as well as the two-year-old son of his present relationship leave the playground one Sunday morning and cross the park, heading for a café. Since he delights in the fact that all of his sons

111 Ibid., 539.

112 Ibid., 530.

${ }^{113}$ Ibid., 531.

${ }^{114}$ See Thomas, Hanif Kureishi, 4. 
admire him and have even taken to imitating him, the protagonist intends to impress his children by kicking their blue ball as high as he can: "What were fathers for if not to kick balls high into the air while their sons leaned back, exclaiming, 'Wow, you've nearly broken through the clouds! How do you do that, Daddy?" "115 However, the father immediately experiences the difficulties of living up to his own expectations and that of his sons: he initially miskicks the ball, and then catapults it into the very top of a tree when he does hit it while himself falling over into the mud.

After his first attempts at getting the ball down by throwing things at it have failed, the father begins to continue their walk, wanting to have a cup of coffee at the café and planning to replace the cheap plastic ball with a new one. However, the protagonist is instantly halted by the following thought: "Did he, though, want his sons to see him as the sort of man to kick balls into trees and stroll away?" " He "grit[s] his teeth", ${ }^{117}$ overcomes his fear of "any act of physical bravery" and climbs into the tree, where he feels insecure, anxious and "a slip away from hospital and years of pain". ${ }^{118}$ When a nine-year-old girl climbs higher into the tree than he does and he has to watch her produce "a tremendous shaking, far greater than his own", the father seizes the opportunity to get down and bring himself into a position where he may "pick up the ball when the girl knocked it down". ${ }^{119}$ However, it takes another man who has noticed the group of bystanders around the tree to climb up, vigorously shake the tree and finally get the ball down by poking at it with a long branch.

This seemingly trivial and highly comic episode may be taken to teach the protagonist an important lesson in two respects. The son of an Indian immigrant has questioned his permissive behavior towards his sons ever since he has met an Indian friend in the park, "who'd been shocked by the disrespect and indiscipline of the father's children" and who has deprecatingly remarked: "I know we live here now, but you have let them become Western, in the worst way!" ${ }^{20}$ However, when the protagonist receives help from another man, he is re-

\footnotetext{
${ }^{115}$ Kureishi, Collected Stories, 486.

${ }^{116}$ Ibid., 488.

${ }^{117}$ Ibid., 490.

${ }^{118}$ Ibid., 489.

${ }^{119}$ Ibid., 490.

${ }^{120}$ Ibid., 485.
} 
minded of the way in which his Papa used to be helped with his car by his neighbors. Thus, he realizes that his permissive style of parenting is not only closely linked with his apparent adaptation to the British and arguably Western way of life, which has him consider himself black British rather than Indian, ${ }^{121}$ but it is also connected with his personal experience of a father capable of conceding weaknesses and accepting help from others. The tree episode has the father become aware of himself and his attitudes towards fatherhood. He concludes:

Much as he might want to, he couldn't bring up his kids by strict rules or a system. He could only do it, as people seemed to do most things in the end, according to the way he was, the way he lived in the world, as an example and guide. This was harder than pretending to be an authority, but more true. ${ }^{122}$

Moreover, the events appear to cause the protagonist to realize that there is no one way of performing a masculine identity. Hitherto, his masculinity has been disrupted by "a kind of exhausting chaos and a struggle, in his mind, to work out what he should be doing, and who he had to be to satisfy others". ${ }^{123}$ However, the successful retrieval of the ball eases his worries and alleviates his fears. It assures the father that he will achieve his objectives and please others if he stays true to himself and "the way he was".

Significantly, the story presents both depicted performances of masculinity as equally worthwhile and effective. The protagonist seems to be the mere opposite of the traditional, patriarchal notion of masculinity. The narrative informs us that he likes eating buttered croissants and drinking "semi-skimmed decaf latte". He is surprised when his children listen to him, and he is bad at practical tasks. Nevertheless, he reaches his goal of retrieving his sons' ball because he is able to accept help from others irrespective of their gender or age.

While the middle-aged man who manages to get the ball does not look the part of the tough, brave and effective male achiever either, he proves "surprisingly strong" and clever. ${ }^{124}$ The father of two girls

\footnotetext{
121 Thus, this short story illustrates how closely issues of masculinity, or gender in general, are interlinked with those of ethnicity (see Connell, "The Social Organization of Masculinity", 75-76).

${ }^{122}$ Kureishi, Collected Stories, 492.

${ }^{123}$ Ibid., 486.

${ }^{124}$ Ibid., 491.
} 
looks unfit and wears thick glasses, a pink shirt and office shoes. Yet, he proclaims self-confidently: "Don't worry, I'm here", ${ }^{125}$ and in a stereotypically masculine manner he "spat in his palms and rubbed them together" 126 before he climbs the tree and gets the ball.

Although "the helpful man" jumps from the tree "with his arms raised in triumph", ${ }^{127}$ adopting a typical male winner's pose, he neither praises himself nor is he praised by any of the other characters as the hero of the story. Instead, both men happily shake hands. In so doing, the office worker appears to thank the father for such a physical adventure, while the latter expresses his gratitude for the former's help in getting their ball. Their handshake seems to symbolize their equal status in contrast to what Connell calls a male relation of "hegemony" and "subordination". ${ }^{128}$ As a result, it may be argued that the tree episode signifies metaphorically that masculinity is performative, and that each man's notion of masculine identity as well as their concomitant conceptions of fatherhood are therefore of equal value.

\section{The depiction of new forms of masculinity in New Stories (2010)}

Whereas masculinity is either the main or a subsidiary subject matter in the overwhelming majority of the short stories collected in Love in a Blue Time, Midnight All Day and The Body and Seven Stories, the short fiction first published as New Stories in Kureishi's Collected Stories contains three out of eight stories that focus on other themes. "The Dogs" thematizes killer dogs, while "Weddings and Beheadings" is concerned with life in a totalitarian regime at war, and "The Assault" deals with the cruelty of putting another person under psychological pressure. Hence, the writer's most recent short fiction demonstrates an increasing interest in subjects other than ethnicity and masculinity. Remarkably, in two of these three stories the protagonists are women.

Those short stories that are concerned with masculinity portray older characters than the earlier collections. The male protagonists are no longer in their thirties or early forties but are forty-five, fifty or in their mid-fifties. While all of these characters go through a mid-life crisis, Jake's ("A Terrible Story") and Mike's ("The Decline of the

125 Ibid., 490.

${ }^{126}$ Ibid., 491.

${ }^{127}$ Ibid., 492.

${ }^{128}$ See Connell, Masculinities, 77-79. 
West") distress results from external causes rather than a self-critical "sense of wasted purpose and many wrong moves made". ${ }^{129}$ Jake is left by his wife for the sake of another man and Mike's suffering is exacerbated by the global financial crisis.

Although most protagonists come to realize how they may solve their predicaments, their solutions are far more pragmatic than those of earlier characters. Jake struggles to accept that he has lost "the woman [he] still love[s] and [has] wanted more than any other", 130 while he sues for custody of their two daughters. In "Long Ago Yesterday", the homosexual theatre and film producer Billy comes to bear his inability to have children of his own, but he decides to abandon his parents' passive way of life and actively strives to fulfil his dream of becoming an artist. Max, the protagonist in "Maggie", learns to live with his past decision to sublimate his personal desires for the sake of a less self-fulfilling and more conventional, apolitical life of a husband and father; he appreciates the value of having a family and intends to find meaning in art: "Writing poetry, drawing, learning to paint." 131 In the short story "Phillip", Fred considers his life "wretched", ${ }^{132}$ but he discovers "even now I am capable still of rebelling against myself", ${ }^{133}$ and he contemplates "go[ing] back to serious scribbling". ${ }^{134}$ Finally, Mike puts up with his sudden unemployment and his unhappy family life, solving his crisis through stoicism or, arguably, failing to resolve it satisfactorily. ${ }^{135}$

Strikingly, all heterosexual protagonists live or have lived in relationships with strong women who seem to epitomize the recent changes in the gender order. Following Connell, Jake's wife Julie may be taken to personify the way in which gender relations of cathexis have changed. She is a rare example in Kureishi's short fiction of a woman who asserts her right to follow her own sexual desires freely by having

${ }^{129}$ Kureishi, Collected Stories, 600, the quote is from the story "Long Ago Yesterday".

${ }^{130}$ Ibid., 668.

${ }^{131}$ Ibid., 519.

132 Ibid., 643.

${ }^{133}$ Ibid., 650.

${ }^{134}$ Ibid., 649.

${ }^{135}$ As the protagonists age, memory and the role of the past for the present become vital concerns. In fact, Billy, Max and Fred solve their dilemmas by being confronted with important figures from their past who enable them both to come to terms with past experiences that continue to trouble them, and to gain a better understanding of themselves at present. 
an extramarital affair and eventually separating from her husband. ${ }^{136}$ Furthermore, Max and Fred are "house-husbands" 137 of highly successful women. While Max's wife, "the glamorous Lucy", ${ }^{138}$ is making a name for herself as a film producer, Fred's unnamed wife is a property investor, who has the couple succeed at property to such an extent that Fred "never ... [has] to do another honest day's work". ${ }^{139}$ Hence, in both couples the production relations characteristic of a patriarchal society are inverted completely: the men perform the traditionally feminine task of caring for house and children, whereas the women act as the families' breadwinners.

While previous Kureishi stories have hinted at several characters' homosexual inclinations, Billy is the first explicitly homosexual protagonist. Thus, he personifies another change Connell discerns in relations of emotional attachment - that "lesbian and gay sexuality" have developed into "a public alternative within the heterosexual order". ${ }^{140}$ In addition, the eponymous character in "Phillip" is the first bisexual character in Kureishi's short fiction, signifying yet a further change in gender relations of cathexis. ${ }^{141}$

The depicted changes in the gender order are frequently concomitant with the male characters' awareness that gender identity is performative. Thus, various protagonists deliberately attempt to bend stereotypical gender roles. Although earlier stories have already portrayed male characters who used to wear make-up and high heels during their adolescence ("That Was Then" in Midnight All Day) or who are willing to support their female partners by fulfilling household duties, these most recent stories explicitly emphasize reversals of gender roles and attempts at transcending gender barriers.

Max is a self-declared "feminist house-husband", who "had "run the house' and attended to the children while his wife established herself as a producer". To his friend Maggie, he boasts: "All I do is sup-

\footnotetext{
${ }^{136}$ According to Connell, women have come to claim "sexual pleasure and control of their own bodies, which has affected heterosexual practice as well as homosexual" (Masculinities, 85).

${ }^{137}$ Kureishi, Collected Stories, 621.

${ }^{138}$ Ibid., 626.

139 Ibid., 647.

${ }^{140}$ Connell, Masculinities, 85.

${ }^{141}$ Since bisexuality is already a main concern of Kureishi's debut novel, Buddha of Suburbia, this development is markedly late.
} 
port women." 142 While Fred used to experiment with a "“feminine' position" in his sexual relationship with Phillip, ${ }^{143}$ he presently defines himself exclusively through his father role. "I was beginning to wonder", the autodiegetic narrator reflects, "that if I wasn't a father, what in fact was I?". ${ }^{144}$ Billy remembers how he used to replace his mother, who was overtaxed by "the uproar and demands of two boys" and "died herself, inside". ${ }^{145}$ He has performed the role of "Dad's girl, his servant, his worshipper" handmaiden" 147 ever since. Having come out as gay in his youth, he also used to apply make-up before catching the train to London. However progressive the characters may seem in this respect, the postfeminist gender order has also deeply disrupted their notions of masculinity. Two out of five protagonists are in therapy (Billy, Max) and a third is being advised to see a psychotherapist (Jake). ${ }^{148}$

While Kureishi's middle works have repeatedly been criticized for their alleged shift in attention from political to personal issues, the explicit critique of materialism, consumerism and capitalism inherent in his latest short stories amply demonstrates how unjustified such accusations have been and continue to be. This is especially apparent in "The Decline of the West", a direct response to the credit crunch. The story provides an instructive example of the new forms of masculinity that Kureishi's latest short fiction tends to portray and relates these emergent notions of masculinity not only to the requirements of a changing gender order but also to other societal developments.

After he has been made redundant from his job in corporate finance unexpectedly, Mike comes home early to find his fifteen-yearold son Tom behave disrespectfully towards him, his eleven-year-old son Billy patronize him and his wife Imogen treat him indifferently, while all of them ask for further material possessions. Thus, the fortyfive-year-old protagonist realizes that his actual wife and children are in stark contrast to the dream vision of his family. During "the most

\footnotetext{
${ }^{142}$ Kureishi, Collected Stories, 621.

${ }^{143}$ Ibid., 640.

${ }^{144}$ Ibid., 643.

145 Ibid., 609.

${ }^{146}$ Ibid., 607.

${ }^{147}$ Ibid., 608.

${ }^{148}$ This is in stark contrast to Harry's initially strong hostility towards his wife's interest in hypnotherapy in the previous collection of short stories ("Goodbye, Mother").
} 
desolate" tube journey of his life "he'd been looking forward to opening the door into the warm hall, hearing the voices of his wife and children, and seeing the cat come down the stairs to rub itself against him". ${ }^{149}$ When a fuse blows and the entire house on the prosperous outskirts of London goes dark and silent, disillusioned and heavily indebted Mike contemplates "how tempting it was - suddenly would be best - to die!". ${ }^{150}$ However, he pulls the lever, metaphorically starting "their awful world ... up once more with its humming and vibrating". 151

Significantly, the protagonist's suicidal thoughts appear to be not only connected to the disruption of patriarchal notions of masculinity but also to the global financial crash. In fact, it may be argued that "The Decline of the West" is Kureishi's first short story that explicitly emphasizes the significance of the socio-historical context for the formation of (gender) identity.

While the heterodiegetic narrator informs us that "Mike and his wife considered themselves to be equals", ${ }^{152}$ this observation only holds true with regard to what Connell terms power relations and relations of cathexis. Although Imogen works for a charity three days a week and is already at home when her husband returns, she does not leave any of the family's organic dinner over for Mike but expects him to live off the frozen meals he finds inedible. Furthermore, her powerful position in their marriage becomes obvious when she orders her husband to clean not only his plate but also those of his entire family. Since she generally refuses to do any of the household duties and their children do not carry out the chores either, the family employs a pregnant Bulgarian immigrant as a cleaner, thereby establishing their Western position of hegemony.

Moreover, Mike and Imogen's relationship is emotionally detached. Imogen is insensitive to her husband's distress and apparently unaware of the fact that he has come home earlier than usual. It is only after having had a few drinks, taking a bath and helping Tom with his homework that she considers listening to the news Mike wants to tell her. She asks, "Is it attention you're after?", ${ }^{153}$ objectifies him by

${ }^{149}$ Kureishi, Collected Stories, 651.

${ }^{150}$ Ibid., 655.

${ }^{151}$ Ibid., 656.

${ }^{152}$ Ibid., 658.

${ }^{153}$ Ibid., 659. 
briefly stroking his head like that of a pet, and insists on her need to relax before they may have a conversation. Hence, Imogen seems to misunderstand gender equality by leading a self-absorbed life, indifferent to her partner. Furthermore, by calling her husband "mad" and a "ridiculous, foolish man" in front of their children, she undermines his position of authority, and arguably power, with regard to their sons and inspires them to treat their father as callously and disrespectfully as she does.

Concerning gender relations of production, however, Mike and Imogen's marriage follows the traditional patriarchal pattern. He performs the role of the breadwinner, whilst she acts as "the family conscience" through her poorly paid work for a charity. The narrative focalized through Mike informs us accordingly: "Unlike some of his friends, he didn't want a woman who worked as hard as him, a woman who was never at home." 154 The protagonist's insistence on traditional production relations suggests the extent to which he suffers from his loss of patriarchal hegemony in every other respect. However, Imogen has "begun to feel "unfulfilled" by her subordinate economic position and she has been "planning to train as a therapist". In so doing, she threatens to invert this type of gender relations within their marriage, too, and challenges her husband's position as the family's only - and, in fact, insufficient - breadwinner: "'Once I'm earning,' she argued, 'this whole family will be much better off." "155 Consequently, Mike will soon be left in a position of power over no one but himself, a power that he has recently proven by giving up smoking. ${ }^{156}$

Although it has become obvious that the disruption of Mike's configuration of masculine practice is directly linked to the reversal of patriarchal gender relations that his self-confident and strong-willed wife demands, it may be argued that it is also triggered off, or at least exacerbated, by the credit crunch. When the protagonist loses his position as the head of department and is forced "to execute the employees he had engaged and, in two weeks' time, pack up and remove himself", ${ }^{157}$ he comes to question both the financial system and the capitalist economy on which it is based. Mike reflects on a remark an ac-

${ }^{154}$ Ibid., 657.

${ }^{155}$ Ibid., 658.

${ }^{156}$ Ibid., 651.

${ }^{157}$ Ibid., 653. 
quainted sculptor has made about the "fundamentalist" nature of his profession and the "cult of money" he is serving, ${ }^{158}$ and he concludes:

Since capitalism was cracking under the weight of its contradictions as the Marxists had predicted - neither the communists or Islamists being responsible for its collapse - the family would have to find a smaller place, sharing the household duties like everyone else. If there was no comfort, what then were the consolations of capitalism? If there was no moral accretion, nor any next life, why would anyone support it? ${ }^{159}$

A more implicit critique of capitalism seems to be inherent in the fact that Mike's twelve-hour working days have alienated him from his family (and vice versa), as well as himself. Not only is he "restless"160 and, as Imogen insists, in need of a hobby, but he also fails to think of anything else that he could do for a living apart from corporate financing. In addition, the short story appears to level a more general criticism at materialism. The depiction of a family that equals an assembly of selfish human beings, each following their own interests and no one genuinely caring for the other, indicates the way in which materialism inspires "vanity and greed", ${ }^{161}$ but effaces immaterial, ideal as well as ethical values and meaningful emotional bonds. Having become unable to provide his family with the "continuous material improvement" they ask for, ${ }^{162}$ Mike realizes that in the eyes of his wife and sons he has become a mere "Delivery Man". They regard him as someone who earns money in order to fulfill their wishes rather than an unconditionally loved husband and father. ${ }^{163}$ This decline in sincere family relationships, respectable behavior towards others and ethical principles becomes strikingly apparent when Tom, who "for fun ... sometimes put his father in a headlock and pulled him round the room", shouts at Mike: "Leave me alone! Don't ever talk to me again! ... Fuck off, evil old man, just die!" 164 The loss of ethical values and decrease in serious, long-lasting relationships is also observable outside the family circle: not only does the family's neighborhood exploit skilled

\footnotetext{
${ }^{158}$ Ibid., 654.

${ }^{159}$ Ibid., 658-59.

${ }^{160}$ Ibid., 651.

161 Ibid., 652.

162 Ibid., 655.

${ }^{163}$ Ibid., 657.

${ }^{164}$ Ibid., 656.
} 
Polish laborers as cheap workforce, ${ }^{165}$ but the unemployed Mike also predicts that his prosperous friends and acquaintances will shun him now that he is unable to maintain the family's high standard of living, rendering him "a sort of "disappeared"". ${ }^{166}$

Thus, this short story seems to be a highly perceptive analysis of contemporary British and, ultimately, Western society concerning not only the shift from a patriarchal society to one defined by gender equality, but also the effects of an excessive belief in materialism. Both social developments result in a severe disruption of the protagonist's notion of masculinity. However, Mike is unable to transform his gender identity in a way that may satisfy him and solves his quandary by stoically putting up with the role of the "Delivery Man" he has been allocated in a materialistic society.

After "My Son the Fanatic" (1994) ${ }^{167}$ this story may once again prove Kureishi's literary prescience. Read against the background of the violent riots in various English cities in August 2011, "The Decline of the West" appears to be a far-sighted warning of the effects that excessive materialism and consumerism may have on people's values and their relationships with others, especially with regard to the generation growing up under the aegis of material possessions. Whereas Mike's involuntary transformation into a "Delivery Man" signals the decline in immaterial values and emotional bonds, Tom personifies the young generation's aggression and violence that results from such a lack of ethical principles and meaningful relationships. Although the protagonist's father used to stress Mike's good fortune of having grown up without the horrible experience of war, arguing that he is "one who escaped the twentieth century", the narrator meaningfully adds: "But not the twenty-first." 168

\section{Conclusion}

Hanif Kureishi's short stories are indicative of the same interest in "the increasingly popular genre of "male testimonial"" that has already

\footnotetext{
165 Ibid., 652.

${ }^{166}$ Ibid., 655.

${ }^{167}$ First published in The New Yorker in 1994, "My Son the Fanatic" is arguably one of Kureishi's most anthologized short stories because it wisely predicts the danger of Islamic fundamentalism that results from the failure of Western societies to permit immigrants a meaningful life in their midst.

${ }^{168}$ Kureishi, Collected Stories, 653.
} 
been particularly apparent in Buddha of Suburbia. ${ }^{169}$ However, in his short fiction Kureishi shifts his focus "From the broad canvas of panoramic, picaresque novels ... inwards, to explore male interiority". ${ }^{170}$ Accordingly, Thomas summarizes the critical reception of Kureishi's middle works by stating that "the main debate ... has centered not on representations of ethnicity [or, the alleged lack of these representations] but on masculinity". And she continues: "Here the critical divide has been between those who see Kureishi exploring new forms of masculinity in a postfeminist era, tackling the contemporary breakdown of heterosexual relationships with honesty and insight, and those who argue that these works are misogynistic." $" 171$

Following Connell's sociological analyses, it has become apparent that Kureishi's short fiction is chiefly concerned with the effects of the post-war changes in gender relations of power, production and cathexis onto the conceptualization of masculine identity. The discussion of select stories typical of the respective short story collections suggest that the exploration of contemporary masculinities proceeds in four steps: first, Love in a Blue Time mainly depicts the disruption of masculinities resulting from the changes of the gender order in the postfeminist era; ${ }^{172}$ second, Midnight All Day chiefly portrays the transformations necessitated by these changes; third, The Body and Seven Stories tends to emphasize the performativity of masculinity as a necessary prerequisite for any transformation; and fourth, New Stories imagines new forms of masculinities such as the homosexual man, the bisexual man, the "house-husband", and the "Delivery Man". These diverse representations of masculinity indicate that the chameleon-like short story genre is highly suited to experiment with various kinds of (gender) identity.

In accord with Ermarth, it may be argued that Kureishi's short fiction does not simply "repeat the same old ... emphases, the same, same, old stories over and over again", ${ }^{173}$ but increasingly uses the power of literary language to transcend traditional, patriarchal notions of masculinity in order to arrive at alternative configurations of mas-

\footnotetext{
${ }^{169}$ Moore-Gilbert, Hanif Kureishi, 192. Moore-Gilbert argues that Hanif Kureishi's Buddha of Suburbia was instrumental in the very foundation of this genre, influencing Nick Hornby's Fever Pitch (1992).

${ }^{170}$ Ranasinha, Hanif Kureishi, 105.

${ }^{171}$ Thomas, Hanif Kureishi, 4.

172 See Volkmann, "Explorationen des Ichs", 149.

${ }^{173}$ Ermarth, "Beyond 'The Subject"”, 415.
} 
culine practice. In so doing, the stories illustrate that masculinity is not an essentialist biological given but a sociocultural construction.

Not only do the short stories question stereotypical notions of gender roles and gender boundaries, ${ }^{174}$ but they also imagine new possibilities for the formation of masculine identity. The majority of $\mathrm{Ku}-$ reishi's short fiction challenge traditional conceptions of masculinity through the portrayal of known alternatives - such as men willing to enter relationships of equal power, rights and status with their female partners, homosexual men or bisexual men. Additionally, a few stories introduce new concepts of masculinity, that is the positively connoted "feminist house-husband" or the "Delivery Man" as the unfavorable by-product of a more and more materialistic society. Thus, the short stories increase the systemic potential of narrating or writing masculinity and, in accordance with Ermarth, "contribut[e] ... directly to social health". ${ }^{175}$ Significantly, male characters like Billy in "D'accord, Baby" and Alan in "Morning in the Bowl of Night" are acutely aware of the savoir littéraire demonstrated by Kureishi's short stories. For, apart from philosophy, they turn to literature for "guidance" on how to construct their masculine identity.

Although Kureishi's short fiction predominantly focuses on masculinities, it is far from misogynistic. While there are unsympathetic female characters like Imogen in "The Decline of the West", the stories also depict an abundance of sympathetic female figures. Indeed, short stories such as "D'accord, Baby", "Four Blue Chairs" and "Goodbye, Mother" allow for an outright pro-feminist reading. Moreover, by having the male protagonists serve as focalizers, the stories provide an unvarnished, unsparing and critical portrait of the mostly middle-aged men who have frequently left their first families and struggle to come to terms with their self-assured female partners. Nevertheless, criticism may be leveled at the fact that in the majority of the short stories female characters merely serve to illustrate the way in which gender relations have been changing and explain the mid-life crises the male characters are suffering. Only four stories possess female protagonists.

In approaching Kureishi's short fiction from a masculinity studies perspective, it becomes obvious that the allegedly postcolonial writer partakes in the contemporary discourse on masculinities. This illus-

\footnotetext{
${ }^{174}$ See especially "Goodbye, Mother" (Kureishi, Collected Stories, 507-48).

${ }^{175}$ Ermarth, "Beyond 'The Subject"”, 411.
} 
trates that the (re)negotiation of masculine identity has become a vital concern in a postfeminist society. But it also points to the inadequacy of both perceiving Kureishi first and foremost as a black rather than a British writer, and reading his works solely through the lens of postcolonial theory. Laurenz Volkmann rightly emphasizes that feminism, gender studies and masculinity studies have yet to discover the "postethnic Kureishi". ${ }^{176}$ Accordingly, the present discussion of the writer's short stories has attempted to show how the frequently neglected middle and recent works may be fruitfully investigated with the tools provided by masculinity studies. After all, the singular breadth and diversity that is characteristic of Kureishi's cuvre can only come to the fore if critics employ a similarly wide range of analytical approaches.

${ }^{176} \overline{\text { Volkmann, "Explorationen des Ichs", } 143}$ (my translation). 


\title{
Of INVISIbLe Men AND NATIVE Sons: Male Characters in Caryl Phillips' Fiction
}

\author{
BÉNÉDICTE LEDENT
}

\begin{abstract}
This essay focuses on the work of Caryl Phillips, a British author of Caribbean origin. It examines how his character-driven fiction has addressed masculinities over the years. The first part starts from the observation of a relative deficit in masculine visibility in Phillips, fiction from The Final Passage (1985) to A Distant Shore (2003) and takes a closer look at these "invisible men", analyzing what features they share and also examining the reasons, narrative and otherwise, behind their relative inconspicuousness. The second part of the essay concentrates on Phillips' latest novel, In the Falling Snow (2009), which is concerned with a "native son" of a kind and his relationships with his own father. The prominent male presence in this book not only begs for a re-examination of the male figures in Phillips' earlier fiction, it also calls into question the dichotomies that often permeate conventional approaches to gender.
\end{abstract}

As readers of this volume may already know, Caryl Phillips can safely be described as one of the most talented and prolific British writers of his generation. With nine novels to his name, he has garnered several prestigious literary prizes - such as the James Tait Black Memorial Prize in 1994 or the Commonwealth Writers Prize in 2004, to mention but a few. In almost thirty years, his fictional work has attracted sustained attention, not only from the international press but also from literary scholars all over the world. This wide-ranging critical success is confirmed by an even cursory glance at the many articles, theses and reviews that have been written on the work of this artist of Carib- 
bean descent. However diverse the approaches adopted by the commentators, most seem to concur on one thing: that Phillips' main preoccupation is the exploration of complex identities, particularly those which are shaped by exile or displacement, whether actual or metaphorical. No wonder, therefore, if notions such as home, belonging, diaspora, and history, but also race, often inform the thematic lenses through which Phillips' body of work has been scrutinized so far. Rightly so. Nevertheless, an overview of Phillipsian scholarship reveals other interesting critical trends. One of them is that gender - like race, one of the major components of identity - has generated comparatively less attention among the critics. It would be quite difficult to provide a definite explanation for this, although one could venture that in the context of what Paul Gilroy has called the Black Atlantic, gender has often been regarded as subordinate to race, even if, as we will see later, the two are in many cases inextricably bound.

Nevertheless, it is a surprising fact that Phillips' essentially character-driven fiction has rarely been examined from a gender perspective, let alone in the context of masculinity, especially when one considers that it has, at the same time, often been praised, albeit mostly in passing, for its sensitive and sympathetic depiction of female protagonists. In the introduction to a 2009 collection of interviews with Caryl Phillips, for example, Renée Schatteman points out that "Various interviewers have commented on Phillips' ability to successfully capture female voices". ${ }^{1}$ And indeed any reader familiar with his work cannot but remember the strong feminine presence in his novels, be it Leila, the Caribbean immigrant to England, in The Final Passage (1985); Emily, the nineteenth-century English woman voyaging to the Caribbean, in Cambridge (1991); Joyce, the vivacious English woman whose fate crosses that of the African diaspora, in Crossing the River (1993); Eva, the Holocaust survivor, in The Nature of Blood (1997); or Dorothy, the English pensioner, in A Distant Shore (2003). My first impression, however, is that Phillips' male protagonists in the same books have - for all their idiosyncrasies - been less memorable, almost as if the female characters in those novels had eventually stolen the show from their male counterparts.

Starting from this possibly subjective observation of a slight deficit in masculine visibility in Phillips' fiction, at least until Dancing in the

\footnotetext{
${ }^{1}$ Renée T. Schatteman, Introduction, in Conversations with Caryl Phillips, ed. Renée T. Schatteman, Jackson, MS: University Press of Mississippi, 2009, xi.
} 
Dark, published in 2005, in the first part of this essay I would like to take a closer look at his apparently "invisible men", to try and see what features they share, and to examine the reasons, narrative and otherwise, behind their relative inconspicuousness. This investigation into Phillips' male characterization will, I hope, yield some insights into the author's complex literary universe - not only its take on gender, but its general philosophy as well. This attempt to retrieve the male voices from the formidable choruses that can be heard throughout the author's novels is to some extent a response to the shift visible in his most recent fiction, and non-fiction too, which has in the last few years been more clearly male-centered, as I will show in the second part of my essay. The focus there will be on In the Falling Snow, Phillips' latest novel, published in 2009, which addresses the intergenerational tensions between three men of Caribbean descent living in contemporary England, and focuses on Keith Gordon, a black Englishman born in England, a "native son" of sorts.

This switch from an apparent male discretion in Phillips' earlier works to some measure of male assertiveness in his more recent writing is conveyed in my title through a reference to two classics of African American literature - Ralph Ellison's Invisible Man (1952) and Richard Wright's Native Son (1940). Significantly, these two books proved decisive catalysts for Phillips' literary vocation. As he writes in an early collection of essays entitled The European Tribe (1987), he bought these two volumes in a Californian bookshop in 1978, on his first visit to the USA and decided after reading Wright's novel that he wanted to become a writer. As Phillips puts it: "The emotional anguish of the hero, Bigger Thomas, the uncompromising prosodic muscle of Wright, his deeply felt sense of social indignation, provided not so much a model but a possibility of how I might be able to express the conundrum of my own existence." 2 There is something anecdotal in this, but the seminal role played by Wright in Phillips' career as a writer could also be viewed as a reminder of the predominantly masculine nature of his main frame of literary references. These, as his many essays and interviews also indicate, include such major figures as Richard Wright, naturally, but also James Baldwin, Shūsaku Endō, Henrik Ibsen, and C.L.R. James, yet comparatively few female figures, with the possible exception of Angela Carter.

${ }^{2}$ Caryl Phillips, The European Tribe, London: Faber and Faber, 1987, 7-8. 
Do not mistake me: I am not arguing here that Phillips has a hidden, masculinist agenda, but I simply want to suggest that, in view of his literary genealogy and of the more perceptible male presence in his latest writing, closer attention should be paid to the male characters and to the expression of masculinities in his early work than has so far been the case. Such an approach would undoubtedly help to bring to the forefront Phillips' interest from the beginning of his career in the "social structures of domination" 3 that have in the course of history contributed to the virtual erasure of black men but would also allow us to better appreciate how his most recent novel strives, through its main character Keith Gordon, towards an articulation of contemporary "progressive black masculinities", which Athena D. Mutua has described as "the unique and innovative performances of the masculine self that on the one hand personally eschew and ethically and actively stand against social structures of domination. On the other hand, they validate and empower black humanity, in all its variety, as part of the diverse and multicultural humanity of others." ${ }^{4}$

In what follows, I first propose to give a brief gendered reading of Phillips' early fiction by going in search of his "invisible men" and seeing what their common features are, in order to try and briefly delineate the Phillipsian version of male archetypes. Even a quick survey of the author's fiction until Dancing in the Dark - which, as I have suggested, seems to mark a turning point in his fictional work in terms of gender characterization - confirms that male characters are, in spite of their presence and their actual role in the narrative, rarely the main focalizers in narratological terms. There are a few exceptions to this, notably A State of Independence (1986), which centers on Bertram Francis, a Caribbean migrant to England who returns to his native island on the verge of independence, and Higher Ground (1989), a tripartite novel whose first two sections concentrate on male individuals. The narrator of the first section, "Heartland", is an unnamed African interpreter working for slave traders, and that of the second, "The Cargo Rap", is Rudi, an African American detained in a high-security prison. In spite of their narrative prominence, however, these three male focalizers - Bertram, the interpreter, and Rudi - do not come

${ }^{3}$ Athena D. Mutua, "Introduction: Mapping the Contours of Progressive Masculinities", in Progressive Black Masculinities, ed. Athena D. Mutua, New York: Routledge, 2006, xi.

${ }^{4}$ Athena D. Mutua, “Theorizing Progressive Black Masculinities”, in ibid., 4. 
across as heroic, imposing or even likeable figures, although their stories still encourage the reader towards a sympathetic understanding of their predicament.

Lonely and isolated, these three characters can be read allegorically as men defeated by neo-colonialism, human greed or racism. As far as I know, among all the male personas created by Phillips only Bertram and the African interpreter have been submitted to a detailed reading focusing on gender. One of these studies is by Elena Machado Sáez, who views $A$ State of Independence as "Phillips' closest engagement with the literary project of nation building", 5 conventionally connoted as masculine, and reads migrating Bertram's relationship with Patsy, his girlfriend who stayed behind in the Caribbean, as "the site for grounding his migrant male subjectivity", but also "as the plane upon which the new world order is inscribed". ${ }^{6}$ The other examination of Phillips' early male protagonists is by Faizal Forrester, who construes the homo-erotic dreams of the African interpreter in Higher Ground as an expression of the commodification and "the process of radical "othering' [suffered by] the black male body" in the context of the transatlantic slave trade. ${ }^{7}$ As these two analyses indicate, the masculinity of the migrant male and the slave is threatened by a larger order over which they do not exert any leverage, a clear sign of their tragic powerlessness.

One question to be asked at this stage is whether this acknowledgement of impotence could equally apply to Phillips' other male characters, whose masculinity has nevertheless not been systematically addressed by critics. What is certain is that, unlike Phillips' female protagonists, the great majority of the men in his fiction are black in an often white environment and have for this reason to bear the burden of a century-long history of segregation and discrimination, which often tragically curtails their ability to take control of their own lives and that of their families, a lack of power often regarded as incompatible with normative masculinity. Such is less often the case for Phillips' white male characters, like Captain Hamilton, the slave trader in Crossing the River, or Stephan Stern, one of the founders of the state

\footnotetext{
${ }^{5}$ Elena Machado Sáez, "Postcoloniality, Atlantic Orders, and the Migrant Male in the Writings of Caryl Phillips", Small Axe, IX/1 (March 2005), 18.

${ }^{6}$ Ibid., 32, 26.

${ }^{7}$ Faizal Forrester, “'Revolting Bodies': Homosexual Dream and Masculine Anxiety in Edgar Mittelholzer's A Morning at the Office and Caryl Phillips' Higher Ground", Caribbean Studies, XXVII/3-4 (July 1994), 321.
} 
of Israel in The Nature of Blood. Both Hamilton and Stern are leaders of men who wield power and have important responsibilities, without being in all respects exemplars of hegemonic masculinity either. This being said, it would be limiting to view Phillips' black male protagonists only in terms of social emasculation or infantilization, however relevant these notions might be to the description of their plights. What I would like to do instead is try to establish a broad-brush typology of black male characters in Phillips' early fiction, keeping in mind that such an exercise presents obvious dangers of simplification and therefore stereotyping, which I will do my best to avoid.

Two major male profiles, not always mutually exclusive, seem to emerge when one looks at Phillips' novels until 2005. The first one is that of the unreliable male or absent father who fails in his family duties, either willingly or not, or lacks accountability, very much like Michael in The Final Passage who leaves his wife Leila and his baby son Calvin very soon after their arrival in the "Mother Country". There is a similar irresponsibility on the part of Bertram in A State of Independence, who returns to his native island after a twenty-year stint in England and comes across a young man called Livingstone, presumably the unacknowledged son that he had by Patsy. In an interview conducted at the beginning of his career Phillips suggested that such behavior was "born of ... an aimlessness of the life which has been bestowed ... by colonialism", ${ }^{8}$ though this also characterizes men who were not properly speaking colonized, but were taken away from their family in various circumstances with political or economic overtones, such as segregation in the United States or labor migration. Take the case of Rudi Williams, the African American prisoner in Higher Ground, who writes uncompromisingly radical letters from his prison cell. Although Rudi refuses "to take a back seat in [his daughter's] life", 9 he never gets a chance to meet her as she was born shortly before his long detention started. Yet another absent father is the Othello figure in The Nature of Blood whose resettlement in Italy as an army general and also a migrant worker of sorts leads to his separation from his African wife and son whom he has, according to a

\footnotetext{
${ }^{8}$ Caryl Phillips, "Interview with Kay Saunders", Kunapipi, IX/1 (1987), 48.

${ }^{9}$ Caryl Phillips, Higher Ground, London: Penguin, 1989, 144.
} 
shockingly moralizing voice erupting into the narrative, conveniently forgotten and "thrust ... to the back of [his] noble mind". ${ }^{10}$

The second type that seems to recur in Phillips' early fiction is that of the "Uncle Tom", a black individual who has been transformed, alienated even, by his meeting with the world of the white man to such an extent that he could in some way be regarded as a traitor to his own community, not to say his own race. The African interpreter in "Heartland", the first section of Higher Ground, the educated and Christianized slave Cambridge in the eponymous novel, Nash Williams, the manumitted African American slave who goes to Liberia on a civilizing mission in Crossing the River, the Othello figure in The Nature of Blood, and even Solomon, the African refugee in contemporary England in A Distant Shore, all could to some degree be described as having compromised with the West for different reasons, including the need for survival but also the desire to be loved and to give meaning to their own existence. Nevertheless, as John Ford reminds us, Phillips' subtle portrayal of these ambiguous figures steers clear of depicting them as mere collaborators: it rather presents them as embodying "the encounter between cultures, flawed, discomfiting but human".

Clearly, then, Phillips' fiction does not encourage the reader to pass judgment on these men, whether those who walk away from their families or those who negotiate with the colonizer or the powers that be. For, in spite of their sometimes questionable moral standards, they are shown to be afflicted individuals, trapped by a world order in which they more often play the role of victims than victimizers, even if the situations described by Phillips tend to reject any simple dichotomy between these two opposite statuses. Perhaps the ultimate illustration of the male predicament in Phillips' fiction is provided by the eighteenth-century African whose voice frames Crossing the River. In the prologue and epilogue to this book, the guilty father explains his

\footnotetext{
${ }^{10}$ Caryl Phillips, The Nature of Blood, London: Faber and Faber, 1997, 181. See the essay by Estrin, where the author discusses "the lost child plot" in The Nature of Blood and sees this central motif as "a vehicle for the imposition of a male order that renders gender as well as race key players in the drive for mastery" (Barbara L. Estrin, "II had rather to adopt a child than get it': Mythical Lost Children in Caryl Phillips" The Nature of Blood", Ariel, XXXIV/4 [October 2003], 23).

${ }^{11}$ John Ford, "Representations of Deference and Defiance in the Novels of Caryl Phillips", in Beyond the Blood, the Beach and the Banana: New Perspectives in Caribbean Studies, ed. Sandra Courtman, Kingston: Ian Randle, 2004, 384.
} 
"desperate foolishness"12 which led him to sell his three children into slavery because his crops had failed. In one go forsaking his offspring and resorting to what he calls "a shameful intercourse" 13 with the slave traders, this character seems to crystallize the ambiguous combination of the patriarchal domination over others (here children) with the hopelessness of the dispossessed that has blighted the lives of many men in the African diaspora.

Arguably, no moral judgment is suggested in Phillips' fiction. One could nevertheless argue that the ethical ambiguity of many of his male characters might be one of the reasons why they seem to be less striking than their female, often white, counterparts, with whom they interact and who tend to display a greater sense of integrity or at least more ability to develop. Phillips' belief in women's moral superiority, which he has expressed in interviews, ${ }^{14}$ can probably explain the prominence of Leila in The Final Passage and of Emily in Cambridge, but this surely cannot be applied wholesale to all of Phillips' often polyphonic fictional production. What is certain, however, is that his novels often give narrative prominence to the female voice at the expense of the male one, both in terms of pages but also of audibility. A Distant Shore, for instance, is framed by the voice of Dorothy, a retired English teacher, who in her dealings with men is ironically "concerned to make sure that the dominant narrative is male". ${ }^{15}$ Still, she begins and ends the narrative, and therefore dominates the voice of Solomon, the African refugee whose childlike status in England seems to contrast with his career as a ruthless soldier when he was still in his native country. Phillips' narrative architecture here might be read at once as subversive of the traditional gender relationships, whereby maleness overshadows femaleness, but also as mimetic of the conventional racial dynamics in the West, which gives precedence to white over black - a complex bringing together of patriarchy

${ }_{12}^{12}$ Caryl Phillips, Crossing the River, London: Bloomsbury, 1993, 1, 237.

${ }^{13}$ Ibid., 1.

${ }^{14}$ See, for example, the Lannan Literary Videos where he says in an interview with Pico Iyer (1995), “[women's voices in historical documents] always seem to be much more honest and direct in tone .... [They] seem to me to be clearer, more impassioned, more complex" (Caryl Phillips, "Caryl Phillips: Lannan Literary Videos", in Conversations with Caryl Phillips, 43).

${ }^{15}$ Caryl Phillips, A Distant Shore, London: Secker and Warburg, 2003, 203. 
and racism which, as Lucie Gillet has shown, is also at the heart of Cambridge. ${ }^{16}$

However, it might be reductive, and in addition not always possible, to assign a clear meaning to the author's choices in terms of characterization, even if more research should be conducted in that area. Crossing the River offers a telling illustration of how difficult it may be to pin down Phillips' gender agenda, provided he has any at all. If one considers the last section of the novel, entitled "Somewhere in England", which is told from the point of view of an English woman called Joyce, it is intriguing to know that it was originally conceived as being narrated from the perspective of Travis, the son of the African father, who ends up as a GI in Yorkshire during the Second World War. As Caryl Phillips mentioned in an interview, and as can also be gathered from his archives, which are held in the Beinecke Library in Yale:

I tried to find a voice for Travis, I travelled down south during the research, drove round Georgia and Alabama for days in search of Travis. I couldn't find him anywhere, but I wasn't prepared to invent a voice. It wasn't working, and if it's not working, I don't care about balance for the sake of balance .... One thing I know is that Joyce was speaking to me forcefully, powerfully, in the dialect I grew up speaking, which is Yorkshire. ${ }^{17}$

That Phillips seems to have felt closer to Joyce than Travis may suggest that identity for him is first and foremost a question of social background rather than race and sex and that his work does not have an indiscriminate gender message to deliver, whether feminist or masculinist. The foregrounding of female voices in his fiction might not be as meaningful in terms of gender as might appear at first sight, as other factors also seem to determine his authorial choices. ${ }^{18}$ Neverthe-

\footnotetext{
${ }^{16}$ See Lucie Gillet, "Omnipresent and Everlasting Imperialism: Race and Gender Oppression in Caryl Phillips' Cambridge and A Distant Shore", in Caryl Phillips: Writing in the Key of Life, eds Bénédicte Ledent and Daria Tunca, Amsterdam: Rodopi, 2012, 321-31.

${ }^{17}$ Caryl Phillips, "Crossing the River: Caryl Phillips Talks to Maya Jaggi”, Wasafiri, X/20 (Autumn 1994), 27.

${ }^{18}$ Phillips expressed himself on this in a recently published interview: "I'm dealing with characters, I'm dealing with their frailties, I'm dealing with their vulnerabilities and part of that is obviously going to be conditioned by their gender. That's just part of what you are dealing with .... You don't sit down and try to write a character to
} 
less and to make matters even more complicated, Joyce's narrative prominence does not prevent a reading of the novel as masculinist either. Indeed, as Elizabeth DeLoughrey has argued, although Crossing the River displays some awareness of the position of women in society, it features two female protagonists, Martha and Joyce, who can come across as inferior in the overall diasporic spirit of the text, because, unlike their male counterparts, neither crosses the Atlantic, "nor ... directly participate[s] in transnational migration". Moreover, Crossing the River nowhere refers to the mother of the sold children, which suggests, for DeLoughrey, "not only a transaction perpetuated through African and European men, but a patriarchal genealogy for the diasporic 'children' of the Americas". ${ }^{19}$ In this novel as in others, women's visibility cannot be automatically equated with power.

As the discussion so far has shown, it is difficult to precisely circumscribe the reasons why the male voices seem more in the background than at the forefront of Phillips' fiction until 2005, let alone conclusively demonstrate that this is actually the case. What is less likely to be questioned, however, is the fact that the two novels that Phillips has published since then - Dancing in the Dark and In the Falling Snow - clearly center on male protagonists whose female partners play a less prominent role. Not surprisingly, these two books directly tackle issues pertaining to masculinity, especially the father and son relationship, a topic which Phillips had so far only extensively addressed in Crossing the River - not only through the overarching absent presence of the African father but also through the ambiguous, incestuous filial bond between Edward Williams and his emancipated slave Nash in the section entitled "The Pagan Coast". ${ }^{20}$ In this narrative, as Maria Mårdberg and Helena Wahlström have pointed out, "Father-son relations ... are complicated even further by the meshing

point up an exploration of certain issues of masculinity or femininity. That's not how fiction operates” (Caryl Phillips, “'Who Are You Calling a Foreigner?': Caryl Phillips in Conversation with John McLeod", in New Perspectives on the Black Atlantic: Definitions, Readings, Practices, Dialogues, eds Bénédicte Ledent and Pilar Cuder, Bern: Peter Lang, 2012, 293-94).

${ }^{19}$ Elizabeth DeLoughrey, "Gendering the Oceanic Voyage: Trespassing the (Black) Atlantic and Caribbean", Thamyris, V/2 (Autumn 1998), 217-18.

${ }^{20}$ See Pilar Cuder-Domínguez, "Roots versus Routes in Caryl Phillips' Crossing the River and Dionne Brand's At the Full and Change of the Moon", in Revisiting Slave Narratives/Les Avatars Contemporains des Récits d'Esclaves, Les Carnets du Cerpac 2, ed. Judith Misrahi Barak, Montpellier: Université Paul Valéry, 2005. Phillips also tackles father and son relationships in his 1982 play Where There Is Darkness. 
of Christianity's myth of divine fatherhood with racist power hierarchies". ${ }^{21}$ The way that Dancing in the Dark and In the Falling Snow deal with the question of fatherhood is, by comparison, more central and straightforward, which confirms a possibly more direct, less diluted interest in matters relating to masculinity.

Concentrating on Bahamas-born Bert Williams and his artistic career as an entertainer on turn-of-the-twentieth-century Broadway, Dancing in the Dark testifies to this new direction in Phillips' fiction, notably because it tackles the intricate link between black masculine identity and the entertainment business in the USA, ${ }^{22}$ a topic already explored by Phillips in an essay dealing with Marvin Gaye in $A$ New World Order. ${ }^{23}$ Given this clear focus, then, the novel begs to be read through a gendered lens. This has been done by Craig Smith, for example, who argues that Dancing in the Dark "bear[s] witness to a history of the silenced traumatic experiences of migrating AfroCaribbean males", ${ }^{24}$ reads it in terms of melancholia, and brings it together with Phillips' A State of Independence. Phillips' following book, not strictly speaking a novel but an original combination of fact and fiction entitled Foreigners: Three English Lives (2007), confirms this increased male visibility in his work: it puts into the limelight three black men who lived much of their lives in England without being recognized as Englishmen, not only a challenge to their humanity but to their sense of masculinity as well. Yet, it is Phillips' latest novel, In the Falling Snow, which crystallizes the author's most exhaustive exploration of masculinity to date, bringing together as it does "invisible men" and "native sons".

In the Falling Snow has been described by a reviewer as "a sharply observed slice of modern British life, cutting across race, class and generational divides to reveal the complexities we're constantly nego-

${ }^{21}$ Maria Mårdberg and Helena Wahlström, "Parenthood in the African Diaspora: Caryl Phillips' Crossing the River", in Seeking the Self - Encountering the Other: Diasporic Narrative and the Ethics of Representation, eds Tuomas Huttunen et al., Newcastle-Upon-Tyne: Cambridge Scholars Publishing, 2008, 294.

${ }^{22}$ See Phillips, "“Who Are You Calling a Foreigner?"”, 294.

${ }^{23}$ Caryl Phillips, "Marvin Gaye", in A New World Order: Selected Essays, London: Secker and Warburg, 2001, 35-59. For more on the gender implications of Williams' blackface performance, see Michelle Ann Stephens, "The Comic Side of Gender Trouble and Bert Williams' Signature Act”, Feminist Review, XC/1 (October 2008), $128-46$.

${ }^{24}$ Craig A. Smith, "Scenes of Trauma: Violent Rites, Migration, and the Performance of Afro-Caribbean Masculinities", Diss. University of Florida, 2010, not paginated. 
tiating". ${ }^{25}$ As such, it offers a remarkable cast of male characters, whose frustrating intricacy makes it impossible to come up with any clear-cut interpretation of Phillips' approach to masculinity. This reminds us, as R.W. Connell points out, that "Masculinity" is not a coherent object" about which one can easily generalize, which is perhaps truer than ever in a globalized world. The best one can do, rather, is distinguish "types of masculinity" and understand the accompanying "dynamics of change". ${ }^{26}$ This is very much what the following analysis of In the Falling Snow attempts to achieve. ${ }^{27}$

Keith Gordon, the protagonist of the novel, is in some important respects an unusual figure in Phillips' fiction, and is all the more interesting for this reason. With Rudi in Higher Ground and the African father in Crossing the River, he is indeed one of the very few "native sons" among Phillips' black male protagonists - "native sons" being understood here in the literal sense, with none of the destructive anger of Richard Wright's Bigger Thomas. Indeed, Keith is an Englishman who has not travelled across seas or oceans and has never left his place of birth, except for a brief tour of Europe with his then future wife Annabelle. This uncharacteristic sense of rootedness in England (even if Keith also feels drawn to a distant, ancestral Caribbean) is compounded by the fact that, unlike the majority of Phillips' black fictional characters, Keith is a socially successful man with a university degree and a safe job, which confers on him a certain amount of social authority. The contemporary setting of the novel goes some way towards explaining the atypical nature of Keith's profile, so entirely different from the historical, ill-fated male figures that people Phillips' earlier fiction, even if he shares with most of them a sense of extreme loneliness.

Through Keith, Phillips presents us with a model of new black masculinity, new in the context of his own fictional work but new also as a synonym for "modern", that is, which reflects twenty-first-century life in England while avoiding the stereotypes still often associated with contemporary urban black masculinities, such as gang life,

25 Siobhan Murphy, "Postcards from Society's Edge", Metro, 20 May 2009: http://metro.co.uk/2009/05/20/postcards-from-societys-edge-128937/. This text was also used as a blurb for the paperback edition of the novel.

${ }^{26}$ R.W. Connell, Masculinities (1995), 2nd edn, Cambridge Polity Press, 2005, 67.

${ }^{27}$ I would like to thank the students who participated in the seminar on "Masculinities and the Literature of the African Diaspora" at the University of Liège in 2011 and whose discussion of In the Falling Snow contributed to my own reading of the novel. 
crime, or sexual violence. If there is something of the everyman in Keith, he could nonetheless also be viewed as a representative of what Mutua has called "progressive black masculinities" in the sense that he has overcome systems of social and racial domination in his private life, and has in his professional life participated in "activities against racism, sexism ... and other systems of oppression that limit the human potential of the black masculine self and others". ${ }^{28}$ Keith's marriage to Annabelle, for example, testifies to the fact that, as a black working-class individual, he has risen above the class and race prejudices of his white, upper middle-class in-laws. And through his job as a social worker, he also contributes to making society more egalitarian, not just for himself but for the other "minorities" as well. Keith is indeed in charge of the local Race Equality unit, which in the course of the novel surprisingly merges with Disability and Women's Affairs. This means for him "learning about the problem of wheelchair accessibility, understanding why rape crisis centres could not be funded if they excluded male rape, coming to terms with the irony of being an able-bodied black man speaking on behalf of disabled white people, and being the highly visible spokesperson for feminist groups, many of whom appeared to despise men". ${ }^{29}$

As this quotation makes clear, Keith's professional duties are evidence of the increased black male visibility and participation in social work - for a long time a white and female stronghold - but they also convey the many ironies that this new state of affairs has engendered, hence the obstacles that might stand in the way of his professional fulfillment and which thus explain why he speaks in a rather cynical way of the "pantomime of his fancy job". ${ }^{30}$ His occupation apart, the newness of Keith's situation also resides in the way he handles his responsibilities towards his teenage son Laurie, with whom he finds it difficult to communicate, especially after his separation from his wife Annabelle, who has their child's custody. Far from being an absent father, however, Keith is closely involved in the upbringing of his son - often at his former wife's request, it must be added - and takes his role as a father to heart. Nevertheless there is some form of awkwardness in the way he exerts his parental duties as shown by the few scenes where he tries "to bond with his son" who, as a teenager, is

\footnotetext{
${ }^{28}$ Mutua, "Theorizing Progressive Black Masculinities", 7.

${ }^{29}$ Caryl Phillips, In the Falling Snow, London: Secker and Warburg, 2009, 33.

${ }^{30}$ Ibid., 252.
} 
"Going through that 'I'm a man' stuff", ${ }^{31}$ which only widens the existing generation gap.

In contrast to his son Keith, Earl, who arrived in England from the Caribbean at the beginning of the 1960s, is not a "native son" but more of an "invisible man". Throughout his life his admittedly discrete presence is hardly acknowledged by anyone. This is already the case on his native island, where he is rejected by his father in favor of his elder brother Desmond who has migrated to the United States, and where, after his own father's death, he is manipulated by his sister Leona into leaving the Caribbean for England so that she can take possession of the family house. Things do not improve in England where Earl's lack of social recognition reaches a climax, as poignantly recalled through Keith's reminiscence of a scene that features his father, Earl, and evokes the title of the novel: "As he walked his father left behind a single step of footprints, and [Keith] remembered lingering by the doorstep and watching closely as the falling snow steadily erased all evidence of his father's presence." 32 The falling snow, and by extension white English society, have metaphorically erased Earl's existence. He is therefore unable to leave a mark on the northern landscape as a human being even if his manpower (a strangely antithetical term here) as a migrant worker was welcome and necessary at some stage for the welfare of the host society.

Moreover, in line with the male figures in Phillips' early novels, Earl is an occasionally absent father - for various reasons, including his own failing mental health. First he is not given a chance to raise his son, then later, after the child's mother dies, he is all of a sudden "asked to play the role of the father", ${ }^{33}$ which seems to be the cause of even more mental suffering. But Earl is also an Uncle Tom of sorts, who has had to give up on his scholarly ambitions and compromise with himself and the system - which is shown to be at best paternalistic, at worst racist - in order to get a job as a janitor and survive in England. Earl's failure both as a father and as a social individual does not inspire admiration in Keith, who views him as a "stubborn" and "unpredictable" man, ${ }^{34}$ leading "a pitiful life". ${ }^{35}$ But this changes after

\footnotetext{
${ }^{31}$ Ibid., 130-31.

${ }^{32}$ Ibid., 321.

${ }^{33}$ Ibid., 317.

${ }^{34}$ Ibid., 52.

${ }^{35}$ Ibid., 266.
} 
he hears his father's deathbed narrative, because it explains how Earl's humanity and his sense of masculinity were taken away from him. Moreover, it provides a moving corrective to his rather negative image as a man "either hospitalised or struggling in his mind"36 that transpires through Keith's memories of him from the beginning of the novel. In a sense, Earl's confession of the various humiliations that he had to suffer during his lifetime puts a dramatic end to his invisibility (or inaudibility) and could vicariously constitute a vindication of the men in Phillips' previous fiction, such as Michael in The Final Passage, whose voices have not been properly heard. Therefore the extent of the humiliation of these characters is not fully understood. ${ }^{37}$ If one takes Phillips' fiction as a whole, there is an almost performative quality to Earl's distressing tale as it somehow demands from the reader to operate a backward reading of Phillips' fictional production and pay closer attention to what his male characters have to say, thereby restoring some of their lost dignity.

As shown by this brief delineation of Keith's and Earl's personas, In the Falling Snow puts side by side two opposite black masculine figures, whose main differences lie in their experience of fatherhood and their degree of social recognition. The divergences in their trajectories could certainly be ascribed to their differences in personality. Keith is a born fighter and has a more driven nature than his father who is of a depressed and withdrawn disposition. But Keith's and Earl's diverging fates are also shaped by the different social contexts in which they evolve and which either favor or thwart their ambitions, and by the fact that they belong to different generations. ${ }^{38}$ This indicates that space and time have a definite impact on the construction of masculinities - as already suggested concerning Laurie - but also that

\footnotetext{
${ }^{36} \mathrm{Ibid} ., 52$.

${ }^{37}$ See, for example, an essay discussing The Final Passage where the critic focuses on Leila and rightly points out that "Oddly enough, we are not given her husband's story of London" (Gail Low, "Separate Spheres? Representing London Through Women in Some Recent Black British Fiction", Kunapipi, XXI/2 [1999], 27).

${ }^{38}$ See Pilar Cuder-Domínguez, "Masculinities and Intergenerational Strife in Recent Black British Fiction", in Migration, Narration, Communication: Cultural Exchanges in a Globalised World, ed. Alicja Witalisz, Frankfurt am Main: Peter Lang, 2011, 2329; Bénédicte Ledent, "Mind the Gaps': Caryl Phillips' In the Falling Snow and the Generational Approach to the Black Diaspora", in Diasporas, Cultures of Mobilities, "Race": 1. Diasporas and Cultures of Migrations, eds Judith Misrahi-Barak and Claudine Raynaud, Montpellier: Presses universitaires de la Méditerranée, 2014, 16175.
} 
the condition of the black male in England might have improved with time, evolving from that of the silent immigrant to that of the socially active professional man. However, bringing together these two male portraits has other implications, which echo some of the key issues that have been at the heart of masculinity studies for a few decades, notably the notion of a masculine essence versus that of the constructed, and thus variable, character of gender identities.

As we have seen, the elements that separate the two men are most visibly context-bound, yet the reader is simultaneously made aware, especially after the eruption of Earl's story into his son's narrative, of several commonalities between the two which a superficial reading of the book might take as suggestive of an essentialist vision of masculinity, almost as if there were features that could define masculinities in a universal way, or at least point towards some permanent characteristics of the male condition. Earl's and Keith's common interest in pubs as places of refuge, which "[feel] like an extension of home", 39 might belong to this category. So could their propensity for taciturnity. Silence indeed pervades the two men's relationship with each other, which in most cases results in hardly anything better than an "awkward exchange", ${ }^{40}$ and with their family, in particular their female partners, coming in the way of satisfying communication. Even Laurie, who is still a child in a sense, tends to "withdraw into a silence that is unmistakably sullen" which his mother describes as "his "big man' behaviour". ${ }^{41}$

Nevertheless, for all the apparent male convergences between fathers and sons, what seems to bind them more than anything, and paradoxically so, is the variable nature of their masculine identity, the fact that they are not always as manly as they might appear at first sight or that their masculinity fluctuates according to circumstances. This, incidentally, also applies to Annabelle's father who first has all the features of the hegemonic male: he is "an ex-army officer who had resigned his commission because he was distressed at having to associate with fellow officers who he regarded as being a cut below by birth". ${ }^{42}$ Yet as the novel unfolds he appears as "weak, pathetic" 43 in

\footnotetext{
${ }^{39}$ Phillips, In the Falling Snow, 177.

${ }^{40}$ Ibid., 185.

${ }^{41}$ Ibid., 168.

${ }^{42}$ Ibid., 41.

${ }^{43}$ Ibid., 29.
} 
his daughter's eyes and he is diminished by cancer so much so that even Keith "felt sorry for him". ${ }^{44}$ Similarly, the way that Keith and Earl come across in the course of the narrative calls into question any normative representation of their masculinity, which is in any case already marginalized by virtue of their race. One might be struck, for example, by the ascendancy exerted by the women, black or white, in their lives. This is the case of Yvette, Keith's mixed-race girlfriend, who "was determining both the pace and the nature of their courtship" 45 and accuses Keith of sexual harassment when he decides to break up with her. Likewise, Brenda, Earl's white English wife, has a generous but dominating personality and she takes it upon herself to have Earl sectioned, thereby contributing to making him a typically weakened, incarcerated male.

Clearly, neither Keith nor Earl are epitomes of traditional patriarchy, yet this does not prevent the former from having predatory instincts towards Danuta, a young Polish girl living in London, nor the latter from expressing his contempt for all women who, he says, are "nothing but trouble". ${ }^{46}$ In addition to this, the narrative contains more or less discrete clues that demonstrate how difficult, and eventually pointless, it is to ascribe rigid masculine characteristics to any man because there is always some form of what is generally viewed as feminine in them. So, in spite of his virile appearance, Keith is also presented as obsessed with domestic cleanliness and order, an attitude which tends to be regarded as feminine. Furthermore, his midlife crisis - which he undergoes in the course of the novel and involves his resigning from his job following Yvette's accusations - makes him vulnerable, depressive even, as he realizes that "there really is no cogent purpose to his day or his life". ${ }^{47}$ The novel's open-ended, final scene shows Keith, now jobless and fatherless, being looked after, almost literally nurtured, ${ }^{48}$ by his ex-wife Annabelle, who seems to want to take him under her wing. At this stage, Keith's masculinity is definitely less assertive than in the first scenes of the book. Earl's masculine identity, too, displays what might be called variable geometry even though he never possesses the same self-assurance as his son. Still, he

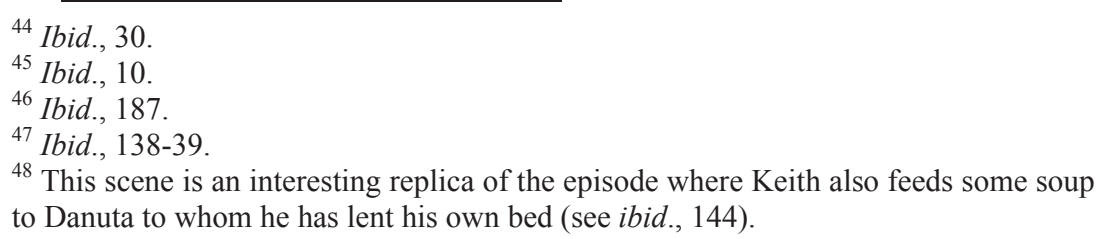


first comes across as a cold, taciturn, possibly indifferent man, but his deathbed narrative makes the reader, and Keith, aware of all the suffering that he bottled up during his lifetime, and which institutions such as the Race and Equality Unit can never effectively redress. More importantly, Earl's life story demonstrates why he can indeed be described, in Brenda's words, as "sensitive like a petal", 49 a qualifier that is far from evoking normative masculine strength and crystallizes his life as a mentally fragile West Indian immigrant in England who "can't afford to be sensitive and decent in a country like this". ${ }^{50}$

If Keith's and Earl's masculinities are shown to diverge from the norm as the narrative unfolds, it is rather the other way round for their son and grandson Laurie who is viewed through much of the story as a boy, with manly ambitions perhaps, but in any case as a child who has to be taken care of and protected. At the end of the novel, however, we learn that his girlfriend Chantelle is pregnant by him and that he decides to face this with a fully responsible attitude and "get it sorted", which doubly testifies to his being a "man", both as a genitor and as an accountable person. Laurie, as a mixed-race person but also one with a gender-neutral name, embodies in the novel the impossibility of a dichotomic approach to identity, whether one is talking of race or of gender. His personality therefore seems to exemplify a statement made by James Baldwin in one of his latest essays: "we are all androgynous ... because each of us, helplessly and forever, contains the other - male in female, female in male, white in black and black in white." 52

Much more could be said about the way masculinities are represented in In the Falling Snow, which is a far more complex and deeper novel than its recurrent attention to apparently trivial details of domestic life might suggest. If anything, this wealth of minutiae, which may be irritating to some readers, should convince us that the study of masculinities is more convincing if it can be grounded in the messiness of everyday life, as this allows the critic to "address the particularity, as opposed to the universality, of male experience" and as a consequence to research "its more intimate and specifically personal

\footnotetext{
${ }^{49}$ Ibid., 221.

${ }^{50}$ Ibid., 291.

${ }^{51}$ Ibid., 327.

${ }^{52}$ James Baldwin, "Freaks and the American Ideal of Manhood", in Collected Essays, ed. Toni Morrison, New York: Library of America, 1998, 828.
} 
dimensions". ${ }^{53}$ Moreover, as already suggested, the thorough exploration of the masculine condition at the heart of In the Falling Snow should also encourage the readers of Phillips' work to return to his earlier, perhaps less rounded male figures, for it clearly demonstrates through Earl's and Keith's fraught relationship that the narratives of the invisible ancestors are necessary for today's native sons to understand themselves, to know where they come from but also more crucially where they might be heading, which again highlights the essential role of literature as a medium for a better understanding of oneself and others. Phillips recently reaffirmed his belief in literature as a tool of human knowledge, for, he said, "it embraces and celebrates a place of no truths, it relishes ambiguity, and it deeply respects the place where everybody", including his invisible men and his native sons, "has the right to be understood". ${ }^{4}$

\footnotetext{
${ }^{53}$ Stefan Horlacher, "Charting the Field of Masculinity Studies; or, Toward a Literary History of Masculinities", in Constructions of Masculinity in British Literature from the Middle Ages to the Present, ed. Stefan Horlacher, New York: Palgrave Macmillan, 2011, 12.

${ }^{54}$ Caryl Phillips, "Colour Me English", in Colour Me English: Selected Essays, London: Harvill Secker, 2011, 16.
} 



\title{
SURROGATE DADS: INTERROGATING FATHERHOOD IN WILl SELF's THE BOOK OF DAVE
}

\author{
DANIEL LUKES
}

"A father is a man who fails every day."

\begin{abstract}
Will Self's sixth novel, The Book of Dave (2006) develops the British writer's ongoing interest in fathers and children, and fatherhood as a key nexus where masculinity and patriarchy are reproduced. The novel channels and critiques various types of narrative, including the "dad lit" genre, best represented by the popular novels of Nick Hornby and Tony Parsons, the post-apocalyptic and dystopian idiolect science fiction tradition of Anthony Burgess' A Clockwork Orange and Russell Hoban's Riddley Walker, and social phenomena such as "new" fatherhood and the "fathers' rights" movement. With wit, insight, anger, and compassion, Self's novel engages and interrogates matters of paternity, patriarchy, power, the religions of the father, the malaise of millennial British working-class masculinities, and the question of what it might mean to be a post-patriarchal dad.
\end{abstract}

The topic of fatherhood is one of Will Self's major concerns, and spans the writer's oeuvre from his early satirical fictions to his latter, weightier works. Self, who has four children, has gravitated throughout his writing to narratives concerning fathers and children, and father-son relationships, in particular ones that involve surrogate, nonbiological, foster- and father-figure mentors. As one of the central places where masculinity is reproduced, and the male body fashioned and coerced into citizenship, Self's fiction recognizes how fatherhood

${ }^{1}$ Michael Chabon, Manhood for Amateurs, New York: HarperCollins, 2000, 7. 
is worthy of particular critical attention, and hovers over this node, returning to it again and again, with observations on how through the paternal junction boys are, or fail to be, molded into men. Fatherhood and its failings are thus central to Self's interrogation of contemporary British and Anglophone social mores, class, and gender relations. This essay will consider Self's The Book of Dave: A Revelation of the Recent Past and the Distant Future $(2006)^{2}$ as a privileged point within Self's corpus: one that gathers, channels, and critiques various literary genres and socio-cultural discourses on the topic of fatherhood. The novel, which tells the story of a Jewish British cab driver whose frustrated rants against his ex-wife become the template for a brutal and repressive religion of the future, represents a culmination of Self's meditations on fatherhood, its redefinitions, and the problematic relation between patriarchal authority and sacred text.

Self's debut novel My Idea of Fun (1993), a sordid and skewed Bildungsroman of mental illness and coming-of-age awkwardness, focuses on the odd relationship between protagonist and narrator Ian Wharton, whose biological father departed when he was a small child, and his mephistophelic guardian and mentor, Mr Broadhurst AKA The Fat Controller. This chameleonic businessman initiates Ian into the male world of business and finance, requiring of him a fealty paid in homicidal acts, including the request for an Abraham-style sacrifice of his child-to-be. In this novel, fatherhood is represented as a double trauma: first of absence, then of perverse and murderous patriarchal homosocial mentorship. Self's second novel, Great Apes (1997), tells of Simon Dykes, an artist who wakes up one day to find every human in the world except himself transformed into an ape. By envisioning humans as apes, who groom each other, and mate repeatedly, seemingly indiscriminately, Self views human interactions through a zoological lens, foregrounding and de-familiarizing behaviors, relating to gender difference, hierarchy and competitiveness, that polite and civilized human society carries out partly through forms of disavowal. Dykes, an estranged father yearning to reconnect with his brood, embodies a double alienation, cut off as he is from his own animality as well as from the animal bond with his pack. Typically, the critical eye

${ }^{2}$ Will Self, The Book of Dave: A Revelation of the Recent Past and the Distant Future, New York: Bloomsbury, 2006. All quotations from Will Self's The Book of Dave are from this edition. 
of Self's fiction encompasses how the biological is subsumed as narrative within the social.

With The Book of Dave, Self intensifies his gaze toward the topic of fatherhood, explicitly positioning it at the center of the novel's concerns, along with such questions as what it means to be a father and how those meanings have changed over the last couple of generations and continue to change; what those changes entail for men, especially those slow or resistant to grasp them; how masculinity is affected and the male body redefined by epistemic and biopolitical shifts regarding fatherhood and the passing of patriarchal systems of social organization; how recalcitrant patriarchal positions and neopatriarchal backlash discourses prey on and trap vulnerable and/or subaltern men; how, within Self's literary universe which is particularly resistant to happy endings or redemption, the fallout of fathers who fail at being fathers create dangers for us all.

An inextricable combination of satire, social realist novel, and work of dystopian/apocalyptic fantasy, The Book of Dave ingests, reworks, and reconfigures various literary strands. One is "dad lit", a sub-genre of the "lad lit" tradition with which Self is often associated, and which explicitly tackles the topic of fatherhood in contemporary Britain. This sub-genre, as best represented by Tony Parsons' Man and Boy (1999) and Nick Hornby's About a Boy (1998), is generally perceived as characterized by portrayals of fatherhood depicted through the particular brand of light humor involved in watching a man "out of his element". A man fumbling as he tries to take care of kids has become a stock character in contemporary Western modernity: an archetype revelatory of epistemic shifts in paternal masculinities in the process of moving, often with considerable discomfort, towards the ability to nurture. Self's The Book of Dave gives this genre a onceover in the key of unpleasant, providing an acerbic commentary on its upwardly mobile paternal aspirations and its desire to depict fathers winning the battle of their re-adjustment to a changed gender landscape. Where other dads muddle through, coming up trumps in the struggle to become a good dad, Dave fails spectacularly, falling from one failure to the next, reaching out from his oblivion by "screaming at the future" (as his second partner Phyllis puts it) in an angry, avenging voice of his total failure to perform fatherhood. ${ }^{3}$

\footnotetext{
${ }^{3}$ Ibid., 418.
} 
A second genre The Book of Dave explicitly channels and reworks is science fiction of the future slang/idiolect variant, in the vein of Anthony Burgess' A Clockwork Orange (1962), but most closely Russell Hoban's Riddley Walker (1980). In many ways The Book of Dave acts as a tribute to Hoban's novel, digging up the topic of failed fatherhood which pervades it in the form of its cold war and anti-nuclear political critique: the politician fathers who have failed us by driving us into nuclear Armageddon. For The Book of Dave, in late 1980s-toearly 2000s Britain, the cold war is the one fought on the front of gender, no apocalypse in sight but the mental collapse of the socially defeated and alienated individual who has lost all dignity and purpose: the eponymous protagonist caught in the grip of his own nervous breakdown, between the mental health ward and the psychopharmaceuticals he has turned to. This delirious condition will spawn the writing of the book that gives the novel its name, an angry misogynistic rant against his ex-wife Michelle Brodie, that will become the foundational text of a brutal post-apocalyptic theocracy to come, fivehundred years after an apocalyptic flood has transformed the British Isles into the neomedieval wasteland of Ing. "Dävinanity", in which men and women conduct separate, segregated purdah lives according to the "Breakup" and children are subject to the "Changeover" at risk of death for disobedience. ${ }^{4}$

Finally, woven into and through its fantastical elements, The Book of Dave also acts as a repository for syntheses and commentaries on sociological perspectives on and narratives concerning "new" fatherhood, and critical understandings of how manifestations of fatherhood unfurl within a post-patriarchal landscape. One in which notions of paternity have undergone legal and socio-cultural mutation, from patriarchal models of fatherhood defined by legitimacy and authority, to current and feminist-inspired ones defined by economic support, domesticity and nurture (and their absence), and technology-produced models of biological and genetic paternity. The Book of Dave's world is one of custody courts and lawyers, restraining orders, visitation rights, and child support (or, in the book's future slang "chyldesuppawt", which has ironically taken on the new meaning of "bride price"). Within this domain which for Dave and his friends takes on shades of the Kafka-esque, the dubiously-cast voice of fathers' rights activists makes itself heard, giving form to a masculinity of defeat that

\footnotetext{
${ }^{4}$ Ibid., 58-59.
} 
retreats into fatherhood as a compensatory fiction for socio-economic failure and social alienation.

Will Self's achievement, with The Book of Dave, is to have woven together these diverse strands into a compellingly organic narrative of fatherhood, failure, and failure to father: a novel that rises above Self's customary satiric sneer to rare, and for him uncharacteristic heights of empathy and catharsis, to form a sustained portrait of millennial masculine malaise; one which also acts as a cautionary tale regarding both unchecked individual male failure, the construction of gender politics as a form of separatist "battle of the sexes", and the socialized misogynistic seductions of patriarchal monotheisms alike.

\section{Making nonsense out of fatherhood}

Though it comfortably sits alongside such British literary fiction portrayals of uncertain and ambiguous fatherhood, as Hanif Kureishi's Intimacy (1998) and Midnight All Day (1999), and Ian McEwan's The Child in Time (1987) and Solar (2010), as I have indicated the genre that The Book of Dave most visibly channels is idiolect science fiction in the tradition of Anthony Burgess' A Clockwork Orange and Russell Hoban's masterpiece Riddley Walker.

Both those books treat the topic of fatherhood with different degrees of explicit attention: in A Clockwork Orange, protagonist Alex's weak, docile, and conformist parents mirror and complement the state's abusive parenting and the protagonist's lawless youthful masculinity; in Riddley Walker it is the state itself that has reverted to a neomedieval form of homosocial mentorship, founded on violence and submission to a spurious patriarchal theology. In The Book of Dave children - and their posthuman counterparts, the "motos" - are relentlessly dragged between parents and slaughtered respectively, by violent state-sanctioned parental separation, upheld by a passive and complicit populace. All three novels share the use of a de-familiarizing idiolect, employed in different ways to undermine, question, and interrogate issues of authority and language, power and resistance. All three negotiate through mockery the triangulation of fatherhood, divinity, and absence: A Clockwork Orange's "Bog or God", Riddley Walker's Eusa, The Book of Dave's Dave.

A Clockwork Orange ostensibly makes use of the Russian-inflected future slang ("Nadsat") adopted by protagonist Alex (a-lex: lawless) and his cohorts, to recreate the gulf of generational separation. From the perspective of parents and children, this novel is about how the 
young and the old fail to understand each other, and talk across one another. Alex and his cohorts' adopted language emphasizes and iterates their self-imposed separation and difference from the generations that precede them: parents and other adults they perceive as sheepish worker drones ("rabbiters") deserving of being despised. Where Alex linguistically performs a rejection and pooh-poohing of his society's conventional morality, the novel's authority figures - particularly the writer character F. Alexander, Alex's victim and brief fatherly standin - appear suspicious and motivated by political intrigue or ineffectu$\mathrm{al}$, as is the case of his parents. There is no Stalinesque dictator father figure or strong man in Burgess' partly Soviet-inspired dystopia. State power appears in the form of ministers, officers, and doctors with a soft paternalist touch and gilded upper-middle-class tongue, assisted by the fists and heavy boots of working-class foot soldiers. As for his family, both Alex's mother and father are characters he looks down upon for their weakness, sentimentality and petty bourgeois conformism: their relationship ends in the novel with Alex's father capitulating to his son's opinion that he is now boss of the household. Alex has finally asserted himself, partly through his linguistic innovations, challenging his parents' world through a new idiom and linguistic displacement he will then abandon when he joins that world.

The novel closes with Alex wishing to become a father. With characteristic awkwardness, Burgess describes this desire, which in another, lesser-known dystopian novel, The Wanting Seed (1962), he terms "paternity lust": 5 the touchy subject of men wanting children. Touchy, perhaps partly because once a product of patriarchal culture (men wanting children, specifically male children, to carry on the family line), the topic of men wanting and seeking children is one our culture has some trouble dealing with. Contemporary fatherhood narratives are thus often narratives about the lack of adequate contemporary fatherhood narratives: where maternity is normalized, expected, and imposed on women, paternity desire is frequently conceptualized through confusion, even embarrassment. As a man, one does not go around telling people that one wants children: it might be awkward, a counterpart to the discourse of women saying they do not want kids. $A$ Clockwork Orange ends with Alex being discovered by his new "droogies" with a photograph of a baby in his wallet, and being roundly mocked for carrying it: what he now desires is to have a baby, and

${ }^{5}$ Anthony Burgess, The Wanting Seed, New York: W.W. Norton, 1963, 67. 
the note the book ends on, after a meeting with his old friend Pete and his new wife, is his contemplation of the task of going out into the cold world to look for a mate.

Russell Hoban's Riddley Walker takes Burgess' future slang concept to fascinating new places. Set over two thousand years after a nuclear war, Riddley Walker's world has regressed to a new Middle Age, one in which technology is iron age-level, and a theocracy reigns, whose savior figure Eusa (St Eustace/USA/USSR) has seemingly replaced Jesus Christ. Language itself has "devolved" into a new Middle English rich in misspellings, puns, and verbal games ("trants mission", "party cools", "tack ticks", "Inner G", etc.). Life is harsh, and guided by the politically-imposed "Eusa Shows": politicians are also travelling puppeteers who re-enact Eusa's tribulations. As during the near thousand years of the Middle Ages when only religious drama was allowed, Eusa shows are permitted exclusively: theology imposed through state-sanctioned ideological entertainment. Language itself is strictly controlled by the fathers in power, and it will be Riddley's innovation to introduce a new and heretic narrative into his world: a new show, based around Punch, of the British seaside resort characters Punch and Judy.

Self directly praises Riddley Walker in his Introduction to the 2002 Bloomsbury edition. Dismissing what he calls the "cod-naturalism" of contemporary realistic literature as "one of the most prosaic delusions of this most neurotic age", Self reads "Riddleyspeak" as a process of "True fictional praxis", a linguistic and literary methodology that rather than offering comforting falsehoods in the form of appeasing and familiar bourgeois naturalist narratives, forces the reader to slow down and rediscover the world through the lens of the unfamiliar:

Riddley writes-cum-speaks to us from the cusp of literate culture, and, in the very phonetic crudeness (from our angle) of his orthography, lies the vigor of his coming-into-being. Riddley wrestles sense out of the inchoate written language, and in doing so demands that we do the same. $^{6}$

The very textual difficulty of the novel, and its need for constant decoding - reading as an act of translation - presents an ethical chal-

${ }^{6}$ Will Self, Introduction, in Russell Hoban, Riddley Walker, London: Bloomsbury, 2002, ix. 
lenge to the reader, one that "naturalistic" literature may comfortably side-step.

Where A Clockwork Orange employs cold war malaise to comment on generational miscommunication, Riddley Walker breaks down and re-builds language to consider the political implications of historical and social miscommunication: how we are cut off from each other, throughout history, by means of the very adaptability, liquidity, and slipperiness of language itself. In a scene of dismally black comedy, the prime minister ("pry mincer") Abel Goodparley performs an act of theological exegesis ripe with error:

$S t$ is short for sent. Meaning this bloak Eustace he dint just tern up he were sent. A.D. 120 thats the year count they used to have it gone from Year 1 right the way to Bad Time. A.D. means All Done. ${ }^{7}$

Religion itself, that narrative which binds and gives official luster to political power, is in Riddley Walker an encyclopedia of errors, misunderstandings, and meanings entirely severed from their original intent. ${ }^{8}$

Riddley Walker is riddled with meditations on fathers and father figures: the narrative opens with the narrator protagonist coming of age, partly through the death of his father: his place is then taken by a variety of substitutes, some more symbolic than others. The figure of Punch, who would fry and eat his baby, lingers heavily over the novel's panoply of devilish politician-types responsible for the nuclear holocaust that has sent history hurtling backwards: the old white men in suits wrestling with each other in Frankie Goes To Hollywood's "Two Tribes" video (1983). Riddley Walker's leaders, all men - this neomedievalist post-apocalyptic future has reverted to a homosocial world in which women are generally reduced to their wombs - betray each other with ease, pouncing on, selling out, and abandoning each other and their sons in the name of survival. An implicit yet harsh critique of patriarchal systems of homosocial power reproduction, which finds apotheosis in the slippery Punch character: a bad father if ever there was one.

\footnotetext{
${ }^{7}$ Hoban, Riddley Walker, 124-25 (emphases in the original).

${ }^{8}$ See also Walter M. Miller, A Canticle for Leibowitz, Philadelphia: J.B. Lippincott, 1960 for a comparable meditation on the intersecting roles of religion, error, misunderstanding, knowledge, and power in the context of neomedieval post-nuclear fantasy, and a possible model for Riddley Walker.
} 
From both novels The Book of Dave appropriates the use of broken and reconstituted language as a tool for the critique of systems of authority, power reproduction, and linguistic complicity and resistance. Where A Clockwork Orange and Riddley Walker are both "voice" novels, offering proud and performative first person monologues from the perspective of the adolescent coming of age, The Book of Dave instead gives the reader a considerably more troubled, muddled, and alienated play of perspectives: a third-person, stream-of-consciousness-heavy perspective of the father, which is doubly broken up by being expressed in the form of alternating chapters set in the present and ones set in a post-apocalyptic/dystopian future. Dave's inner and outer voice grumbles from the front of the cab like a backing track turned down low, to then reappear, mutated and chopped up almost beyond recognition, in the mouths of the inhabitants and cruel rulers of Ing. Deprived of a voice in the present, Dave's subaltern mumble is transmogrified into the absurd dogma of the future.

Where Burgess and Hoban concern themselves primarily with how language reproduces and resists power structures, and how the individual stakes their place in relation to the punishing mechanisms of late modernity, with the literary self brought into being by way of the resistance of linguistic estrangement, Self's The Book of Dave turns this process on its head, emptying out the alienated individual's head of the frustrations it has been absorbing over a lifetime, and imagining a state re-organized through that nonsense logic, with help from the absolving hand of religion, and its alchemical transformations of the seemingly fantastic and the nonsensical into the official, the accepted, the status quo. The absurdities of Dave's theocracy, with its priests with taxi cab mirrors attached to their heads ("Drivers"), its rituals of gender and parental separation, its rigorous bans on heresy ("flying") not only underscore the extent to which contemporary secular Western life disavows and provides special dispensation to the religious and comment on how, in today's Britain, epistemic social discourse itself, with its secular medical and legal apparatuses, medicalizations of negative affect, and essentializing gender narratives, assumes the unshakeable certainty of a faith for the era in which it operates, only seeming absurd in retrospect, or prospectively as speculative fiction. We are living in Dave's world: we just do not know it yet. 


\section{Mistranslating fatherhood: beyond dad lit}

As its Gulliveresque incursions into the alien land of Ing traffic in traditional Enlightenment rationalism, The Book of Dave's novelistic strength also draws deeply from the well of Swiftian disgust, envisioning the predicaments of fatherhood through the category of the abject. Self has been here before, with The Book of Dave marking his return to gender science fiction territory, which he'd first broached in his Angela Carter style tale of sexual metamorphosis and Greek mythtype male pregnancy, Cock and Bull (1992). In the fable that constitutes the second half of that book, the eponymous Bull, a "large and heavyset young man" develops a vagina behind his left knee, ${ }^{9}$ and ends up impregnated by his doctor. The book's tone is one of whimsy, its meditations on the deconstructions of the gender binary characterized by comic aloofness and fantastical conceit. The Book of Dave offers a deeper, lower register, one more interested in the particular juxtapositions created by social realism, satire, and fantasy: while the present-tense sections have something of the Houellebecquian about them, the future dystopian passages in places recall the fantastical urban worlds of China Miéville.

The novel's eight present-tense chapters, set in non-chronological order between 1987 and 2003, draw from, conflate and critique at least one contemporary literary tradition: dad lit. Sociologists Abigail Gregory and Susan Milner see contemporary understandings of fatherhood as defined between two narratives: an "optimistic" model connected with "new fatherhood", and fathers who offer a positive presence in their children's lives, even in post-divorce scenarios; and a "pessimistic" model defined by paternal absence, alienation, and child support negligence. ${ }^{10}$ The dad lit genre offers a narrative that aspires to move from the latter towards the former, or rather, from a position in which fatherhood is disavowed or rejected, towards one in which it is desired and accepted. The genre thus represents a type of discourse of male nurture, of men yearning to be fathers, of the struggle to express the male desire for fatherhood and paternity, and to arrive at a form of adulthood equated with fatherhood. As in A Clockwork Orange, fatherhood represents an end to aimless adolescence and the

\footnotetext{
${ }^{9}$ Will Self, Cock and Bull, New York: The Atlantic Monthly Press, 1992, 149.

${ }^{10}$ Abigail Gregory and Susan Milner, "What is 'New' about Fatherhood? The Social Construction of Fatherhood in France and the UK", Men and Masculinities, XIV/5 (December 2011), 589.
} 
beginning of adulthood defined by "settling down". Under usually fairly light-hearted guises, dad lit's narratives embody portrayals of fatherhood depicted through the particular brand of humor involved in watching a man "out of his element", though slowly coming into it.

Tony Parsons' Man and Boy and Nick Hornby's About a Boy are both positive narratives, close to the self-help genre, embodying lessons on how to integrate as a father, and how to grow up as a man by becoming a father. In Man and Boy the protagonist narrator Harry Silver is abandoned with a four-year-old child by his wife after he cheats on her, before losing his job. Though the birth of his child had, by his own account, made him into a man - "Today I became a man" - where the other "supposed landmarks of manhood - losing my virginity, getting my driving license, voting for the first time" - had merely left him "fundamentally unchanged, still a boy", ${ }^{11}$ it is only when his partner leaves (for Japan, fulfilling the novel's notion of upwardly-mobile, global business-woman) that he is forced to learn to become a full-time dad. Up to this point he had played a marginal role in his child's upbringing, leaving the heavy work of rearing to his partner, whereas now he is forced to take on the role of the primary care-giver. The bittersweet narrative that Man and Boy articulates is a now-familiar one also expressed by countless television adverts featuring a similar scenario: dad left at home with the kids learns to manage somehow, whether it be cleaning the house or cooking something that is not burnt or inedible for the kids to eat. At the end mum comes home and order is restored: and in Parsons' novel Silver will find another woman to recreate the postmodern nuclear family with.

Hornby's About a Boy is a little more cunning and interesting, and comes at the topic of fatherhood awry: protagonist Will Freeman lives up to his name by being rich enough to not need a job, and free of emotional entanglements, a "kidult" who spends his time watching television, listening to music, and going for long drives. He shuns fatherhood and looks down on his friends who settle down to family life, as fools who have capitulated to a thankless ideology of servitude and bourgeois dullness. After one breakup too many however, he hits upon the idea of pretending to be the father of a young boy, in order to hit on single mothers: an action that buys into, and calls attention to ideas about men with family ties being perceived as less threatening than a man alone, and the difference between single men and those

\footnotetext{
${ }^{11}$ Tony Parsons, Man and Boy, London: HarperCollins, 2000, 4.
} 
more socially integrated due to fatherhood. At a party he thus becomes interesting to a woman he will end up dating only after getting her to believe that he is a single dad - the single dad being a particularly poignant character, as exemplified by Harry Dean Stanton's portrayal of Jack Walsh, the single, unemployed father of Molly Ringwald's character in the film Pretty in Pink (1986). Part of the book's humor revolves around the short-sightedness and immaturity of this dating strategy.

Central to About a Boy is the relationship between Will and Marcus, a teenager who actually takes Will at face value concerning his desire to be a father, his own being a rather absent one since breaking up with his mother. Comedy is produced from Will being cajoled, even bullied by the awkward teenager into this role, his own personal development taking place between the teenager status he wishes to cling to, seemingly forever, and adulthood in the form of the surrogate fatherhood imposed on him, by a child no less. The novel ends with a meditation against reductionist biological notions of fatherhood, putting forward the idea that there is a lot more to fatherhood than mere biology: the novel's happy ending involves an acceptance that as families become more susceptible to reconfiguration, and surrogate parenthood more common, friendship becomes a more valuable model through which to understand parenting rather than blood. New families forge, involving fathers and children not biologically related, and with these new links, new levels of psychological and emotional growth and development may be achieved for those involved, as families contort to fit the shape of a changing world in which divorce is a common occurrence.

The Book of Dave embodies a darker response to lad-lit's optimism, focusing on two aspects of the contemporary fatherhood narrative identified by Gregory and Milner, which Parsons and Hornby's books respectively tackle: "matricentrality" and "geneticization", 12 two often interconnected nodes.

Matricentrality refers to how the making and looking after babies and children still continue to be largely considered women's work, a position which risks the production of fatherhood as alienated from the process. "Whatchew knowabout kids? Wotchew know? You push them out, yeah?' She slapped her bellies and they shivered. 'You push

\footnotetext{
${ }^{12}$ See Gregory and Milner, "What is 'New' about Fatherhood?", 589-90.
} 
them out your cock?'", ${ }^{13}$ yells Berenice to Dave, who is helping his friend Gary look for his children after their mother has left with them in tow. For sociologist Michael Kimmel, rekindling nurture is where paths for new masculinities lie. Men must become more caring. Referring to Robert Bly's Iron John, Kimmel writes that "We need more Ironing Johns, not more Iron Johns". ${ }^{14}$ In its depictions of fatherly domesticity, Cormac McCarthy's post-apocalyptic tale of father-son bonding The Road (2006) successfully takes on board this challenge. Unfortunately for Dave, who is not equipped with the right tools for this particular task, nurturing fatherhood offers no such redemption, and he takes out his frustrations upon the child by beating him, ultimately replicating the retrograde relationship of fierce silence and misunderstanding he had had with his own father.

Geneticization denotes how new technologies have introduced notable qualitative differences in how paternity is understood as located between the intersections of biology, kinship, and economics. As sociologist Nancy E. Dowd explains: "For much of the history of common law, paternity was not a certainty. Based on modern technology, it now is." " Michelle's pregnancy had been the reason they had married, with Dave, "the sap"16 taking on the cuckoo-like responsibility foisted upon him. Michelle had had an affair with a married man, and later on will return to that man, restoring the child to his biological father. The discovery that Dave's son is not biologically his own occurs gradually, like the unfolding of a trauma, providing a biological narrative which Dave half-consciously grasps at in order to explain to himself his fatherly failings:

Fucker Finch had said, 'Iss uncanny, yeah, but you'll recognize 'em from the off. Thass what iss bin like wiv awluv mine. I fought 'Oh, so iss you issit ...' But Dave didn't recognize this miraculous, shiny fruit at all; it had fallen from a strange tree. ${ }^{17}$

\footnotetext{
${ }^{13}$ Self, The Book of Dave, 221.

${ }^{14}$ Michael S. Kimmel and Michael Kaufman, "Weekend Warriors: The New Men's Movement", in The Politics of Manhood: Profeminist Men Respond to the Mythopoetic Men's Movement (And the Mythopoetic Leaders Answer), ed. Michael S. Kimmel, Philadelphia: Temple University Press, 1995, 19.

${ }^{15}$ Nancy E. Dowd, Redefining Fatherhood, New York: New York University Press, 2000, 130.

${ }^{16}$ Self, The Book of Dave, 332.

${ }^{17}$ Ibid., 207.
} 
The slow discovery of this lack of a biological tie to his son complements and overshadows Dave's inability to maintain a relationship with the child: the separation is then rendered complete and given official sanction by the injunction barring him from visiting rights.

Self here tackles an ages-old topic, one given great importance within the Judeo-Christian tradition: paternity anxiety. The central preoccupation that according to Friedrich Engels, in The Origin of the Family, Private Property and the State (1884), underwrites the newly agricultural society's installation of the patriarchal model. Self tackles the subject by way of the new spin and new-fangled knowledge of genetic paternity testing. Yet geneticization here takes on the guise of a reduction of fatherhood to paternity, and thus insemination, providing a biological narrative that problematically complements the matricentrality of child-rearing: if fatherhood is reduced to insemination, what role do fathers have in bringing up children? Where Parsons and Hornby seek to fill that gap and provide optimistic readings of surrogate (social) fatherhood and paternal nurture, The Book of Dave's focus on biology opens up and underscores those gaps: the weaknesses, vulnerabilities and blind spots that emerge between these various and intersecting economic, legal, social, and biological conceptions of fatherhood, as we move from frameworks of legitimacy and marriage to ones of biology, genetic determination, and economic responsibility (child support).

Within the context of late twentieth-century and contemporary speculative fiction that rejects and looks beyond patriarchal paradigms, and critical theory that deconstructs and expresses wariness about biologicality as generative of new forms of patriarchal power reproduction, The Book of Dave is in good company. In State of Exception (2003) Giorgio Agamben traces the difference between auctoritas and potestas in Roman law, the former based on biological fatherhood which is naturalized as a form of legal power. ${ }^{18}$ Toni TrippReimer and Susan E. Wilson discuss the ancient Roman rite of amphidromies, in which fatherhood was established thus: a man "picked up the infant in his arms and, before witnesses, walked around the house

${ }^{18}$ Giorgio Agamben, State of Exception, trans. Kevin Attell, Chicago: University of Chicago Press, 2005. And let us once again reflect on the etymological relationships between author and authority, between auctor (literally he who grows, raises, increases) and auctoritas. 
three times". ${ }^{19}$ Contemporary British fantastic and speculative literature offers various enactments of performative rejections of patriarchal "nature" or "God"-given rights of fathers to assert their authority over women and children through appeals to biology or blood. Iain Banks' debut The Wasp Factory (1984) depicts a family constituted by such centrifugal movements out and away from de-legitimized paternal authority: Angus Cauldhame is a man who has hidden his teenage son Frank from the authorities for his entire existence, constructing out of his life an elaborate mythology of castration and gender confusion. The novel ends with Frank assembling his identity as an adult human being through the discovery of the truth about himself and the rejection of his father's usurped authority over him. China Miéville's debut novel King Rat (1998) centers around the struggle between the protagonist, Saul Garamond, and his biological father, the eponymous King Rat, who has murdered Saul's surrogate father who raised him. "We're blood", ${ }^{20}$ King Rat keeps telling Saul after his crime has been discovered, but Saul does not want to know, asserting himself against and beyond this tenuous claim based on biology alone.

The final lesson of The Book of Dave's future parts reprises Hornby's insistence on the value of social/surrogate fatherhood over reductivist notions of biological paternity, deconstructing the father from the one to the many: "The only recrimination that Carl allowed himself was to mourn this foolish quest for a dad he'd never known when right at hand there had always been a bloke who was prepared to be a true father to him .... U, Uve awlways bin a dad 2 me, Tonë, nah cummon me öl mayt." 21

The Book of Dave also dedicates ample space to chronicling the British Fathers' Rights movement, which has been given mainstream publicity in the UK by Bob Geldof in recent decades, through Dave's involvement with "Fathers First", after a restraining order denies him access to his son. The movement is portrayed by Self with a mixture of both scorn and sympathy, as a motley assortment of increasingly desperate men, easy targets for an unscrupulous shark such as the "Skip Tracer" who takes advantage of their tendencies to see them-

\footnotetext{
${ }^{19}$ Toni Tripp-Reimer and Susan E. Wilson, "Cross-Cultural Perspectives on Fatherhood", in Fatherhood and Families in Cultural Context, eds Frederick W. Bozett and Shirley M.H. Hanson, New York: Springer, 1991, 7.

${ }^{20}$ China Miéville, King Rat, New York: Tor, 1998, 218.

${ }^{21}$ Self, The Book of Dave, 451.
} 
selves as victims. These are men who, feeling disenfranchised from traditional masculine identities related to work and feeling betrayed by the state, or the "bureaugamy" as sociologist and male rights activist Lionel Tiger terms the process of the state standing in for absentee fathers ${ }^{22}$ turn instead to fetishize their children as a form of compensatory fiction. To these men, who fail to construct a meaningful social identity outside of an idealized version of the nuclear family, the apparent loss of their children comes to assist their self-definition as victims: "If I don' 'ave those kids in me life I've got nuffing. Nuffing.", says Finch ${ }^{23}$ whilst Dave, who had "made no investment in life beyond his wife and son", ${ }^{24}$ at one point worries "I'm gonna be one of those blokes what doesn't have kids - not ever." 25

With their propensity for stunts in super-hero costumes, ${ }^{26}$ one of which will claim the life of a friend of Dave's (Gary "Fucker" Finch), the Fathers First members appear as a British and sadly debased counterpart to the neo-fascistic male-bonding militias envisioned in Chuck Palahniuk's Fight Club. A militia which also claims a victim: the breasted, testicle-less Robert Paulson, played in David Fincher's 1999 film by Meat Loaf. Though the fathers' rights scene, is according to many analysts, one of the last bastions of patriarchal male entitlement, invested in the production of a politics of resentment out of frustrated male privilege, Self treats these men with a sympathetic eye: he intuits the ridicule in their actions, yet also finds place for the melancholic, tragic component of their plight at the bottom of self-loathing masculinity; licking its wounds and helpless to self-rehabilitate. While Self may see their solutions, if not their entire worldview as misguided, he never fails to understand them as human beings helplessly caught up in the seismic socio-cultural shocks of epistemic shifts in gender relations and their correlating alterations within the social machinery.

${ }^{22}$ Lionel Tiger, The Decline of Males, New York: Golden Books, 1999, 159.

${ }^{23}$ Self, The Book of Dave, 220.

${ }^{24}$ Ibid., 340.

${ }^{25}$ Ibid., 463 (emphasis in the original).

${ }^{26}$ This Fintan Walsh reads as a performative self-conscious attempt to recoup and restore a sense of masculinity that has been lost or damaged (see Fintan Walsh, Male Trouble: Masculinity and the Performance of Crisis, Basingstoke: Palgrave Macmillan, 2010, 151-65). 
While it may be the case, as Kimmel argues, that most custody cases are settled to the satisfaction of both parents, ${ }^{27}$ The Book of Dave maintains ears for the exception, constructing a nightmare machinery out of custody injustice. In a particularly grim court scene, Carl Dévúsh, the young protagonist of the Ing sections, and his teacher and surrogate father Antonë Böme are tried "for the most grievous flying". ${ }^{28}$ Within a Kafka-like view of justice as cathartic spectacle, of cruelty in the service of the upkeep of the state as dehumanizing mechanism, the neomedievalist courtroom and "Chief Examiner" are compared by Carl's teacher to a machine: "The law is the very engine of Dave's cab. Here the sacred and the secular aspects of the Knowledge gear into one another, each functionary is a part of that engine, his robe patterned so as to resemble cog, wheel and alternator", explains the teacher to the student. ${ }^{29}$ In this scenario, in a stroke of unfair dogma in the place of justice, Carl is denied knowledge of his father by a bureaugamous collusion against the paternal link thus defined by discontinuity:

No lad may be denied knowledge of his dad, [the Chief Examiner] barked, and nor shall you be, Carl Dévúsh. However, your crimes are of such an extent and so singular, your flying so high and fast, that no mitigation can be allowed for them. Petition denied! $!^{30}$

The consequence of the state subsuming the fatherly role involves the necessary deletion of the father.

\section{Gender dystopia of the present}

From the perspective of genre, The Book of Dave also stands inside the neomedievalist gender dystopia subgenre, a field best exemplified by Margaret Atwood's The Handmaid's Tale (1985) and Doris Lessing's The Marriages between Zones Three, Four and Five (1980). The dystopian format has in recent decades been harnessed to articulate commentaries on gender politics, ideologies, and discourses, and has to winning effect also been envisaged through a neomedievalist aesthetic framework. In The Handmaid's Tale a theocratic state gov-

\footnotetext{
${ }^{27}$ Michael S. Kimmel and Michael Kaufman, The Guy's Guide to Feminism, Berkeley, CA: Seal Press, 2011, 98.

${ }^{28}$ Self, The Book of Dave, 425.

${ }^{29}$ Ibid., 426.

${ }^{30}$ Ibid., 429.
} 
erns and regulates procreation in strict pro-natalist fashion; ${ }^{31}$ Lessing's novel assembles a neomedievalist fantasy world in which unseen gods insist on politically-motivated arranged marriage, a solution upsetting to both male and female partners involved.

Post-apocalypses, by contrast, tend to be male-dominated affairs Riddley Walker gets women out of the way rather quickly: "A womans voyce said, 'You know there women here and carrying.' Which there come some shuffling and that musve been them carrying women carrying their selfs out." 32 The Book of Dave takes on both traditions, incorporating both the post-apocalyptic homosocial model and the gender dystopia. Set in the Ing Archipelago five-hundred years from now after a flood that has seemingly destroyed British civilization, The Book of Dave's world is a largely bucolic one, in which the country has replaced the city, and Nú Lundun is being re-built somewhere further up the Thames. As in Riddley Walker and other speculative fiction fantasies built around civilization-annihilating disasters, ${ }^{33}$ a desire for nature permeates The Book of Dave, which also follows Burgess' The Wanting Seed (1962) and its Brave New World dialectic between dystopian society obsessed with rigorously controlling reproduction, and countryside world of nature in which reproduction occurs comparatively unchecked. In The Wanting Seed, Huxley's "natives" and "savages" have become a comic neomedieval world of bawdy and unleashed sexuality. The Book of Dave's Middle Age, however, is closer to Atwood's, in its rigid gender separatism and theologicallyordained statist reproductive politics. What The Book of Dave's structure of alternating chapters permits, however, is an ongoing conversation between contemporary present and neomedieval fantasy, weaving into the text a commentary on the dialectic between dystopian fantasy and its contemporaneous "real life" counterpart. In The Book of Dave it is the present with all of its biopolitical trapdoors that is represented as a gender dystopia, to which the repressive dystopian patriarchal theocracy of the future offers an even less appealing corollary.

\footnotetext{
${ }^{31}$ Atwood has been prescient to the degree that the current war on women and arguments over women's bodies in the United States now resembles the novel's farcical sex act with the handmaid in question, reduced to a vessel of reproducibility.

${ }^{32}$ Hoban, Riddley Walker, 215.

${ }^{33}$ See John Wyndham's The Day of the Triffids (London: Hutchinson, 1951); and Brian Aldiss' Greybeard (London: Faber and Faber, 1964), which depicts a world in which no more children are being born, almost thirty years before P.D. James' The Children of Men (London: Faber and Faber, 1992).
} 
Describing the mystery of why courtly love poetry came about precisely when it did, Jacques Lacan refers to the Middle Ages as "a time when the historical circumstances are such that nothing seems to point to what might be called the advancement of women or indeed their emancipation", and in which the woman, "is, strictly speaking ... nothing more than a correlative of the functions of social exchange". ${ }^{34}$ Gender dystopias such as Atwood's frequently adopt the Middle Ages as negative term of comparison to a liberal, democratic present, partly constructed by means of feminist and anti-patriarchal gender politics championing the emancipation of women, children, and LGBT citizens: they underscore the fragility of these gains and the necessity of defending them against conservative and neopatriarchal forces on the rise, especially in the contemporary US. The Handmaid's Tale in particular seeks to warn of what might occur should those forces once again become the status quo.

The Book of Dave's position is possibly more troubling, and as is often the case with texts that deal with the politics of masculinities, less ideologically clear-cut: not only is it Dave's misery and loss in the present that appears to the reader as dystopian, but it is this very misery that provokes the rant that will act as founding theological text to the future theocracy of Dävinanity. Where dystopias generally leave to the reader the act of applying their teachings to the present or not (between the two positions "we must make sure this doesn't happen here" vs. "thankfully, our world isn't like that"), by means of an ongoing dialogue within the text between realist present and fantastic dystopia, Self here backs away from any chance of positing the Middle Ages as unilaterally negative and terrifying antithesis to a present that might remain unchallenged. Showing us instead how the dystopian genre should work, to critique the present rather than let us feel good about it, The Book of Dave depicts its protagonist slipping through the cracks of our world, not those of some dystopian otherworld. Self's novel thus works meta-dystopianly to the degree that it explicitly articulates the genre's obligations to shine its critical lights not only on social injustices and failings of the past or global Other, but also of the contemporary Western present. In this case, attention is drawn to the plight of alienated, self-destructive men caught between the shifting

\footnotetext{
${ }^{34}$ Jacques Lacan, The Seminar of Jacques Lacan: Book VII, The Ethics of Psychoanalysis, 1959-1960, trans. Dennis Porter, ed. Jacques-Alain Miller, New York: Norton, 1992, 147.
} 
gears of the transition from patriarchy to post-patriarchal sociocultural arrangements, which claim victims through mental illness, suicide, early death.

\section{Authority and text: written on the body, broken on the wheel}

The Book of Dave's narrative catalyst depicts how under the strain of a breakup with his wife Michelle, who takes custody of their son Carl, Dave succumbs to depression, obesity, and psychopharmaceuticals, and in a psychotic delirium pens a lengthy rant which he then has printed on steel sheets, and which he buries in the garden of the house where Michelle is now living with former flame Cal Devenish, the man who turns out to be Carl's biological father.

Dave's document is many things: primarily, it is an attempt to communicate more honestly with his son than he has ever been able to do in life, a homosocial and fatherly attempt to pass "the Knowledge" (also the name for the mental map of London every cab driver must know) on to his son, a stab at carving out a father-to-son chat in print which circumstance has prevented him doing in the flesh. Like his stream of consciousness mumble, Dave's words come out garbled, producing what over time will become a nonsense idiolect ("Mokni"):

Epistles, the intent of which was to SET THE RECORD STRAIGHT and tell Carl MAN-TO-MAN what truly happened between his mother THE BITCH and his POOR OLD DAD ... nothing less than A COMPLETE REEVALUATION OF THE WAY MEN AND WOMEN should conduct their lives together. Which, as the Driver saw it, was mostly apart, the mummies crossing over into purdah on the far bank. ${ }^{35}$

Five-hundred years and one apocalyptic flood later, a brutal and primitive neomedievalist theocratic society has emerged, with Dave's book acting as its foundational theological text: in Dävinanity "daddies" and "mummies" live separate lives - children must change hands, at penalty of death for transgressors, once a week between fathers and mothers:

This is a most revolting congress, and it must cease at once! Dave ordained the Breakup, and the Breakup must be entire! Only at Changeover can there be any communication between noble Dave and perfid-

${ }^{35}$ Self, The Book of Dave, 349-50 (emphases in capitals in the original). 
ious Chelle! O Hamstermen! Speak only of childsupport to your mummies, as it is ordained in the Book! ${ }^{36}$

The novel's odd and even chapters flit back and forth between Dave's unraveling present and England's feverish future, in which the seemingly endless reconstruction of "Nú Lundun" proceeds like a new Babel: a proliferating, pulsating urban sprawl in which heretics are "broken on the wheel". In "Ing" (the name for what is left of England), the minutiae of Dave's monadic world cooped up inside his London black cab, become the verbal reference points for the future England's washed-up society, in which our floating refuse, "daveworks", are recycled into meaning: the "screen" is the sky, "curry" is food, "kipper" is winter, the creation the "MadeinChina" and the common form of greeting the formula "ware2 guv?", the taxi driver's first question to his fare. A glossary helps keep track. ${ }^{37}$

The Book of Dave's satirical charge concerns the origins of religion, and the regulating religious text as one born out of enmity, political intrigue, revenge and misogyny. As one of Dave's doctors describes the book:

"Oh, you know, the usual stuff, how the community should live righteously, the rules for marriage, birth, death, procreation. It's a bundle of proscriptions and injunctions that seem to be derived from the working life of London cabbies, a cock-eyed grasp on a mélange of fundamentalism, but mostly from Rudman's own vindictive misogynism." 38

From this perspective, The Book of Dave aligns itself with two arguments, one theoretical, the other literary, concerning the patriarchal and misogynistic origins of the religions of the book, both of which theorize some of their dogmas as the product of gender wars, specifically of masculine attempts to confine, regulate, and dominate women: Julia Kristeva's notions of "mother-phobia" and "semiotics of biblical abomination", ${ }^{39}$ by which procreation, which supposedly renders women abject and impure, thus necessitates their regulation and

\footnotetext{
${ }^{36}$ Ibid., 189.

${ }^{37}$ See ibid., 479-96.

${ }^{38}$ Ibid., 281.

39 Julia Kristeva, Powers of Horror: An Essay on Abjection, New York: Columbia University Press, 1982, 65 (mother-phobia), 99 (semiotics of biblical abomination).
} 
separation through the restrictions of the biblical text; and Salman Rushdie's The Satanic Verses (1988), which sees the prophet Mohammed (Mahound) locked in a furious struggle with three goddesses he seeks to suppress and exclude from his monotheism. Dävinanity's purdah is similarly the product of Dave's vindictive frustration towards his ex-wife Michelle, whom he comes to feel unmanned by: Dave's "turn to religion", is here his own Hubbard-like creation of a new faith.

Julia Kristeva's Powers of Horror: An Essay on Abjection (1982) argues that the monotheistic biblical text articulates and embodies a discourse and ideology of misogynistic patriarchal oppression, through which women are constituted as impure (because of their procreative purposes) and thus configured as needy of social ablutions and legal strictures. Women's reproductive capabilities are feared by men as a form of power, and women are thus regulated and confined: through categories of "filth", "defilement", "abomination", and "im/purity": the Jewish biblical text sanctions and endorses this oppression under the guise of the sacred, limiting and containing women through a matrilineal legitimacy anxiety officially sanctioned and codified as sacred law. Salman Rushdie's The Satanic Verses (1988) makes a comparable argument regarding the Quran and misogyny, and Mahound's excision of the goddesses al-Lat, al-Uzza, and Manat from his revelations. His political and sexual struggle with Hind, the Machiavellian wife of the ruler of Jahilia, and renunciation of the "Satanic verses" as inspired by the devil and not God are then codified into the new faith. The initial command to worship the three female goddesses - referred to as "Exalted Birds" 40 - is reversed, and Islam, through the work of Mahound becomes a monotheistic patriarchal religion.

Self's The Book of Dave joins this debate by satirizing the birth of a monotheistic faith from the mind of a London cabbie, a premise which almost necessitates that the ensuing religion be an oppressive one, full of malice transformed into the mindless repetition of gestures entirely divorced from their original meanings and intents. Comic potential of a Monty Python stamp is thus wrought through the transformation of Dave's written rant, the only text that has survived the flood in full because it is printed on metal plates, into a religion in

${ }^{40}$ Salman Rushdie, "The Disappeared: How the fatwa changed a writer's life", The New Yorker, Monday 17 September 2012, 54: http://www.newyorker.com/reporting/ 2012/09/17/120917fa_fact_rushdie. 
which men and women are forced to repeat rituals of whose origin and purpose they have not the faintest knowledge. Religion and religious ritual themselves thus appear as not just empty but absurd signifiers, designed to merely regulate and discipline an oppressed populace which complicitly acquiesces, "passively conforming to an invented belief system", as the narrator of Self's 2008 postcolonial novel The Butt notes of its hapless protagonist. ${ }^{41}$ Heresy is met with torture, ostracism, and death, and the future portion of the novel in part revolves around the attempts of a heretic, Symun Dévúsh, to counter the prevailing theology by maintaining the existence of a second book of Dave which renounces the doctrines of the first - which Dave wrote once he had regained his mind, and which $\mathrm{Cal}$ and Carl Devenish had buried in a film canister alongside the first.

Central to The Book of Dave is a version of a debased and brutalized working-class male body. Comparable to the father in D.H. Lawrence's Sons and Lovers (1913), Dave is degraded by his job, physically damaged by being in the cab so long; but unlike Walter Morel, who is an outsider inside his own family and home, scorned and hated by his wife and children, who aspire higher and feel dragged down by his working-class and uncouth ways, Self's Dave is an outsider outside his own family. In the novel's geneticizing twist on Victorian family drama, Dave, as un-biological father, was never inside this family to begin with.

It is thus with sympathy that the Dave character is primarily depicted. The "Dave" figure first appears in Self's short story "Dave Too" in Tough, Tough Toys for Tough, Tough Boys (1998). An everyman to be found wherever you look, an interchangeable "bloke":

Dave is waiting for me in the café .... There are two other Daves who are usually in the café at this time of the morning. Dave and I call them respectively, Fat Dave and Old Dave .... My Dave is, I like to think, a kind of Ur-Dave, a primary Dave. His Daveness, his Davidity, his Davitude, is unquestionable. In a world with so many Daves, Daves running, Daves walking, and Daves standing, desolate, crumpled betting slips at their feet, it's infinitely reassuring to feel that within my grasp is some part of the essential Dave. ${ }^{42}$

${ }^{41}$ Will Self, The Butt, London: Bloomsbury, 2009, 351.

${ }^{42}$ Will Self, Tough, Tough Toys for Tough, Tough Boys, New York: Grove Press, 1998, 71-75. 
Dave is an unavoidable, if unappealing presence: a ubiquitous interchangeable masculine one; a generic masculinity writ large. In The Book of Dave he is fully fleshed-out as individual, a victim. A victim of circumstance, of class, of culture and his adamant lack of it; a victim of gender, and the vilifying narratives of masculinity he has internalized; and a victim of sex, a loser, like Neil Strauss' "AFC - Average Frustrated Chump" 43 at the mercy of his unrequited libido vulnerable to offers of affection such as the one seemingly put forth by the scheming Michelle, who is also stumbling through life without a rudder. Though also a victim of her less than auspicious circumstances, being more desperate and calculating than Dave, and determined to rise socially, Michelle's actions will turn out to have sadistic rather than masochistic results, along her journey from trodden-uponby-life and miserable failure - modeling "had used her up" more successful position, living in Hampstead with her own boutique. Self depicts her ascent as a form of successful Darwinian selfpreservation, via the cynical triumph of feminine masquerade. A contemporary Becky Sharp, "Her childhood had, she felt, been banal, her youth exposed and obvious - now her womanhood would be mysterious". ${ }^{45}$ Michelle and Dave's time together is predictably disastrous, a physical and psychological mismatch: "it wasn't that she was too big for him - he was too small for her. Michelle hadn't meant to; it was a skill she'd sucked up with her mother's formula - belittling a man until he was the size of a toy soldier, then putting him away in a box." 46

As for Dave, Self injects copious humanity into the figure of the cab driver: that old chestnut of British yobbishness, and clichéd caricature of reactionary, backwards-looking white working-class masculinity, increasingly unsure of itself and its worth in a changing world. Self's satirical sympathy with the object of his scrutiny - bedraggled, self-loathing contemporary masculinity - reveals a Houellebecqian influence. Dave's self-effacement, expressed at the level of bodily disgust ("then down into the temple of hiss and piss, where he could wring the neck of his suicidal dick" ${ }^{" 47}$ ) and his unhappiness with his

${ }^{43}$ Neil Strauss, The Game: Penetrating the Secret Society of Pickup Artists, New York: HarperCollins, 2005, 10.

${ }^{44}$ Self, The Book of Dave, 100.

45 Ibid., 332.

${ }^{46}$ Ibid., 330.

${ }^{47}$ Ibid., 153. 
overweight body and balding head recall the self-effacing corporeality of Bruno in The Elementary Particles, reduced to abject penis: "What was between his legs was a piece of oozing, putrefying meat devoured by worms." 48 Dave's descent, following the disappointments of love and family entanglement, into the contemporary mise en abyme of the mental ward also recalls Bruno. Self is vicious in his representations of Dave's low self-image: "Now what was he? A crushed carrot lying in the gutter, a headless doll, a pissed-upon shadow of a man." ${ }^{49}$ As with Houellebecq, Dave is the kind of contemporary male who measures his self-worth in terms of sexual conquest, and similarly vulnerable to self-destruction when life has become devoid of sexual potential. In "The Gospel According to Dave", M. John Harrison describes the protagonist as defined by a kind of gendered inertia, a masculinity defined by a dangerous lack of self-understanding:

Despite his evident articulacy, Dave can't say what's happened to him - he can't lay blame. It wasn't his upbringing, it wasn't the job, it wasn't Michelle, or even, really, the loss of his relationship with his son; it wasn't the depression, or the drugs, or the psychosis, or his book, or even his eventual recovery. Those things, and the indescribably complex feedback relationships between them, serve only to suggest something else, something deeper, some malaise that can only be articulated by a description of its symptoms. As with Dave, so with his times. ${ }^{50}$

In contrast to Dave's unraveling and too loose family entanglement, his occupation as cab driver is too tight, and experienced by him as a form of technological imprisonment. Re-reading the concept of masochism through Michel Foucault's analysis of social disciplinary regimes, John K. Noyes asks in what new ways the story of masochism may be told, finding that it is through an understanding of submission to the machine, that one may still find the masochistic narrative a useful one. ${ }^{51}$ Dave's symbiotic relationship with his cab, the

${ }^{48}$ Michel Houellebecq, The Elementary Particles, trans. Frank Wynne, New York: Vintage International, 2001, 128.

${ }^{49}$ Self, The Book of Dave, 325.

${ }^{50}$ M. John Harrison, "The Gospel According to Dave", The Guardian, Saturday 27 May 2006, not paginated: http://www.theguardian.com/books/2006/may/27/fiction. hayfestival2006.

${ }^{51}$ See John K. Noyes, The Mastery of Submission: Inventions of Masochism, Ithaca, NY: Cornell, 1997, 11-12. 
Fairway "he'd spent half his adult life in ... [which is] not juss a motor - it's almost fucking human", ${ }^{52}$ gradually becomes a "rubbish bin of old sandwich wrappers" $" 53$ and his own bodily wastes. As Dave begins to resent the machine with which his body comes to be almost welded ("Comfortable for who? You try getting your porky trotters down under this dash, it's like putting your legs in a coffin, mate, a vibrating bloody coffin." 54 ), his masculine pride, once embodied by this occupation he had so admired in his cab driver grandfather Benny Cohen, eventually morphs into a form of unmanning, and the instrument of his work becomes a monadic, monastic cell through which he experiences the world at a remove.

Drawing from Dave's rage, in Ing's Mokni the sky becomes the "screen" and "drivers" (priests) may only look at their interlocutors by means of a mirror, a prosthetic eye attached to their body. Firmly rooted to one spot, Dave experiences London as a blurred sequence of dizzying images which revolves around him, in a scenario that reconfigures Leopold Bloom's heavy-hearted flaneurie through the city of Dublin in Ulysses into the contemporary isolationist experience of a human who experiences life largely through a screen of some kind and as one or another form of simulacrum. Like Bloom's, his speech is an unending muttered monologue ${ }^{55}$ a broken text that bounces back, to him and us, its fragmented sequence of hiccupped rants and smashedup speechery mirroring the monadic isolation of the man and the enclosed centrality of his body, broken on the (steering) wheel, and encased within a metallic shell around which chaotic worlds churn. Dave's final abandonment of the cab is soon followed by his death.

His apotheosis as the divinity in a new neopatriarchal cosmogony will then follow. But dogmas, old or new, do not provide the right answer to gender troubles, argues Self: an ethical politics of gender cannot be based on archaic and decontextualized texts. Robert Bly's much-critiqued neomedievalist call for masculine separatist identity reboot, Iron John (1990), appeals to and fetishizes medieval legends re-articulated by the Brothers Grimm, as narratives that may reconnect

\footnotetext{
${ }^{52}$ Self, The Book of Dave, 52 (emphasis in the original).

${ }^{53}$ Harrison, "The Gospel According to Dave", not paginated.

${ }^{54}$ Self, The Book of Dave, 37 (emphasis in the original).

${ }^{55}$ This new archetype, a contemporary version of Plato's cave-dweller, is present also in Houellebecq's The Possibility of an Island ([2005], trans. Gavin Bowd, New York: Vintage, 2007) in which cloned posthumans live in monadic compounds and communicate with each other exclusively via the computer.
} 
alienated modern man to his "deep male" self. ${ }^{56}$ Its talk of kings and princes partakes of an aristocratic neomedievalism that ignores and disavows class difference, and the specific challenges faced by working class masculinities. For Bly in this respect, all men are the same. The future sections of The Book of Dave, by contrast, violently underscore class-based hierarchy and inequality, imagining a new Middle Ages which are both harshly rural and brutally urban, with a frenzied rabble overseen by a cruel and arbitrary aristocratic judicial system and envisioned through a form of Rabelaisian carnivalesque.

Instead of a solemn, solid, metallic, statuesque model of medieval masculinity, or noble bearded wild man to appeal to in times of epistemic male uncertainty, as in Bly's much criticized formulations, Self's neomedieval man is bodily buffeted hither and thither, and subject to the emasculating body modification of torture. This is the case of "heretic" Symun Dévúsh, who travels from the Isle of Ham (Hampstead, where the protagonists live) to New London to preach of Dave's second, recanting book, and finds himself locked up in the tower, broken on the wheel, deprived of his tongue, and recast as the local bogeyman when he is deported back home to Ham: "So it was that the journey to London began, in haste and in sadness: the Beastlyman left lying at Nimar, gulls lunging down to peck at him, his black mouth open, his red nubbin of a tongue struggling to form the most significant words. $" 57$ The bearded wild man is not a lord or king, but an outcast of the community, an Agambenian "homo sacer" who has been silenced and has had his tongue cut out.

\section{Looking beyond patriarchal paradigms}

Though The Book of Dave appears partly under the guise of a "timeless" story of fathers and sons who fail to connect, cyclically and repeatedly, its preoccupations are also palpably political, its target the representation of a specific chronological moment in which old models of fatherhood and masculinity are being toppled and deconstructed, and new ones have yet to be solidified or even formulated. It is important, Self appears to argue, that within this epistemic fracture the seductive, decontextualized, and often arbitrary narratives of "tradition" be firmly resisted, especially neopatriarchal religious ones. For all his failings, Dave is arguably above all a man without a narrative,

\footnotetext{
${ }^{56}$ Robert Bly, Iron John: A Book About Men, New York: Vintage, 1990, 6

${ }^{57}$ Self, The Book of Dave, 238.
} 
without a story to which to adhere to, and through which to make sense of the dizzying confusion of his lifeworld. The book he pens is his gospel, and the one to which he belongs an apocryphal addition to the New Testament which foregrounds an often overlooked biblical character: that uncomplaining non-biological father Joseph.

The family trio of "noble Dave and perfidious Chelle" 58 is completed by one of Self's growing collection of posthuman characters, in the wake of the distorted and hideous zoo-bound "humans" of Great Apes: the "motos". These childish posthuman pig-like creatures, who recall the "pigoons", genetic pig/human splices of Margaret Atwood's Oryx and Crake (2003), reprise the "emotos" of Self's own short story "Caring, Sharing" (1998) in which prissy Manhattanites are taken care of by babyish giant nannies, "inner children" who have been enslaved and put to work in the service of the rich and powerful. In The Book of Dave the repressed emoto returns as moto, a creature somewhere between animal and child, defined in the glossary as a "large, vivaparous, omnivorous, mammalian creature native to Ham and found nowhere else. Used by the Hamsters as a source of meat and oil alone. The moto has the functional intelligence of a two-and-a-half-year-old human child." ${ }^{59}$ Within the linguistic economy of the novel, the moto offers a further level of communicative breakdown, its lisp making its words even harder to parse than other Mokni speakers, though its supplicant intent is often clear, as is its inability to comprehend the gender struggle of the parents:

Perhaps Self's most intriguing invention is the moto, a curious creature that is combination enormous baby and pig. The Hamsters (denizens of the island of Ham outside New London) cherish these gentle beasts, constantly cuddling them and stroking their soft neck waddles despite their rather repulsive appearance. But, as beloved as they are, the motos are ritually slaughtered for their blood - the invaluable "moto oil' that keeps Ham running. As their necks are slit and the blood pours out of them, these pitiful beasts call out in childlike voices "Itun hwurting, Cwarl. Mwy nek hwurtin.” Throughout the book the motos are subject to never-ending abuses. In a way, they have become the

\footnotetext{
58 Ibid., 189.

${ }^{59}$ Ibid., 491.
} 
misshapen remnants of the childlike trust and innocence that Dave tries to connect with when he wrote his first, ill-conceived book. ${ }^{60}$

The motos are arguably also children of a "men are pigs" philosophy and its internalization among men and women ("You're a pig not a man"61). At the novel's end Carl, Antön and the moto Tyga will take a stand against the moto slaughter that has been ordained by representatives from New London. Both this scene, and Dave's second book, his "EPISTLE TO THE SON" in which he advocates to "RESPECT MEN AND WOMEN BOTH, to strive always for RESPONSIBILITY, to understand that WE MAKE OUR OWN CHOICES IN LIFE, and that BLAMING OTHERS is not an option. Children NEED BOTH THEIR MOTHERS AND THEIR FATHERS, yet if their union does not last there should be no CONFLICT, no tug of HATE ... there can be no EXCUSE for not TRYING TO DO YOUR BEST and live right ${ }^{\prime 62}$ articulates a first step towards a reconciliatory approach between the sexes which the novel despairs in for the present, but augurs for the future, a step away from gender separatism characterized as a "battle of the sexes": "a wake-up call to readers about the importance of family and communication. It's better to communicate your feelings - your secret Mummyself - openly, rather than burying everything where it can be dug up and misconstrued later." ${ }^{63}$ The Book of Dave ends on a positive note, with an invitation to new narratives, in the form of strong critiques, deconstructions, and mockeries of old ones, posing the question of how to imagine and construct a politics of gender and the family beyond and against the questionable authority of patriarchal sacred texts, essentializing and backlash discourses of gender warfare, and the process of depatriarchalization.

${ }^{60}$ Dan Murphy, "A Society Based on One British Cabbie's Delusions", Buffalo News, 15 Apr 2007, G.4.

${ }^{61}$ Self, The Book of Dave, 216.

${ }^{62}$ Ibid., 420-21 (emphases in capitals in the original).

${ }^{63}$ Murphy, “A Society Based on One British Cabbie's Delusions”, G.4. 



\section{NOTES ON CONTRIBUTORS}

Mark Bracher is Professor of English at Kent State University, Ohio, co-founder of the Association for the Psychoanalysis of Culture and Society, and Founding Editor of the association's journal, Psychoanalysis, Culture and Society. His books include Being Form'd: Thinking through Blake's Milton (1985); Lacan, Discourse, and Social Change: A Psychoanalytic Cultural Criticism (1993); The Writing Cure: Psychoanalysis, Composition, and the Aims of Education (1999); Radical Pedagogy: Identity, Generativity, and Social Transformation (2006); Social Symptoms of Identity Needs: Why We Have Failed to Solve Our Social Problems, and What to Do about It (2009); Educating for Cosmopolitanism: Lessons from Cognitive Science and Literature (2013) and Literature and Social Justice: Protest Novels, Cognitive Politics, and Schema Criticism (2013). His articles have appeared in journals such as PMLA, College English, JAC, College Literature, and Studies in English Literature.

Richard Collier is Professor of Law at Newcastle University, UK. He has published widely in the area of law and gender, with a particular focus on issues surrounding men and masculinities. His books include: Masculinity, Law and the Family (1995); Masculinities, Crime and Criminology: Men, Corporeality and the Criminal(ised) Body (1998); Fathers' Rights Activism and Law Reform in Comparative Perspective (edited with Sally Sheldon, 2007); Fragmenting Fatherhood: A SocioLegal Study (2008, with Sally Sheldon) and Men, Law and Gender: Essays on the 'Man' of Law (2010). He is presently conducting a research project on male lawyers, masculinities and work-life balance in the legal profession, entitled Fathers, Lawyers and Work-Life Balance, and is researching the book Family Men: Fatherhood, Law and Gender from the Late Nineteenth Century to the Present. Richard Collier has also recently commenced a funded study of wellbeing in 
the legal profession and university law schools; and is an editorial board member of Social and Legal Studies: An International Journal.

Raewyn Connell is Professor Emerita at the University of Sydney and was formerly Professor of Sociology at the University of California, Santa Cruz (1992-95), Professor of Australian Studies at Harvard University (1991-92) and Professor of Sociology, Macquarie University, Sydney (1976-91). Born 1944 in Sydney, Australia; BA Hons, with majors in history and psychology, University of Melbourne; $\mathrm{PhD}$ in government with thesis in political sociology, University of Sydney. She is author or co-author of twenty-one books, including Making the Difference (1982); Gender and Power (1987); Schools and Social Justice (1993); Masculinities (1995); The Men and the Boys (2000); Southern Theory (2007); Confronting Equality (2011); and Gender: in World Perspective (with Rebecca Pearse, 2014). A past president of the Sociological Association of Australia and New Zealand, she has been an activist in the labor and peace movements, and a contributor to research journals in sociology, education, political science, gender studies, and related fields. She is recognized as a leading contributor to international social research and theory on gender, giving keynote addresses at conferences on gender issues in many countries.

Rainer Emig is Chair of English Literature and Culture at Leibniz University in Hannover, Germany. He is particularly interested in the link between literature and the media and in literary, critical, and cultural theory, especially theories of identity, power, gender and sexuality. His publications include the monographs Modernism in Poetry (1995); W.H. Auden (1999); and Krieg als Metapher im zwanzigsten Jahrhundert (2001) as well as edited collections on Gender $\leftrightarrow$ Religion (with Sabine Demel, 2008); Hybrid Humour (with Graeme Dunphy, 2010); Performing Masculinity (with Antony Rowland, 2010); Commodifying (Post)Colonialism (with Oliver Lindner, 2010); and Treasure in Literature and Culture (2013). He is one of the editors of the Journal for the Study of British Cultures.

Stefan Horlacher is Chair of English Literature at Dresden University of Technology. He holds degrees from Mannheim University, from the University of Paris IV (Sorbonne), was visiting scholar at Cornell University, at Kent State University and at the English and Foreign 
Languages University, Hyderabad, and Distinguished Max Kade Visiting Professor at Ohio State University. His monographs include Visuality and the Criticism of Visuality in the Work of John Fowles (1998, in German) and Conceptions of Masculinity in the Works of Thomas Hardy and D.H. Lawrence (2006, in German), which won the Postdoctoral Award of the German Association of Professors of English. He is on the editorial board of the International Journal of Sociology and Anthropology, corresponding editor of Men and Masculinities and has edited Conceptions of the Feminine and Gender Role Stereotyping in the Later Work of D.H. Lawrence (2002, in German), "When is a Woman a Woman? - When is a Man a Man?" Constructions of Gender from an Interdisciplinary and Diachronic Perspective (2010, in German) and Constructions of Masculinity in British Literature from the Middle Ages to the Present (2011). He has co-edited In Search of Truth (1996, in German); The Sense of Nonsense (1997, in German); Forms of the Sonnet (1999, in German); Sexuality and the Poem (2000, in German); Beyond Extremes (2004, in German); Literature and the Art of Living (2008, in German); Gender and Laughter: Comic Affirmation and Subversion in Traditional and Modern Media (2009); Transgression and Taboo in British Literature from the Renaissance to the Present (2010) as well as Post World War II Masculinities in British and American Literature and Culture: Towards Comparative Masculinity Studies (2013).

Fatemeh Hosseini was educated at Qom University and at Allameh Tabatab'ee University, Iran, where she was awarded a BA in English language and literature and an MA in English literature, both with Honors. She started her teaching and translating career in 2000. Since then she has published several articles and translations in Iranian literary journals and critical series. Her area of study is modern literary theory, in particular, gender studies and psychoanalysis. From 2007 to 2010 she worked on her PhD dissertation on Ian McEwan at Dresden University of Technology, where she was awarded a scholarship and taught literature classes. Currently she is teaching in Mashhad, Iran.

Christoph Houswitschka studied English and American literatures, modern and medieval German literature and history at the universities of Regensburg and Illinois at Champaign-Urbana. In 1991 he received his $\mathrm{PhD}$ from the University of Regensburg. He has taught at the universities of Regensburg, Dresden, Northern Iowa, Freiburg, and was 
visiting professor at Jiaotong University, Xi'An. Since 2002 he is professor of English Literature at the University of Bamberg. He has published on late-medieval English literature, eighteenth-century literature, migration literature, and contemporary drama. He is also coeditor of an introduction into English and American Studies (2nd edn, 2007) and of several conference volumes (for example, Healers and Redeemers, 2010).

Bénédicte Ledent is a professor at the Université de Liège (Belgium) where she teaches English language and postcolonial literatures, particularly those of the African Diaspora. She has published on contemporary Caribbean and Black British writing and is the author of a monograph on Caryl Phillips (2002). She has co-edited several volumes, including Caryl Phillips: Writing in the Key of Life (2012), in collaboration with Daria Tunca, and The Cross-Dressed Caribbean: Writing, Politics, Sexualities (2013), in collaboration with Maria Cristina Fumagalli, and Roberto Del Valle Alcalá.

Daniel Lukes has a $\mathrm{PhD}$ in Comparative Literature from New York University. His dissertation, "Omega Males: Critical Masculinities in Fiction and Theory", examines representations of masculinity and failure in works of British, North American, and French contemporary fiction, sociology, and psychoanalysis.

Sebastian Müller studied English Philology, German Philology and Philosophy at the University of Mannheim and the National University of Ireland in Galway. From February 2007 to August 2010, he was employed as an assistant lecturer at the chair for English Literature and Cultural Studies at the University of Mannheim. In his current dissertation project, he analyzes the influence of the intellectual and socio-cultural developments of the post-war period on masculine selfrepresentations in post-war and contemporary British literature. He currently works as an Inside Sales Executive for an international software company near Heidelberg.

Todd W. Reeser is Professor of French and Director of the Gender, Sexuality, and Women's Studies Program at the University of Pittsburgh. He has published two monographs on masculinity, the first on moderation and masculinity in early modern France and the second on theoretical approaches to masculinity. He has edited or co-edited vol- 
umes on French masculinities and on transgender France. His latest book, Setting Plato Straight: Translating Ancient Sexuality in the Renaissance, is forthcoming.

Bettina Schötz studied English Philology, German Philology and Educational Science at Leipzig University, where she graduated with a first-class Staatsexamen in 2009. Since then she has been a research assistant and $\mathrm{PhD}$ student at the Chair of English Literature at Dresden University of Technology. She has taught undergraduate courses on a variety of topics, and her primary research interests include literary and cultural theory, especially theories of identity and community, postcolonial literature and theory, black British writing, as well as the short story form. 



\section{INDEX}

adultery, 154 (see also affair, extramarital)

adulthood, 280-82

affair, extramarital, 90, 228, 242, 283 (see also adultery)

African American, 254, 256; literature, 253

African diaspora, 252, 258

Agamben, Giorgio, 284

agent, 42, 76-77

aggression, 99, 103, 108-109,

$112,116,118-22,139,208$ 209, 212, 215, 228

Aldiss, Brian, Greybeard, 288 allegory, in Jude the Obscure, 165-67

altruism, in As You Like It, $111,113,116,120$

American Dream, 180, 182

Amis, Martin, Money, 184

Anderson, Eric, 24

anger, 171, 174-75

angry decade, 170, 185, 187

anxiety, 20, 35, 93, 102, 189,

199, 220; of the female,

176; and Lacan, 200-201;

and patriarchal hegemony,

83; power and, 75-76, 78,

84-85; of queerness, 30

approaches to masculinity, an-

thropological, 36; categori-

cal gender research, 41; cri-

sis, 20; ethnicity, 25; gay,
28-29; hegemonic masculinity, 21; historical, 20; homosocial, 30; male sex role, 13-14; moderate, 3536; movement centered, 30 , 34-35; mythopoetic, 18; narrative, 5,13 ; new men's studies, 15; poststructuralist, 28, 144; psychosocial, 62, 64-65

Armstrong, Dorsey, 76, 79

Ashe, Fidelma, 54, 68, 73-74

Atwood, Margaret, The Handmaid's Tale, 287-89; Oryx and Craig, 298

audience, in James Bond, 186, 188; in Shakespearean comedy, 15, 96, 100-104, 106-108, 117, 122, 124 authentic self, 108, 116, 165, 183-84

authority, 31, 56, 153, 205, $245,275,279,284$; paternal, 193, 196, 274, 285, 290 autonomy, 57, 59-60

Balaji, Murali, 26, 37

Baldwin, James, 253, 268

Banks, Iain, The Wasp Factory, 285

Beasley, Christine, 37, 44, 62, 69 
behavior, gendered, 40, 63-64, 70, 98; male, 76, 87, 99, 103, 108, 208; of men, 64; behavioral scripts, 100-101 Bell, David, 70

Bhabha, Homi, 34

Bible, in Jude the Obscure, 147, 164

Bildungsroman, 146, 150, 200, 272

Billson, Janet Mancini, 25 biology, in The Book of Dave, 282-85

birth, 212-13

black British Literature, 219

blackness, 25

Bly, Robert, 17-18, 283, 29697

body, in The Book of Dave, 296; gendered, 16, 31, 66$67,70,73,77,144-45,222$; male, $8,16,27-28,31,35$, 40, 75, 77, 84-87, 90, 92, $139,211,271,273,293$; in The Man of Feeling, 133, 139; in Morte Darthur, 8486,88 ; representative of power, 84; sexed, 66 Bond, James, 169-70, 185-87;

Movies: Casino Royale, 185-87, Moonraker, 185, Quantum of Solace, 185,

Tomorrow Never Dies, 185, You Only Live Twice, 185 boys, 41, 46, 99, 102, 132, 268 Braine, John, Room at the Top, 9, 169-70, 180-81, 183, 185 breadwinners, 242, 245 Brod, Harry, 2, 15-16, 18, 26
Brooke, Henry, The Fool of Quality, 129

Brothers Grimm, 296

Burgess, Anthony, A Clockwork Orange, 271, 274-80; The Wanting Seed, 276, 288

Bush, George W., 115, 123

butch subjects, 33-34

Butler, Judith, 5, 10, 30-31, 144, 188, 217, 221-23, 237

Butler Education Act, 171-72

Cadden, Michael, 16-17

Carter, Angela, 253, 280

cathexis, 223, 228, 241-42, 244

child, 177, 199-200, 203, 208, 213, 234, 257, 266, 268, 272, 281-84, 298; childcare, 59, 174, 197; support, 274, 280, 284, 291; childhood, 176, 198-99, 204, 243, 294

chivalric prowesse, 78-79, 81 , $85,87-88,90,92-93$; chivalry, $75,81,84$

class, 41, 43, 131-32, 136, 142, $172,218,261,263,272$, 294; conflict, 169, 178-79; domination, 193; emerging middle-class ethos, 137-38; in legal studies, 61, 66, 71, 73 ; lower, 172; upper, 171 72,187 ; upper middle, 178 79, 187; working, 172-75

Coltrane, Scott, 18 coming of age, 272, 278-79; of masculinity studies, 11, 16 
competitiveness, 99, 272

conflict, between masculinities, 97, 209; gender, 55; racial, 24-25; unsolved mother, 176-77

Connell, Raewyn / R.W., 3-4, 6, 7, 11, 20-24, 37, 39-51, $53,56,58,61-65,187,194-$ 95, 222-23, 227-28, 231, 235, 239-42, 244, 262

Conway-Long, Don, 36 corporeality, 60, 295

Craig, Daniel, 186-87 criminology, 59, 62-66 crisis, 4, 20, 241, 267 (see also masculinity, in crisis)

Cromwell, Jason, 33

Crotty, Martin, 19

death, 9; in As You Like It, 103, 109, 113-14, 118; in The Book of Dave, 274, 290-91, 293, 296; in Ian McEwan's novels, 191, 194-97, 201, 204, 209-11, 214; in Jude the Obscure, 149-51, 156-59, 163, 16566

de-colonization, 39, 47 deferral, 34, 141, 154, 160-62 DeLoughrey, Elizabeth, 260 Demetrious, Demetrakis, 23, 62

Derrida, Jacques, 162-63 depression, 99, 114-16, 11824, 232, 290, 295 desire, 29, 40, 121, 137, 157 58, 199-201, 206-207, 211,
$257,273,276,282$; homosexual, 45

Dickens, Charles, Great Expectations, 235; The Mystery of Edwin Drood, 30 disability, 32, 196 discourse, 32-34, 145, 222 , 233; gender, 41 ; of masculinity, 58-59, 64, 67, 71, 280; of oppression, 292 discursive condition, 6,145 46; universe, 141, 165-66 disguise, 107-108 diversity, 21, 62, 70, 73, 19293,250 divorce, 152-53, 231, 282 Donaldson, Mike, 48, 62, 199, 211

Dowling, Linda, 143 Dowd, Nancy E., 58-59, 63

Easthope, Antony, 16 Edley, Nigel, 23, 195 effeminacy, 25, 32; effeminate, $26,46,49,134,139,174-$ $75,178,188$

Elias, Norbert, 172, 183 Ellis, Markman, 135-36 Ellison, Ralph, Invisible Man, 253

empire, 37, 46-47

Endō, Shūsaku, 253

Eng, David L., 25-26

Engels, Friedrich, 284

equal power, relationship of, 220, 230, 234, 236, 249

Erhart, Walter, 8, 144, 223 
Ermarth, Elisabeth Deeds, 10, $145,165,168,225-26,248$ 49

essentialism, 35-36, 57, 69, 139

ethnicity, 6, 11, 25-26, 43; in Hanif Kureishi's short fiction, 218-20, 239-40, 248; in legal studies, 61, 66, 68, $71,73-74$

failure, of fatherhood, 275; of masculinity, 130, 148, 179, 196, 210-12, 221, 227, 273, 304; of Western society, 247

family, 99, 175; in The Book of Dave, 276, 282, 284-85, 293, 299; breadwinner, 242, 245; in Caryl Phillips' novels, 255-57, 266; entanglement, 295; in Hanif Kureishi's short fiction, 227, 232-34, 237, 241-47; in Ian McEwan's novels, 196, 202, 210, 215; law, 54, 57, 59-60, 67; man, 150 ; in Morte Darthur, 81-83

Fanon, Frantz, 25

fascism, 47

father, absent, 177, 256, 263 64, 286; African, 259-60, 262; becoming, 228, 276, 281; biological, 272, 283 , 285, 290; desire to be, 282 ; failing, 273; fear of, 200; identification with, 202, 211; imitation of, 203; knowledge of, 287; loss of,
102, 132, 147, 175-77, 196, 210-11, 264-65, 278; in power, 277; reign of, 193; rejection by, 264; as role model, 175, 202; role of, 226, 236-37, 243, 263; and son relationship, 260, 266, 297; subjection to, 177; tyrannical, 212; father figure, 271, 278; fatherhood, 60; in The Book of Dave, 272-77, 279-85, 287, 289, 291, 293, 295, 297; in Caryl Phillips' novels, 261, 265; divine, 261; in Hanif Kureishi's short fiction, 228, 236-37, 239-40; struggle, 280; father's rights, 7, 10, 53, 63, $69,73,274,285-86$

fellowship of the Round Table, 87,91

feminism, 16-17, 28, 49, 54$55,61,68,173,185,211$, 237, 250; legal, 55, 64; feminist, 17, 28-29, 55-56, 65, 98 192; legal studies, 56-59, 72, 74

Ferrebe, Alice, 183-84 fetishism, 199

Fielding, Sarah, The Adventures of David Simple, 129

Fincher, David, Fight Club (film), 286

fixation, 159-60, 198

Fleming, Ian, Casino Royale, 185-87

Flood, Michael, 22, 54

Foucault, Michel, 34, 63 
freedom, 57, 141, 145, 147,

$151,153,165,167-68,181$, 222, 226

Freud, Sigmund, 2, 25, 40, 176-77, 193, 195, 197-200, $205,211,230$

Geertz, Clifford, 4 gender, categories, 68-69, 72, 223; close-focus research, 44-45; crisis tendencies, 223-24, 227; equality, 49, 73, 193, 229, 231, 245, 247; hegemony, 33; hierarchies, 24, 47, 78; identity, 5-6, 55, 77, 98, 144, 147, 157-58, 165, 167, 192, 210, 220, 222, 225-26, 234, 237, 242, 247, 266; identity (male), 1, 3, 8-9, 142, 149, 157-58, 164-65, 167, 235; identity formation, 188; ideology, 46; neutrality, 55, $69,73,268$; performativity, 217, 221-22, 235, 237, 248; politics, 26, 48, 51, 275, 287, 289, 299; practices, 7, 10, 22, 39-40, 42, 77, 195, 223-24

genderlessness, 211-12 gender relations, 22, 30, 32, $42,51,62,68,77,146,192$, 272, 286; contemporary, 55; in Hanif Kureishi's short fiction, 222-23, 225, 227, 230, 237, 245, 249; oppressive, 70; post-war, 227; of power, 232, 237, 248 gender roles, 66, 173, 237, 242, 249; inflexible, 192; sedimented, 188; traditional, 191 gender scripts, 95, 98-99 gender separatism, 288, 299 gender studies, 7, 12, 28, 46, $90,144,221,224,250$, 302-303

Gillet, Lucie, 259

Gilmore, David D., 36, 144

God, 89, 92, 161-62, 285, 292 Goldsmith, Oliver, The Vicar of Wakefield, 129-30

Gramsci, Antonio, 22

Gregory, Abigail, 280, 282

Guetzloe, Eleanor C., 150

Gutterman, David S., 35

Halberstam, Judith/Jack, 3132,34

Hardy, Thomas, 7-9, 141-43, 146-53, 155-56, 160-61, 163-67; Works: Jude the Obscure, 8-9, 141-68; The Mayor of Casterbridge, 142 Harrison, John, 295-96 Hearn, Jeff, 68-69, 71 hegemonic masculinity, 18 , 20-25, 28, 32-33, 35, 37, 43-45, 48, 61-64, 68, 73, 78, 194-99, 202-203, 206, 208-209, 211-15, 223-24, 256, 266; ideal of, 197 , 211-12; whiteness of, 24, 27; hegemony, 21-22, 47, 69, 240, 244

Herdt, Gilbert, 36-37 
heterosexuality, 21, 29, 58-59,

$72,178,211$

Hoban, Russel, Riddley

Walker, 271, 274-75, 277-

79,288

Hobbes, Thomas, 181

homosexual, 45, 248-49; ho-

mosexuality, $6,11,14,16$,

$20,24-25,28,34,67$

homosociality, 12, 28-29, 33,

56,290

Hondagneu-Sotelo, Pierrette, 18,26

Horlacher, Stefan, 1-10, 11-12, $38,141-68,217,221,224-$

26,269

Hornby, Nick, 281-82, 284;

About a Boy, 273, 281-82,

Fever Pitch, 248

Houellebecq, Michel, 180, 294-95; The Elementary

Particles, 295

Howe, Adrian, 63, 65, 68

Huesmann, Rowell L., 98, 101, 103

Hume, David, 129, 135

husband, 80, 214, 234-35, 241$42,244-45$

Huxley, Aldous, 288

Ibsen, Henrik, 253

id, 63, 205

identity, construction of, 145 ,

148; formation, 175, 178,

180, 221, 224-25; male, 9,

$74,127,151,169-70,184-$

85, 202-203, 209, 212, 215;

masculine, 20, 63, 70, 150,

168, 179, 188, 198, 210-11,
213-14, 217, 220, 226-27, 231-32, 235, 239-40, 24850,266

individuality, 80, 82-83, 87 integrity, 84-87, 92, 130, 258 intersectionality, 58 invisible men, 253-54, 261

Jacobus, Mary, 142

James, C.L.R., 253

James, P.D., The Children of Men, 288

Jameson, Frederic, 145

Jardine, Alice, 16-17

justice, 49, 57, 154, 287

Kaufman, Michael, 18, 283, 287

Kent, Susan Kingsley, 135, 138-39

Kimmel, Michael S., 11, 16, 18-19, 40, 53-54, 77, 139, 283, 287

knights, 75-76, 79-81, 84-93

Konishi, Shino, 27

Kristeva, Julia, 168, 291-92

Kureishi, Hanif, 10, 217-20, 224, 226-33, 235-36, 23844, 247-49; Works: The Body and Seven Stories, 219, 235-36, 240, 248;

Buddah of Suburbia, 248;

Intimacy, 275; Love in a

Blue Time, 217-20, 226, 230, 233, 240, 248; "Hullabaloo in the Tree", 236-37; "My Son the Fanatic", 227, 247; "Nightlight", 230, 
232; "The Real Father",

236; "Sucking Stones", 233

Lacan, Jacques, 9, 28, 144-45, 149, 151, 159, 166, 197, 200, 205, 289

langue, 145, 225-26

law, 7, 53-74, 147, 151-57, 161-62, 164-66, 197, 287, 301

Lawrence, D.H., 150, 164;

Sons and Lovers, 293

Lee, John, 20-21

legal studies, 7, 53-59, 62, 66$67,69,72,74,302$

Lennon, John, 41

Lessing, Doris, The Marriages

Between Zones Three, Four and Five, 287-88

Lord, Albert B., 162-63

love, 68, 74, 201, 209-10, 215, 230, 295; in As You Like It, 109, 111-12, 117-18, 120, 122-23; interracial, 27; in The Man of Feeling, 132, 137-38; in Morte Darthur, 76, 79-81, 83, 87-91; motherly, 176

loyalty, 80-81, 83, 113

Luhmann, Niklas, 180, 183, 224

McCarthy, Cormac, The Road, 283

McEwan, Ian, 7, 9, 191-215, 275, 303; Works: The Cement Garden, 193-97, 200 204, 207, 209-10, 212-14;

The Child in Time, 192,
194, 197-200, 209, 212, 214, 275; The Comfort of Strangers, 193-94, 205-10, 212-14; Enduring Love, 194; The Innocent, 194, 205, 208-209, 212-15; Saturday, 184, 215-16

Machado Sáez, Elena, 255

Mackenzie, Henry, 7-8, 127, 129-31, 133, 135-38; The Man of Feeling, 8-9, 127 39

McLeod, John, 219, 260

McLuhan, Marshall, 182

McNeal, James, 192-93

Majors, Richard, 25

maleness, 30-31, 33, 57, 206

Malory, Thomas, 7-8, 75-93;

Morte Darthur, 8, 75-94

de Man, Paul, 165

manhood, 17, 19, 30, 36, 77, $150,209,213,215,268$, 281

manliness, 199, 213-14

Mårdberg, Maria, 260-61 marriage, 83, 91, 109, 120, $123,131,180,284,291$; in Hanif Kureish's short fiction, 228, 230-31, 233-34, 244-45; in Jude the Obscure, 148, 152-54, 158 masculine honor, 103, 105 masculine visibility, 10, 25152

masculinism, 56 masculinist, 259-60 masculinity, African American, 25; alternative, 95, 97, 209, 214-15; Asian Ameri- 
can, 25-26; black, 24-26, 37 ; and the body, 130; configurations of, 7-8; contemporary configurations of, 910; and crime, 45, 65, 263; in crisis, $20,178,188-89$, 220, 222-23; critique of dominance, 95, 97; disruption of, 217, 223, 226-27, $229,232,235,244-45,247-$ 48; dominance, 8, 14, 21, $35,47,69,95,97,100$, 102-107, 109, 111, 117-19, 122-23, 127, 139, 198; female, 31-32, 34; hegemonic script of, 214-15 (see also hegemonic masculinity); heterosexual, 30, 60; ideal of, 93, 96, 99, 195, 199; interracial, 27; Jewish, 26; male, 31-32; master narratives of, 147, 151, 157; modern, 9, 127; Native Americans, 26; progressive black, 254, 263; psychological, 13-14; relational, 111, 113, 116; struggle, 96, 230-31, 249; transgender, 33; violence, 47, 50; white, 27

masculinity scripts, 95, 97-

$102,108,123$; reparative,

$116,121,124-25$

masochism, 295 mass media, 41, 103; representation, 169-70, 185 materialism, 243, 246-47 matriarchal order, 210; matricentrality, 282, 284 méconnaissance, 149, 157-58 memory, 68, 74, 103, 211, 241 men, 22, 283; American, 16, 19; bisexual, 248-49; body of, 60; dominance, 21, 49; heterosexual, 29, 178; homosexual/gay, 18, 21, 28, $32,45,49,243,248-49$; power, 20, 58

Messerschmidt, James W., 24, $43,45,61,63$

Messner, Michael A., 18, 26, 44-45, 50, 54

metaphysics, 167-68

metropole, 46-47

Middleton, Peter, 62, 70-71

Miéville, China, 280, 285;

King Rat, 285

Milner, Susan, 280, 282

Mirandé, Alfredo, 26

misogyny, 177, 184, 211, 237, 248-49, 291-92

mistress, 86-87, 159

money, 86, 182, 186, 193, 236, 246

Moore-Gilbert, Bart, 218-20, 227, 248 mother, 49, 98, 130, 147, 174, 176-77, 260, 266; in The Book of Dave, 282-83, 290, 299; in Hanif Kureishi's short fiction, 234-37, 243, 249; in Ian McEwan's novels, 193, 196-201, 203-205, 211; mother-phobia, 291 multiplicity, 15, 28, 118, 122, 145,165 murder, 155, 159, 194, 205, 209, 213-14 
Murphy, Peter F., 4, 144, 226, 299

Mutua, Athena D., 254, 263

mythopoetic, 17-18

narration, 1, 5, 183, 186, 224, 265; autobiographical, 18384

nature, 36, 97, 181, 288; gendered, 55, 60; of man, 59; patriarchal, 285; neoliberalism, 48

Noyes, John K., 295

object, sexual, 177

objectification, 29

Oexle, Gerhard Otto, 80-83

Orwell, George, 173

Osborne, John, Look Back in Anger, 9, 169, 174-79

Othello figure, 256-57

Palahniuk, Chuck, Fight Club, 286

parents, 14, 41, 132, 177-78, 192, 241, 275-76, 287, 298

parole, $145,225-26$

Parsons, Tony, 281-82, 284;

Man and Boy, 273, 281

paternity, 10, 50, 271, 274,

276, 280, 283-84

patriarchal; dividend, 22, 49,

63; gender order, 220; gender practice, 23; gender relations, 245; patriarchy, 10, $22,78,130,132,188,192-$

94, 196, 206, 215, 258, 271, 290

Pentecostal Oath, 79-81, 87 perception, 35, 98, 197

Phillips, Caryl, 10, 251-62, 264-66, 269; Works:

Crossing the River, 252, 255, 257-60, 262; A Distant Shore, 251-52, 257-59; The Final Passage, 252, 256, 258, 265; Higher Ground, 254, 256-57; In the Falling Snow, 251, 253, 260-66, 268-69; The Nature of Blood, 252, 256-57; A State of Independence, 254-56, 261

physicality, 179, 181-82, 18485

Pinter, Harold, 184, 208

Pleck, Joseph H., 13-15

Pocock, J.G.A., 136-37

popular culture, 16, 213

postcolonial literatures, 304305

postethnic, 217, 219

post-war years, 170-71, 173

power, and desire, 40; destructive, 89; and discourse, 34; and gender, 41, 68; lack of, 255; of law, 56; male, 75 76, 78; networks of, 73; over children, 236; over oneself, 245; political, 89, 278 ; positions of, 77 ; relational, 21; relations, 46, 70, $83,194,212,223,228$, 236; of reproduction, 292; social, $55,61,172$; structures, $6,70,188,279$ primal patricide, 193 privilege, 44, 127 
procreation, 288, 291

Proust, Marcel, À la Recherche du Temps Perdu, 156, 168

psyche, gendered, 21

psychotherapy, 99-100

Punch, 277-78

Putin, Vladimir, 48

Pynchon, Thomas, The Crying of Lot 49, 165

queer, 30,67

queer theory, 30, 60, 64, 74

race, 6, 41, 46, 219-20; in

Caryl Phillips' novels, 252, 257, 259, 261, 267-68; in legal studies, 61, 66, 68, 71, 73-74; in masculinity studies, 15, 22, 24-25, 27-28

Reckwitz, Andreas, 175, 178, 180

Reeser, Todd W., 3, 6-7, 11 38,78

rejection, 32, 57, 95, 97, 177 -

78, 197, 276, 285

religion, 10, 26, 159, 271, 278-

79, 291-93, 302

repression, 17, 111, 138, 199,

205

reproduction, 56, 60, 67, 288;

reproductive arena, 42

resistance, 23, 42, 69, 203,

275,279

Roberts, Kathleen Glenister, 26

Robeson, Lisa, 80, 87

role model, male, 170, 177,

235

Rubin, Henry, 33
Rushdie, Salman, 218, 292;

Satanic Verses, 292

Said, Edward, 26

Sartre, Jean-Paul, 167

de Saussure, Ferdinand, 151, 225

savoir littéraire, 8, 10, 217, 224, 228, 235, 249

scholarship boy, 174-75, 178

Seaboyer, Judith, 205-206, 208

Sedgwick, Eve K., 11-12, 28 30

Segal, Lynne, 58, 62, 173-76, 180

segregation, 255-56

Seidler, Victor J., 34, 127-28

self-made man, 148, 224

self-reaffirmation, 179, 186

self-representation, 5, 131

Self, Will, 208, 271-73, 289, 293-94, 297; Works: The Book of Dave, 7, 10, 27199; Great Apes, 272, 298; My Idea of Fun, 272; "Caring, Sharing", 298

Sentimentalism, 128-29, 134 sex, 139, 259; discourse, 67; female, 159; and gender, 27, 30, 55, 66; male, 13, 30, 34,138 ; same, 14; sex (intercourse), 206, 230, 294; sexes, 76, 134, 191-92, 299; battle of the, 189; sex role strain (SRS), 14; sex role theory, 13-15, 40-41, $49,55,61$; sexuality, 32 , $34,98,129,133,142,148$, 180, 302-304 
Shakespeare, William, 7-9, 12, 30, 95-98, 100, 102, 107, 109, 113, 121, 123, 125, 134; Works: As You Like It, 8, 95-125; Much Ado about Nothing, 134

Sheldon, Sally, 60, 69, 73, 301 Showalter, Elaine, 17 silence, 104, 127, 266, 283 Sillitoe, Allan, 7, 184, Saturday Night and Sunday Morning, 169, 184

Sinfield, Alan, 170-75, 178, 180-81

Sinha, Mrinalini, 26 slave, 119,255 ; slave traders, 254-55, 258

Smart, Carol, 57-58, 67, 74

Smith, Adam, 135

Smith, Paul, 16-17

social justice, 7, 39

split personality, 183-84

Staples, Robert, 24-25

status symbols, $170,182-84$

stereotypes, 3, 14, 127, 237,

242,262

sterility, 210-11

Sterne, Laurence, A Sentimental Journey, 129

Storey, David, 184 subculture, 169-70, 178, 188 subjectivity, 12, 35, 56, 62-63, $65-66,69,73-74,83,145-$ 46,225

subordination, 21-22, 24, 228, 240

symbolic order, 151, 158, 16667, 197, 200, 204 sympathy, 129, 134-36, 285, 293

teachers, 95, 124-25, 258, 287 testosterone, 30-31, 33 textuality, 147, 165-66 Todd, Janet, 128-29 Tönnies, Ferdinand, 82-83 Tosh, John, 19 Traister, Bryce, 20 transcendental, 141, 143, 146, 160

transformation, 77, 135, 160, 191-92, 194, 212, 219, 223, 232-33, 248, 292

transgender, 6, 11, 33 transgender studies, 2, 33 trauma, 201, 261, 272, 283 Tripp-Reimer, Toni, 284-85

values, $17,34,51,63,77,79$ $80,84,139,142,172,202$, 241, 282, 285; ethical, 246; exchange, 86; patriarchal, 210

verbal aggression, 109, 111, 122-23

victims, 76, 110, 135, 152, 205, 257, 286, 294

violence, 181, 205, 209, 213 , 215, 247, 275; against women, 49; and combat, 85 ; gendered, 41; knighthood, 87, 97; of men, 65; physical, 99, 102-103, 10910, 181, 183; scripts, 103 virginity, male, 77,89 virtue, 23, 31, 110, 128-29, 134-39, 267 
voyeurism, 207

vulnerability, 59, 85, 97, 99,

$102,108,111,121-23,196-$

$99,259,284$

Wahlström, Helena, 260-61

Wallace, Maurice O., 25

war, 26, 75-76, 78, 87, 123,

171, 208, 240, 247, 288;

cold, 209, 274

wealth, 20, 22, 47-48, 103, 131-32, 137, 268

Weber, Max, 81

Wesker, Arnold, 184

Wetherell, Margaret, 23, 195

White, T.H., The Once and

Future King, 75

Whitehead, Stephen, 54, 59, 62,68

Wilson, Susan E., 284-85

women, 16, 20, 25, 40-41, 49,

76, 80, 97-99, 107, 111,

$134,144,179,182-83,187-$

$88,232-35,241,267,281-$

82, 288-89; authority/ control/power over, 14, 21 , 24, 34, 44, 194-95, 211-12, 285, 291; blaming, 231;

emancipation of, 228, 289; equal power, 230, 234; exclusion of, 15 ; identification with, 45; in legal studies, 56-57, 60, 66-67, 7273 ; and male homosociality, 29, 278; and masculinity, 6, 33, 40, 44, 237; maternal, 213, 276; moral superiority of, 258 ; movement, 17, 39; objectification of, 28, 206; oppression/subordination of, 22$23,77,195,223,292$; position of, 20, 40, 48, 174, 260 ; role of, 32,92 ; successful, 17, 242 women's studies, 15-16, 27 world order, new, 255, 261 worship, 79-80, 137, 199, 292 Wright, Richard, 253, 262 